
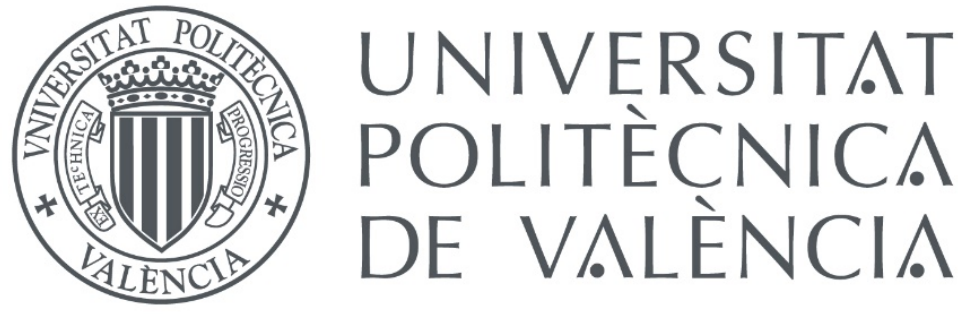

Universitat Politècnica de València

Doctoral Thesis

Doctoral Programme in Biotechnology

\title{
ROLE OF IONS IN STEM CELLS SIGNALLING
}

Hayk Mnatsakanyan Movsesyan

$9^{\text {th }}$ April, 2019

Supervised by:

Dr. Patricia Rico Tortosa

Dr. Roser Sabater i Serra

Prof. Manuel Salmerón Sánchez 


\section{Acknowledgments}

Quienes me conocen, saben que no soy muy dado a este tipo de textos de agradecimiento, por lo que no me juzguéis muy severamente.

Tras más de cuatro años realizando esta tesis doctoral, casi 12 años estudiando en la universidad, y habiendo realizado 2 proyectos final de carrera y uno final de master, creo que ya es momento de mirar atrás y reconocer, o al menos dejar por escrito, que todo esto, todas las oportunidades que he tenido han sido gracias a la gente que me rodea. Sus ánimos y confianza en mí, en algunos casos acompañados de sacrificios inmensos, me han obligado siempre a superarme e ir hacia delante. Ellos han estado siempre a mi lado apoyándome y apostando por mí, incluso cuando yo no lo hacía. Debo reconocer que todas las oportunidades que he tenido se lo debo a mi familia y especialmente a mi madre, que ha trabajado muy duro para que no me faltase nada y siempre me ha empujado a ser la mejor versión de mí mismo, lo cual a veces se hacía muy complicado. También debo agradecer a mi familia el haberme cuidado y educado, enseñándome que siempre tengo que aspirar a más y no conformarme, y que los limites están donde uno los ponga. En cuanto a mi familia, no puedo olvidarme de mi pareja y amiga, quien ha estado más cerca de mí en los momentos de flaqueza, apoyándome y animándome para seguir adelante.

Pero, como se suele decir, la familia no solo son la gente que comparte vínculos genéticos contigo, también son los amigos que vas haciendo a lo largo de tu vida, y que te enriquecen como persona. Ellos siempre me han apoyado, criticado cuando tenían que hacerlo, y han estado orgullosos de mi cuando, raras veces, he hecho las cosas bien. Entre ellos también han estado mis maestros, que desde joven me han enseñado que la vida me va a dar muchos golpes, y que no debo tirar la toalla tan fácilmente. A todos ellos les agradezco el formar parte de mi vida.

También me gustaría reconocer el mérito a mis compañeros del CBIT en esta tesis doctoral, los cuales nunca han dudado en hacer una pausa en sus trabajos para echarme una mano cuando lo necesitaba, probablemente no hubiera llegado hasta este punto sin su ayuda. 
No puedo olvidarme de mis directores, los cuales han confiado en mí y me han dado la oportunidad de hacer este trabajo y tomar decisiones, permitiéndome crecer como investigador. Sé que les he dado más de un disgusto, pero espero que en general estén satisfechos, o al menos conformes, con los resultados.

Por último, la presente tesis doctoral no se podría haber realizado sin la financiación del Ministerio de Ciencia, Innovación y Universidades a través de la beca BES-2013-064052 y los proyectos MAT2012-38359-C03-01 y MAT201569315-C3-1-R.

Espero que el documento que sigue a este texto esté a la altura de las expectativas que todos los que han estado a mi lado han puesto en mí. Sin duda, he dado, o al menos lo he intentado, lo máximo de mí en este trabajo, y espero que algún día este granito de arena sirva para construir un mundo mejor y sostenible, y que la gente sea consciente de que el dinero que va destinado a la ciencia y la educación no es un gasto, sino una inversión de futuro. 


\section{Index}

Resumen

Resum

Summary 13

Glossary 15

Introduction 17

Multicellular organisms development and signals ................................... 17

Self-regeneration problems in adult organisms........................................ 21

Signals that regulate cell fate .............................................................. 26

Ion mediated signalling in stem cells ........................................................ 31

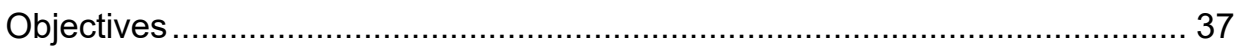

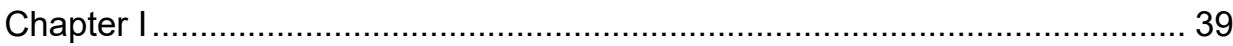

Zinc enhances myogenic differentiation through Akt activation via zinc transporter Zip7

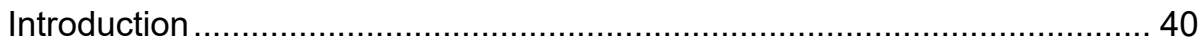

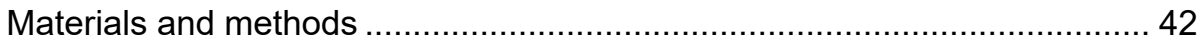

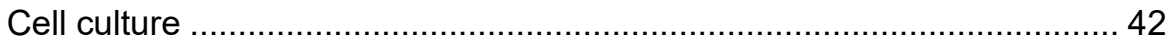

Live dead (cytotoxicity) and proliferation (total cell density and BrdU)

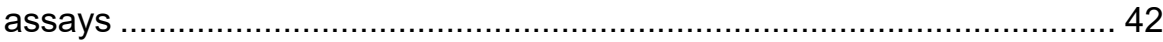

Myogenic differentiation visualisation..................................................... 43

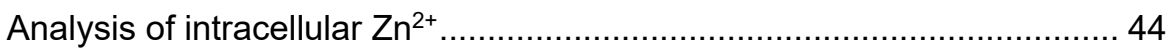

Gene expression analysis by quantitative real time PCR ........................ 44

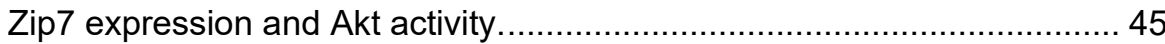

RNA interference (RNAi) experiments. ................................................ 45

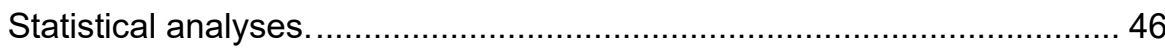

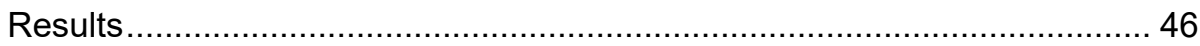

$\mathrm{Zn}^{2+}$ increases myoblasts viability and proliferation. ................................ 46

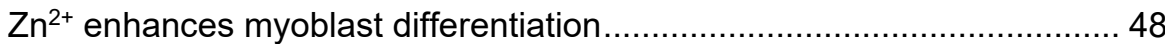

Intracellular $\mathrm{Zn}^{2+}$ increases in differentiated myoblasts .......................... 51 
Expression of subcellular Zip7 transporter regulates Akt activity 54

Effects of Zip7 silencing in myoblasts ................................................... 56

Silencing of Zip7 alters intracellular $\mathrm{Zn}^{2+}$ content ................................... 58

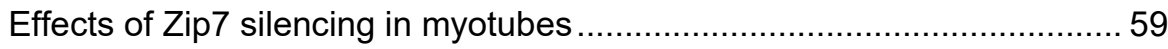

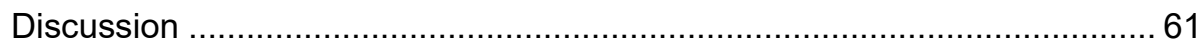

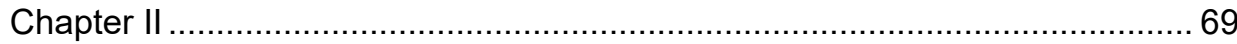

Zinc maintains embryonic stem cells pluripotency and multilineage

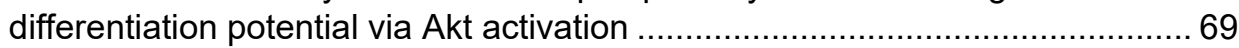

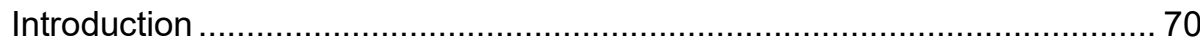

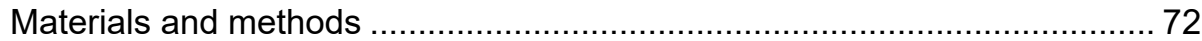

ESCs culture and embryoid bodies formation ....................................... 72

ESCs intracellular $\mathrm{Zn}^{2+}$ homeostasis................................................ 73

Immunofluorescence, staining, and histology methods. .......................... 73

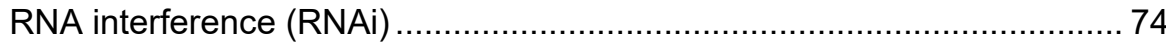

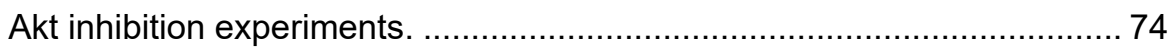

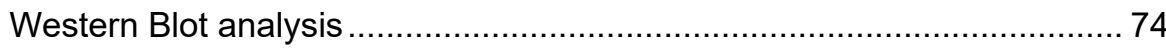

Gene expression analysis by quantitative real time PCR …..................... 75

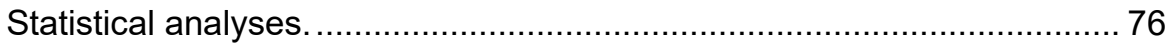

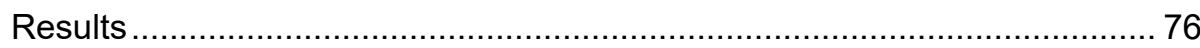

$\mathrm{Zn}^{2+}$ effects on ESCs viability and proliferation .................................... 76

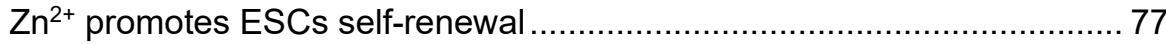

$\mathrm{Zn}^{2+}$ maintain ESCs stemness activating Zip7 transporter and Akt signalling

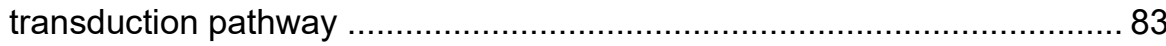

$\mathrm{Zn}^{2+}$-mediated activation of Akt is strongly associated with intra-nuclear

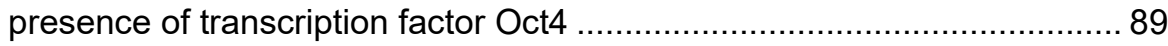

$\mathrm{Zn}^{2+}$ maintains ESC pluripotency in long-term cultures ............................ 91

$\mathrm{Zn}^{2+}$ maintains ESC differentiation capacity after long-term cultures......... 94

$\mathrm{Zn}^{2+}$ maintains a stable ESCs pluripotent state after long-term cultures . 100

The combination of LIF and $\mathrm{Zn}^{2+}$ strongly increases LIF effects............. 103

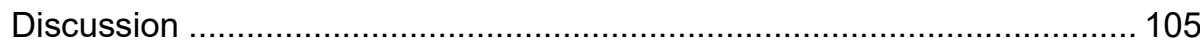

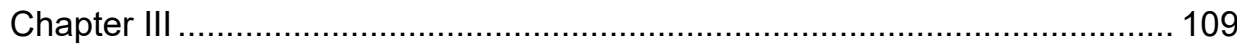

Lithium inhibits GSK3 $\beta$, activating $\beta$-catenin and promoting ESCs differentiation towards hemogenic endothelium.... 


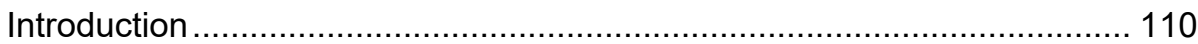

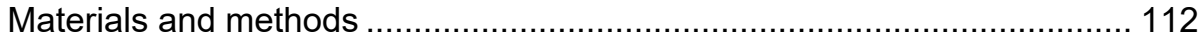

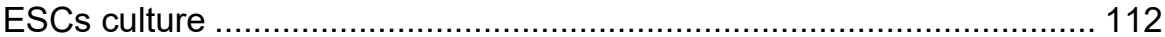

ESCs viability and proliferation in presence of different concentrations of

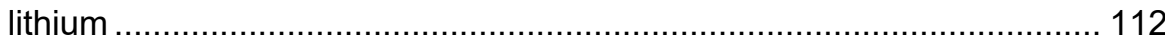

ESCs differentiation experiments .................................................... 113

Hemogenic endothelium differentiation experiment.............................. 113

Immunofluorescence and stains ....................................................... 113

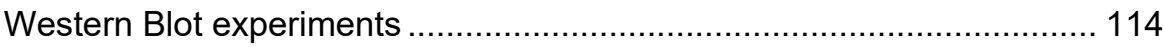

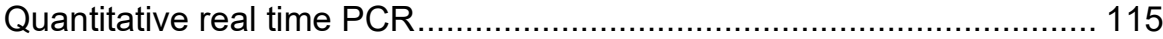

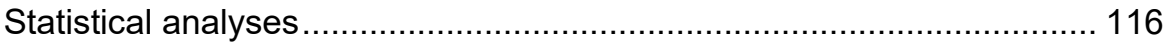

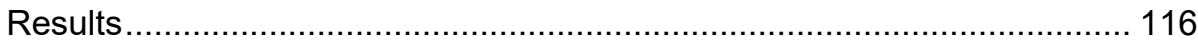

High concentrations of $\mathrm{Li}^{+}$are toxic for ESCs and can reduce cell

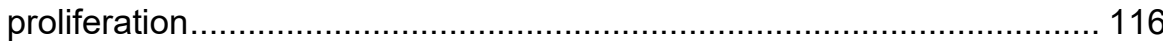

$\mathrm{Li}^{+}$inhibits GSK3 $\beta$ activity without affecting ESCs spontaneous

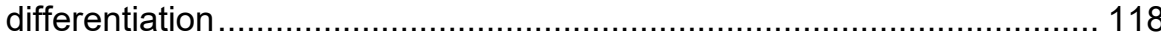

$\mathrm{Li}^{+}$-mediated inhibition of GSK3 $\beta$ increases over time and enhances $\beta$ catenin expression and nuclear translocation.....

Nuclear accumulation of $\beta$-catenin activates Brachyury/T and $\mathrm{Cdx} 2$ expression

High concentration of $\mathrm{Li}^{+}$leads to ESCs differentiation to Sca1 and CD31 positive endothelial cells.

ESCs-derived hemogenic endothelial cells can be maturated to obtain HSCs

Discussion

Discussion 133

Conclusions 139

Contributions

References 145 


\section{Resumen}

Los procesos de comunicación celular permiten a las células desarrollar una acción coordinada durante la embriogénesis, asimilar de forma coherente las señales recibidas a través del entorno y reclutar células madre desde sus nichos para llevar a cabo la regeneración de un tejido dañado. Algunas de las moléculas señalizadoras más usadas en la clínica y la investigación son los factores de crecimiento y citoquinas. Sin embargo, existe una tendencia creciente en el uso de otro tipo de moléculas, como los iones metálicos. Algunos iones como el calcio y el zinc actúan como segundos mensajeros intracelulares, transmitiendo señales en cascada. Otros como el litio son capaces de inactivar proteínas quinasa alterando rutas de señalización. En el desarrollo de esta tesis doctoral, se ha estudiado el efecto del zinc en células musculares de ratón (mioblastos), el papel del zinc en la auto-renovación replicativa de células madre embrionarias (CMEs), y el papel del litio en la diferenciación de CMEs.

El estudio del efecto del zinc sobre los mioblastos demostró que el zinc es capaz de estimular la diferenciación de los mioblastos generando un mayor número de miotubos y más desarrollados. El análisis del zinc intracelular, en los diferentes estadios de diferenciación de las células musculares, demostró que los miotubos (mioblastos diferenciados) eran capaces de albergar mayor cantidad de zinc en su interior. Los resultados mostraron que la adición de zinc extracelular estimula la fosforilación y activación de la proteína quinasa Akt, cuyo papel en la diferenciación de los mioblastos ha sido bien estudiado por otros autores. Ha sido demostrado que el transportador de zinc, Zip7, es crítico en el proceso de diferenciación celular mediado por el zinc, y que tras su activación se incrementa la fosforilación de Akt. La inhibición de Zip7 mediante ARN interferente, originó una reducción en los niveles de fosforilación de Akt y consecuentemente unos niveles menores de diferenciación de los mioblastos expuestos a zinc extracelular. Nuestros resultados demuestran que altas concentraciones de zinc extracelular producen un incremento en la diferenciación de los mioblastos debido a la activación de Akt mediada por Zip7.

Para el segundo estudio, se analizó el efecto del zinc sobre las CMEs. Como control de mantenimiento de la pluripotencia se usó medio suplementado con 
factor inhibidor de leucemia (LIF). Se ha observado que la adición externa de concentraciones de zinc superiores a $100 \mu \mathrm{M}$ produce un incremento inmediato de la concentración de zinc intracelular, lo cual resulta en la activación de Akt mediada por Zip7. Se han realizado experimentos para estudiar el efecto del zinc en la diferenciación de las CMEs. Los resultados demuestran que las células tratadas con altas concentraciones de zinc mantienen su capacidad de autorenovación. El papel de Akt en la auto-renovación de las CMEs se ha descrito múltiples veces. Para demostrar que el efecto observado del zinc en CMEs está asociado a la activación de Akt mediada por Zip7 se inhibió la fosforilación de Akt y se silenció el transportador Zip7. Ambos abordajes dieron como resultado un incremento en la diferenciación de las células tratadas con zinc, y por lo tanto una menor capacidad de auto-renovación de las CMEs. Por otro lado, CMEs cultivadas durante 30 días en presencia de zinc, fueron capaces de retener su pluripotencia, mientras que el control sin zinc presentaba rasgos claros de diferenciación celular espontánea, así como la perdida de la capacidad de diferenciación dirigida. Por último, la combinación de LIF con zinc produjo un incremento importante del efecto del LIF en cuanto al mantenimiento de la capacidad de auto-renovación celular.

Por último, se ha estudiado el efecto del litio en la diferenciación de las CMEs. El litio es un inhibidor de la glucógeno sintasa quinasa 3 beta (GSK3 $\beta$ ). En términos de CMEs, GSK3 $\beta$ activa los mecanismos de diferenciación, por lo que su inhibición mantiene la auto-renovación de las CMEs. Los resultados obtenidos indican que altas concentraciones de litio $(10 \mathrm{mM})$ son capaces de fosforilar y por tanto inhibir fuertemente la proteína GSK3 $\beta$. Sin embargo, en lugar de mantener la pluripotencia, las células madre se diferenciaron hacia el linaje del mesodermo tras 3 días de cultivo. Después de un total de 6 días, las células tratadas con $10 \mathrm{mM}$ de litio presentaron características de endotelio hemogénico. La fosforilación de GSK3 $\beta$ dio como resultado la activación de la proteína $\beta$ catenina, cuya actividad transcripcional es necesaria para la hematogénesis embrionaria. La capacidad de las células endoteliales con potencial hemogénico obtenidas a partir de CMEs tratadas con litio de derivar en células madre hematopoyéticas fue confirmada tras su maduración durante 11 días, dando como resultado agregados de células redondeadas positivas para Sox17. 


\section{Resum}

Els processos de comunicació cel·lular permeten a les cèl/lules desenvolupar una acció coordinada durant la embriogènesis, assimilar de forma coherent als senyals rebudes a través de l'entorn i reclutar cèl-lules mare des dels seus nínxols per dur a terme la regeneració d'un teixit danyat. Algunes de les molècules senyalitzadores més usades en la clínica i la investigació són els factors de creixement $\mathrm{i}$ citocines. No obstant, hi ha una tendència creixent en l'ús d'un altre tipus de molècules, com els ions metàl-lics. Alguns ions com el calci i el zinc són capaços de dur a terme funcions de missatger secundari, transmetent senyals en cascada. Altres com el liti són capaços d'inactivar proteïnes quinasa alterant rutes de senyalització. Durant el desenvolupament d'aquest treball de tesi doctoral, s'ha estudiat l'efecte del zinc sobre mioblasts de ratolí, el paper del zinc en l'auto-renovació de les cèl-lules mare embrionàries (CMEs), i el paper del liti sobre la diferenciació de les CMEs.

L'estudi de l'efecte del zinc sobre els mioblasts ha demostrat que el zinc és capaç d'incrementar la diferenciació dels mioblasts, generant un major nombre de miotubs i més desenvolupats. L'anàlisi del zinc intracel-lular ha demostrat que els mioblasts diferenciats eren capaços d'albergar major quantitat de zinc intracel-lular. Els resultats han mostrat que suplementar les cèl-lules amb zinc extracel-lular produïx una major fosforilació i activació de la proteïna quinasa Akt. El paper de Akt en la diferenciació dels mioblasts ha sigut ben estudiat per altres autors. D'altra banda, s'ha observat que el transportador de zinc Zip7 es crític per a la diferenciació cel-lular mediada pel zinc. S'ha demostrat que l'activació d'aquest transportador mitjançant zinc extracel-lular és capaç d'incrementar la fosforilació d'Akt. La inhibició d'aquest transportador mitjançant ARN interferent ha donat com a resultat una menor fosforilació d'Akt i una menor diferenciació dels mioblasts exposats a zinc. Aquests resultats demostren que altes concentracions de zinc extracel/lular produeixen un incrementar la diferenciació dels mioblasts a causa de l'activació d'Akt per mitja de Zip7.

Per al segon estudi, s'ha analitzat l'efecte del zinc sobre les CMEs. Com a control de manteniment de la pluripotència es va usar medi suplementat amb factor inhibidor de leucèmia (LIF). S'ha observat que les concentracions extracel/lulars 
de zinc a partir de $100 \mu \mathrm{M}$ produïxen un increment immediat de la concentració intracel-lular, produint l'activació d'Akt per mitja de Zip7. Els experiments per estudiar la diferenciació de les CMEs han demostrat que les cèl-lules tractades amb altes concentracions de zinc mantenen l'auto-renovació. El paper d'Akt en l'auto-renovació de les CMEs s'ha descrit múltiples vegades. Per demostrar que aquest efecte està associat a l'activació d'Akt mediada per Zip7 es va inhibir la fosforilació d'Akt i es va silenciar el transportador Zip7. Tots dos abordatges han donat com a resultat un increment en la diferenciació de les cèl-lules tractades amb zinc. D'altra banda, les CMEs van ser capaços de retenir la seva pluripotència després de ser cultivades durant 30 dies en presència de zinc, mentre que el control sense zinc presentava trets clar de diferenciació cel·lular. Finalment, la combinació de LIF amb zinc ha produit un increment sinèrgic de l'efecte del LIF.

Finalment, també s'ha estudiat l'efecte del liti en la diferenciació de les CMEs. El liti és un inhibidor de la glicogen sintasa quinasa 3 beta (GSK3 $\beta$ ). En termes de CMEs, aquesta proteïna activa els mecanismes de diferenciació, en conseqüència, la seva inhibició manté l'auto-renovació de les CMEs. Els resultats obtinguts indiquen que altes concentracions de liti $(10 \mathrm{mM})$ tenen la capacitat de fosforilar i inhibir fortament la proteïna GSK3ß. No obstant això, en lloc de mantenir la pluripotència, les CMEs es van diferenciar cap al llinatge del mesoderma després de 3 dies. Després d'un total de 6 dies, les cèlllules tractades amb $10 \mathrm{mM}$ de liti presentaven característiques d'endoteli hemogénic. La fosforilació de GSK3 $\beta$ va donar com a resultat l'activació de la proteïna $\beta$ catenina, l'activitat trasncripcional d'aquesta proteïna és necessària per a la hematogénesis embrionària. La capacitat de les cèllules endotelials amb potencial hemogénic obtingudes a partir de les CMEs de derivar en cèlllules mare hematopoètiques va ser confirmada després de la seva maduració durant 11 dies, donant com a resultat agregats de cèlllules arrodonides positives per Sox17. 


\section{Summary}

The cell signalling process allows cells to develop a coordinated action during embryogenesis, assimilate coherently the signals received through the environment and recruit stem cells from their niches to achieve the regeneration of damaged tissues. Some of the most currently used signalling molecules in clinics and research are growth factors and cytokines. However, there is a growing trend in the use of other types of molecules, such as metal ions. Some ions such as calcium and zinc are able to carry out secondary messenger functions, transmitting signals in cascade. Others ions, such as lithium, are capable to inactivate protein kinases altering signalling pathways. During the development of this doctoral thesis, we investigated the effect of zinc on mouse muscle cells (myoblasts), the role of zinc in embryonic stem cells (ESCs) selfrenewal, and the role of lithium in the differentiation of ESCs.

In the first chapter, we showed that zinc is able to increase the differentiation of myoblasts, generating a greater number of myotubes with increased hypertrophy. The analysis of intracellular zinc indicated that the differentiated myoblasts were capable to harbour higher concentration of intracellular zinc than undifferentiated ones. Addition of high concentration of extracellular zinc increased protein kinase Akt phosphorylation and activation. Akt activity is critical for myoblasts differentiation and has been well studied by other authors. Our results indicated that zinc transporter Zip7 was critical for zinc-mediated cell differentiation. It was prior demonstrated that the activation of this transporter by extracellular zinc increased the phosphorylation of Akt. The inhibition of Zip7 by interfering RNA resulted in a lower phosphorylation of Akt and reduced differentiation of the myoblasts exposed to extracellular zinc. These results demonstrated that high concentration of extracellular zinc enhances the differentiation of myoblasts through activation of Akt mediated by Zip7.

In the second chapter, we have analysed the effect of zinc on ESCs. Leukaemia inhibitory factor (LIF) was used as pluripotency sustaining factor. We observed that extracellular supplementation of $100 \mu \mathrm{M}$ zinc produced an immediate increase of the intracellular concentration, which resulted in the activation of Akt mediated by Zip7 transporter. ESC differentiation experiments showed that cells 
treated with high concentrations of zinc maintained self-renewal. The role of Akt on ESCs self-renewal has been well established in the literature. To demonstrate that this effect is associated with the activation of Akt mediated by Zip7, we inhibited Akt phosphorylation and silenced the expression of Zip7. Both approaches resulted in an increase in the differentiation levels of the ESCs treated with zinc. We further demonstrated that ESCs treated with zinc during 30 days were able to retain their pluripotency, while the control condition cultured 30 days without zinc presented evident traits of spontaneous cellular differentiation. Finally, the combination of LIF with zinc produced a synergistic increase in the effect of LIF on ESCs self-renewal.

Finally, we addressed the effect of lithium on the differentiation of ESCs. Lithium is an inhibitor of glycogen synthase kinase 3 beta (GSK3 $\beta$ ). In terms of ESCs, GSK3 $\beta$ activates differentiation mechanisms. Therefore, GSK3 $\beta$ inhibition is associated with ESCs self-renewal. Our results indicated that high concentration of lithium (10 $\mathrm{mM})$ was able to phosphorylate and strongly inhibit the activity of GSK3 $\beta$. However, instead of maintaining pluripotency, ESCs differentiated into the mesoderm lineage after 3 days of culture. After a total of 6 days, ESCs treated with $10 \mathrm{mM}$ lithium showed haemogenic endothelium characteristics, expressing CD31, Sca-1 and CD31/Sca-1 positive cells. The phosphorylation of GSK3 $\beta$ resulted in the activation of the $\beta$-catenin protein, whose transcriptional activity is necessary for embryonic hematogenesis. The ability of endothelial cells with hemogenic potential obtained from lithium-treated ESCs to derive into hematopoietic stem cells was confirmed after maturation of these cells, resulting in rounded cell aggregates positive for Sox 17. 


\section{Glossary}

\begin{tabular}{|c|c|}
\hline Akt & Protein kinase $B$ \\
\hline AP & Alkaline phosphatase \\
\hline BM & Basal medium \\
\hline BMP & Bone morphogenetic protein \\
\hline BSA & Bovine serum albumin \\
\hline CK2 & Casein kinase 2 \\
\hline DMEM & Dulbecco's modified Eagle's medium \\
\hline DNA & Deoxyribonucleic acid \\
\hline DPBS & Dulbecco's phosphate-buffered saline \\
\hline ECM & Extracellular matrix \\
\hline EpiSC & Epiblast stem cells \\
\hline ER & Endoplasmic reticulum \\
\hline Erk & Extracellular signal-regulated kinases \\
\hline ESC & Embryonic stem cells \\
\hline esiRNA & Endoribonuclease-prepared siRNA \\
\hline FBS & Foetal bovine serum \\
\hline FDA & Food and drug administration \\
\hline FGF & Fibroblast growth factor \\
\hline GAPDH & Glyceraldehyde-3-phosphate dehydrogenase \\
\hline GSK3 $\beta$ & Glycogen synthase kinase 3 beta \\
\hline HGF & Hepatocyte growth factor \\
\hline HSC & Hematopoietic stem cell \\
\hline ICM & Inner cell mass \\
\hline IGF & Insulin like growth factor \\
\hline IL & Interleukin \\
\hline ITS & Insuline-Transferrine-Selenium \\
\hline JAK & Janus kinase \\
\hline KIf4 & Kruppel-like factor 4 \\
\hline KSR & Knockout serum replacement \\
\hline LIF & Leukaemia inhibitory factor \\
\hline MEF & Mouse embryonic fibroblasts \\
\hline MHC & Myosin heavy chain \\
\hline MSC & Mesenchymal stem cells \\
\hline NGF & Nerve growth factor \\
\hline
\end{tabular}




\begin{tabular}{|l|l|}
\hline PIS & Penicillin/Streptomycin \\
\hline PSC & Pluripotent stem cells \\
\hline PVDF & Polyvinylidene difluoride \\
\hline RNA & Ribonucleic acid \\
\hline RNAi & RNA interference \\
\hline ROS & Reactive oxygen species \\
\hline RT-qPCR & Real time quantitative polymerase chain reaction \\
\hline Sca-1 & Stem cells antigen-1 \\
\hline SDS-PAGE & Sodium dodecyl sulfate polyacrylamide gel electrophoresis \\
\hline siRNA & Small interfering RNA \\
\hline Slac39a7 & Solute carrier family 39 member 7 \\
\hline TBS & Tris-buffered saline \\
\hline TGF & Transforming growth factor \\
\hline TNF & Tumour necrosis factor \\
\hline Tr & Trophectoderm \\
\hline VEGF & Vascular endothelial growth factor \\
\hline
\end{tabular}




\section{Introduction}

\section{Multicellular organisms development and signals}

'Life is a self-sustained chemical system capable of undergoing Darwinian evolution' (1). This 'chemical Darwinian' definition of life, increasingly accepted, entails a very complex and sophisticated crosstalk of chemical and physical interactions between multiple molecules, in a given context. These interactions allow the formation of complex structures and signals able to interact between them and with their environment, taking energy from their surroundings, and selfsustaining. The minimal functional and structural component constituting a living entity is the cell (2). Cell structures are composed by many chemically different molecules being most of them organic molecules such as carbohydrates, lipids, peptides or polypeptides and nucleic acids (2). Besides of organic molecules, there are other inorganic molecules, such as water, the largest component of the cells, and trace elements which interact with organic molecules to form functional structures and accomplish signalling activities (2). Cells cytoplasm is subdivided into numerous functional and structural elements such as macromolecules and organelles (3). The organelles individually are equipped with molecular tools, such as enzymes or other macromolecules, necessary to realize very specific function into the cell. Moreover, these structures are simultaneously connected and interact with other organelles to respond coordinately to stimuli (3). The 
function of these organelles covers from the synthesis of proteins by ribosomes, energy transferring from complex molecules to other functional molecules by mitochondria, or storage and management of the information necessary to achieve a living organism by the nuclei, in eukaryote cells (2-4). This information is encoded in a complex and long macromolecules, deoxyribonucleic acid (DNA). This molecule contains necessary information and instructions used for cells to growth, develop, interact with the environment and to replicate them-self arranged into units known as genes (4). DNA constitutes the genetic material of biological organisms. However, to translate this information to other action executor molecules, such as proteins, it is necessary the gene transcription into messenger ribonucleic acid (mRNA). These molecules are complementary sequences of expressing regions of DNA, and subsequently will be translated into proteins (2). These synthetised proteins by ribosomes, after being correctly folded by chaperones or post-translationally modified, execute genome encoded instructions such as synthesis of molecules, metabolic activities, signalling, gene expression or cell self-replication (5). Furthermore, these intermolecular interactions allow not only the communication among cell components, but also provide the necessary mechanisms to form multicellular complexes such as tissues, organs and finally a multicellular organism (6). Definitely, evolutionary pattern between each type of multicellular organisms makes that the pool of molecules and signals differs, observing different proteins and other organic macromolecular composition between plants, fungus or animals (6). Even between animals, it can be found remarkable differences depending on the evolutionary branch. We can find a large variability in their physical appearance, behaviour and development pattern between insects, reptiles, mammalians and others (6).

This molecular communication is especially important when we consider multicellular animas, in which each cell is, in some way, connected to the others, giving rise to a coordinated response in the organism (6). During embryonic development of multicellular organisms, they grow and conform every tissue from just a couple of totipotent cells (6-8). These cells are able to self-divide symmetrically resulting in two totipotent cells or asymmetrically giving rise trophectoderm cells and pluripotent stem cells (Fig. 1). In those contexts, signalling mechanism takes even more importance. Derived pluripotent cells afterwards differentiate and become committed to primary germ layer lineages (mesoderm, endoderm, ectoderm). Then, they continue differentiating and perform embryo morphogenesis (6). If we focus our attention on mammalian 
animals, they have a common evolutionary origin (9), and consequently share many common features such as developmental mechanisms. For these organisms, to find the first asymmetry point that drives post fecundated totipotent cells to differentiate into trophectoderm (Tr) or inner cell mass (ICM) is a challenge $(10,11)$. For mammalians, which gestation, with few exceptions, is done in the utter of the female, it was suggested that the first signals that drive zygot to morula development comes from the host (Fig. 1) (10). The embryo is dependent on stored maternal mRNA until at least the maternal-zygotic transition, when transcription of embryonic genes begins at the 2-cell stage and blastomeres development (10). Moreover, specific labelling of blastomeres suggest that the plane of the first cleavage specifies embryonic polarity (10). This indicates that the first asymmetry point occurs in 2-cell stage and specify each blastomere to differential contribution to the future ICM or $\operatorname{Tr}$ (10). Gene expression pattern that establish embryonic development stages, starts with the degradation of maternal mRNA followed to the three successive waves of zygotic gene expression, which provides necessary signals for morula compaction and blastocyst cavitation (10).

Subsequently to totipotent cells differentiation into extraembryonic tissue and development of pluripotent embryonic stem cells (ESCs), start the differentiation and morphogenesis process. This process is maintained until complete formation of every tissue present in the multicellular organism $(6,12,13)$. The signalling balance in the different lineage commitment is controlled by different transcription factors which activate linage-specific gene expression. Pluripotent cells differentiation occurs as a consequence of Oct4 repression by $\mathrm{Cdx} 2$ expressed from outer $\operatorname{Tr}(10,11)$. Cdx2 also down-regulates Nanog, altering Nanog/Gata6 balance, and consequently differentiating ICM cells in different population with Nanog positives cells, pluripotent, and Gata6 positive cells, primitive endoderm committed cells $(10,11)$. Pluripotent stem cells, from ICM or epiblast stem cells, are able to self-sustain and proliferate for long time under appropriate conditions or differentiate to primary germ layers (mesoderm, endoderm and ectoderm) (14). 

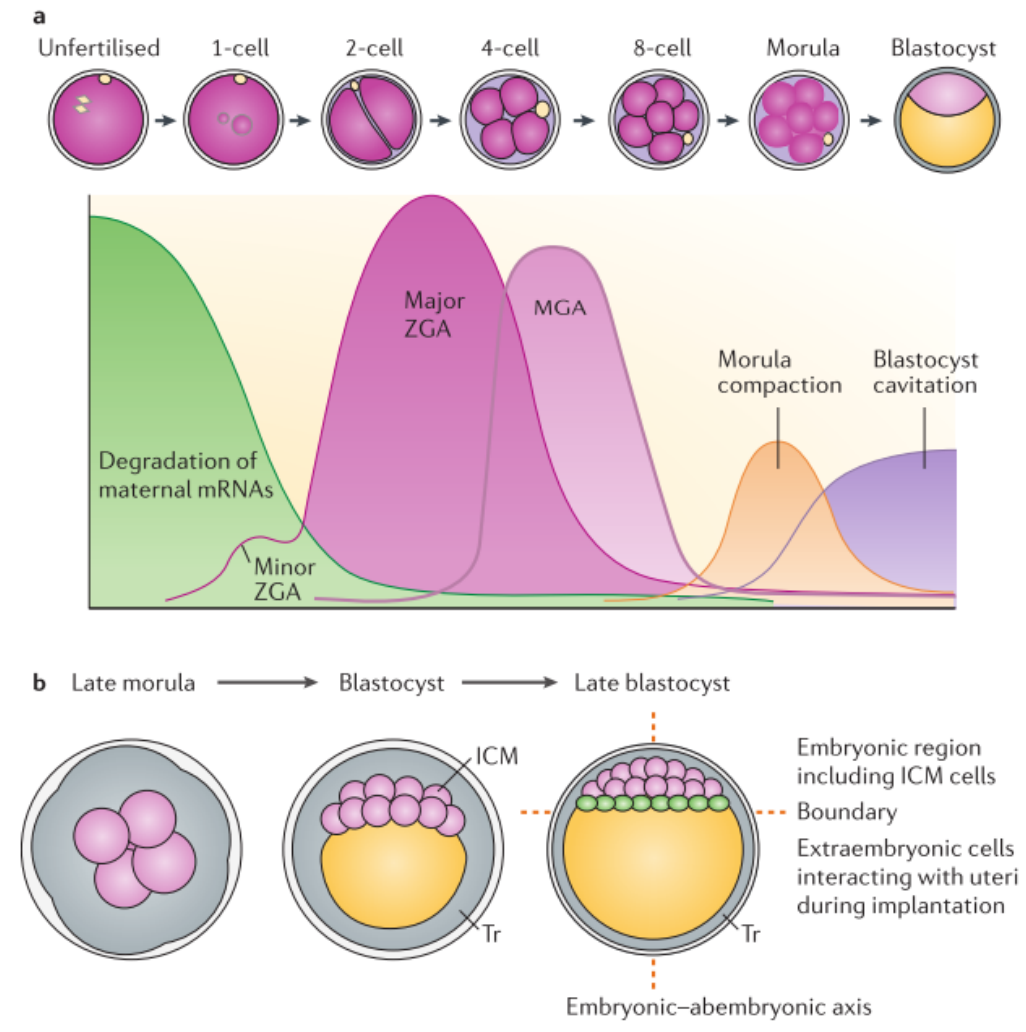

c

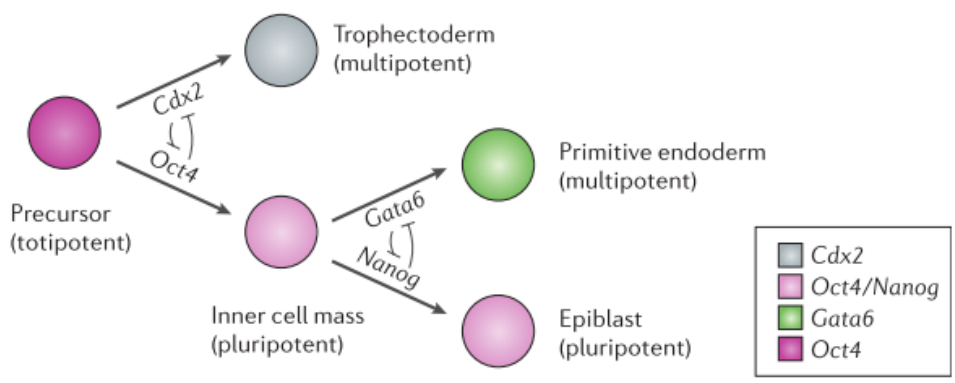

Figure 1. Representation of the sequence of events followed by post fecundated egg until the first stages of morphogenesis.

a) Egg fertilisation and posterior division until formation of blastocyst.

b) Morula polarisation in ICM progenitor and Tr.

c) Interaction between transcription factors in lineage commitment (10).

Figure obtained from H. Wang and S. Dey, Nature Reviews Genetics. 2006. 
In each step of embryo development, ESCs become differentiated until they disappear (15). Then, cells committed to specific lineages will continue differentiating and diverging until reaching every specialized cell types, with different morphologies, functions and interactions in their tissue context (16). Besides of these somatic cells, in some niches there are a few population of adult stem cells whose function is supporting and renew damaged or lost cells, maintaining tissue homeostasis (Fig. 2) (17-19). Between the various types of identified adult stem cells, some of most studied are mesenchymal stem cells, neural stem cells, satellite muscle cells or hematopoietic stem cells (17). These adult stem cells are classified as multipotent stem cells, being able to self-renew and increase their population or, in the appropriate context, to differentiate into specialised cells $(18,19)$. However, this differentiation is subjected to the lineage with which these cells were committed during emriogenesis (20). Hence, mesenchymal stem cells are able to differentiate to adipocytes, osteoblasts or chondrocytes, cells associated to connective tissue, whilst neural stem cells have only the option to differentiate to cells of nervous tissue lineages (20).

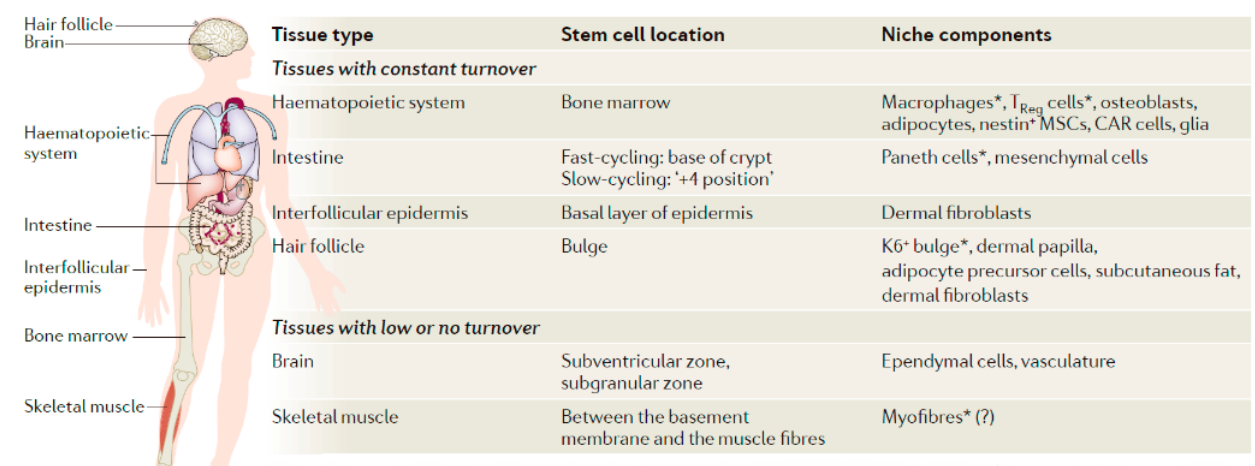

Figure 2. Representation of the different type of adult stem cells present in the body and its niche (17).

Figure obtained from Y. Hsu and E. Fuchs, Nature Reviews. Molecular Cell Biology. 2012.

\section{Self-regeneration problems in adult organisms}

All animals in Nature can heal and most can also regenerate some of their tissues and body parts. Regenerative capabilities among animals can vary from the limited wound-healing abilities of humans to the remarkable capacity of some 
worms to reform their entire bodies from small clumps of cells (21). Some examples of animals presenting regenerative abilities are salamanders presenting limb generation, Zebrafish heart regeneration, and the axolotl that can regenerate its limbs, spinal cord, heart, and other organs (21).

However, in mammalian organisms, tissue regeneration is commonly associated to the replacement of lost body parts, restoring mass and function $(22,23)$. Hence, this terminus could be referred to the small and local damages as a consequence of the normal activity of a living organism. This makes necessary the substitution of some lost cells by minor damage, cell death or aging to keep tissue homeostasis (22). Nevertheless, the most relevant and challenging type of tissue regeneration refers to tissue replacement after substantial trauma such as an amputation or ablation (22).

Immediately after an injury, the main biological response is the production of reactive oxygen species (ROS), which appear as universal injury-induced signals (24). Even though ROS signals present different sources and activities, they appear necessary to begin the first stages of regeneration processes (25). Furthermore, ROS are key signalling molecules in the progression of inflammatory process $(24,26)$. This immune response involves components of the innate immune system such as neutrophils and macrophages (Fig. 3). These cells, after being recruited, start to express pro-inflammatory cytokines such as tumour necrosis factor- $\alpha$ (TNF- $\alpha$ ) and interleukins IL-1b and IL- 6 to maintain inflammation in response to necrotic cells $(24,27)$. This response provide an instant defence against potential pathogens invading the damaged tissue (24). Recruitment of these inflammatory responsive cells constitutes the first steps of tissue regeneration process (Fig. 3) (24). Subsequently to inflammation, a long chain of events is triggered such as the secretion of cytokines and other signalling molecules. Secreted factors recruit scavenger cells to the site of injury, extracellular matrix secretor cells, scarring cells and multipotent stem cells or progenitors to repair the injured area $(22,24)$. Among inflammatory chemokines, stromal cell-derived factor-1 (SDF-1) and prostaglandin E2 (PGE2) have been extensively studied for its capacity to mobilise progenitor cells and promote angiogenesis (28). In this context the balance of signalling between regeneration or scarring of the injured area is critical for tissue regeneration (28). Elevated proinflammatory signals are detrimental for a correct tissue restoring(Fig. 3) (28). 


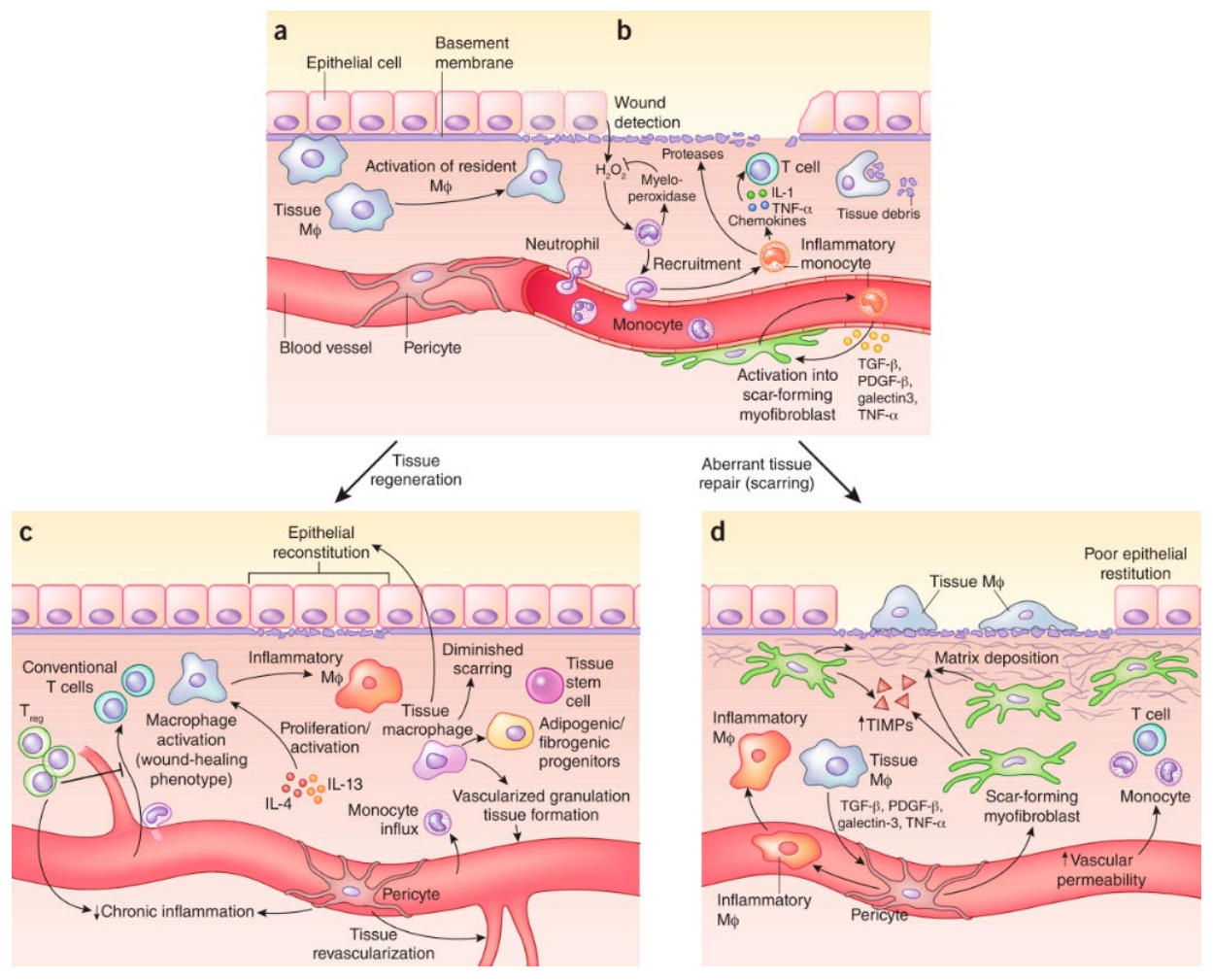

Figure 3. Differences among tissue regeneration process in:

(a) Healthy tissue with minimal damage. (b) A tissue damage that resulted in the loss of epithelia and activation of immune system. (c) Epithelia is regenerated by cell proliferation and extracellular matrix secretion. Cells are recruited to decrease chronic inflammation. (d) Continued activation of inflammatory cells resulted in aberrant tissue regeneration with excessive scarring (24).

Figure obtained from S. Forbes1 and N. Rosenthal, Nature Medicine. 2014.

Despite the presence of adult stem cells in the tissues, some damages are unable to heal as a consequence of the loss of a big population of cells or higher damaged area (22). This causes a strong activation of pro-inflammatory signals balancing the regeneration in favour of scar tissue formation (28). In these cases, the result is the formation of the scar fibrous connective tissue $(25,27)$, and consequently the alteration of tissue specific functions (24). However, in some scenarios such as big bone fractures, the loss of a large portion of tissue or sectioned tissue, such as damages in nervous system, make these wound unrepairable. Consequently the damage results in a dysfunctional tissue which need for surgery intervention $(29,30)$ or use of regenerative medicine strategies 
(Fig. 4). Regenerative medicine is the branch of medicine that develops methods to regrow, repair or replace damaged or diseased cells, organs or tissues (30). Regenerative medicine includes the generation and use of therapeutic stem cells, bioactive molecules or tissue engineering (29-31). Tissue engineering involves the combination of material science, cell therapy, use of growth factors, extracellular matrix proteins or other bioactive molecules to enhance and drive tissue regeneration (Fig. 4) (30). Many of these strategies entail the use of stem cells to proliferate and differentiate self-integrating in the damaged area, restoring tissue functions $(25,30,32)$.

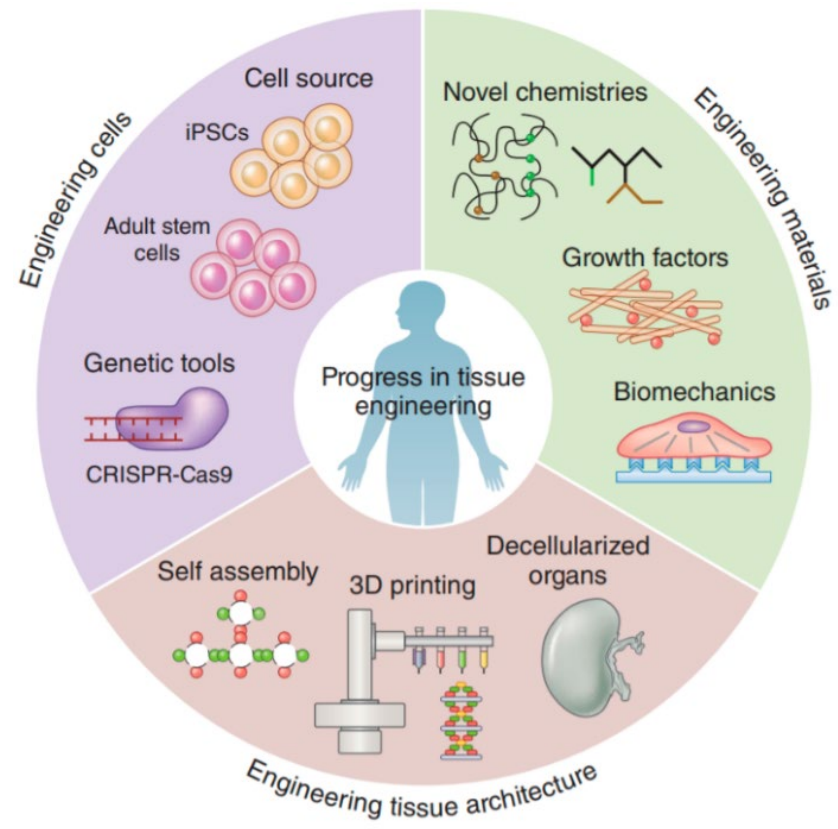

Figure 4. Strategies implemented for regenerative medicine approaches (32). Figure obtained from A. Khademhosseini and R. Langer, Nature Protocols. 2016.

Depending on the tissue, it is necessary an appropriate type of stem cells and stimuli balance to drive those cells to differentiate coherently for restoring damaged parts $(25,30)$. Moreover, it is important to keep in mind that adult stem cells have a limited differentiation capacity, and its use is restricted to the tissue within they have been committed to (33). Nevertheless, often, the main problem is to find the cell source. Although adult stem cells are present in many tissues, and some of them could be isolated without excessive problems, for instance hematopoietic stem cells (HSCs) or mesenchymal stem cells (MSCs) from bone 
marrow or adipose tissue, their number in an adult organism is very low $(34,35)$. Adult stem cells are present in the bone marrow in a frequency of 0.7 to 1.5 $\mathrm{HSCs} / 10^{8}$ nucleated marrow cells (36) and 0.1 to $1 \mathrm{MSCs} / 10^{5}$ nucleated marrow cells (37).

This makes adult stem cells isolation, identification and characterizations extremely difficult or non-viable depending on the type of stem cells (38-40). Furthermore, even if it was possible to obtain those cells from a xenologous donor, the following problem to address would be the immune system response as a consequence of the different surface antigens (41). Besides immune rejection, there are other important problems to consider, such as phenotypical changes of stem cells as a result of their culture outside of in vivo niche $(19,42)$. This is especially relevant for stem cells isolated from cardiac tissue or bone marrow (40). Stem cells constitutes a very small percentage of the total cells in the adult body. Consequently, their use for therapeutic approaches makes necessary previous steps of amplification and purification $(38,43)$. This in vitro amplification entails many obstacles such as: i) the loss of stem cells phenotype, ii) aging or activation of senescence programs and iii) spontaneous differentiation, giving rise an heterogeneous population which is not representative of the original isolated sample (40). Moreover, isolated stem cells usually display a great heterogeneity in their population, which is also affected by their culture outside their niche $(44,45)$. Overall, the use of stem cells in regenerative medicine is a challenge due to the problems for their isolation and their subsequent maintenance outside the niche.

The discovery of somatic cells reprograming to pluripotent cells by Takahashi and Yamanaka in 2006 (45) opened a wide window of possibilities for regenerative therapies. In their work, authors described that just four factors, Oct4, Sox2, Kruppel-like factor 4 (KIf4) and cMyc, were needed to turn back a somatic cell to a pluripotent state (45). These induced pluripotent stem (IPS) cells present the same properties of inner cell mass ESCs, with the ability of grow indefinitely or differentiate and contribute to all somatic cell types of the body $(46,47)$. Moreover, IPS cells also share with ESCs epigenetic traits, such as low DNA methylation, and exhibit an elevated telomerase activity (48). Initial approaches for somatic cell reprograming involved the use of retrovirus or lentivirus vectors for reprograming factors delivery. Nevertheless, these strategies hinder IPS cells use for therapeutic applications due to the possible genetic variation of reprogramed cells as consequence of genomic integration of reprograming viral 
vectors and alterations in genomic DNA $(49,50)$. However, emerging technologies based in non-integrative methods of reprograming, allows to obtain IPSs cells without the use of transgenes. These technologies could be classified as non-integrative viral vectors, such as transfection with adenoviral/sendai virus for reprograming factors delivery, or non-viral methods, based on the direct delivery of reprograming factors mRNAs, microRNAs, episomal vectors or direct delivery of reprograming proteins or other small molecules (51). Even though the use of non-integrative reprograming methods are a promising therapeutic approach (52), they are not extensively used and still produce low reprograming efficiency making integrative methods more attractive for research applications. IPS cells have been already used for many applications such as disease modelling, drug screening and other biomedical approaches (53). Furthermore, in the last decade, the use of both ESCs and IPS cells as a source of specialized cells is becoming more and more present in clinical trials for different tissues regeneration $(54,55)$. In the case of IPS, even though this technology is already in use for clinical trials to treat heart diseases and retinal degeneration $(55,56)$, one of the most important challenges is to demonstrate that these cells are safe for medical applications.

Even considering the large number of commonalities between IPS and ESCs, still they present some differences which makes challenging their use in developing technologies (57). Depending on the somatic cells source, the reprograming methods and posterior differentiating linage, these cells exhibit important differences necessary to be resolved before their use for tissue regeneration $(57,58)$. Besides, cells derived from pluripotent stem cells, commonly result in immature cells with heterogeneous population needed to be screened before possible regenerative applications (31). There is a need for addressing all these questions before to stablish IPS cells as a common alternative to obtain specialised cells for regenerative medicine.

\section{Signals that regulate cell fate}

As has been mentioned above, controlling the fate of stem cells is a challenge. Multipotent adult stem cells are located in specific and restricted environments known as stem cell niches $(17-19,42)$, which provide the required signalling and stimuli to prevent their differentiation $(18,19)$. These stimuli include the niche specific extracellular matrix (ECM), the paracrine factors released by other cells 
present in the niche and the effective range of the signals (Fig. 5) (18). Despite the majority of stem cells niches share some characteristics, such as the presence of blood vessels or neural inputs, making possible recruitment and directing these cells to injured regions, not all of mentioned elements are present in all niches (18). It depends on the type of stem cell and its role in the body.

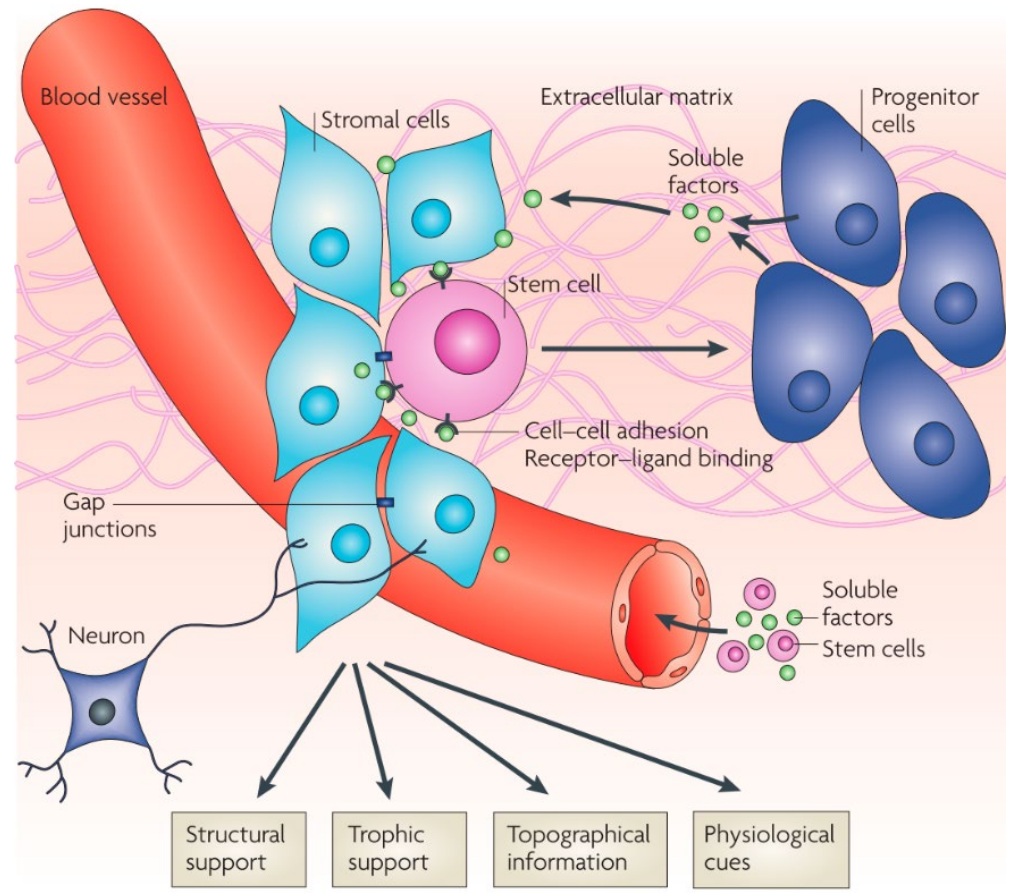

Figure 5. Representation of different cellular components and functions of the stem cell niches (18).

In this environment stem cells co-exist with other supporting cells and tissues that release soluble factors and keep stem cells protected from damage, sustain their multipotency and allow their recruitment when is needed.

Figure obtained from D. Jones and A. Wagers, Nature reviews. Molecular cell biology. 2008.

The signals provided by the stem cells niches can proceed from other cells present in the environment or from mechanical stimuli (18). For some stem cells, such as mesenchymal or hematopoietic cells, hypoxia promotes quiescence, avoids stem cell differentiation and protects these cells against ROS $(26,59)$. Moreover, ROS signals are important proliferation and differentiation promoter signals coming from injured tissues $(24,26)$. Generated forces within the niche 
can be transferred to the stem cells via cell-cell cadherin junctions (60) or through extracellular matrix (ECM) via focal adhesion complexes $(60,61)$. ECM and intracellular pathways are biochemically coupled by mechanotransduction pathways (60). Formation of focal adhesion and mechanical forces promotes phosphorylation and consequently activation of focal adhesion kinases (FAK) and mechanoresponsive signalling elements, such as mitogen-activated protein kinase (MAPK) and transforming protein Ras homolog gene family member A (RHOA). These mechanoresponsive signals downstream activate myosin light chain (MLC) phosphorylation to generate actomyosin forces and consequently nuclei translocation of transcriptional regulators, orchestrating the cellular response to a mechanical signal (60). These mechanical signals are especially relevant for musculoskeletal tissues, since they promote stem cells differentiation and trigger bone mineralisation and muscle hypertrophy (25).

The other cells present in the niche participate releasing soluble mediators of cellular response that directly interact with the stem cells or with other intermediary cells (17). Among these soluble mediators, the role of fibroblast growth factor-2 (FGF2) has been deeply studied. FGF2 appears an important signal of self-renewal and proliferation for mesenchymal, embryonic and other stem cells by targeting intracellular pathways such as Akt or MAPK $(62,63)$. Other relevant released factor is Leukaemia inhibitory factor (LIF), which promotes pluripotency associated genes expression in mouse ESCs through signal transducer and activator of transcription 3 (STAT3) translocation into the nuclei, or insulin like growth factors (IGF1/2) which prevents mouse and human ESCs from differentiation by activation of Phosphoinositide 3-kinase (PI3K)/Akt cascade (62-64). Besides soluble delivered factors, cadherins mediated cell-cell contacts are also an important self-renewing signals in many stem cells niches $(42,65)$. Cell-Cell junctions not only allow the transmission of mechanical forces. Interaction among two extracellular domains of cadherin trigger intracellular domain binding with $\beta$-catenin and $\alpha$-catenin, which are intermediary proteins for cytoskeleton binding and formation of stable adherent junctions $(19,42,65)$. The removal of E-Cadherin from contacting escort cell or follicular stem cell in Drosophila leads the departure of those cells from the niche (19), indicating that cadherin junctions are necessary to keep niche integrity. Moreover, cadherin signalling is also involved in the signal transduction for Akt phosphorylation in a similar way to soluble factors (42). 
The presence of blood vessels is especially relevant for stem cell niche. These structures allow long distance endocrine signalling to start stem cells proliferation and chemotaxis as response after injury $(17,24)$. Nevertheless, although there is some knowledge about the components and interaction in the niche, the complexity of this environment and the interaction of a great number of components makes it difficult to determine what type of signals reach the stem cells $(19,66,67)$ and to reproduce these conditions in vitro. Consequently, longterm culture of stem cells outside their environment results in a difficult issue due to loss of three dimensional tissue structure and the lack of specific signals from the niche. Especially considering that, overall, adult stem cells are present in the body in a reversible quiescent state and only proliferate under specific signals such as tissue damage $(68,69)$.

It is important to consider that extracellular soluble mediators, after binding to an activated receptor, trigger several intracellular signalling cascades. Consequently, the downstream signal integration will contribute to control cell behaviour by promoting protein post-translational modifications, activation of gene expression and altering cell metabolism $(23,70,71)$. There are many signalling pathways especially relevant for stem cells in terms of differentiation or self-renewal such as PI3K/Akt, Extracellular signal-regulated kinases (Mek/Erk), Ras/Raf, glycogen synthase kinase 3 (GSK3) or Janus kinase (JAK) between others $(62,72-74)$. Nevertheless, often the same pathway does not involve the same response in different stem cells, and depends of the role of the target protein in that specific cell. Insulin like growth factor (IGF1/2) binding with its receptor activates PI3K/Akt signalling, which promotes self-renewal mechanisms activation in ESCs (75). However, the same mechanism is responsible of the differentiation of adult stem cells such as mesenchymal stem cells(76) or muscle satellite cells $(77,78)$. Signalling context is extremely important for its transduction. The same signal can lead to one behaviour or another depending on the signals coexisting at the same moment (79). For example, GSK3 $\beta$ inhibition triggers mesoderm differentiation of ESCs (80), however, simultaneous inactivation of both GSK3 $\beta$ and ERK promotes ESC self-renewal(81). Hence, to link one signal with one response is a difficult issue because of the complexity of the crosstalk of different transcription factors, protein kinase and other molecules which regulate stem cell fate.

Signals involved in stem cell fate not only come from injured tissues or stem cell niche. Dietary incorporation, supplementation of culture medium with small 
molecules or cell released factors (such as growth factors or hormones), or even alteration of the composition and structure of cell environment are important signals to direct stem cell behaviour $(66,82-84)$. These strategies are commonly used for in vitro study of stem cells biology (85). Understanding of molecular cues of these soluble factors allows designing new therapies for tissue regeneration. In the last years FDA has approved the use of many drugs based in cell released molecules (29). The study of some cell released growth factors such as bone morphogenetic proteins 2 and 7 (BMP2, BMP7) was developed for non-union bone fractures healing (30). Other soluble mediator of cell response released by cells such as platelet derived growth factor (PDGF) was used pharmacologically to treat periodontal defects or lower extremity diabetic ulcers (30). Nevertheless, the study of these molecules does not stop here. There is an increasing trend for developing of different therapies for regeneration of non-healing tissues based in these biomolecules. Insulin or FGF2 were studied for stop and repair Alzheimer disease related neural degeneration $(29,86)$. Moreover, IGF1/2 were also used to promote skeletal muscle regeneration and improve its hypertrophy $(78,87)$.

In the last decade, several alternatives to growth factors have emerged due to the adverse side effects associated to the use of growth factors. Besides of the difficulties in the synthesis and the purification, FDA has already warned about the increased risk of some clinical approved growth factor in terms of cancer progression $(88,89)$. Some emerging strategies are the use of other kind of small molecules such as Plerixafor, which drives HSC mobilization from bone marrow niches, or Pleiotrophin to promote expansion of the HSC pool in vivo(29). In addition to the aforementioned molecules, the research in this field is not just focused on organic compounds. The use of inorganic ions-based strategies to stimulate stem cell response is growing in regenerative medicine applications $(90,91)$.

Although the presence of metal ions is essential for biological and physiological functions, ions relevance in terms of signalling lies in the concentration (91). Among these ions, calcium, sodium, zinc, iron, copper and boron have been focused several times (91). The relevance of some of these molecules has been reviewed in the literature, coupling the effect of higher concentrations of calcium (92-94), zinc $(95,96)$ or iron (97-99) with significant changes in specific gene expression or post-translational modifications, allowing to control stem cell fate.

Finally, we should consider that regardless of the source and the type of signal, intracellular changes are the ones controlling cell behaviour. Therefore, there is 
some redundancy in the effect of many molecules as a consequence of a common intracellular target (100). Intracellular protein expression and activity can be regulated by genetic engineering or RNA interference triggering overexpression of some protein $(101,102)$, and consequently increasing its role in cell signalling context, or even down regulating or supressing other proteins removing its signalling (103). Even though these approaches are controversial in terms of regenerative medicine applications, they are very useful tools for the investigation of the signalling and regulatory networks to understand stem cells biology (104).

\section{Ion mediated signalling in stem cells}

Cell cytosol is composed by many soluble molecules classified as inorganic ions, metabolites and macromolecules such as proteins $(105,106)$. Ionic composition regulates cell electric potential, ion transporters (channels and pumps) and metalloproteins activity $(105,107)$. The electric potential is a consequence of the difference of ion composition and concentration between cytosol and extracellular environment. This property provide some cells (neurons) their ability to conduct (through activation of ion transporters), transmit, and receive electric signals (106). Moreover, membrane potential allows cells to sense electric field and respond to it (108). In the case of metalloproteins (proteins bound to metal ions), their sensitivity to ion composition is mediated by their specific ion binding region, which are able to discriminate between the correct metal and others $(107,109)$. Metalloprotein activity is restricted to ion-protein binding, which enable its activity. This family of proteins are responsible to carry out biological processes such as gene transcription, respiration, molecular oxygen reduction or protein degradation $(107,109)$. Hence, metal sensing elements are important regulators of cell behaviour.

As has been mentioned before, ion-mediated signalling and its consequences in many diseases such as cancer is a growing research field (Fig. 5) $(94,97,110,111)$. Some of the most studied ions and their aberrant signalling consequences are calcium, iron and zinc $(92,94,97,111)$. The binding of the ion to protein alters its shape and charge, two properties that govern the protein activity (92). Therefore, concentrations of these ions in the metalloproteins environment are directly linked with the activity of these metal sensing elements, translating ions concentration signalling to a protein interaction context (92). The 
understanding of the function and signalling of ion-responsive elements allows designing ion-based strategies to drive stem cell fate. Calcium is one of most relevant metallic ions in the organism and is involved in many signalling processes in the cells (Fig. 6). Transient changes in intracellular concentration of $\mathrm{Ca}^{2+}$ works as an intracellular second messenger (112) downstream regulating several processes such as cell motility, muscle cell contraction, neural regeneration, cardiac regeneration or hematopoietic cells differentiation $(92,112)$. These transient changes in intracellular concentration of $\mathrm{Ca}^{2+}$ occurs as a consequence of the activation of $\mathrm{G}$ protein coupled receptors (GPCR) by binding with its ligand, which subsequently activates phospholipase $C \beta$ (PLC $\beta)$ and tyrosine kinase receptors (TKR), triggering a series of events which conclude with 1,4,5-inositol trisphosphate $\left(I_{3}\right)$ binding to the $I_{3}$ receptor $\left(I_{3} R\right)$ in endoplasmic reticulum (ER). IP3Rs are cationic channels that conduct $\mathrm{Ca}^{2+}$ allowing its diffusion from the ER to increase intracellular concentration of $\mathrm{Ca}^{2+}(92,94)$. The rapid increase of intracellular concentration of $\mathrm{Ca}^{2+}$ leads its binding to $\mathrm{Ca}^{2+}$ sensor and adaptor proteins such as calmodulin, producing changes on its conformation, triggering their ability to relieve protein autoinhibition (92). After being activated, calmodulin will be recruited by its target protein promoting their activity and signalling. Among the numerous calmodulin dependent proteins, calmodulin protein kinase (CaM-kinase) family are especially important because they are involved in several signalling pathways and transcriptional activity (92). 


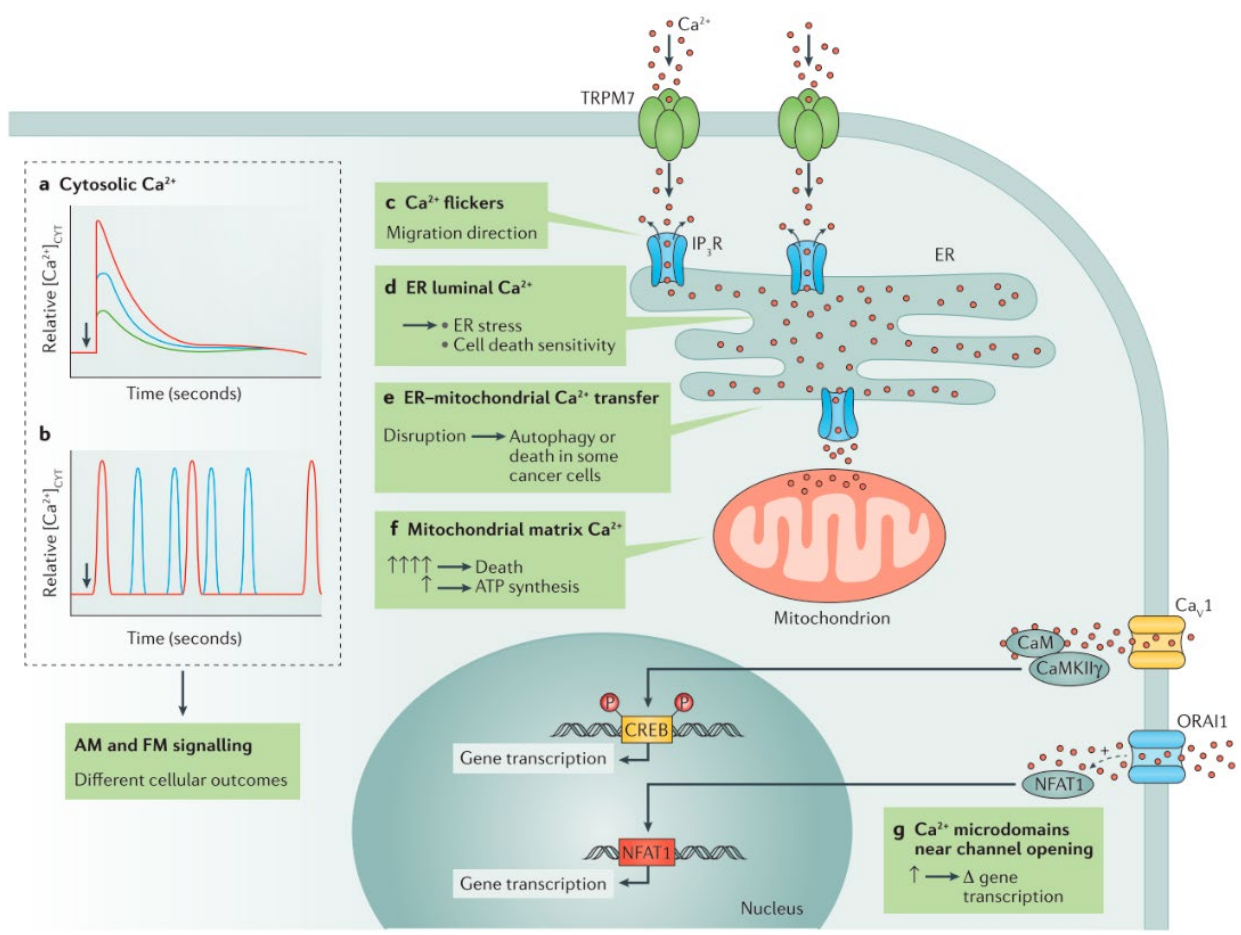

Figure 6. Diversity of calcium signalling mechanisms in the cells (94).

Variation in the concentration of calcium activates/inactivates several signalling mechanisms triggering protein post-translational modifications an altering gene expression.

Figure obtained from G. Monteith et al., Nature Reviews. Cancer. 2017.

However, $\mathrm{Ca}^{2+}$ signalling is not only restricted to its intracellular action as a consequence of extracellular signalling. The calcium-sensing receptor (CaSR) is a widely expressed homodimeric GPCR located in cell membrane which act as a $\mathrm{Ca}^{2+}$ sensor (113). Stimulation of this receptor with increasing concentrations of extracellular $\mathrm{Ca}^{2+}$ entail downstream activation of many proteins such as IP3, releasing intracellular $\mathrm{Ca}^{2+}$ and activating $\mathrm{Ca}^{2+} /$ calmodulin depending cascade, or other protein kinases such as Erk1/2, Akt, phospholipase C (PLC) or C-Jun Nterminal kinase $(\mathrm{JNK})(113)$. Activation of these proteins triggers important changes in some stem cell behaviour. CaR stimulation in osteoblasts and subsequently activation of PLC, Erk1/2 and JNK signalling cascades is associated with osteoblast migration and differentiation promoting bone remodelling (113). Besides CaSR role was identified as an important regulator of hematopoietic stem cells niche localisation in bone marrow. The bone marrow 
niche contains abundant $\mathrm{Ca}^{2+}$ on its composition, which stimulate CaSR signalling and direct HSC towards bone (8).

Another important ion participating in stem cell signalling, which in turn acts also as a second messenger, is zinc (114). $\mathrm{Zn}^{2+}$ is an essential transition metal present in the organism and involved as a co-factor in the activity of hundreds of proteins. The role of $\mathrm{Zn}^{2+}$ is critical to achieve structural, regulatory and catalytic functions, controlling several metalloproteins dynamics such as enzymes and transcription factors $(95,110)$. However, its function as a second messenger involves even a greater number of processes related with intracellular levels of $\mathrm{Zn}^{2+}$, making it even more interesting in signal transduction processes. After extracellular stimulus of high affinity immunoglobulin $E$ ( $(\mathrm{gE})$ receptor, intracellular release of $\mathrm{Zn}^{2+}$ through intracellular $\mathrm{Zn}$-transporters triggers cytoplasmic increase of $\mathrm{Zn}^{2+}$ concentrations. This phenomenon, also known as zinc wave, inhibits phosphatase activity modulating some protein kinase signalling such as Erk, JNK or PI3K/Akt $(114,115)$. The upgraded kinase activity of these proteins results in significant changes in cell behaviour, such as cell motility or proliferation (114). Regulation of $\mathrm{Zn}^{2+}$ influx intro the cytoplasm is critical for $\mathrm{Zn}^{2+}$ mediated signalling. Intracellular concentrations of $\mathrm{Zn}^{2+}$ are mostly controlled by $\mathrm{Zn}^{2+}$ importers (ZIP) and $\mathrm{Zn}^{2+}$ exporters ( $\mathrm{ZnT}$ ) (Fig. 7). The function of ZIP family transporters is to channel the entry of zinc into the cytoplasm, whilst the function of $\mathrm{ZnT}$ transporters is to evacuate zinc from the cytoplasm to intracellular stores or extracellular environment (95). These two types of transporters regulate intracellular concentration of free $\mathrm{Zn}^{2+}$ modulating its levels. $\mathrm{Zn}^{2+}$ mediated signalling has been often related with ZIP family of $\mathrm{Zn}^{2+}$ transporters. ZIP12 transporter is highly expressed in brain, compared with other ZIP family transporters, and its ablation is closely related with alterations in neurite growth, being involved with nervous system development (116). Similarly, ZIP14 transporter have been related to GPCR-mediated CAMP-CREB signalling, resulting in growth defects in mice lacking ZIP14 transporter (110). 


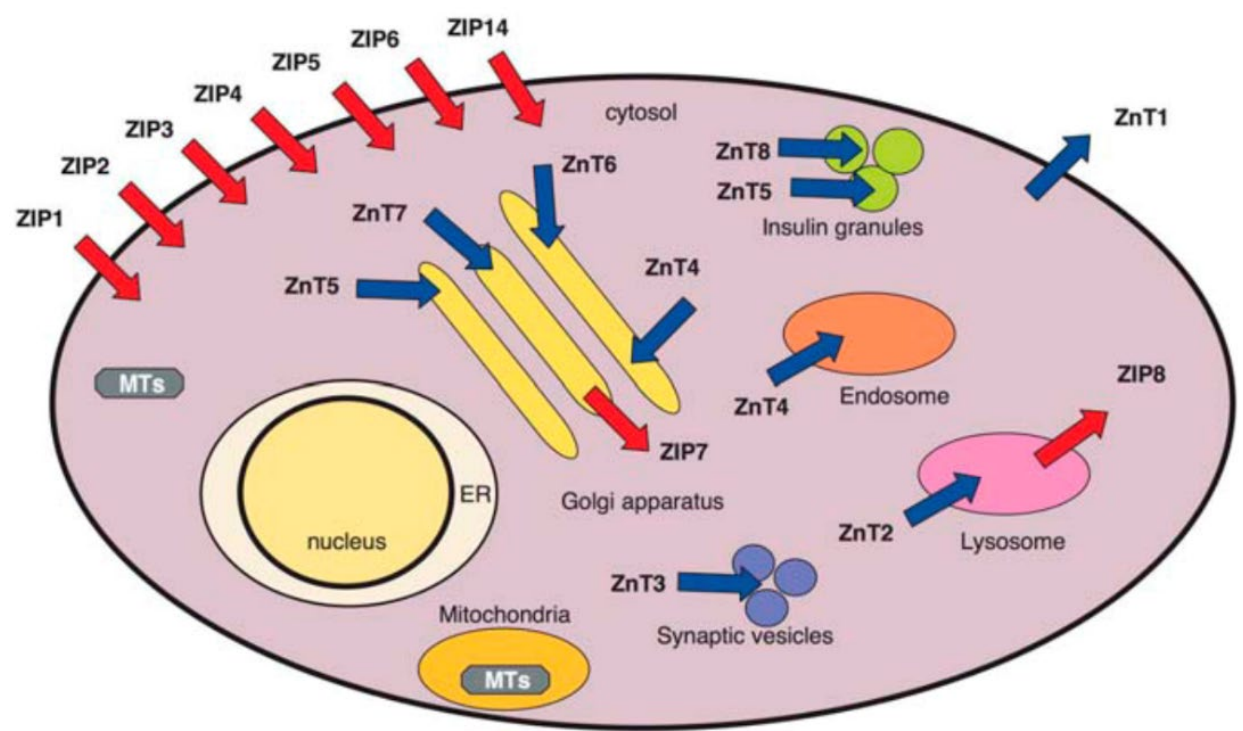

Figure 7. Representation of subcellular localization of $\mathrm{Zn}^{2+}$ transporters and $\mathrm{Zn}^{2+}$ homeostatic cycle (95).

Zip transporters allows $\mathrm{Zn}^{2+}$ influx from extracellular medium or organelles to cytosol. ZnT proteins control $\mathrm{Zn}^{2+}$ efflux from cytosol to intracellular storages or extracellular medium. Figure obtained from M. Murakami and T. Hirano, Cancer Science. 2008.

Nevertheless, in terms of direct signalling by increasing extracellular concentrations of $\mathrm{Zn}^{2+}$, the most studied transporter is ZIP7 $(96,115)$. Located in ER, Zip7 is activated in the presence of high concentration of extracellular $\mathrm{Zn}^{2+}$, producing downstream signal transduction into the cell through the "zinc wave" (115). The increase of extracellular concentration of $\mathrm{Zn}^{2+}$ produce casein kinase 2 (CK2) mediated phosphorylation of ZIP7 transporter that in turn induces $\mathrm{Zn}^{2+}$ release from intracellular storages such as ER. The intracellular increase of $\mathrm{Zn}^{2+}$ inhibits phosphatase activity upgrading their associated protein kinase signalling (115). ZIP7 depletion or mutation significantly alters $\mathrm{Zn}^{2+}$ wave and consequently $\mathrm{Zn}^{2+}$-mediated phosphorylation of both, Akt and ERK1/2 (115). Among these kinases, ERK1/2 are specially interesting because they could be responsible of $\mathrm{Zn}^{2+}$-mediated stimulation of cell proliferation for many cell types such as myoblasts (117). Besides, $\mathrm{Zn}^{2+}$ has been associated with a transient inhibition of embryonic stem cells differentiation (118), making zinc an interesting element of research for stem cell signalling. 
Another well studied ion in biological systems is lithium. Even though there is some controversy regarding if lithium is essential for living organisms, its role in signalling processes is remarkable (119). The signalling role of lithium is associated to protein kinase activity. Extracellular supplementation of $\mathrm{Li}^{+}$ produces glycogen synthase kinase 3 alpha and beta (GSK3 $\alpha / \beta)$ phosphorylation in serine 21 for GSK3 $\alpha$ and serine 9 for GSK3 $\beta$ (120). Phosphorylation of these residues negatively regulates the activity of GSK3 $(120,121)$. Both isoforms of GSK3 are serine/threonine kinases involved in numerous signalling transductions through phosphorylation of its target proteins and regulating gene expression (121). Despite $\mathrm{Li}^{+}$is a non-specific inhibitor of GSK3, this activity of $\mathrm{Li}^{+}$results especially relevant in stem cells because one of the most important targets of GSK3 $\beta$ is $\beta$-catenin (122-124). GSK3 $\beta$-mediated phosphorylation of $\beta$-catenin promotes the activation of the $\beta$-catenin destruction complex disrupting its signalling (120). The relevance of $\beta$-catenin in stem cell biology and embryo development rely in its dual function as a structural protein involved with cadherin and actin cytoskeleton binding, and its function as a transcriptional regulator, controlling the transcription of several relevant genes involved in developmental processes $(125,126)$.

The multifunctional activity of some ions makes them an interesting object of study as key regulators of stem cell behaviour. As previously mentioned, metallic ions can be used for both, activate signalling pathways through phosphorylation of molecular switches such as Akt, ERK or JAK, and inactivate other such as GSK3. Moreover, specific binding regions in some proteins makes their activity metallic ion-binding dependent. Hence, ion signalling can both stabilise and act as a co-factor for metalloproteins or directly be involved in signal transduction playing a role as a second messenger or disrupting some signalling pathways. Thus, some ions can successfully activate/inhibit several signalling pathways. Overall, the use of ions constitutes an important alternative for tissue engineering applications instead of using other signalling molecules such as growth factors, cytokines or hormones. 


\section{Objectives}

Stem cells regulatory mechanisms are based in complex interactions among multiple molecular effectors with different individual roles that are delicately balanced. Variation in the expression or activity of one of these molecules can imbalance the diverse molecular processes, driving stem cells fate towards differentiation, self-renewal or apoptosis. Many approaches in the literature report different strategies for controlling stem cell behaviour. However, the molecules used to supply these signals, and consequently drive stem cell fate, are generally members of the family of growth factors, cytokines, hormones and organic small molecules. These molecules possess great power but they are normally required at high doses, that can cause undesired side effects such as cancer. Thus, there is a real need for the development of alternative strategies to control stem cell fate.

lons are involved in multiple signalling pathways regulating cell fate and behaviour. In this doctoral thesis we hypothesise that metallic ions can be used to trigger specific stimuli to lead stem cells fate, being a powerful alternative to cytokines, hormones and small molecules, representing a simple, cost-effective, stable and safest approach to be implemented in tissue engineering applications.

In order to demonstrate our hypotheses, in this work we have addressed the following specific objectives:

1. Determine the role of zinc on cell proliferation and differentiation in murine muscle cells (myoblasts). 
2. Study the role of molecular cues activated by zinc in murine muscle cells (myoblasts).

3. Analyse the role of zinc on self-renewal and pluripotency in murine embryonic stem cells (ESCs).

4. Study the role of molecular cues activated by zinc implicated in ESCs pluripotency.

5. Analyse the role of lithium on viability, proliferation and differentiation in murine embryonic stem cells (ESCs).

6. Study the role of molecular cues activated by lithium implicated in ESCs hemogenic endothelial differentiation. 


\section{Chapter I \\ Zinc enhances myogenic differentiation through Akt activation via zinc transporter Zip7}




\section{Introduction}

Skeletal muscle is an heterogeneous, dynamic and plastic tissue, which comprises approximately the $40 \%$ of the adult human body mass. Through contraction and relaxation, skeletal muscles provide movement and stability to the body. Muscle tissue contributes significantly to the correct metabolic functions serving as the major body's reservoir of amino acids needed to maintain protein synthesis in vital tissues and organs (127). Furthermore, muscle tissue provides storage for carbohydrates and other elements such as zinc or calcium $(127,128)$. Alterations in muscle mass may cause some of the most common diseases and conditions such as obesity and diabetes in addition to others chronic diseases (128).

Muscle tissue is the largest cellular compartment of the body, characterized in physiological conditions by a relatively slow turnover (129). It is composed by a combination of myofibres bound by connective tissue $(127,130)$. Satellite cells, mostly in a quiescent state and located between the basal lamina and the plasma membrane of myofibres, are the main source of myogenic precursors and provide skeletal muscle remarkable ability to regenerate after injury (34).

In response to a muscle injury, satellite cells become activated, leave quiescence and start to proliferate. Activated satellite cells progress to become fusioncompetent myoblast (131). Eventually, these myoblasts proliferate and differentiate creating new myofibres and restoring tissue damage (132). Various mechanisms and signalling molecules play an important role during muscle regeneration. In the first steps of post-injury, muscle degeneration and posterior inflammation result in the activation of resident macrophages, which release chemoattractant molecules recruiting neutrophils and monocytes. Subsequently, inflammatory mediators such as tumour necrosis factor alpha (TNFa) are also released. Immune, myogenic, and fibroblastic cell interactions are coordinated to eventually carry out muscle restoration (133).

Several growth factors such as insulin-like growth factor (IGF), basic fibroblastic growth factor (bFGF), hepatocyte growth factor (HGF) or nerve growth factor (NGF) play a variety of relevant functions during muscle regeneration, enhancing damaged muscle healing. Among the signalling processes which lead to muscle regeneration, IGF/PI3K/Akt cascade is one of most studied because of its role in initial cell proliferation, myoblast commitment, and posterior differentiation and maturation to obtain new myofibrils $(78,87,134)$. Protein kinase Akt activation by IGF/PI3K cascade enhances the activity of the transcription factor MyoD in 
myoblasts cells, inducing them to terminal differentiation into myocytes and subsequent fusion into regenerating myofibers (135-137).

Skeletal muscle possesses a robust innate capability for repair, however severe injuries that result in significant loss of muscle mass exceed the innate regeneration and require intervention to restore its normal function (138). The main strategies currently under investigation to address skeletal muscle disorders and regeneration are based on drugs/biomolecules delivery, cell therapies, or a combination of both approaches. Exogenous addition of specific molecules that involve PI3K/Akt signalling pathway, such as apelin-13 peptide, Sphingosine 1phosphate lipid (S1P) $(139,140)$, anabolic steroids $(141)$ or growth factors, such as IGF or vascular endothelial growth factor (VEGF) have shown promising results as a potential therapeutic approach $(142,143)$. However, the use of growth factors has been controversial as typically involves supra-physiological doses to be effective, which increases cancer risk and other off-target lateral effects (144146).

In this context, cell exposure to heavy metal ions, such as $\mathrm{Zn}^{+2}$ and $\mathrm{Cu}^{+2}$ has been reported to stimulate $\mathrm{PI} 3 \mathrm{~K} / \mathrm{Akt}$ signalling, which is known to be antiapoptotic and cytoprotective $(147,148)$. Zinc is one of most important transition metals present in eukaryote cells and plays a key role in the regulation and functioning of many signalling and structural proteins and transcription factors $(149,150)$. To achieve the control of zinc homeostasis in cells, there are several ion transporters responsible for allowing the influx of zinc from extracellular medium or different vesicles (zincosomes, Golgi apparatus or endoplasmic reticulum (ER)) to the cytoplasm. Influx zinc transporters are classified into the family of solute carriers Zip (or Slc39a) and divalent metal transporters DMT-1 $(86,95)$. In addition of the influx transporters aforementioned, there are other transporters which drive the efflux of zinc from cytoplasm to extracellular medium and vesicles, classified into the family of Slc30a, also known as ZnT $(86,95)$. Among the Zip family of metal ion transport proteins, zinc transporter Zip7 (or slc39a7) is one of most studied as it is involved in signalling pathways and diseases such as cancer $(111,151)$. Zip7 is also the most expressed transporter among the Zip family in myoblast cells (152). The activity of Zip7 by phosphorylation of casein kinase 2 (CK2) and posterior release of zinc from ER might be required for the activity of several protein kinases (153).

Zinc homeostasis is of major significance in skeletal muscle tissues. Marginal zinc deficiency is manifested as muscular tissue degeneration and loss of muscle 
mass. It has been reported that recovery from muscle injury in mice might be partly impaired and delayed with a diet poor in zinc (154). Furthermore, zinc can act as secondary messenger, performing signal transduction and activating some signalling pathways such as PI3K/Akt and Mek/Erk, which are highly involved in skeletal muscle regeneration $(114,115,155)$. The role of zinc in cell proliferation via PI3K/Akt and Mek/Erk pathways has been described by several authors, demonstrating the mitogenic activity of zinc $(117,156)$. These evidences suggest that zinc could play a key role in the regulation of muscular tissue regeneration as it is involved in several signalling pathways relevant for both myoblast proliferation and myogenic differentiation.

In this chapter, we investigate whether exogenous zinc promotes myogenic differentiation, to assess the potential of zinc to promote muscle regeneration in the absence of growth factors. We use $\mathrm{C} 2 \mathrm{C} 12$ murine myoblasts, a cell line widely accepted to study muscle development (157). We investigated Akt activity as well as Zip7 expression and distribution in both undifferentiated and differentiated cells exposed to $\mathrm{Zn}^{2+}$ to unveil the role of zinc in myoblast differentiation.

\section{Materials and methods}

\section{Cell culture}

Murine myoblasts (C2C12, Sigma-Aldrich) were cultured in high glucose Dubelcco's Modified Eagle's Medium (DMEM, Biowest) supplemented with 10\% of Foetal bovine serum (FBS, Thermofisher) and $1 \%$ of $100 \mathrm{X}$ Penicillin/Streptomycin (10,000 U/ml Penicillin-10,000 $\mu \mathrm{g} / \mathrm{ml}$ Streptomycin, P/S, ThermoFisher) in a humidified atmosphere at $37^{\circ} \mathrm{C}$ and $5 \% \mathrm{CO}_{2}$. Cells were routinely passaged after reaching $70 \%$ confluence. Zinc chloride (Sigma-Aldrich) was used as source of $\mathrm{Zn}^{2+}$ for in vitro experiments.

\section{Live dead (cytotoxicity) and proliferation (total cell density and BrdU) assays}

Cytotoxicity was tested for myoblast and myotubes. For myoblast cytotoxicity, C2C12 were seeded at low density $\left(10,000\right.$ cells $\left./ \mathrm{cm}^{2}\right)$ in growth medium (DMEM $+10 \% \mathrm{FBS}+1 \% \mathrm{P} / \mathrm{S})$. After $24 \mathrm{~h}$ allowing cell adhesion, culture medium was substituted for differentiation medium (DMEM $+2 \%$ FBS $+1 \% \mathrm{P} / \mathrm{S}$ ) and supplemented with $20,40,60$ and $80 \mu \mathrm{M}$ of $\mathrm{Zn}^{2+}$ during 1, 3 and 5 days using 
Live/Dead Viability/Cytotoxicity Kit (ThermoFisher). Different zinc concentrations were added in each additional medium change. Medium without $\mathrm{Zn}^{2+}$ was used as a control $\left(\mathrm{w} / \mathrm{o} \mathrm{Zn}^{2+}\right)$. As a positive control of cytotoxicity, Triton X-100 (SigmaAldrich) was added at $0.01 \%$ to culture medium and incubated for 10 minutes before performing the cytotoxicity assay. Cytotoxicity values were obtained by fluorescent quantification of calcein-AM (Ex 485/Em 535) with plate reader Victor III (Perkin Elmer) device. Results were represented as the ratio between number of viable cells $+\mathrm{Zn}^{2+} /$ number of viable cells w/o $\mathrm{Zn}^{2+}$ ).

For myotube cytotoxicity, C2C12 were seeded at high density $\left(20,000 \mathrm{cells} / \mathrm{cm}^{2}\right)$ in growth medium (DMEM $+10 \% \mathrm{FBS}+1 \% \mathrm{P} / \mathrm{S})$. After $24 \mathrm{~h}$ allowing cell adhesion, culture medium was substituted for differentiation medium (DMEM + $2 \% \mathrm{FBS}+1 \% \mathrm{P} / \mathrm{S}$ ). After 6 days of culture when myotubes were formed, medium was supplemented with $20,40,60,80$ and $100 \mu \mathrm{M}$ during 1,3 and 5 days.

Note that for myoblast and myotube conditions we used differentiation medium to evaluate zinc effects in low serum conditions.

C2C12 were seeded at very low density $\left(5,000 \mathrm{cells} / \mathrm{cm}^{2}\right)$ for determination of total cell density, and low density $\left(10,000\right.$ cells $\left./ \mathrm{cm}^{2}\right)$ for BrdU (proliferation) assay, previous synchronisation of cell cycle by serum starvation for $24 \mathrm{~h}$. Then, culture medium was substituted for differentiation medium (DMEM + 2\% FBS + 1\% P/S) supplemented with different concentrations of $\mathrm{Zn}^{2+}(20$ and $40 \mu \mathrm{M})$ and $10 \mu \mathrm{M}$ of $\mathrm{BrdU}$ for proliferation assay. To analyse cell proliferation in medium supplemented with insulin-transferrin-selenium (ITS, Thermofisher), cell density was assessed as above was described substituting $2 \%$ FBS for $1 \%$ ITS.

Myoblasts were fixed with $4 \%$ formaldehyde after 1, 3 and 5 days of culture for determination of total cell density, and after 1 day for BrdU assay. Total cell density was analysed after image analysis quantification (Image J) of total nuclei stained with Hoechst (dil: 1/7,000; Sigma-Aldrich). For BrdU proliferation analysis, results were obtained as the ratio between BrdU positive cells / total number of cells.

\section{Myogenic differentiation visualisation}

For myoblast differentiation experiments, $\mathrm{C} 2 \mathrm{C} 12$ cells were seeded at confluence density $\left(20,000\right.$ cells $\left./ \mathrm{cm}^{2}\right)$ or low density $\left(10,000 \mathrm{cells} / \mathrm{cm}^{2}\right)$ onto polystyrene plates in culture medium. After $24 \mathrm{~h}$, culture medium was changed for differentiation medium (DMEM $+2 \% \mathrm{FBS}+1 \% \mathrm{P} / \mathrm{S}$ ) supplemented with $\mathrm{Zn}^{2+} 20$ and $40 \mu \mathrm{M}$. After 6 days of culture, cells were fixed with $4 \%$ formaldehyde and 
blocked with TBS / BSA $1 \%$ for $1 \mathrm{~h}$ at room temperature. Then cells were incubated with anti-Myosin Heavy Chain (anti-MHC, dil: 1/200; Developmental Studies Hybridoma) over night at $4^{\circ} \mathrm{C}$. After primary antibody incubation, samples were rinsed and incubated with secondary antibody anti-mouse Alexa 488 (dil: 1/500; Thermofisher). Hoechst (dil: 1/7,000; Sigma-Aldrich) was used for cells nuclei staining. Samples were mounted with $85 \%$ glycerol and imaged by a Nikon Eclipse i80 fluorescence microscope. MHC positive cells were quantified by image analysis with image J software, and represented as the ratio between MHC positive cells / total cell number (ratio of differentiated cells) and the ratio between multinucleated myotubes / mononucleated MHC positive cells (ratio of multinucleated myotubes).

\section{Analysis of intracellular $\mathrm{Zn}^{2+}$}

C2C12 cells were seeded at low density $\left(10,000\right.$ cells $\left./ \mathrm{cm}^{2}\right)$ and intracellular $\mathrm{Zn}^{2+}$ was analysed at two different time points: $24 \mathrm{~h}$ and after myotube formation (6 days). Intracellular amount of $\mathrm{Zn}^{2+}$ was determined after addition of 20 and $40 \mu \mathrm{M}$ of $\mathrm{Zn}^{2+}$ in the culture medium. After cell culture, cells were washed with PBS and intracellular $\mathrm{Zn}^{2+}$ was labelled by means of FluoZin3-AM $(2 \mu \mathrm{M})$ system detection (Thermofisher). Fluorescence emission was analysed by Victor III plate reader (Perkin Elmer). Cells were imaged using Nikon Eclipse i80 microscope. A parallel assay was used for Hoechst staining for total cell density quantification by image analysis with image J software.

For analysis of intracellular $\mathrm{Zn}^{2+}$ after silencing of Zip7, Zip7 silenced $\mathrm{C} 2 \mathrm{C} 12$ cells were incubated with FluoZin3-AM $(2 \mu \mathrm{M})$ for $40 \mathrm{~min}$. and washed with PBS. After that, medium with different concentrations of zinc were added (20 and $40 \mu \mathrm{M})$ and fluorescence emission was measured every 40 seconds during approximately 40 minutes.

\section{Gene expression analysis by quantitative real time PCR}

Total RNA from C2C12 cells cultured for 3 and 6 days was extracted using Quick RNA Miniprep kit (ZYMO Research) and its quantity and integrity was measured using Q3000 micro volume spectrophotometer (Quawell). RNAs were reverse transcribed using Maxima First Strand cDNA synthesis kit with thermolabile dsDNAse (Thermofisher). Real-time qPCR was carried out using the PowerUp SYBR Master Mix (Thermofisher) and 7500 Real Time fast PCR system from Applied Biosystems. The reactions were run four times (independent biological experiments). The primers used for amplification were designed based on 
sequences found in the GenBank database and included: MyoD1 (Forward: 5'CGCTCGTGAGGATGAGCAT-3', Reverse: 5'-AGCGTCTCGAAGGCCTCAT3'), Myogenin (Forward: 5'-TGCCGTGGGCATGTAAGGT-3', Reverse: 5'TGCGCAGGATCTCCACTTTAG-3') and GAPDH was used as a housekeeping gene (Forward: 5'-AGGTCGGTGTGAACGGATTTG-3', Reverse: 5'-TGTAGA CCATGTAGTTGAGGTCA-3'). The fractional cycle number at which fluorescence passed the threshold (Ct values) was used for gene expression quantification using the comparative $\Delta \Delta C T$ method (158). Sample values were normalized to the threshold value of housekeeping gene GAPDH.

\section{Zip7 expression and Akt activity.}

Distribution of Zip7 was analysed in non-differentiation (after $24 \mathrm{~h}$ ) and differentiation (after 6 days) cell stages by immunofluorescence, using specific antibody against Zip7 (dil: 1/200; Santa Cruz Biotechnologies). Primary antibody was incubated over night at $4^{\circ} \mathrm{C}$. After washing, anti-goat Dye Light 488 (dil: 1/500; Thermofisher) secondary antibody was added and incubated for $1 \mathrm{~h}$ at room temperature. Cell cytoskeleton was labelled using Alexa Fluor 555 Phalloidin (dil: 1/100; Thermofisher) and cell nucleus with Hoechst. Cells were imaged by Nikon Eclipse i80 fluorescence microscope.

For protein expression analysis, total protein extraction was performed with RIPA buffer supplemented with protease inhibitor cocktail tablets (Roche). Proteins were separated in $12 \%$ SDS-PAGE as described previously (159). Primary antibodies against Zip7 (dil: 1/300, Santa Cruz Biotechnologies), Akt (dil: 1/1,000; Thermofisher), phospho Akt (pAkt-serine 473, clone 14-6) (dil: 1/700; Thermofisher) and Glyceraldehyde 3-phosphate dehydrogenase (GAPDH, dil: $1 / 5,000$; Thermofisher) were incubated over night at $4^{\circ} \mathrm{C}$. Then, membranes were washed and incubated with HRP- linked secondary antibody for chemiluminiscence band detection with ECL-Plus reactive (Thermofisher). Fujifilm Las-3000 imager device was used for protein bands visualisation.

\section{RNA interference (RNAi) experiments.}

C2C12 were seeded at confluence density $\left(20,000\right.$ cells $\left./ \mathrm{cm}^{2}\right)$ in growth medium. After $24 \mathrm{~h}$ cells were transfected with MISSION esiRNA (Sigma-Aldrich) in XtremeGENE siRNA Transfection Reagent (Roche), following manufacturer's instructions. Cell transfection was carried out in Opti-MEM Reduced Serum medium (Thermofisher). MISSION siRNA Fluorescent Universal Negative Control 1, Cyanine 3 (NC. Sigma-Aldrich) was used as transfection control. 
Transfected myoblasts were cultured for 3 days with differentiation medium (DMEM $+2 \%$ FBS $+1 \% \mathrm{P} / \mathrm{S})$. Then, myogenic differentiation was assessed by immunofluorescence of MHC.

\section{Statistical analyses.}

Each experiment was performed at least four times unless otherwise noted. Data were reported as mean \pm standard deviation. To establish if obtained data followed a normal distribution, D'Agostino-Pearson omnibus test was resorted. Results were analysed by one-way ANOVA using GraphPad Prism 6.0. When differences were determined to be significant, pairwise comparisons were performed using a Tukey in case of normal distribution of data or a Dunn's test in the opposite case. A 95\% confidence level was considered significant.

\section{Results}

\section{$\mathrm{Zn}^{2+}$ increases myoblasts viability and proliferation.}

Cell viability was analysed after 1,3 and 5 days in presence of increasing concentrations of $\mathrm{Zn}^{2+}$ from 20 to $80 \mu \mathrm{M}$ in order to determine $\mathrm{Zn}^{2+}$ mediated toxicity on myoblasts (Fig. 8 a and 8 b). After 1,3 and 5 days of culture, cell viability was maintained in myoblast supplemented with $\mathrm{Zn}^{2+}$ concentrations up to $40 \mu \mathrm{M}$, nevertheless, for higher $\mathrm{Zn}^{2+}$ concentrations $(80 \mu \mathrm{M})$, cell viability decreased dramatically (Fig. 8b).

For proliferation experiments, we selected only viable amounts of $\mathrm{Zn}^{2+}$ based in cytotoxicity results, thus we discarded 60 and $80 \mu \mathrm{M}$ concentrations. Myoblast total cell density (total nuclei/ $\mathrm{cm}^{2}$ ) was analysed after supplementing cells with 20 and $40 \mu \mathrm{M} \mathrm{Zn}^{2+}$. Results show that $\mathrm{Zn}^{2+}$ increases cell density after 1, 3 and 5 days compared with control medium (without $\mathrm{Zn}^{2+}$ ) (Fig. 8c). The zinc mitogenic effect is stronger at the initial steps of proliferation ( 1 day) and the trend is maintained after 3 days of culture. Nevertheless, cell proliferation is reduced for longer periods (from 3 to 5 days) as the cell density increases coming near to confluence. 
a)

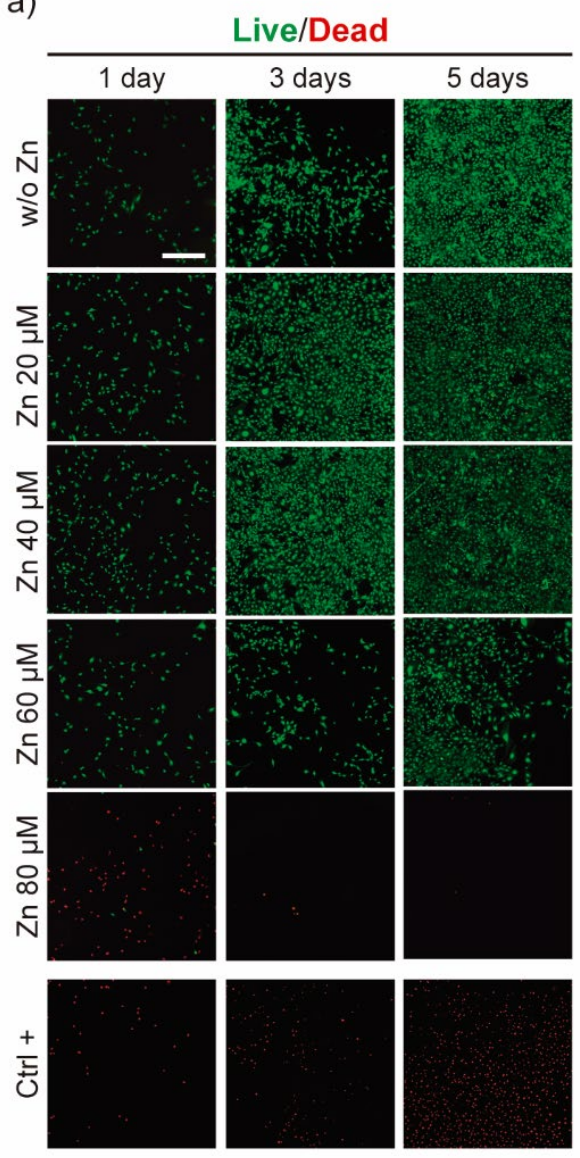

b)

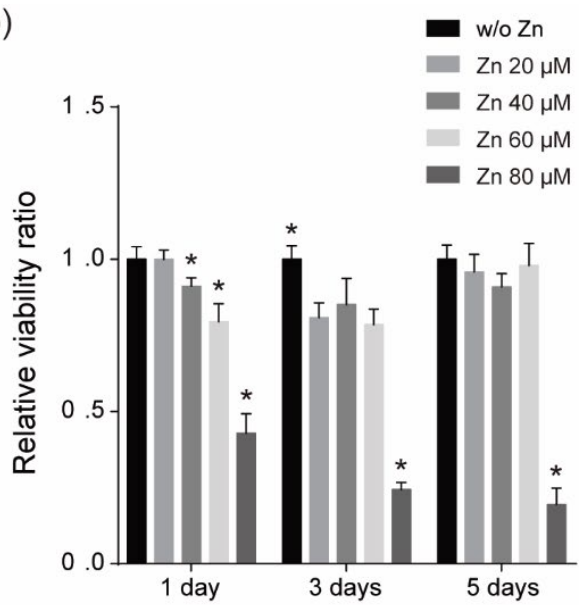

c)

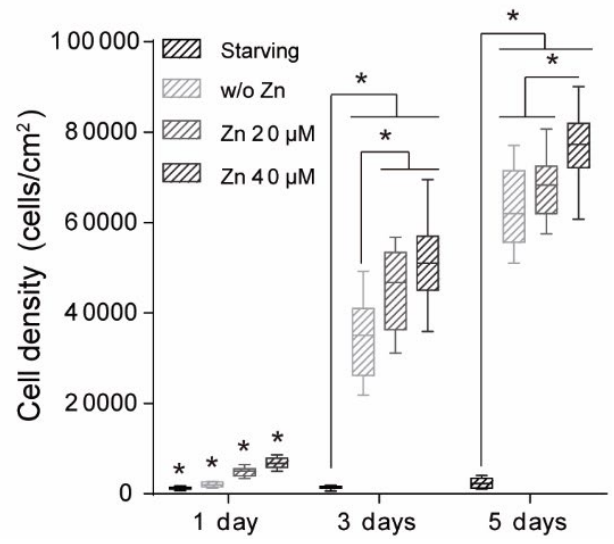

Figure 8. Determination of toxic concentrations of $\mathrm{Zn}^{2+}$ for undifferentiated muscle cells.

a) Live/Dead images of myoblasts (non-differentiated cells) (Scale bar: $400 \mu \mathrm{m}$ ).

b) Viable cells ratio (number of viable cells with $\mathrm{Zn}^{2+} /$ number of viable cells w/o $\mathrm{Zn}$ ) obtained by quantification of calcein-AM fluorescence signal measured with plate reader device.

c) Total cell density obtained after 1,3 and 5 days determined by image analysis quantification of positive Hoechst cells $/ \mathrm{cm}^{2}$. $(n=6)$.

Graphs show mean \pm standard deviation. Significant differences were determined by ANOVA test; ${ }^{*} p<0.05$. 


\section{$\mathrm{Zn}^{2+}$ enhances myoblast differentiation}

To investigate the effect of $\mathrm{Zn}^{2+}$ on myoblast differentiation we evaluated two myogenic regulatory factors essential for muscle differentiation, MyoD and Myogenin. Real time qPCR reactions were performed for $\mathrm{C} 2 \mathrm{C} 12$ cells cultured in the presence of 20 and $40 \mu \mathrm{M}$ of $\mathrm{Zn}^{2+}$ under differentiation conditions $(20,000$ cells $/ \mathrm{cm}^{2}$ ) after 3 and 6 days of culture (Fig. 9). After 3 days of culture, no relevant differences were observed in MyoD and Myogenin levels among the different conditions analysed (Fig. 9). After 6 days of culture, differentiated myotubes were observed in the presence of 20 and $40 \mu \mathrm{M}$ of $\mathrm{Zn}^{2+}$ and indeed, Myogenin expression increased for $40 \mu \mathrm{M}$ of $\mathrm{Zn}^{2+}$, although no differences were observed for MyoD expression (Fig. 9b).

a)

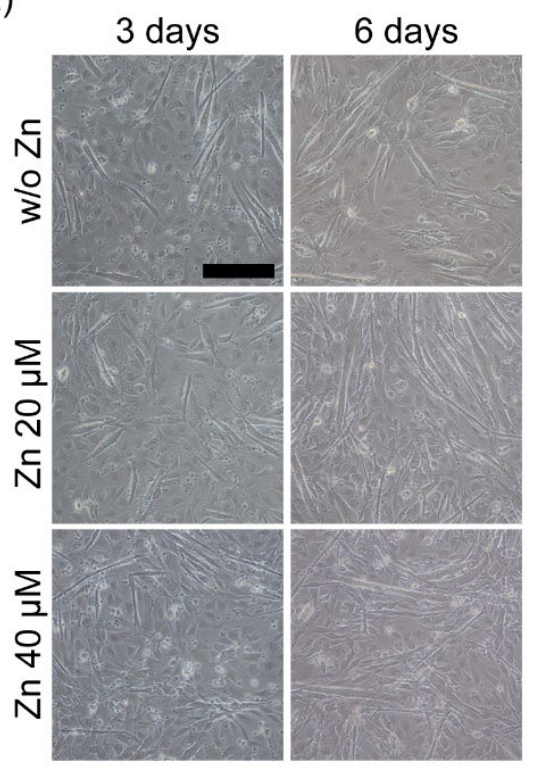

b)
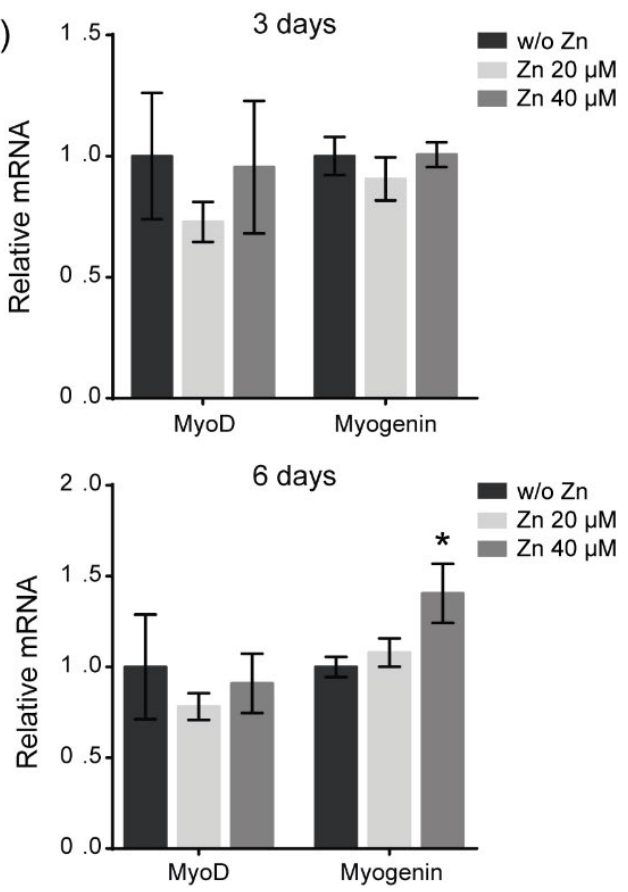

Figure 9. Effects of $\mathrm{Zn}^{2+}$ in myoblast differentiation after 6 days.

a) Bright field images of differentiated myoblasts after 3 and 6 days under different conditions (Scale bar: $200 \mu \mathrm{m}$ ).

b) Analysis of relative mRNA expression of MyoD and Myogenin after 3 and 6 days of culture under differentiation conditions. $(n=4)$.

Graphs show mean \pm standard deviation. Significant differences were determined by ANOVA test; ${ }^{*} p<0.05$. 
To further evaluate the effect of $\mathrm{Zn}^{2+}$ in myoblast differentiation we quantified the expression of Myosin Heavy Chain (MHC) and the presence of myotubes, as markers of muscle differentiation, after supplementing $\mathrm{C} 2 \mathrm{C} 12$ growing cells seeded at initial high density $\left(20,000\right.$ cells $\left./ \mathrm{cm}^{2}\right)$ under differentiation conditions with 20 and $40 \mu \mathrm{M}$ of $\mathrm{Zn}^{2+}$ in $\mathrm{C} 2 \mathrm{C} 12$. Figure 10 shows the percentage of $\mathrm{C} 2 \mathrm{C} 12$ differentiation after 6 days of culture. The results indicate that $\mathrm{Zn}^{2+}$ addition enhances $\mathrm{C} 2 \mathrm{C} 12$ proliferation, promotes myogenic differentiation as quantified by either the ratio between $\mathrm{MHC}$ positive and negative cells or the percentage of mature myotubes. (Fig. 10c, 10d and 10e). Indeed, myotube morphology was affected under $\mathrm{Zn}^{2+}$ presence presenting an increment of myotube diameter (Fig. 10f). 
a)
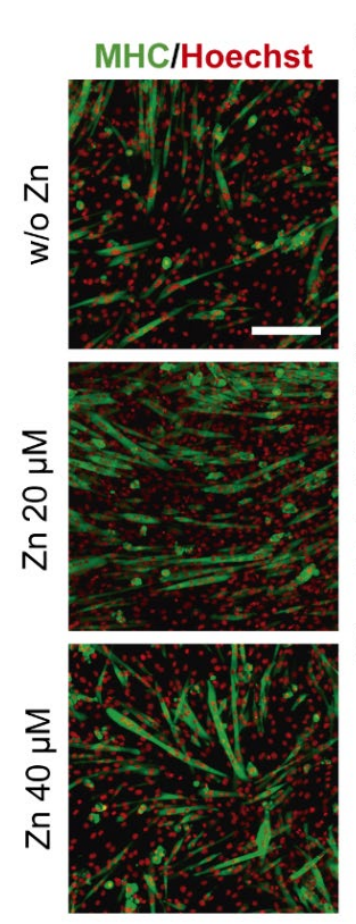

b)

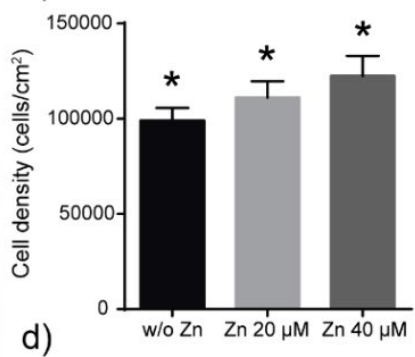

d)

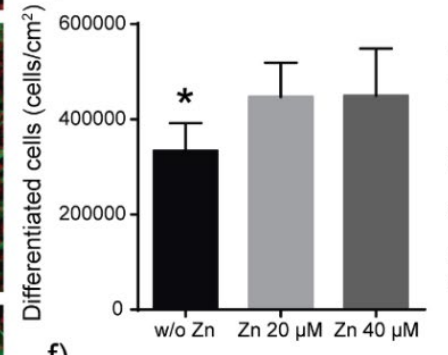

f)

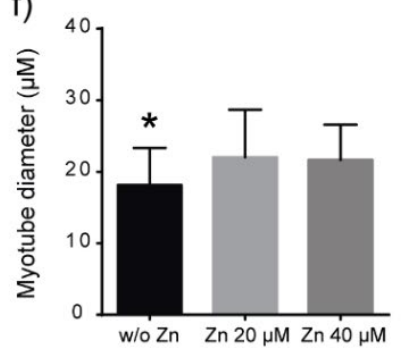

c)
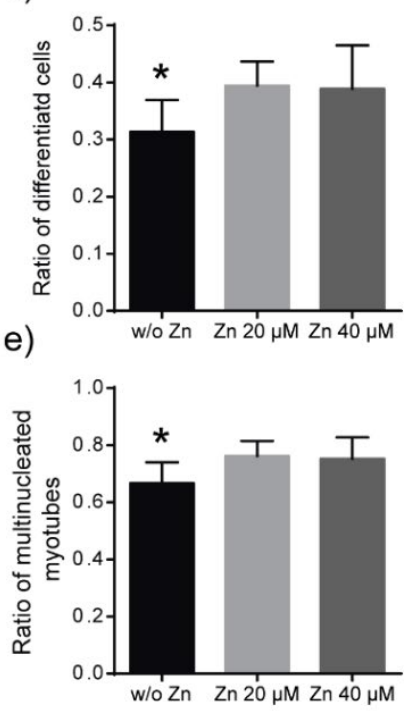

Figure 10. Effects of $\mathrm{Zn}^{2+}$ in myoblast differentiation after 6 days.

a) Immunofluorescence images of MHC positive staining (green) of differentiated myotubes after 6 days of culture and supplemented with different zinc concentrations (Scale bar: $200 \mu \mathrm{m}$ ). Quantitation of the differentiated assay parameters were represented in points from b) to f).

b) Quantification of total cell density after myogenic differentiation represented as the total Hoechst positive cells $/ \mathrm{cm}^{2}$ (total nuclei).

c) Quantification of total differentiated cells represented as the ratio between MHC positive cells / total cell number.

d) Quantification of differentiated cell density represented as the total of MHC positive cells/cm2.

e) Quantification of multinucleated myotubes represented as the ratio between multinucleated myotubes/mononucleated MHC positive cells.

f) Myotube diameter quantification obtained after analysis of at least 30 myotubes from 5 random imaged fields. Only myotubes with 4 or more nuclei were measured $(n=5)$.

Graphs show mean \pm standard deviation. Significant differences were determined by ANOVA test; " $p<0.05$. 


\section{Intracellular $\mathrm{Zn}^{2+}$ increases in differentiated myoblasts}

To gain insights into the mechanisms induced by soluble $\mathrm{Zn}^{2+}$ first we analysed cytosolic intake of $\mathrm{Zn}^{2+}$. We quantified intracellular $\mathrm{Zn}^{2+}$ concentration in relation to the concentration of extracellular $\mathrm{Zn}^{2+}$. Free intracellular $\mathrm{Zn}^{2+}$ was labelled with FluoZin3-AM dye and fluorescence emission was quantified for both undifferentiated and differentiated cells (Fig. 11a and 11b). Cells seeded for $24 \mathrm{~h}$ in presence of 20 and $40 \mu \mathrm{M}$ of $\mathrm{Zn}^{2+}$ (non-differentiated stage) presented a significant increase in intracellular fluorescence emission although it was not directly proportional to the concentration of extracellular $\mathrm{Zn}^{2+}$ (Fig. 11a). In contrast, when we analysed new formed differentiated myotubes after 6 days of culture, intracellular $\mathrm{Zn}^{2+}$ rose monotonically as extracellular concentration did (Fig. 11b). The uptake of $Z^{2+}$ by differentiated myotubes seemed to be higher compared to undifferentiated myoblasts (Fig. 11a). Indeed, $\mathrm{Zn}^{2+}$ cellular distribution changes in dependence of cell stage, being localised around nuclei in undifferentiated cells and more spread throughout the cell cytoplasm in mature myotubes. 
a)

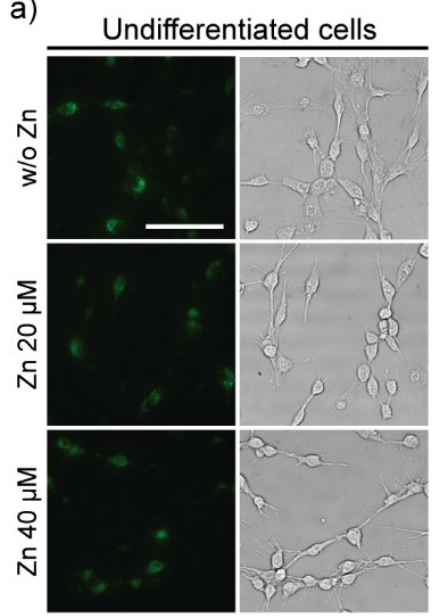

FluoZin3-AM

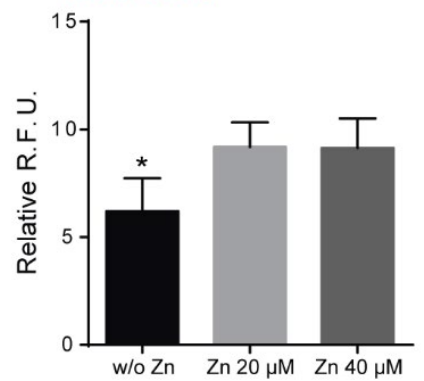

b)

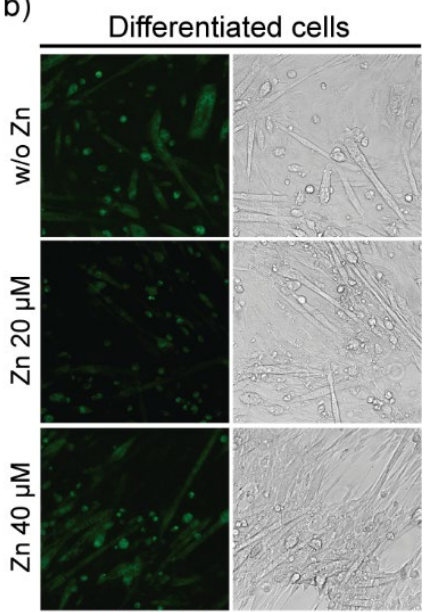

FluoZin3-AM

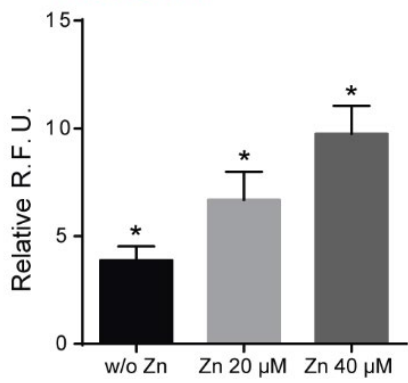

Figure 11. Quantification of intracellular $\mathrm{Zn}^{2+}$.

a) Bright field and fluorescence images of intracellular $\mathrm{Zn}^{2+}$ in undifferentiated $\mathrm{C} 2 \mathrm{C} 12$ after Fluozin3-AM labelling.

b) Bright field and fluorescence images of intracellular $\mathrm{Zn}^{2+}$ in differentiated $\mathrm{C} 2 \mathrm{C} 12$ (myotubes) after Fluozin3-AM labelling. Values are represented as relative fluorescent units (R.F.U.) for intracellular zinc. (Scale bar: $200 \mu \mathrm{M})$. ( $n=7)$.

Graphs show mean \pm standard deviation. Significant differences were determined by ANOVA test; * $p<0.05$.

In order to clarify cell stage-dependent differences between $\mathrm{Zn}^{2+}$ uptakes, we next performed a new cytotoxicity assay for differentiated cells (Fig. 12). C2C12 cells were cultured under differentiation conditions for 6 days. After obtaining new formed myotubes, their viability was measured after 1, 3 and 5 days of culture testing increasing concentrations of $\mathrm{Zn}^{2+}$ from 20 to $100 \mu \mathrm{M}$. Obtained values indicated that $\mathrm{Zn}^{2+}$ concentrations up to $60 \mu \mathrm{M}$ are not affecting myotube viability, results in concordance with those obtained for undifferentiated cells (Fig. 8b). However, the viability results obtained with higher zinc concentrations of 80 and 
$100 \mu \mathrm{M}$ suggest that differentiated stage of the cells is influencing their zinc tolerance, as myotubes seem to be less affected by higher doses of zinc compared to undifferentiated cells (Fig. $8 \mathrm{~b}$ and Fig. 12b).

a)

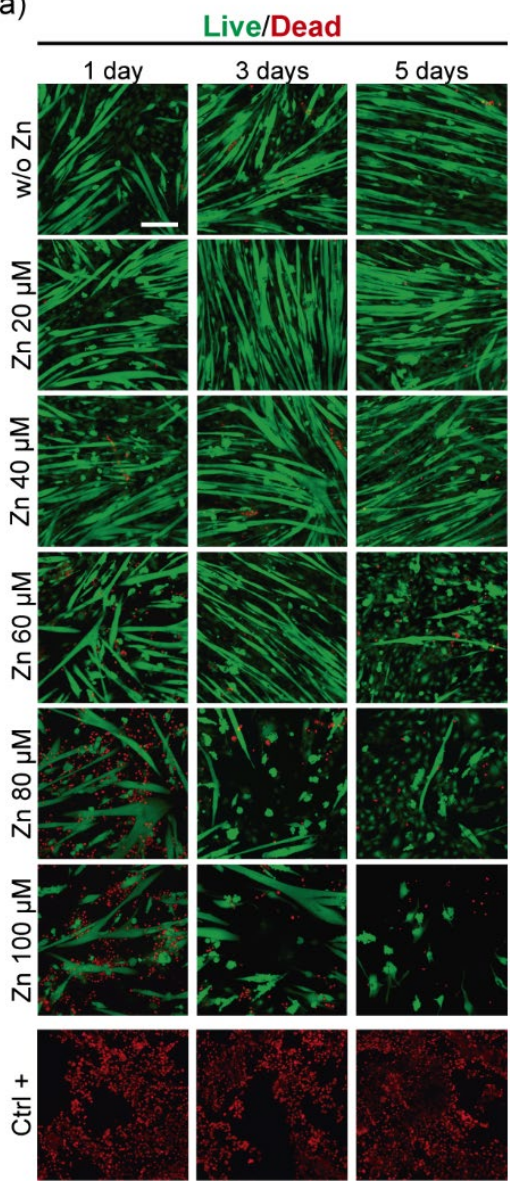

b)

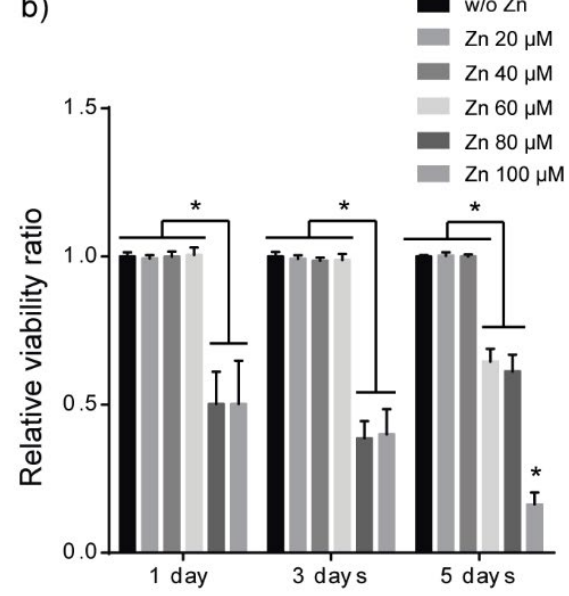

Figure 12. Effect of extracellular concentration of $\mathrm{Zn}^{2+}$ on myotubes viability.

a) Live/Dead images of myotubes (differentiated cells).

b) Viability values represented as viable cells ratio (number of viable cells with $\mathrm{Zn}^{2+} /$ number of viable cells w/o $\left.\mathrm{Zn}^{2+}\right)$. (Scale bar: $\left.200 \mu \mathrm{m}\right) .(\mathrm{n}=7)$.

Graphs show mean \pm standard deviation. Significant differences were determined by ANOVA test; ${ }^{*} p<0.05$. 


\section{Expression of subcellular Zip7 transporter regulates Akt activity}

$\mathrm{Zn}^{2+}$ transporter Zip7 has been identified as a key zinc transporter highly expressed in muscle cells (160). It is localised in the endoplasmic reticulum (ER), Golgi apparatus and cytoplasmic vesicles $(151,161)$. Zip7 homodimers transport zinc into the lumen of compartments of the early secretory pathway. In order to investigate the role of Zip7 on myoblast differentiation we then analysed Zip7 protein expression and subcellular localisation in myoblast and myotubes. $\mathrm{C} 2 \mathrm{C} 12$ cells were cultured for 1 day (undifferentiated myoblasts) and for 6 days (differentiated myotubes) under differentiation conditions. Zip7 staining was detected around cell nuclei in undifferentiated cells (Figure 13a, top images), resembling the distribution of intracellular $\mathrm{Zn}^{2+}$ observed in figure 11a. Nevertheless, when myoblasts fused into myotubes, Zip7 become more homogeneously distributed throughout the cell (Fig. 13a, bottom images). Zip7 western blot quantification showed a significant increase in Zip7 protein levels in differentiated myotubes (Fig. 13b and 13c) compared to undifferentiated cells. However, neither protein levels nor Zip7 distribution depended on the levels of free zinc in the medium, suggesting that $\mathrm{Zn}^{2+}$ is not directly participating in upregulation of Zip7 expression.

In addition to the transporter function, Zip7 is able to activate several protein kinases such as Akt(148,156). For clarifying the role of zinc in cell proliferation and differentiation, we evaluated Akt signalling in undifferentiated myoblasts and mature myotubes. We examined whether zinc induced phosphorylation of Akt in serine $473\left(\mathrm{pAkt}^{\mathrm{S473}}\right.$ ), a requirement for full activity of this protein kinase, using western blot analysis. No differences were observed in total Akt expression between differentiated and undifferentiated cells (Fig. 13d). Nevertheless, Akt phosphorylation (pAkt/Akt ratio), increased in differentiated myotubes after 6 days of culture. The higher levels of pAkt were obtained in conditions supplemented with concentrations of 20 and $40 \mu \mathrm{M}$ of zinc, which indicates a role of $\mathrm{Zn}^{2+}$ in Akt activity (Fig. 13e). 
a)
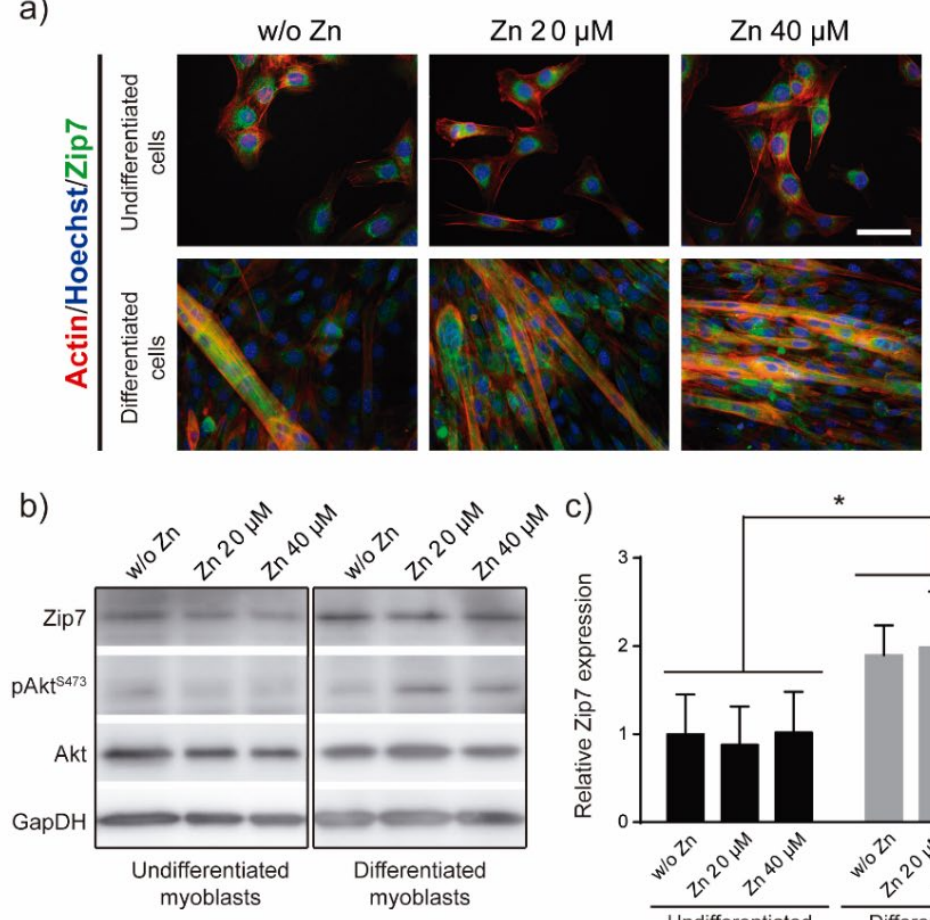

d)
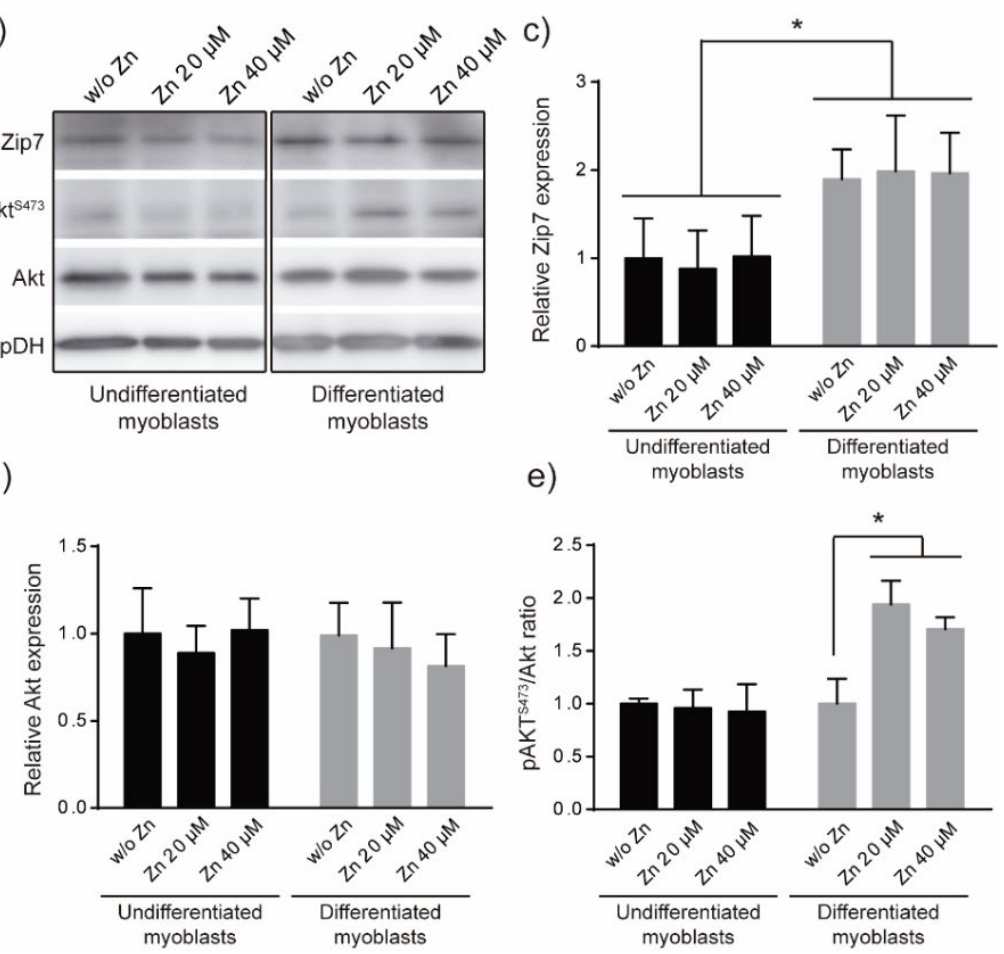

Figure 13. Role of Zip7 transporter and Akt activity in myoblast differentiation.

a) Zip7 detection by immunofluorescence (green) in undifferentiated cells (after 1 day of culture) and differentiated myotubes (after 6 days of culture). Scale bar: $50 \mu \mathrm{M}$.

b) Western blot detection of Zip7 transporter, Akt, and $\mathrm{pAkt}^{\mathrm{S} 473}$. GAPDH was used as loading control protein.

c, d, e) Densitometric quantification of Zip7, Akt and pAktS473/Akt ratio bands, respectively. $(n=4)$.

Graphs show mean \pm standard deviation. Significant differences were determined by ANOVA test; ${ }^{*} p<0.05$ 


\section{Effects of Zip7 silencing in myoblasts}

We next silenced the Zip7 transporter expression by using RNA interference (RNAi). Transfected cells were analysed after 0,3 and 6 days of culture under differentiation conditions. Zip7 levels were assessed by immunofluorescence (Fig. 5a) and western blot (Fig. 14). Myoblast knocked down by RNAi showed the lowest levels of Zip7 immunostaining compared to RNAi negative control (NC) and untreated cells (UC) (Fig. 14a). Western blot experiments revealed reduced levels on Zip7 expression (23.5\%) on cells transfected with siRNA against Zip7 after 1 day of culture compared with untreated cells (Fig. 14b and 14c). After 3 days of culture, the levels of Zip7 protein expression increased until $27.5 \%$, and after 6 days Zip7 levels were restored to the original ones (Fig. 14b and 14d) as we expected due to the transitory effect of this RNAi silencing. Addition of 20 and $40 \mu \mathrm{M}$ of $\mathrm{Zn}^{2+}$ did not result in any significant effect in Zip7 silencing at the different time points analysed. However, Zip7 knocked down modified Akt activity. pAkt ${ }^{\$ 473} / A k t$ ratio diminished immediately after RNAi treatment, (control at day 0 , Fig 14b and 14c) progressively raised after 3 days and was fully restored after 6 days (Fig. 14e). After 6 days of culture, and considering that after this time the silencing was not effective, we observed again that $\mathrm{Zn}^{2+}$ presence affected pAkt/Akt ratio increasing the levels of Akt phosphorylation. Similar results were obtained for zinc transporter expression after 6 days of culture, which restored Zip7 expression to control levels (Fig. 14e). 
a)

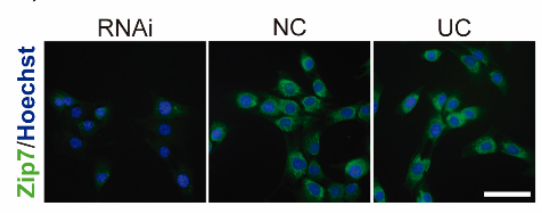

b)
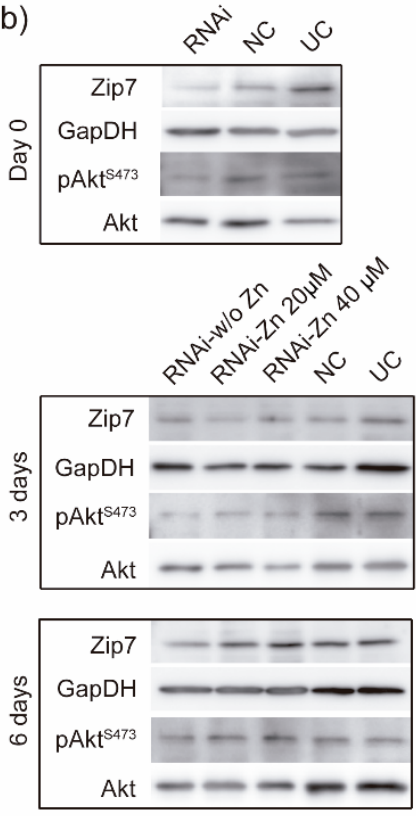

d)

e) c)

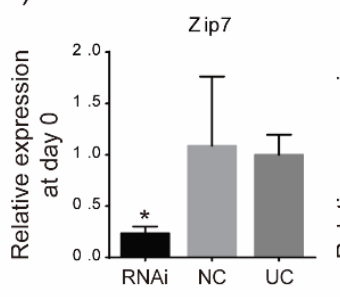

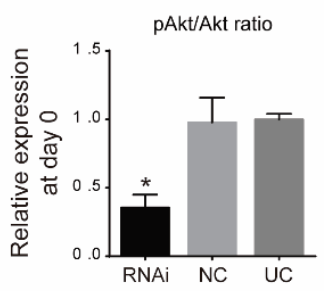
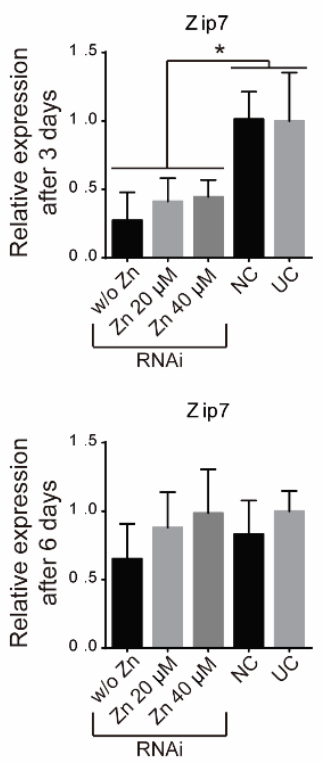
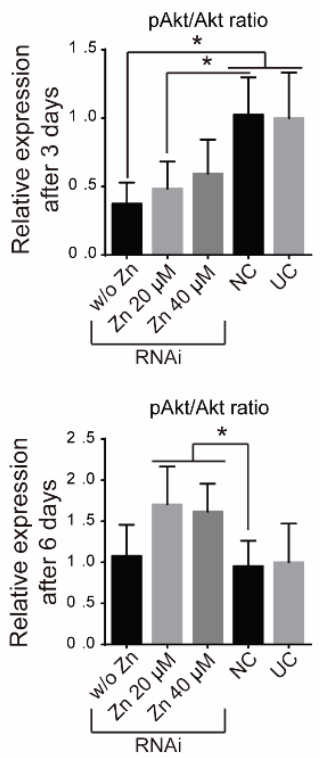

Figure 14. Effects of Zip7 silencing in myoblasts.

a) Zip7 detection by immunofluorescence (green) after mRNA silencing (Scale bar: 50 $\mu \mathrm{m})$.

b) Western blot of Zip7, pAkt and Akt expression after 0, 3 and 6 days of culture. GAPDH was used as loading control protein.

c, d, e) Densitometric quantification of Zip7 and pAktS473/Akt ratio bands after 0, 3 and 6 days of culture, respectively. NC: RNAi negative control, UC: untreated cells. $(n=4)$. Graphs show mean \pm standard deviation. Significant differences were determined by ANOVA test; ${ }^{*} p<0.05$. 


\section{Silencing of Zip7 alters intracellular $\mathrm{Zn}^{2+}$ content}

To further investigate the role of Zip7 in intracellular zinc homeostasis, we next quantified intracellular $\mathrm{Zn}^{2+}$ concentration after Zip7 silencing. We labelled free intracellular $\mathrm{Zn}^{2+}$ with FluoZin3-AM dye. After that, cells were supplemented with $\mathrm{Zn}^{2+} 20$ and $40 \mu \mathrm{M}$ and fluorescence emission was quantified every 40 seconds. Figure 15 shows that immediately after addition of zinc-supplemented medium to untreated cells $(\mathrm{UC})$, intracellular concentration of $\mathrm{Zn}^{2+}$ increased significantly compared to control condition w/o $\mathrm{Zn}^{2+}$ (Fig. 15a-green labels). Nevertheless, the measured values of intracellular $\mathrm{Zn}^{2+}$ obtained in Zip7-deficient cells were lower in all conditions compared to the equivalent UC (Fig. 15a-blue labels). Despite intracellular zinc concentration rapidly increased after zinc addition, the values progressively decreased until stabilisation, and this effect was more pronounced in Zip7-silenced cells. This observation together with the fact that the basal amount of intracellular zinc (condition w/o zinc) is strongly reduced in Zip7deficient cells, confirm the role of Zip7 in intracellular zinc homeostasis. Note that the basal amount of intracellular zinc in control condition (w/o Zn) can be only originated by zinc-released from intracellular organelles.

In addition, cell proliferation was also affected after Zip7 silencing. We evaluated $\mathrm{Zn}^{2+}$-dependent cell proliferation in Zip7-deficient cells by BrdU assay. Figure 15b shows that BrdU positive cells rise monotonically as extracellular concentration of zinc does in control condition, whereas this effect was reverted after Zip7 silencing with no differences in BrdU levels regardless of the concentration of $\mathrm{Zn}^{2+}$ in the culture medium. 
a)

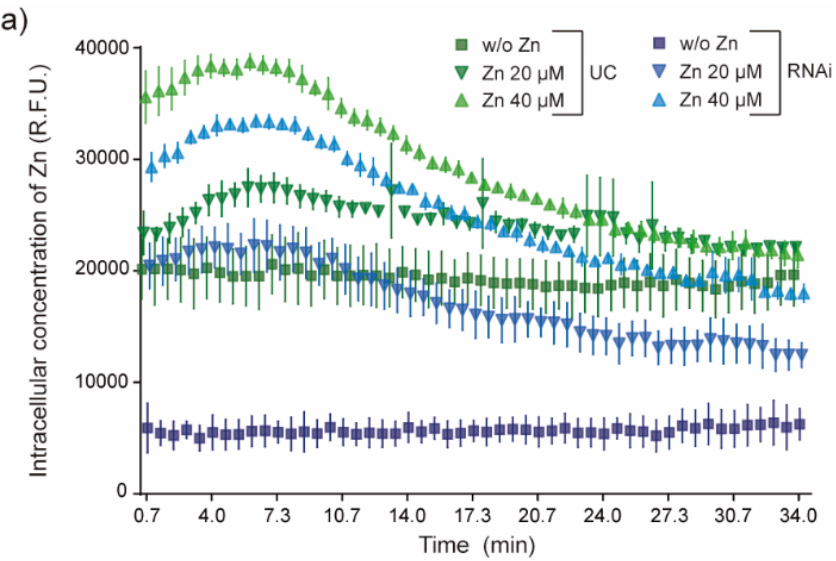

b)

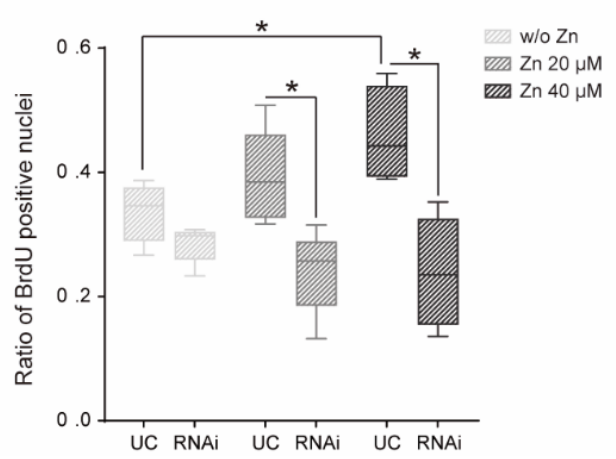

Figure 15. Effects of Zip7 silencing in intracellular $\mathrm{Zn}^{2+}$ homeostasis and proliferation.

a) Intracellular $\mathrm{Zn}^{2+}$ measurements after Fluozin3-AM labelling in control and Zip7deficient cells. Fluorescence emission was measured every 40 seconds. Values are represented as relative fluorescent units (R.F.U.). $(n=6)$.

b) Myoblasts proliferation was determined by BrdU labelling and detection by immunofluorescence. Values are represented as the ratio between BrdU positive cells / total nuclei $(n=5)$. UC: untreated cells.

Graphs show mean \pm standard deviation. Significant differences were determined by ANOVA test; ${ }^{*} p<0.05$.

\section{Effects of Zip7 silencing in myotubes}

We next evaluated the effects of blocking Zip7 protein expression in myotube formation. Zip7 knockdown had no effect either on total cell density or on ratio of total differentiated cells (control condition w/o $\mathrm{Zn}^{2+}$ ) expressing $\mathrm{MHC}$ compared to untreated cells (Fig. 16). However, in cell cultures supplemented with 20 and 
$40 \mu \mathrm{M}$ of $\mathrm{Zn}^{2+}$, blocking of Zip7 protein expression resulted in a significant reduction of the ratio of differentiated cells expressing $\mathrm{MHC}$ despite the slight increase in cell density (Fig. 16a, 16b and 16c). Quantification of myotubes formed after Zip7 silencing resulted in a considerably reduction of the ratio of multinucleated myotubes formed in presence of $\mathrm{Zn}^{2+}$, although the total $\mathrm{MHC}$ positive cells was similar in all conditions (Fig. 16d, 16e). In addition, the myotube diameters diminished in Zip7-deficient cells, with a significant reduction of diameter up to $31 \%$ (Fig. 16f).

a)
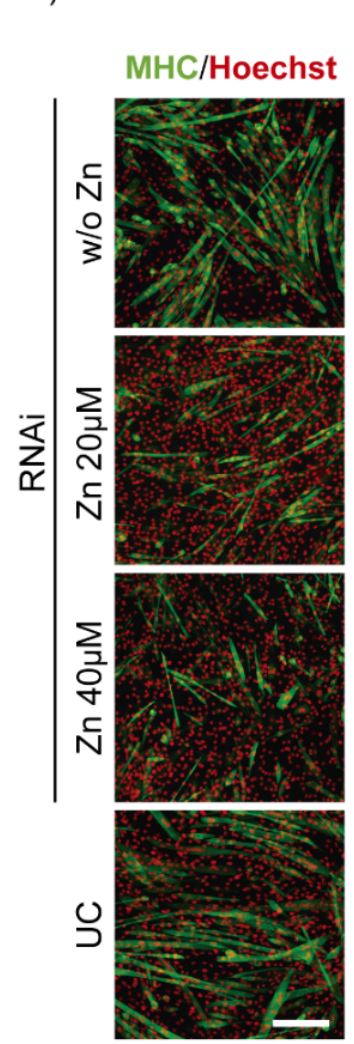

b)
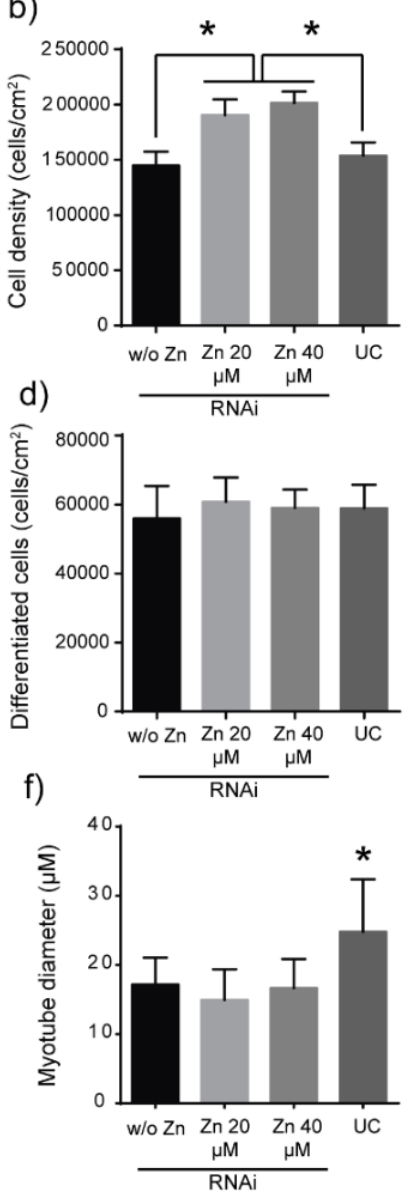

c)

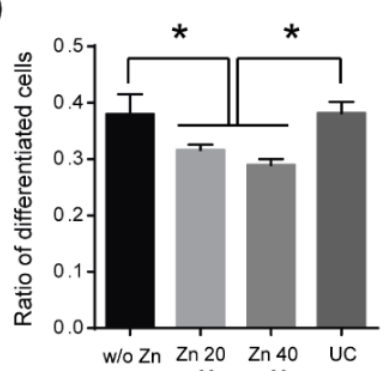

e)

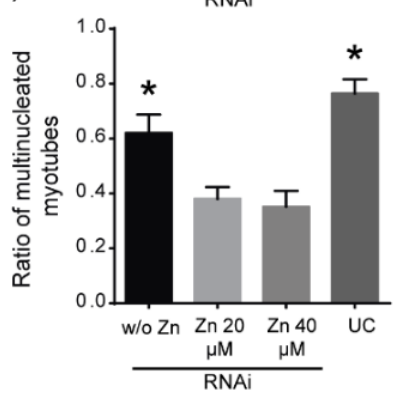

Figure 16. Effects of Zip7 silencing in myotubes formation after 6 days.

a) Immunofluorescence images of MHC positive staining (green) of differentiated Zip7deficient myotubes after 6 days of culture and supplemented with different zinc concentrations. (Scale bar: $200 \mu \mathrm{m}$ ). 
b) Quantification of total cell density after myogenic differentiation represented as the total Hoechst positive cells $/ \mathrm{cm}^{2}$ (total nuclei).

c) Quantification of total differentiated cells represented as the ratio between MHC positive cells/total cell number.

d) Quantification of differentiated cell density represented as the total of MHC positive cells $/ \mathrm{cm}^{2}$.

e) Quantification of multinucleated myotubes represented as the ratio between multinucleated myotubes/mononucleated MHC positive cells.

f) Myotube diameter quantification obtained after analysis of at least 30 myotubes from 5 random imaged fields. Only myotubes with 4 or more nuclei were measured.

Graphs show mean \pm standard deviation. $(n=5)$. Significant differences were determined by ANOVA test; ${ }^{*} p<0.05$.

\section{Discussion}

Zinc is one of the essential trace elements, ubiquitous in cell metabolism, and essential to carry out eukaryote cells biological processes $(149,162)$. $\mathrm{Zn}^{2+}$ exhibits anti-apoptotic properties and enhances cell survival and proliferation $(163,164)$, however $\mathrm{Zn}^{2+}$ overload results toxic for all cells. High levels of free $\mathrm{Zn}^{2+}$ in the cytoplasm can induce both cell necrosis and apoptosis $(165,166)$. Toxic concentration of $\mathrm{Zn}^{2+}$ is dependent on cell-types $(167,168)$. We have

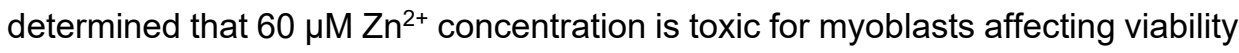
at early culture times (Fig. 8), while $80 \mu \mathrm{M}$ concentration is detrimental for cells. Sub-toxic concentrations of $\mathrm{Zn}^{2+}\left(\mathrm{Zn}^{2+}\right.$-concentrations 20 and $\left.40 \mu \mathrm{M}\right)$ increased cell proliferation monotonically (Fig. $8 \mathrm{c}$ and supplementary Fig. 17), thus we have confirmed the mitogenic effects of $\mathrm{Zn}^{2+}$ in C2C12 (117).

Myoblast proliferation and differentiation are two closely linked events involved in skeletal muscle regeneration. Cell proliferation allows cells to reach confluence and triggers the exit of the cell cycle $(169,170)$ which in turn initiate myoblast differentiation cascade (171). 
a)
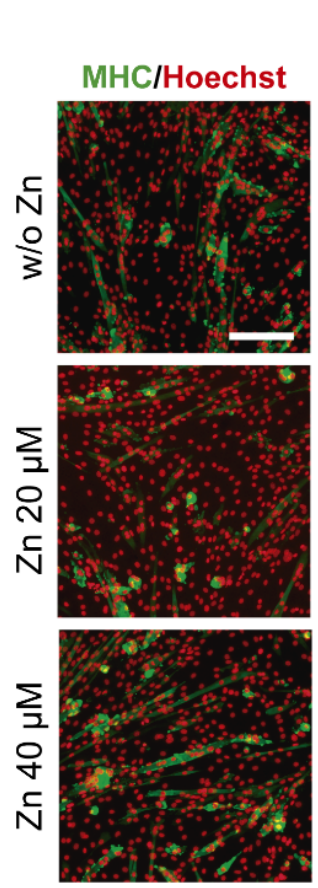

b)

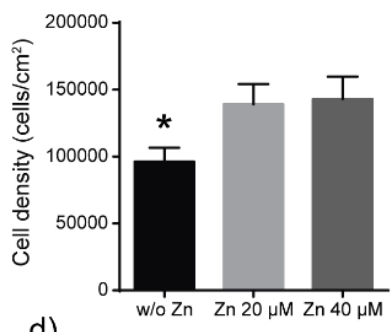

d)

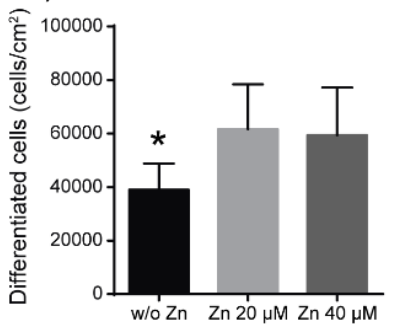

f)

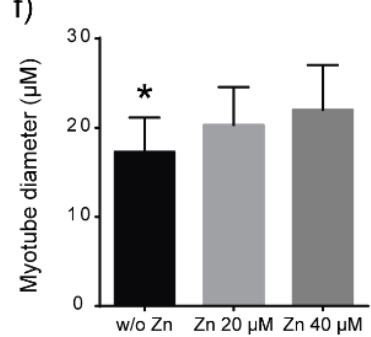

c)

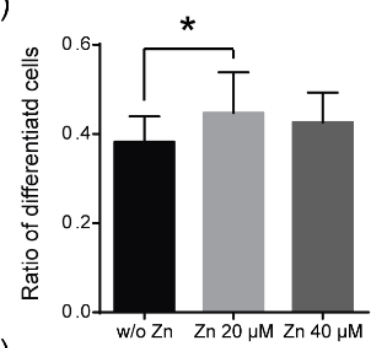

e)

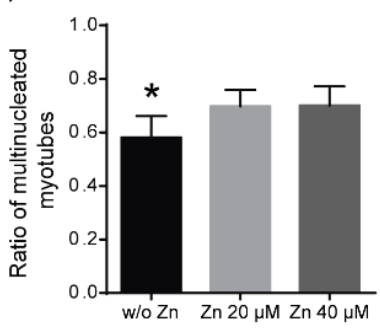

Figure 17. Influence of $\mathrm{Zn}^{2+}$ on myoblast differentiation with low initial cell density $\left(10.000\right.$ cells $\left./ \mathrm{cm}^{2}\right)$.

a) Immunofluorescence images of MHC immunostaining (green) of differentiated myotubes after 6 days of culture and supplemented with different zinc concentrations (Scale bar: $200 \mu \mathrm{m}$ ).

b) Quantification of total cell density after myogenic differentiation represented as the total Hoechst positive cells $/ \mathrm{cm}^{2}$ (total nuclei).

c) Quantification of total differentiated cells represented as the ratio between MHC positive cells / total cell number.

d) Quantification of differentiated cell density represented as the total of MHC positive cells $/ \mathrm{cm}^{2}$.

e) Quantification of multinucleated myotubes represented as the ratio between multinucleated myotubes / mononucleated MHC positive cells.

f) Myotube diameter quantification obtained after analysis of at least 30 myotubes from 5 random imaged fields. $(n=5)$.

Graphs show mean \pm standard deviation. Significant differences were determined by ANOVA test; ${ }^{*} p<0.05$. 
Our results regarding zinc mitogenic effects are in agreement with those previously reported by Ohashi et al. ${ }^{37}$. However, we have found opposite results in regards to myoblast differentiation. Note that in all the experiments, we have cultured cells under low serum ( $2 \%$ FBS, differentiation media that also allowed cell proliferation), standardised as a more relevant approach to mimic the physiological environment surrounding myoblasts after muscle injury, where proliferation precede differentiation (77). In Ohashi's work, they used insulintransferrin-selenium (ITS 1\%) as differentiation medium, in order to minimally supplement the media in absence of serum. Absence of serum provokes arrest of cell proliferation and promotes cell differentiation. Note that for the sake of comparison with previous published work we have also reproduced Ohashi's experiments using ITS $1 \%$ instead of $2 \%$ FBS (Fig. 18). Then, we obtained similar results: zinc supplementation affected neither myoblast proliferation nor differentiation in serum-free media conditions ${ }^{37}$. The different culture media used in both cases explains the differences obtained (Fig. 10 and Fig. 17). 
a)

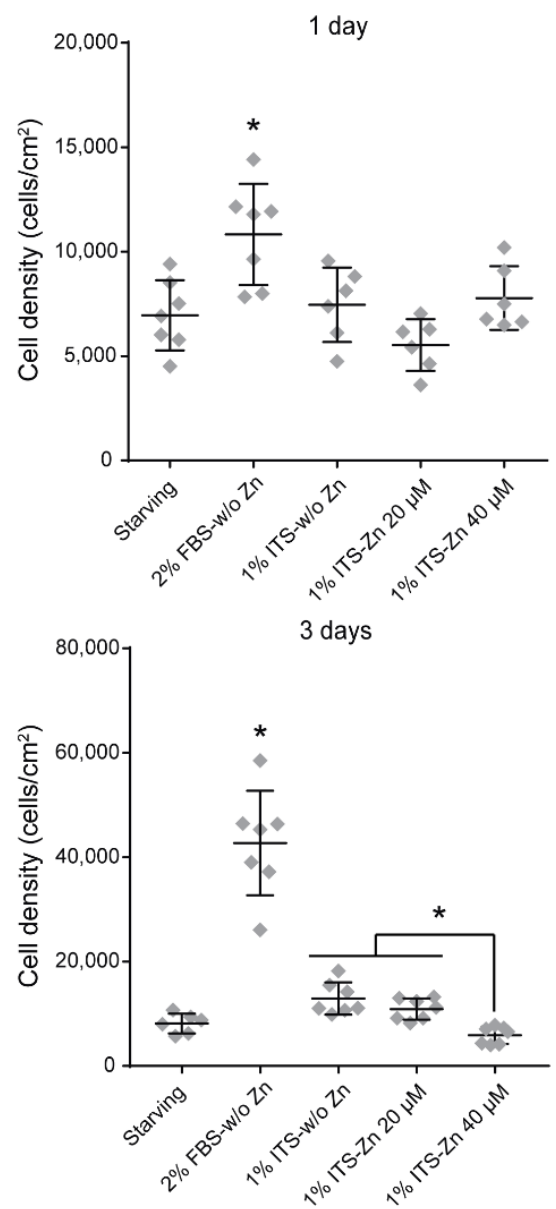

b)
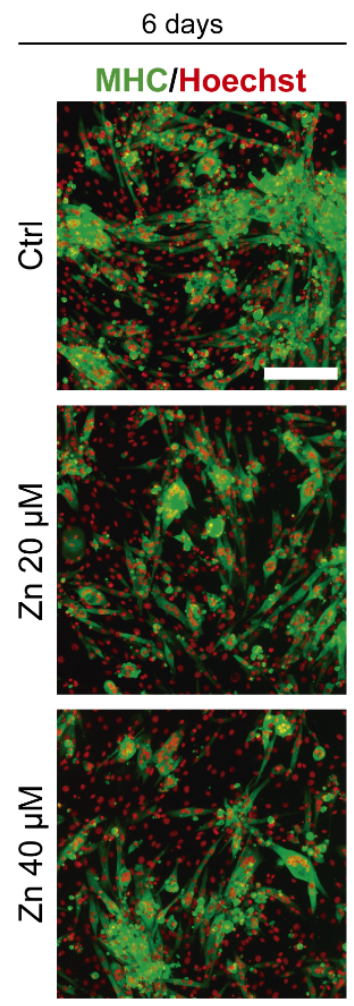

Figure 18. Analysis of myoblasts proliferation and differentiation using serum-free medium supplemented with $1 \%$ ITS.

a) Total cell density obtained after 1 and 3 days of culture determined by image analysis quantification of positive Hoechst cells / cm2. ( $n=7$ independent experiments performed). $2 \%$ FBS medium was used as a control for proliferating cells condition.

b) Immunofluorescence images of MHC immunostaining (green) of differentiated myotubes after 6 days of culture and supplemented with different zinc concentrations.

Graphs show mean \pm standard deviation. Significant differences were determined by ANOVA test; ${ }^{*} p<0.05$.

It is important to note that although in our results cell density is dependent of the concentration of zinc presence in the medium (Fig. 9), this monotonic increase in cell proliferation is not directly related to cell differentiation which occurred at similar levels after the addition of 20 or $40 \mu \mathrm{M}$ of $\mathrm{Zn}^{2+}$. Addition of $\mathrm{Zn}^{2+}$ induced 
myotube maturation, with more and thicker multinucleated myotubes (Fig. 10 and Fig. 17).

We have analysed the effects of $\mathrm{Zn}^{2+}$ in the gene expression of MyoD and Myogenin, two essential transcription factors of myogenesis, that are differentially expressed / repressed in dependence of the cell-specific differentiated stage (172). Results suggest that MyoD expression, which is associated with proliferating myoblasts (173), was not dependent on the presence of $\mathrm{Zn}^{2+}$ after 3 or 6 days of culture (Fig. 9). However, Myogenin, which is involved in myotube maturation (173), significantly increased after 6 days of culture in the presence of $40 \mu \mathrm{M}$ of $\mathrm{Zn}^{2+}$, along with increased myotube diameter (Fig. 10f), suggesting the role of zinc in the expression of the terminal muscle phenotype rather than in early commitment of cells to myogenic lineages.

Intracellular $\mathrm{Zn}^{2+}$ balance is involved in many biological activities. Intracellular zinc measurements in undifferentiated myoblasts were not correlated with the concentration of $\mathrm{Zn}^{2+}$ in the medium. However, after differentiation, myotubes increased the intracellular $\mathrm{Zn}^{2+}$ intake monotonically proportional to the extracellular concentration that distributed homogeneously throughout myotubes (Figure 11). These results suggest that, similarly as calcium storage within the sarcoplasmic reticulum (SR) (174), differentiation of myoblasts and subsequent formation of SR involve $\mathrm{Zn}^{2+}$ storage, an essential element for endoplasmic reticulum function and protein folding $(175,176)$. This storage function of the SR is correlated with the fact that myotubes are viable in environments with higher extracellular $\mathrm{Zn}^{2+}$ concentrations than undifferentiated cells as high as $100 \mu \mathrm{M}$ for 3 days (Fig. 12) 


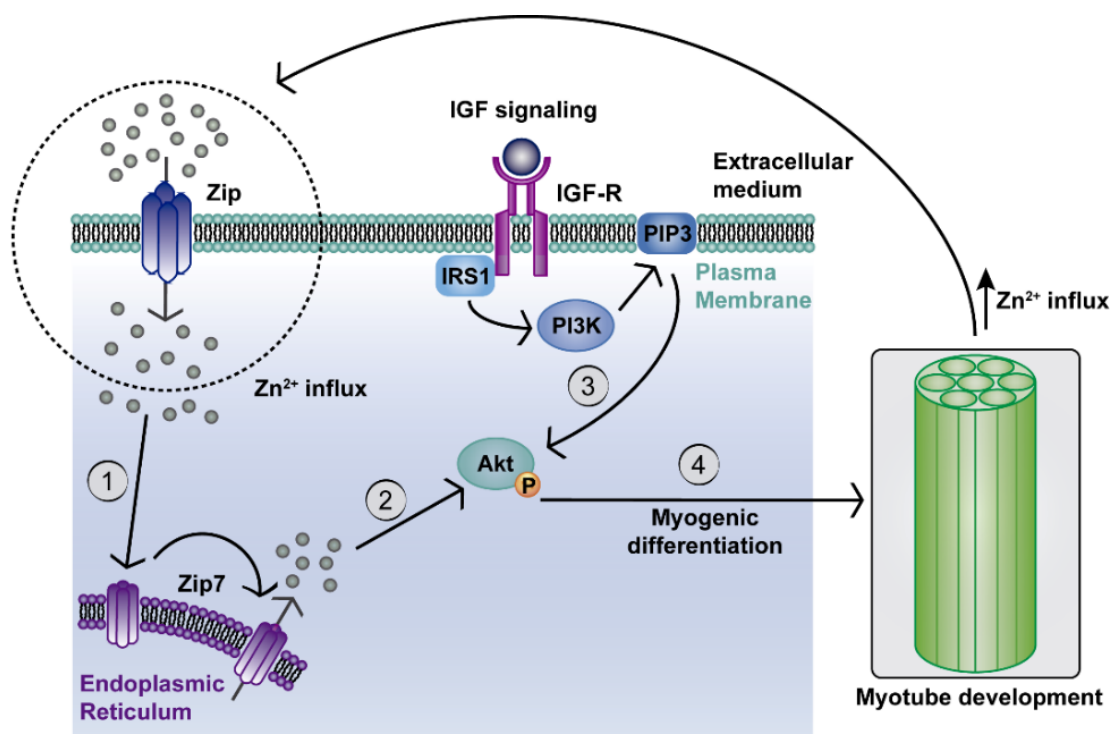

Figure 19. Scheme of cascade of events representing the role of zinc in the regulatory crosstalk promoting myogenesis.

Zinc ions influx from extracellular medium through membrane Zip transporter mediate phosphorylation of Zip7 endoplasmic reticulum transporter. Activation of Zip7 produces a release of intracellular storage of $\mathrm{Zn}^{2+}$ and subsequent phosphorylation of protein kinase Akt and consequently enhances myogenic differentiation. Myotube formation in turn stimulate $\mathrm{Zn} 2+$ extracellular uptake enhancing myogenic differentiation process and myotubes development. (1) Ref: (86,115). (2) Ref: (115). (3) Ref: (78,117). (4) Ref: (78)

Zinc transporter Zip7 localised within the endoplasmic reticulum in undifferentiated cells but its location changes after myoblast differentiation, being homogeneously distributed, and more expressed, throughout the sarcoplasmic reticulum in differentiated cells, following the pattern of intracellular zinc (Fig. 13a). After Zip7 knock down myoblasts exhibit altered $\mathrm{Zn}^{2+}$ homeostasis, with lower intake of extracellular zinc and minimal release from cytoplasmic organelles (Fig. 15a), demonstrating that Zip7 plays a key role in intracellular zinc regulation. Zip7-deficient cells also presented reduced proliferation rates (Fig. 15b) confirming that proliferative effect of zinc is dependent of Zip7 activity.

Moreover, Zip7-deficient myoblasts presented a reduction in the percentage of differentiated cells in $\mathrm{Zn}^{2+}$-treated cells (Fig. 16c), as well as in the ratio of multinucleated cells and myotube diameter (Fig. 16e). Altogether, these results point out the crucial role of Zip7 protein in $\mathrm{Zn}^{2+}$-mediated induction of myoblast differentiation and myotube maturation, in agreement with RT-qPCR results 
obtained for Myogenin expression (Fig. 9). The importance of Zip7 has been recently shown in drosophila. Negative mutation in drosophila catsup gene, mammalian Zip7 orthologous gene, causes Notch abnormal accumulation in endoplasmic reticulum and Golgi apparatus, promoting self-renewal, and inhibiting myogenic differentiation $(175,177)$.

Both in vitro and in vivo studies have shown that Akt activity, which regulate many processes including cell proliferation, survival and metabolism, is critical for optimal muscle growth and regeneration (178). The protein kinase Akt is involved in myoblast proliferation and differentiation process $(134,179,180)$ and essential in earliest stages of myogenic differentiation (136). We show that increased extracellular $\mathrm{Zn}^{2+}$ levels, below toxic concentration, induces an over proliferation of myoblasts and enhances cell differentiation and myotubes development. It has been reported the important role for the zinc ions in Akt phosphorylation via Zip7 tyrosine kinase activator activity (151), in a similar way to IGF/PI3K/Akt cascade $(115,117)$. Figure 19 depicts the chain of events leading to regulatory crosstalk between zinc and myoblasts. Zinc ions influx from extracellular medium through Zip membrane transporter. $\mathrm{Zn}^{2+}$ activates phosphorylation of Zip7, which in turn increase cytoplasmic levels of $\mathrm{Zn}^{2+}$ promoting the activation of Akt phosphorylation. The phosphorylation of these proteins kinase activates mitogenic molecular pathways, enhancing myoblast proliferation $(117,179,181)$. We found not significant differences in Akt phosphorylation after 1 day of culture (undifferentiated cells) (Fig. 13d), whilst after 6 days (differentiated cells) (Fig. 13e), pAkt in $\mathrm{Zn}^{2+}$-treated myoblasts is significantly higher than untreated cells. These findings suggest that exogenous $\mathrm{Zn}^{2+}$ triggers Akt activation, promoting cell differentiation and myotube maturation as shown in the scheme in figure 19. Myogenic differentiation assessed with Zip7-deficient myoblasts (Fig. 16) shows that exogenous $\mathrm{Zn}^{2+}$ hinders myogenic differentiation at the expense of increased cell proliferation. Cell density in Zip7-deficient myotubes was found to be $32-39 \%$ higher in $\mathrm{Zn}^{2+}$-treated cells compared to non-treated and non-transfected cells (Fig. 16b). Moreover, Zip7 knockdown resulted in reduced Akt phosphorylation up to 3 days (Fig. 14d), suggesting that the rise of cell proliferation by $\mathrm{Zn}^{2+}$ action is not directly related with Akt activity, which agrees with several studies were cell proliferation was found to be related to Mek/Erk activation by $\mathrm{Zn}^{2+}(115,117,151)$. Our results demonstrate that the enhancement of myotube maturation and development induced by exogenous $\mathrm{Zn}^{2+}$ is closely related to Zip7 transporter and its downstream Akt activation. 


\section{Chapter II}

\section{Zinc maintains}

\section{embryonic stem cells}

\section{pluripotency and} multilineage differentiation potential via Akt activation 
Zinc maintains embryonic stem cells pluripotency and multilineage differentiation potential via Akt activation

\section{Introduction}

Embryonic stem cells (ESCs) are the main cellular source during embryogenesis in multicellular organisms, giving rise to the three embryonic germ layers (mesoderm, endoderm and ectoderm) which are the precursors required for the development of functional tissues (182-184). ESC present a pluripotent phenotype, being able to self-renew and propagate indefinitely in appropriate conditions or differentiate into all embryonic cell lineages spontaneously (185) or in a directed way $(84,186-189)$. This multilineage differentiation potential, makes ESCs a key tool to investigate biological processes, develop new prospects for medical treatments of different pathologies and as a cell source for regenerative medicine strategies $(16,190)$.

ESCs can be obtained from the inner cells mass of preimplantation blastocyst stage $(185,191)$. In vitro expansion of ESCs is challenging as a consequence of its marked tendency to spontaneously differentiate to all primary germ layers $(192,193)$. Therefore, ESCs need to be cultured in very specific conditions that mimic in vivo niche, to inhibit the activation of differentiation mechanisms and promote self-renewal(194,195). The most common method for maintenance of undifferentiated ESCs phenotypes in vitro is their co-culture onto a feeder layer of inactivated mouse embryonic fibroblasts (MEF) $(195,196)$, which provide ESCs paracrine factors for stemness maintenance (195). However, these feeder cells exhibit a heterogeneous population with different surface markers and phenotypes (197) which entail a source of variability during ESCs culture. Between the pool of molecules released by the feeder layer of cells, some growth factors and cytokines have been identified involved in the inhibition of ESC differentiation, such as Leukaemia inhibitory factor (LIF) (195). LIF binds to glycoprotein 130/LIF-receptor and activates multiple signalling pathways including the tyrosine kinase Janus (JAK) $(184,198,199)$. When JAK phosphorylates, it downstream activates both PI3K/Akt cascade and the transcription factor STAT3, regulating the expression of self-renewal associated genes (200). Other factors identified are fibroblast growth factor-2 (FGF2), Activin A, Gremlin 1 or transforming growth factor $\beta 1$ (TGF $\beta 1$ ) which inhibit human ESC differentiation (194). It is, however, often necessary to combine more than one molecule to achieve a strong inhibition of ESC differentiation (194), particularly for human ESCs. Besides cell released factors, there is a growing trend towards the investigation of small molecules to drive ESC fate (201). Among these small molecules, it has been shown that GSK3 $\beta$ inhibitors (such as CHIR 99021 
$(73,196))$ or ERK1/2 inhibitors (such as SC1 $(202)$ or PD184352 $(63,203)$ ) target directly or indirectly over the group of transcription factors Oct4, Sox2, Nanog, KIf4 $(201,204)$ or protein kinases, such as PI3K/Akt, which conform pluripotency associated regulators (75).

PI3K/Akt signalling is crucial to promote ESCs survival by inhibiting apoptosis through phosphorylation and inactivation of Bad or Caspase-9 $(205,206)$. In addition, Akt is able to downstream regulate the activity of protein kinases and transcription factors such as GSK3 $\beta$, NFK $\beta$, MEK/ERK $(74,75)$ or Oct4 (207), which control the activity and expression of proliferation and pluripotency associated genes. Particularly, GSK3 $\beta$ and ERK activity are commonly associated to loss of pluripotency. GSK3 $\beta$ binds and phosphorylates $\beta$-catenin, triggering its proteasomal degradation (208) and consequently disrupts Wnt/bcatenin signalling, necessary for preserving ESC integrity and somatic cell reprograming $(64,209)$. In the same way, ERK activity is closely related to the suppression of ESC self-renewal and specification to endoderm lineage (203). Inhibition of both protein kinases (GSK3 $\beta$ and ERK) known as $2 i$ condition, enhances ESC self-renewal, avoiding differentiation (210). On the other hand, $\mathrm{NF \kappa} \beta$ and Oct 4 transcriptional activity are absolutely necessary to pluripotency gene expression (74). The role of PI3K/Akt pathway in the regulatory process of ESCs survival and pluripotency, makes it an interesting target to promote ESCs self-renewal. Among the molecules that activate PI3K/Akt cascade, growth factors such as Fgf2 $(70,211)$, IGF1/2, Insulin $(70,71)$ or small molecules such as SC79 (212) or zinc have been reported (96).

Zinc is a transition metal involved in the activity of several proteins such as transcription factors or enzymes and may act as a neurotransmitter (95). In addition, it has been stablished the role of $\mathrm{Zn}^{2+}$ as an intracellular second messenger down regulating phosphatase activity (114), which upgrades phosphorylation of several protein kinases such as ERK, JNK or Akt $(114,115)$, promoting its activity. Several authors have reported that zinc ions are involved in the activation of PI3K/Akt cascade through phosphorylation of Akt $(115,213,214) . \quad \mathrm{Zn}^{2+}$ treatment, by means of increasing extracellular concentration, is associated with the release of intracellular $\mathrm{Zn}^{2+}$, a phenomenon that is controlled by Zip7 transporter, located in endoplasmic reticulum $(96,114,115)$. Subsequently Zip7 inhibits phosphatase activity and triggers Znassociated Akt phosphorylation similarly to growth factor stimuli (115). Only recently it has been described the role of $\mathrm{Zn}^{2+}$ in the transient inhibition of murine 
ESCs differentiation, associating this behaviour with the activation of STAT3 transcription factor (118). However, it is noteworthy that STAT3 activity is regulated by the protein EZH2 which in fact is a substrate for Akt-mediated phoshortlation $(215,216)$, opening up the possibility that STAT3 activity might be a consequence of upstream activation of PI3K/Akt pathway.

Here we unravel the mechanism by zinc ions are involved in ESCs behaviour, which set up new strategies to control pluripotency of embryonic stem cells. We report the role of extracellular $\mathrm{Zn}^{2+}$ on mouse embryonic stem cells (ESCs) fate, focusing on the PI3K/Akt signalling cascade. We demonstrate that the solely addition of $\mathrm{Zn}^{2+}$ induces self-renewal mechanisms and maintenance of pluripotency after long-term cultures. Further, we show that $\mathrm{Zn}^{2+}$ successfully reinforce LIF effect avoiding ESCs differentiation even in spontaneous differentiation conditions. We propose zinc as an alternative to the various and complex cocktail of small molecules and growth factors classically used for stable maintenance of ESC in vitro.

\section{Materials and methods}

\section{ESCs culture and embryoid bodies formation}

Murine embryonic stem cells D3 (ESCs, ATCC) were cultured in feeder-free conditions in basal medium (BM) composed by DMEM high glucose (Lonza) supplemented with 10\% Knockout Serum Replacement (KSR, ThermoFisher), 1\% Foetal Bovine Serum (FBS, Gibco), 1\% 100X Nucleosides (Millipore), 1\% LGlutamine (Sigma-Aldrich), 1\% Non-essential Amino Acids (Sigma-Aldrich), 1\% of 100X Penicillin/Streptomycin $(10,000 \mathrm{U} / \mathrm{ml}$ Penicillin-10,000 $\mathrm{\mu g} / \mathrm{ml}$ Streptomycin, P/S, ThermoFisher) and $10 \mathrm{mM}$ 2-Mercatoethanol (Gibco) at $37^{\circ}$ $\mathrm{C}$ in a humidified incubator containing $5 \% \mathrm{CO}_{2} .1,000 \mathrm{U} / \mathrm{ml}$ Leukaemia inhibitory factor (LIF, Millipore) was used to inhibit mESC differentiation (growth medium). Before seeding, culture dishes were coated with $0.2 \%$ gelatine (Sigma-Aldrich). Zinc chloride (Sigma-Aldrich) was used as source of $\mathrm{Zn}^{2+}$ for in vitro experiments.

For embryoid bodies (EBs) formation, mESC previously growth for 30 days (30dESC) in BM (30d-BM), BM supplemented with Zn $100 \mu \mathrm{M}$ (30d-Zn) or LIF (30dLIF), were cultured in hinging drops (1,000 cells / $20 \mu \mathrm{L}$ drop). EBs for histological cuts were collected after 5 days of culture and transferred to non-adhesive flasks. They were cultured for 10 additional days prior to its histological analysis. EBs 
used for spontaneous differentiation of ESC were cultured in medium DMEM/F12 (Sigma-Aldrich) supplemented with 10\% FBS, 1\% L-Glutamine,1\% P/S.

\section{ESCs intracellular $\mathrm{Zn}^{2+}$ homeostasis}

For analysis of intracellular $\mathrm{Zn}^{2+}$ wave induction, cells were incubated with FluoZin3-AM $(2 \mu \mathrm{M})$ for $40 \mathrm{~min}$ and washed with PBS. After that, medium with different concentrations of zinc were added (40, 100 and $140 \mu \mathrm{M})$ and fluorescence emission was measured every 40 seconds during approximately 60 minutes. BM and BM supplemented with LIF were used as control. Fluorescence emission was analysed by Victor III plate reader (Perkin Elmer).

\section{Immunofluorescence, staining, and histology methods.}

For immunofluorescence protein detection, cells were fixed with $4 \%$ formaldehyde during $20 \mathrm{~min}$ at room temperature. Then, cells were washed with TBS and blocked with TBS/Triton X 100 0.1\%/BSA 2\% for $1 \mathrm{~h}$ at room temperature. Cells were incubated with primary antibody overnight at $4{ }^{\circ} \mathrm{C}$ (Supplementary table 1). The samples were subsequently washed and incubated with secondary antibodies for $1 \mathrm{~h}$ at room temperature (Supplementary table 1 ). Hoechst (dil: 1/7,000, Sigma-Aldrich) was used for nuclear staining. Samples were mounted with $85 \%$ glycerol and imaged by a Nikon Eclipse i80 fluorescence microscope. The percentage of protein staining was quantified by image analysis with imageJ software.

\begin{tabular}{|c|c|c|}
\hline Primary antibodies & Dilution & Reference \\
\hline Goat anti-Oct4 & $1 / 400$ & SantaCuz Biotechnology \\
\hline Rabbit anti-Sox2 & $1 / 500$ & ThermoFisher \\
\hline Rabbit anti-Sox10 & $1 / 500$ & Abcam \\
\hline Goat anti-Sox17 & $1 / 500$ & R\&D systems \\
\hline Goat anti-Zip7 & $1 / 300$ & SantaCuz Biotechnology \\
\hline Mouse anti- $\beta$ III-tubulin (Clone Tuj1) & $1 / 1000$ & Neuromics \\
\hline Rabbit anti-CD31 & $1 / 300$ & Abcam \\
\hline Rabbit anti-CD34 & $1 / 300$ & Abcam \\
\hline Rabbit anti- $\beta$ Catenin & $1 / 500$ & ThermoFisher \\
\hline Mouse anti-phospho Akt-serine 473 (Clone 6F5) & $1 / 500$ & Millipore \\
\hline Secondary antibodies & Dilution & Reference \\
\hline Alexa 488 conjugated goat anti-mouse & $1 / 700$ & ThermoFisher \\
\hline Alexa 555 conjugated goat anti-mouse & $1 / 700$ & ThermoFisher \\
\hline Alexa 488 conjugated goat anti-rabbit & $1 / 700$ & ThermoFisher \\
\hline Alexa 555 conjugated goat anti-rabbit & $1 / 700$ & ThermoFisher \\
\hline Alexa 633 conjugated goat anti-rabbit & $1 / 300$ & ThermoFisher \\
\hline DyLight 488 conjugate donkey anti-goat IgG & $1 / 700$ & ThermoFisher \\
\hline
\end{tabular}


Zinc maintains embryonic stem cells pluripotency and multilineage differentiation potential via Akt activation

To analyse the number of alkaline phosphatase (AP) positive colonies, ESCs were fixed with $4 \%$ formaldehyde and stained with Naphthol AS-MX/Fast Red TR (Sigma-Aldrich) for $30 \mathrm{~min}$ at room temperature as previously described(217). After staining, cells were rinsed and nuclei were labelled with Hoechst. The samples were imaged by a Nikon Eclipse i80 fluorescence microscope. The percentage of AP stained colonies were evaluated with imageJ software.

For histological sections, EBs were fixed with $4 \%$ overnight at $4^{\circ} \mathrm{C}$. EBs were embedded into low gelling temperature agarose (Sigma-Aldrich) and paraffin included (Polyester Wax, Electron microscopy) for $6 \mu \mathrm{m}$ histological sections obtained with HM $350 \mathrm{~S}$ (ThermoFisher). Paraffin sections were histochemically stained with Haematoxylin/Eosin (Sigma-Aldrich) as was previously described(218).

\section{RNA interference (RNAi)}

ESCs were seeded at high density $\left(40,000\right.$ cells $\left./ \mathrm{cm}^{2}\right)$ in growth medium (+ LIF). After $24 \mathrm{~h}$, cells were transfected with MISSION esiRNA (Sigma-Aldrich) against Zip7 transporter in X-tremeGENE siRNA Transfection Reagent (Roche), following manufacturer's instructions. Cell transfection was carried out in OptiMEM Reduced Serum medium (ThermoFisher) supplemented with LIF. MISSION siRNA Fluorescent Universal Negative Control 1, Cyanine 3 (NC, Sigma-Aldrich) was used as negative control. Transfected ESCs were cultured for $24 \mathrm{~h}$. Then, transfection medium was changed for basal medium supplemented with $100 \mu \mathrm{M}$ $\mathrm{Zn}^{2+}, 1,000 \mathrm{U} / \mathrm{mL}$ LIF or just BM for next ESCs culture for 7 additional days.

\section{Akt inhibition experiments.}

For Akt/PI3k specific inhibition, we used 2-(4-Morpholinyl)-8-phenyl-1(4H)benzopyran-4-one hydrochloride, (LY-294002, Sigma-Aldrich) at concentration of $10 \mu \mathrm{M}$. ESCs were seeded at 20,000 cells $/ \mathrm{cm}^{2}$ in growth medium. After $24 \mathrm{~h}$,

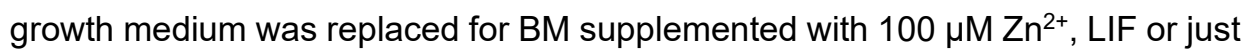
BM all of them also supplemented with LY-294,002. After two days, medium was changed normally without further LY-294,002 addition for 7 additional days.

\section{Western Blot analysis}

For protein expression analysis, total protein extraction was performed with RIPA buffer supplemented with protease inhibitor cocktail tablets (Roche). Proteins were separated in $10 \%$ SDS-PAGE with Mini-PROTEAN Electrophoresis System (Bio-Rad) and transferred to a PVDF (GE-Healthcare) membrane by Trans-Blot 
Semi-Dry Transfer Cell (Bio-Rad). Then, membranes were blocked with 5\% BSA (Sigma-Aldrich) in TBS/0.1\% Tween 20 (Sigma-Aldrich). For subsequent incubation with primary antibodies (Table 2) they were diluted on TBS $0.1 \%$ Tween 20 and $3 \%$ BSA and incubated overnight at $4{ }^{\circ} \mathrm{C}$. Membranes were washed and incubated with HRP linked secondary antibody (Table 2) for $1 \mathrm{~h}$ at room temperature for chemiluminiscence band detection by ECL-Plus reactive (ThermoFisher). Fujifilm Las-3000 imager device was used for protein bands visualisation.

\begin{tabular}{|l|l|l|}
\hline \multicolumn{3}{|l|}{ Table 2. Antibodies and dilutions used for western blot experiments } \\
\hline Primary antibodies & Dilution & Reference \\
\hline Goat anti-Zip7 & $1 / 300$ & SantaCruz Biotechnologies \\
\hline Rabbit anti-Akt (Clone J.314.4) & $1 / 1500$ & ThermoFisher \\
\hline $\begin{array}{l}\text { Mouse anti-phospho Akt-serine 473 (Clone } \\
\text { 6F5) }\end{array}$ & $1 / 1500$ & Millipore \\
\hline $\begin{array}{l}\text { Mouse anti-phospho STAT3-threonine 705 } \\
\text { (Clone 9E12) }\end{array}$ & $1 / 1500$ & Millipore \\
\hline Rabbit anti-GSK3ß (Clone 3D10) & $1 / 1500$ & ThermoFisher \\
\hline $\begin{array}{l}\text { Rabbit anti-phospho GSK3ß-serine 9 (Clone } \\
\text { C.367.3) }\end{array}$ & $1 / 1000$ & ThermoFisher \\
\hline Rabbit anti-GAPDH & $1 / 3000$ & ThermoFisher \\
\hline Secondary antibodies & Dilution & Reference \\
\hline Rabbit anti-goat HRP conjugate & $1 / 10000$ & ThermoFisher \\
\hline Donkey anti-mouse HRP conjugate & $1 / 10000$ & GE Healthcare \\
\hline Donkey anti-rabbit HRP conjugate & $1 / 10000$ & GE Healthcare \\
\hline
\end{tabular}

\section{Gene expression analysis by quantitative real time PCR}

Total RNA from ESCs was extracted using Quick RNA Miniprep kit (ZYMO Research) and its quantity and integrity was measured using Q3000 micro volume spectrophotometer (Quawell). RNAs were reverse transcribed using Maxima First Strand cDNA Synthesis Kit with Thermolabile dsDNase (ThermoFisher). Real-time qPCR was carried out using the PowerUp SYBR Master Mix (Thermofisher) and ViiA 7 Real-Time PCR System (ThermoFisher). The reactions were run four times (independent biological experiments). The primers used for amplification are indicated in Table 3 . The fractional cycle number at which fluorescence passed the threshold ( $C_{t}$ values) was used for gene expression quantification using the comparative $\Delta \Delta \mathrm{C}_{\mathrm{t}}$ method. Sample values were normalized to the threshold value of housekeeping gene GAPDH. 
Zinc maintains embryonic stem cells pluripotency and multilineage differentiation potential via Akt activation

\begin{tabular}{|c|l|l|}
\hline \multicolumn{2}{|l|}{ Table 3. RT-qPCR primer sequences. } \\
\hline Primers & Sequence \\
\hline \multirow{2}{*}{ Oct4 } & 5'-Forward & ATGCCGTGAAGTTGGAGAAG \\
\cline { 2 - 3 } & 5'-Reverse & TGTACCCCAAGGTGATCCTC \\
\hline \multirow{2}{*}{ Nanog } & 5'-Forward & CCTGAGCTATAAGCAGGTTAAGACC \\
\cline { 2 - 3 } & 5'-Reverse & TGGATGCTGGGATACTCCAC \\
\hline \multirow{2}{*}{ KIf4 } & 5'-Forward & AACATGCCCGGACTTACAAA \\
\cline { 2 - 3 } & 5'-Reverse & TTCAAGGGAATCCTGGTCTTC \\
\hline \multirow{2}{*}{ Foxa2 } & 5'-Forward & TAGCGGAGGCAAGAAGACC \\
\cline { 2 - 3 } & 5'-Reverse & CTTAGGCCACCTCGCTTGT \\
\hline \multirow{2}{*}{ Brachyury/T } & 5'-Forward & GGTGGCTTGTTCCTGGTGC \\
\cline { 2 - 3 } & 5'-Reverse & GTAGGTGGGCTGGCGTTAT \\
\hline \multirow{2}{*}{ Sox1 } & 5'-Forward & AGACAGCGTGCCTTTGATTT \\
\cline { 2 - 3 } & 5'-Reverse & TGGGATAAGACCTGGGTGAG \\
\hline \multirow{2}{*}{ Gata6 } & 5'-Forward & ACTGAAGTAAGAAGAGATGGGCTTT \\
\cline { 2 - 3 } & 5'-Reverse & ATCTCTCAATCTTCCTTAGCAGACA \\
\hline \multirow{2}{*}{ FgF5 } & 5'-Forward & AAAGTCAATGGCTCCCACGAA \\
\cline { 2 - 3 } & 5'-Reverse & GGCACTTGCATGGAGTTTTCC \\
\hline \multirow{2}{*}{ GAPDH } & 5'-Forward & AGGTCGGTGTGAACGGATTTG \\
\cline { 2 - 3 } & 5'-Reverse & TGTAGACCATGTAGTTGAGGTCA \\
\hline
\end{tabular}

\section{Statistical analyses.}

Each experiment was performed at least four times unless otherwise noted. Data were reported as mean \pm standard deviation. To establish if the obtained data followed a normal distribution, D'Agostino-Pearson omnibus test was resorted. Results were analysed by one-way ANOVA using GraphPad Prism 6.0. When differences were determined to be significant, pairwise comparisons were performed using a Tukey in case of normal distribution of data or a Dunn's test in the opposite case. A 95\% confidence level was considered significant. The linear regression of immunofluorescence images quantification and Pearson's $R$ correlation values were obtained by $\mathrm{R}$ software.

\section{Results}

\section{$\mathrm{Zn}^{2+}$ effects on ESCs viability and proliferation}

To determine the toxic concentrations of zinc in ESCs, cell viability was analysed using concentrations ranging from 40 to $240 \mu \mathrm{M}$ at 1,4 and 7 days (Fig. 20). ESCs viability was maintained with $\mathrm{Zn}^{2+}$ concentrations up to $140 \mu \mathrm{M}$, whereas for 160 and $240 \mu \mathrm{M}$ concentrations, cell viability decreased significantly (Fig. 20a). 

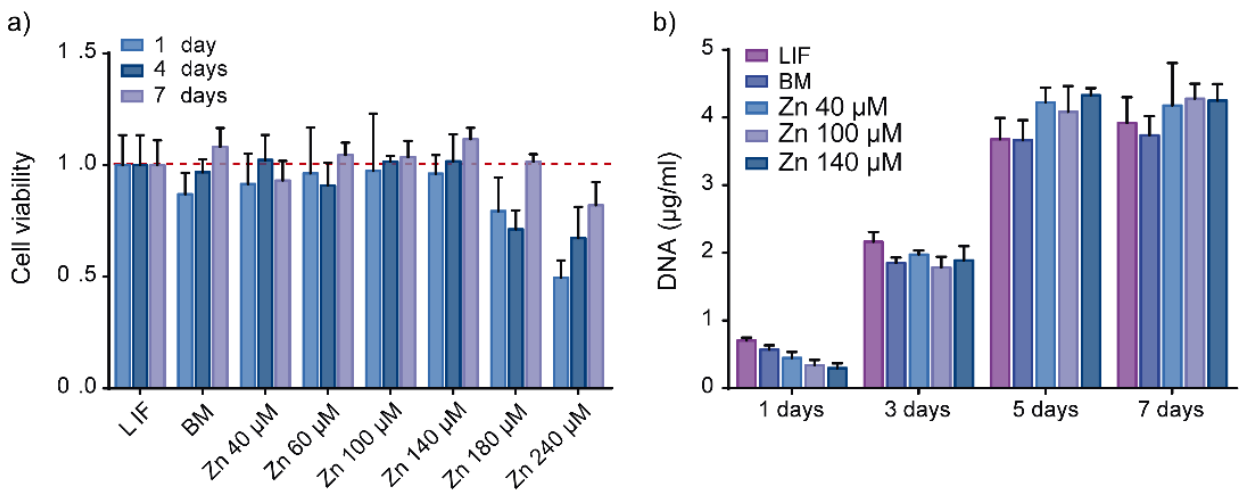

Figure 20. Effects of zinc in ESCs viability and proliferation

a) Viability of ESCs cultured with different concentrations of $\mathrm{Zn}^{2+}$ and analysed by live/dead assay after 1, 4 and 7 days of culture. Viable cells were determined by Calcein3AM fluorescence detection $(n=4)$. b) Proliferation activity of ESCs cultured with different concentrations of $\mathrm{Zn}^{2+}$ and analysed by total DNA quantification after 1, 3, 5, and 7 days of culture. $(n=6)$. Graphs show mean \pm standard deviation.

For proliferation experiments, we used $\mathrm{Zn}^{2+}$ concentrations that maintain ESC viability, and thus we discarded 160 and $240 \mu \mathrm{M}$ concentrations from now on. Total DNA was measured after supplementing cells with 40,100 and $140 \mu \mathrm{M} \mathrm{Zn^{2+ }}$ for $1,3,5$ or 7 days. Figure 20b shows no differences in cell proliferation for the different concentrations of $\mathrm{Zn}^{2+}$ used, which remains similar to LIF and basal medium conditions.

\section{$\mathrm{Zn}^{2+}$ promotes ESCs self-renewal}

To gain insights into the mechanisms induced by soluble $\mathrm{Zn}^{2+}$ in ESCs, we first measured cytosolic intake of $\mathrm{Zn}^{2+}$. We quantified the intracellular concentration of $\mathrm{Zn}^{2+}$ in dependence of the extracellular $\mathrm{Zn}^{2+}$ supplementation after 1, 3 and 5 days of culture. Free intracellular $\mathrm{Zn}^{2+}$ was labelled with FluoZin3-AM (Fig. 21). Intracellular $\mathrm{Zn}^{2+}$ rose monotonically with the concentration of extracellular $\mathrm{Zn}^{2+}$. The culture was maintained for 5 days. Afterwards, $\mathrm{Zn}^{2+}$ was removed from the medium and the culture maintained for $1 \mathrm{~h}$, which led to a drastic decrease in intracellular $\mathrm{Zn}^{2+}$ concentration (reaching similar levels of basal medium (BM, Fig. 21). These results demonstrate that intracellular zinc concentration in ESCs is regulated by extracellular $\mathrm{Zn}^{2+}$ presence in the culture medium. 
Zinc maintains embryonic stem cells pluripotency and multilineage differentiation potential via Akt activation

FluoZin3-AM

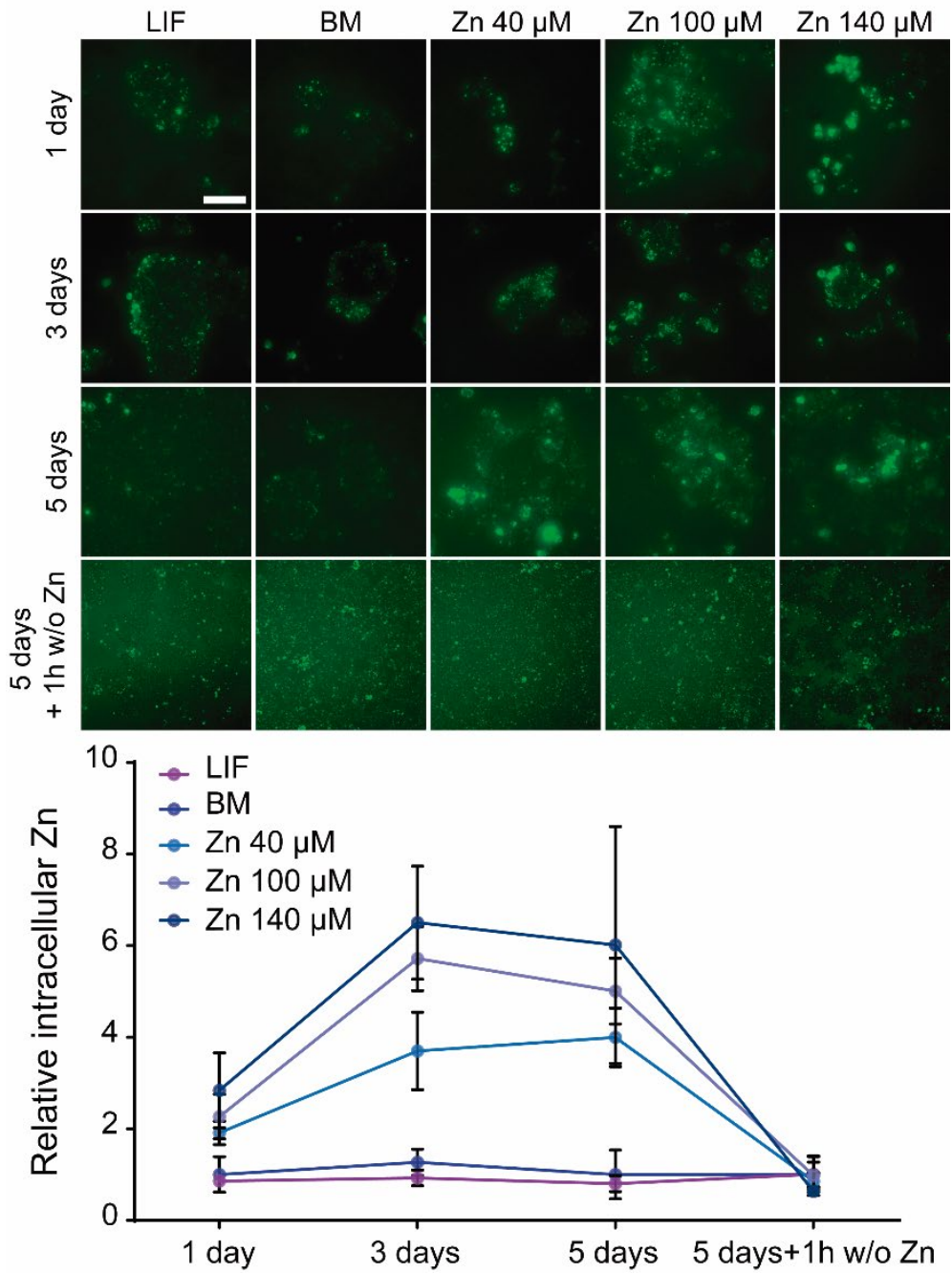

Figure 21. Intracellular concentration of free zinc in ESCs after 5 days

Intracellular $\mathrm{Zn}^{2+}$ concentration of ESCs cultured with different extracellular $\mathrm{Zn}^{2+}$ concentrations was determined by FluoZin 3-AM after 1, 3 and 5 days of culture. After 5 days of culture, culture medium was replaced for zinc-depleted medium and intracellular $Z^{2+}$ was measured again after $1 \mathrm{~h}(5 \mathrm{~d}+1 \mathrm{~h}$ w/o $\mathrm{Zn})($ Scale bar: $200 \mu \mathrm{m})(\mathrm{n}=4)$.

Graphs show mean \pm standard deviation.

$\mathrm{Zn}^{2+}$ is an intracellular secondary messenger involved in multiple cellular events(114). Then, we measured intracellular "zinc waves" in ESCs after the addition of $\mathrm{Zn}^{2+}$ in the culture medium. Figure 22 shows that intracellular $\mathrm{Zn}^{2+}$ 
rose quickly upon addition of $100 \mu \mathrm{M}$ and $140 \mu \mathrm{M}$ and reached a plateau after 10

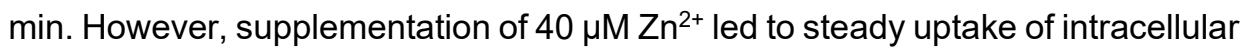
$\mathrm{Zn}^{2+}$ which was still increasing after $60 \mathrm{~min}$. Basal medium (BM) and LIF supplemented medium (LIF) were used as a controls and resulted in no increase in intracellular $\mathrm{Zn}^{2+}$.

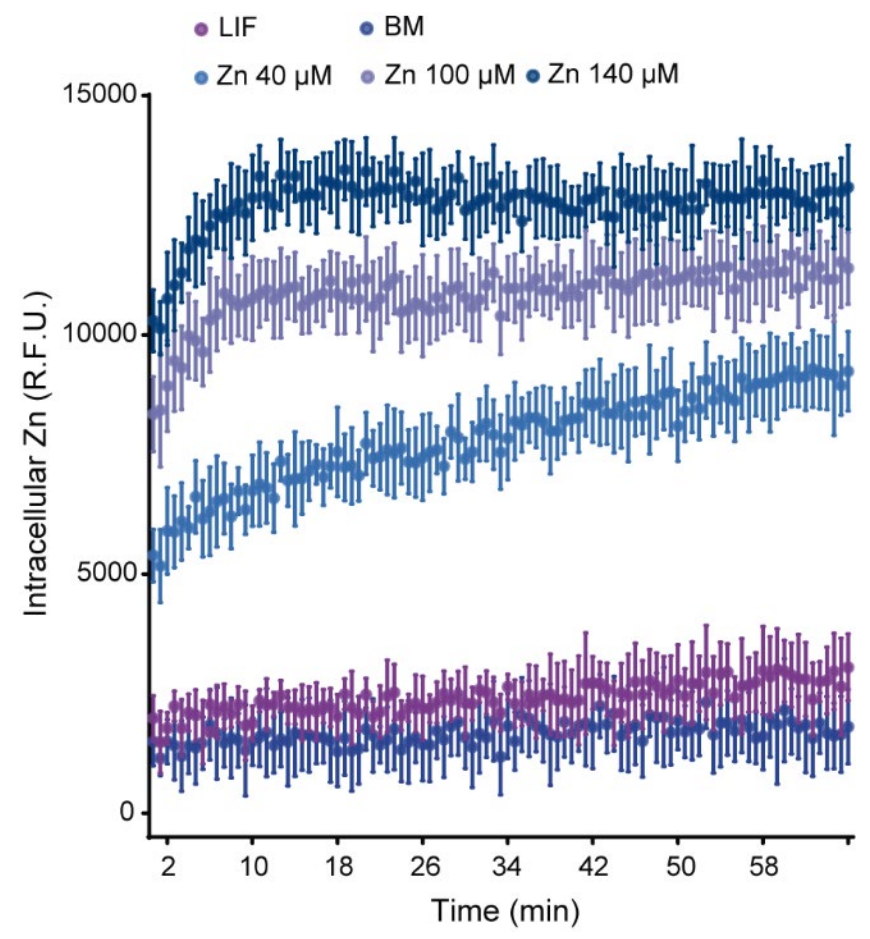

Figure 22. Intracellular zinc wave in ESCs exposed to different concentration of zinc. Intracellular $\mathrm{Zn}^{+2}$ wave determined by FluoZin3-AM labelling (data points were taken every 40 s) subsequent to exposure of cells to different concentrations of extracellular $\mathrm{Zn}^{2+}$. Cells were kept at $37^{\circ} \mathrm{C}$ throughout the analysis $(n=6)$.

Graphs show mean \pm standard deviation.

We next assessed the effect of $\mathrm{Zn}^{2+}$ on ESCs self-renewal using basal medium

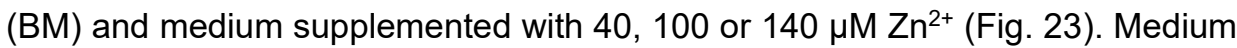
supplemented with LIF was used as a positive control of stemness maintenance. ESCs were seeded at low density $\left(10,000 \mathrm{cells} / \mathrm{cm}^{2}\right)$ on gelatine coated plates until sub-confluence ( 3 days) and subsequently were sub-cultured for a total of 6 days in culture. We used Oct4, Sox2 and Alkaline phosphatase (AP) as pluripotency markers and Sox17 as marker of spontaneous differentiation. Figure 23 shows that the only the presence of 100 and $140 \mu \mathrm{M}$ of $\mathrm{Zn}^{2+}$ resulted in high 
Zinc maintains embryonic stem cells pluripotency and multilineage differentiation potential via Akt activation

levels of Oct4 and Sox2 expression, as well as bigger AP positive colonies

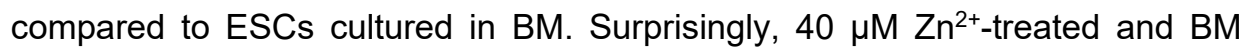
cultured cells showed similar expression for pluripotency markers. Further, $40 \mu \mathrm{M}$ $\mathrm{Zn}^{2+}$-treated ESCs expressed the highest values of Sox17. These results demonstrate that addition of high concentrations of $\mathrm{Zn}^{2+}$ to the culture medium maintain ESCs stemness after 6 days.
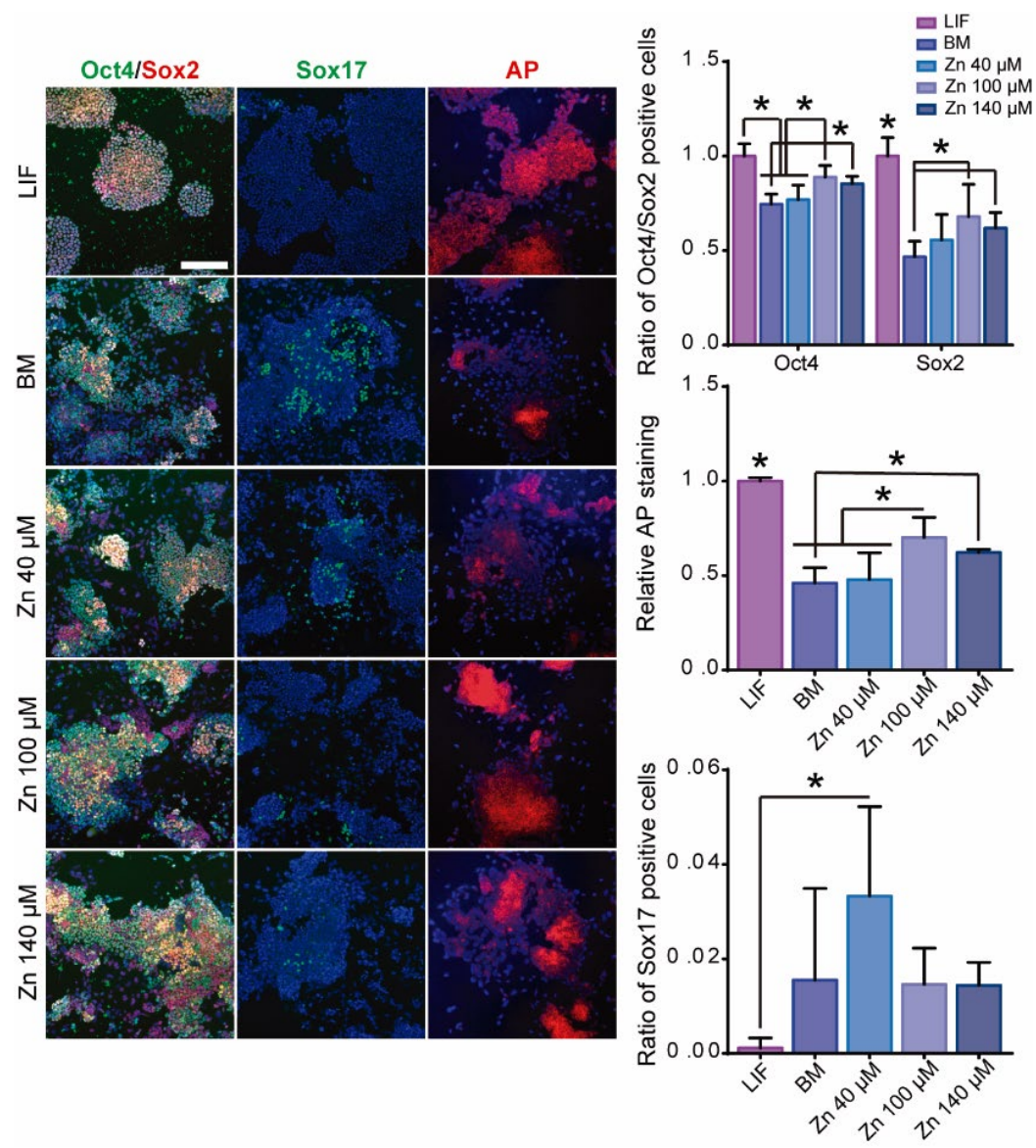

Figure 23. Role of zinc in ESCs self-renewal.

Immunofluorescence detection of pluripotency markers (Oct4 and Sox2) and staining of AP in ESCs after 5 days of culture in BM, medium supplemented with LIF or medium supplemented with different concentrations of $\mathrm{Zn}^{2+}(\mathrm{n}=5)$. Scale bar: $200 \mu \mathrm{m}$.

Graphs show mean \pm standard deviation. Significant differences were determined by ANOVA test; ${ }^{*} p<0.05$. 
To demonstrate that $\mathrm{Zn}^{2+}$ promotes ESCs self-renewal, we performed additional experiments to induce cell differentiation using defined media in presence of $\mathrm{Zn}^{2+}$. ESCs were seeded at 10,000 cells $/ \mathrm{cm}^{2}$ on gelatine coated plates in BM supplemented with LIF. After $24 \mathrm{~h}$ of culture, medium was replaced by BM supplemented with $5 \% \mathrm{KSR}$ (to stimulate ESC differentiation(219)) and $100 \mu \mathrm{M}$

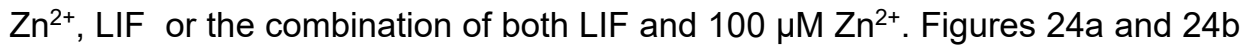
show immunofluorescence and qPCR expression values of pluripotency (Oct4 and Sox2) and primary germ layers differentiation markers (endoderm: Foxa2; mesoderm: Brachyury/T; ectoderm: Sox 1 ) after 5 days of culture. 
Zinc maintains embryonic stem cells pluripotency and multilineage differentiation potential via Akt activation
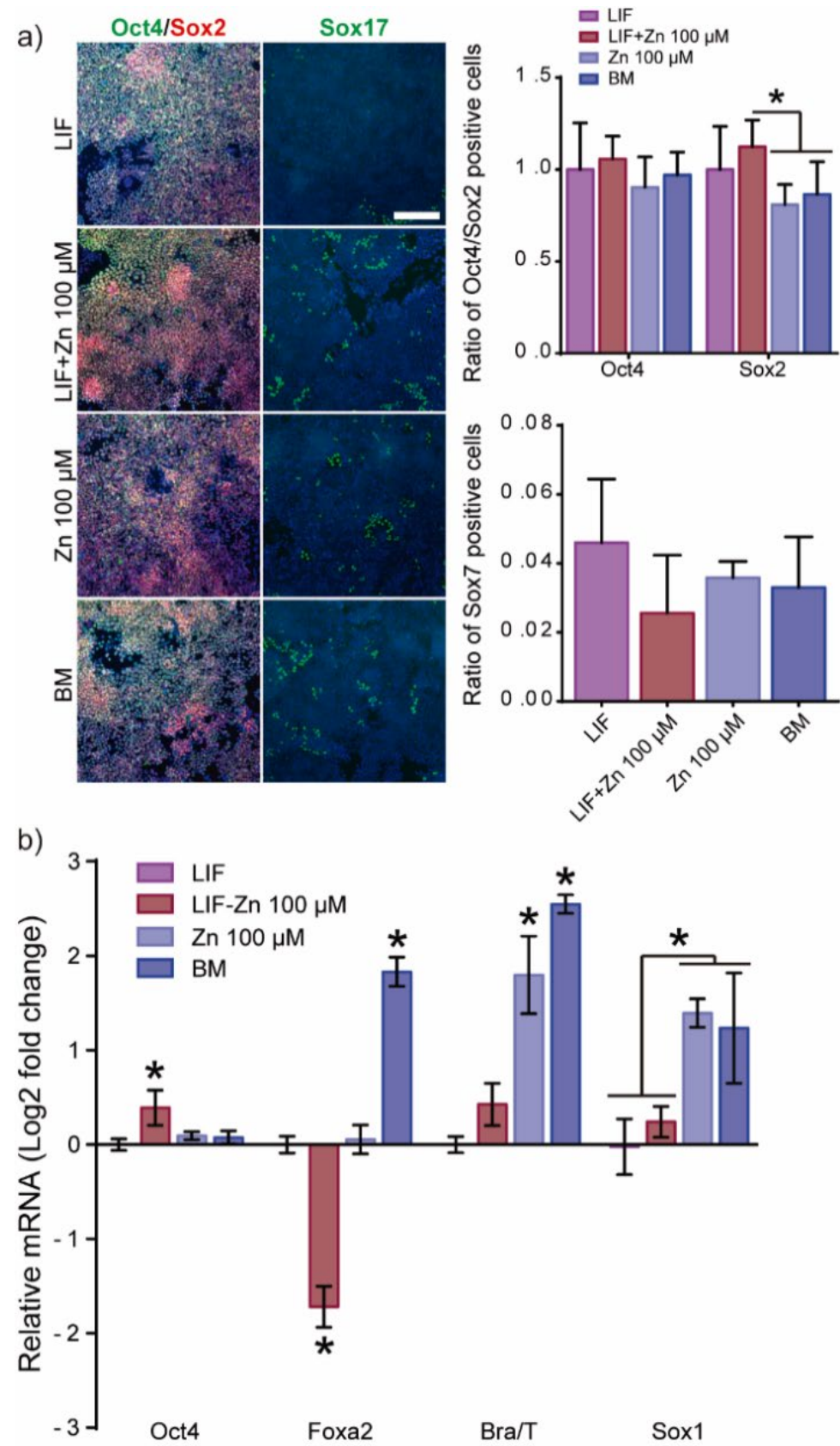

Figure 24. Role of zinc in ESCs self-renewal in differentiation conditions.

a) Immunofluorescence detection of pluripotency (Oct4 and Sox2) and differentiation markers (endoderm: Sox17) determined after 5 days of culture in accelerated differentiation conditions (medium supplemented with $5 \%$ KSR) $(n=5)$. Scale bar: $200 \mu \mathrm{m}$. 
b) qPCR detection of pluripotency markers (Oct4) and differentiation markers (endoderm: Foxa2, mesoderm: Brachyury/T and ectoderm: Sox1) determined after 5 days of culture in accelerated differentiation conditions (medium supplemented with $5 \% \mathrm{KSR}$ ) ( $\mathrm{n}=4$ ). Graphs show mean \pm standard deviation. Significant differences were determined by ANOVA test; ${ }^{*} p<0.05$.

ESCs treated with either LIF or $\mathrm{Zn}^{2+}$ showed lower expression of differentiation markers compared to BM control. Endoderm markers expression (Foxa2 and Sox17) were similar between $\mathrm{Zn}^{2+}$ and LIF treated cells. However, $\mathrm{Zn}^{2+}$-treated ESCs showed upregulated expression of ectoderm and mesoderm markers (Brachyury/T and Sox1). Nevertheless, the best results in terms of pluripotency

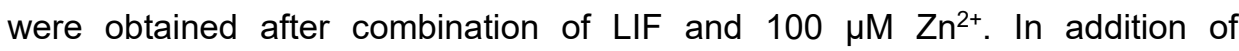
downregulated expression of differentiation markers, ESCs treated with LIF-100 $\mu \mathrm{M} \mathrm{Zn^{2+ }}$ also displayed a slight overexpression of Oct4. These results further demonstrate that zinc maintains the self-renewal potential of ESCs even under accelerated differentiation conditions.

\section{$\mathrm{Zn}^{2+}$ maintain ESCs stemness activating Zip7 transporter and Akt signalling transduction pathway}

$\mathrm{Zn}^{2+}$ transporter Zip7 is localised in different organelles and cytoplasmic vesicles associated to $\mathrm{Zn}^{2+}$ storage $(151,161)$, and drives $\mathrm{Zn}^{2+}$ influx from intracellular storages to cytoplasm. Zip7 activation has been extensively associated with Akt phophorylation(96), which is a key protein kinase regulator of ESC self-renewal pathway (220). To investigate the role of Zip7 and Akt in ESCs we designed two experiments to evaluate the effect of zinc: i) Akt inhibition with the Akt/PI3K chemical inhibitor LY-294002, and ii) transient down regulation of Zip7 transporter using siRNAs.

For the first approach, ESCs were cultured in BM, medium supplemented with

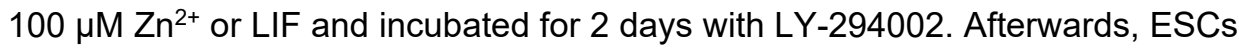
were cultured 5 more days prior measurement of the expression of pluripotency markers (Oct4 and AP). After $24 \mathrm{~h}$ of treatment with LY-294002 Akt phosphorylation levels were reduced in all conditions regardless of the presence of $\mathrm{Zn}^{2+}$ or LIF in the culture medium (Fig 25-a). After 7 days of culture, and PI3K/Akt inhibition, Oct4 and AP levels decreased significantly for ESCs cultured with $\mathrm{Zn}^{2+}$ and in $\mathrm{BM}$ conditions, while their levels remained unaltered in LIFsupplemented cells, presenting similar values to those obtained in the control 
Zinc maintains embryonic stem cells pluripotency and multilineage differentiation potential via Akt activation

without LY294002 inhibitor (Fig. 25). These results demonstrate that Akt signalling is involved in the maintenance of ESC self-renewal using zinc but not LIF.

a)

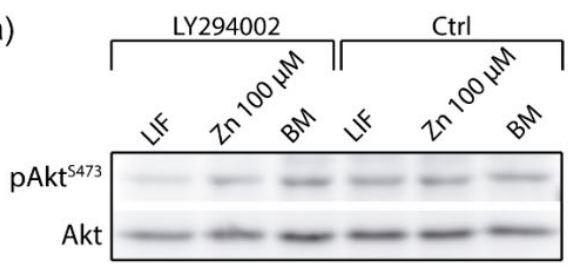

b)
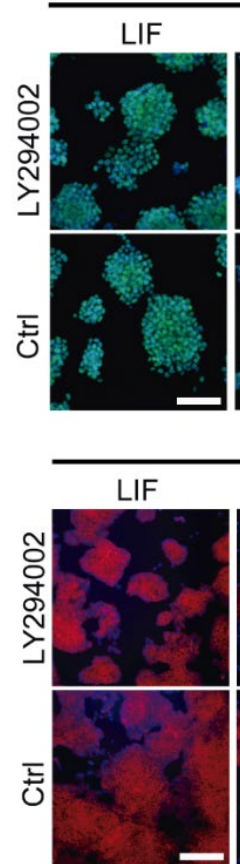

Oct4

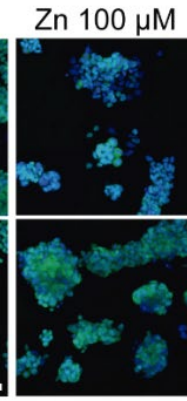

AP

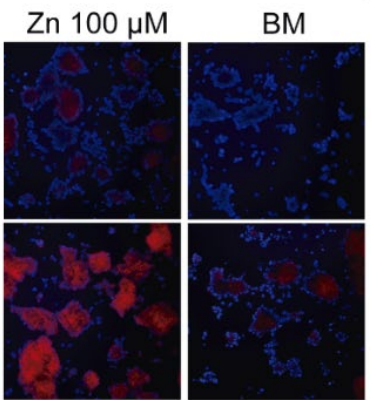

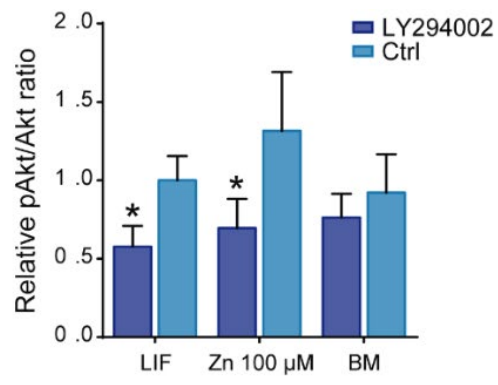
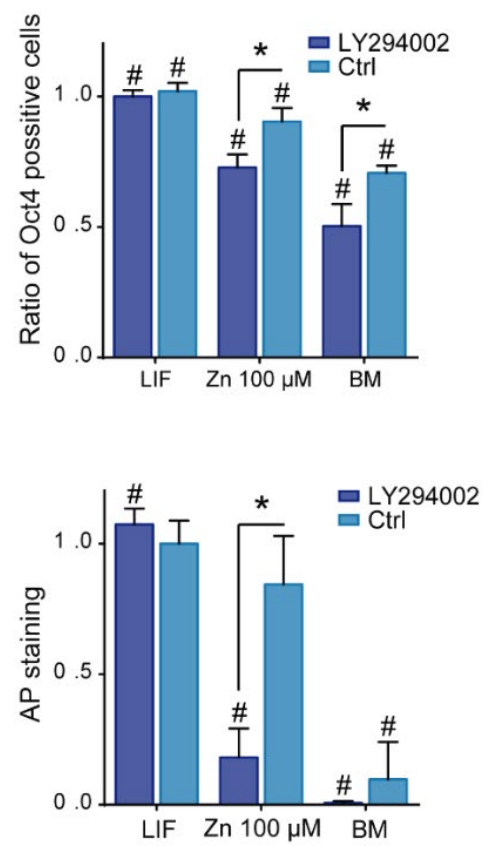

Figure 25. Role of Akt activity in ESCs stemness maintenance.

a) Analysis of pAkt/Akt ratio by western blot after Akt inhibition with LY-294002 $10 \mu \mathrm{M}$ during $24 \mathrm{~h}$ in cells cultured in BM, medium supplemented with LIF or medium supplemented with $100 \mu \mathrm{M}$ of $\mathrm{Zn}^{2+}$. GAPDH was used as loading control protein. ( $\left.n=4\right)$.

b) Immunofluorescence detection (Oct4-green) and staining (Alkaline phosphatase-red, AP) of pluripotency markers determined after 7 days of culture in BM, medium supplemented with LIF or medium supplemented with $100 \mu \mathrm{M}$ of $\mathrm{Zn}^{2+}$, and treated $48 \mathrm{~h}$ with Akt inhibitor LY-294002 (Scale bar $100 \mu \mathrm{m})$. ( $\mathrm{n}=4)$.

Graphs show mean \pm standard deviation. Significant differences were determined by ANOVA test; between groups: ${ }^{*} p<0.05$; within group: \#p $<0.05$. 
As a second approach, we treated ESCs with RNAi against Zip7 transporter. After 3 days of Zip7 silencing, ESCs were cultured in BM, medium supplemented with

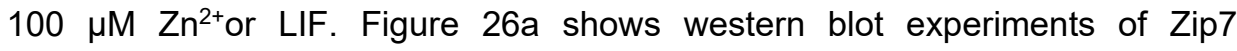
expression after silencing by RNAi. We observed that Zip7 expression decreased significantly in all conditions compared with RNAi negative control (NC). 

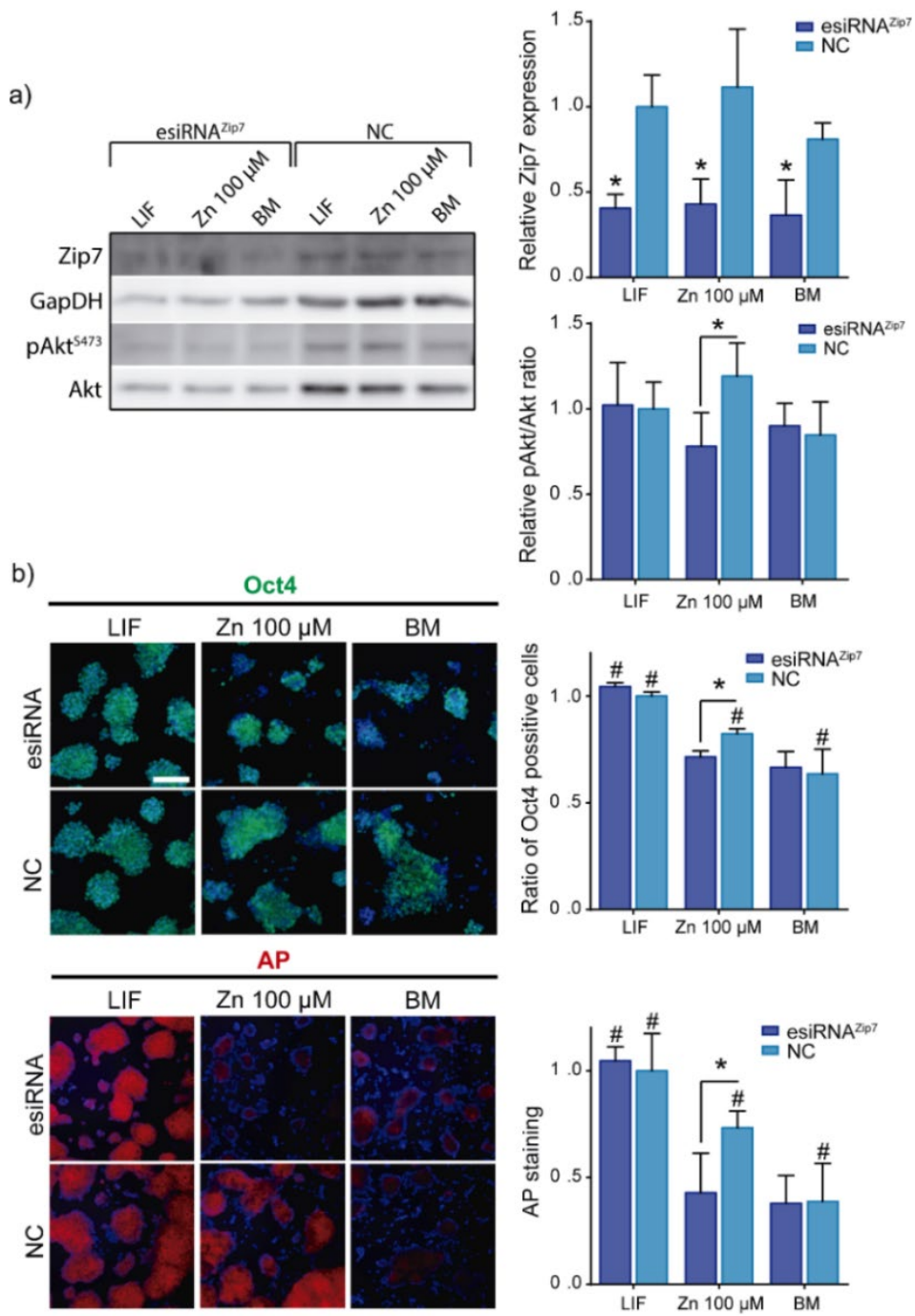

Figure 26. Role of Zip7 in Akt activity and ESCs stemness maintenance.

a) Analysis of Zip7 expression and pAkt/Akt ratio by western blot after Zip7 silencing with RNAi after 3 days of culture. GAPDH was used as loading control protein. $(n=4)$. Cells were cultured in BM, medium supplemented with LIF or medium supplemented with 100 $\mu \mathrm{M}$ of $\mathrm{Zn}^{2+}$.

b) Immunofluorescence detection (Oct4-green) and staining (Alkaline phosphatase-red, AP) of pluripotency markers determined after 7 days of culture in BM, medium supplemented with LIF or medium supplemented with $100 \mu \mathrm{M}$ of $\mathrm{Zn}^{2+}$, and Zip7 silenced with RNAi during 3 days (Scale bar $100 \mu \mathrm{m})$. $(\mathrm{n}=4)$.

Graphs show mean \pm standard deviation. Significant differences were determined by ANOVA test; between groups: ${ }^{*} p<0.05$; within group: \#p $<0.05$. 
Akt phosphorylation after Zip7 silencing, decreased significantly only in ESCs supplemented with $\mathrm{Zn}^{2+}$ (Fig. 26), suggesting that inhibition of zinc transport strongly affects Akt phosphorylation. Note that both Zip7 expression and pAkt/Akt ratio followed a similar trend in control conditions, being the higher levels in cells

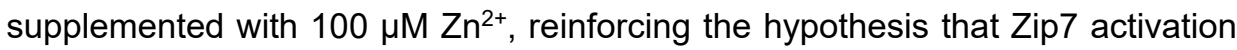
promotes Akt phosphorylation.

We further analysed the expression of Oct4 and AP markers after Zip7 knock down. Figure 25b shows a significant reduction in the self-renewal effect induced by $\mathrm{Zn}^{2+}$, diminishing the expression values of Oct4 and AP to the BM levels. It is interesting to note that Zip7 knock down is transient, and after 6 days of culture, both Zip7 expression and pAkt/Akt ratio were completely recovered (Fig. 27). However, silencing of Zip7 impairs maintenance of stemness markers, even after 7 days of culture and in the presence of $\mathrm{Zn}^{2+}$, demonstrating that the effect of zinc in self-renewal maintenance is dependent of $\mathrm{Zn}^{2+}$ transporter ZIP7.
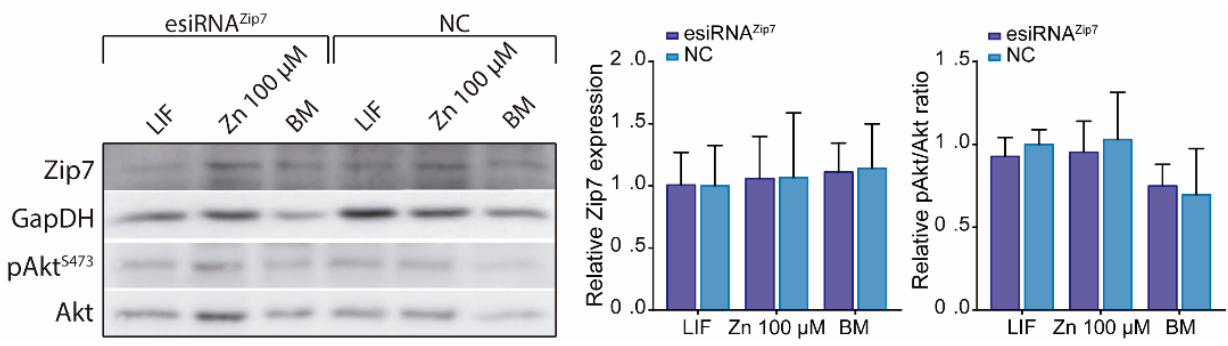

Figure 27. Role of Zip7 in Akt activity and ESCs stemness maintenance.

Analysis of Zip7 expression and pAkt/Akt ratio (S473) by western blot after Zip7 silencing with RNAi after 6 days of culture. GAPDH was used as loading control protein. Cells were cultured in BM, medium supplemented with LIF or medium supplemented with $100 \mu \mathrm{M}$ of Zn2+. After 6 days of culture, both Zip7 expression and pAkt/Akt ratio were completely recovered.

Graphs show mean \pm standard deviation. $(n=4)$. Significant differences were determined by ANOVA test; ${ }^{*} p<0.05$.

To determine if $\mathrm{Zn}^{2+}$-mediated Akt activation further stimulate downstream phosphorylation of Akt target substrates, we then evaluated GSK3 $\beta$ phosphorylation. ESCs were cultured in BM, medium supplemented with $100 \mu \mathrm{M}$ $\mathrm{Zn}^{2+}$ or LIF. Figure 28 shows no differences in pAkt/Akt or pGSK3 $/$ GSK3 $\beta$ ratios after $4 \mathrm{~h}$ of culture for the different conditions used. However, after $24 \mathrm{~h}$, both Akt and GSK3 $\beta$ phosphorylation increased for $\mathrm{Zn}^{2+}$ - supplemented cells, whilst LIF and BM conditions showed similar lower values. These results support the 
Zinc maintains embryonic stem cells pluripotency and multilineage differentiation potential via Akt activation

hypothesis that zinc maintains ESCs self-renewal by inducing Akt phosphorylation, that then promotes phosphorylation of downstream target proteins such as GSK3 $\beta$, inactivating its activity and resulting in stemness maintenance.

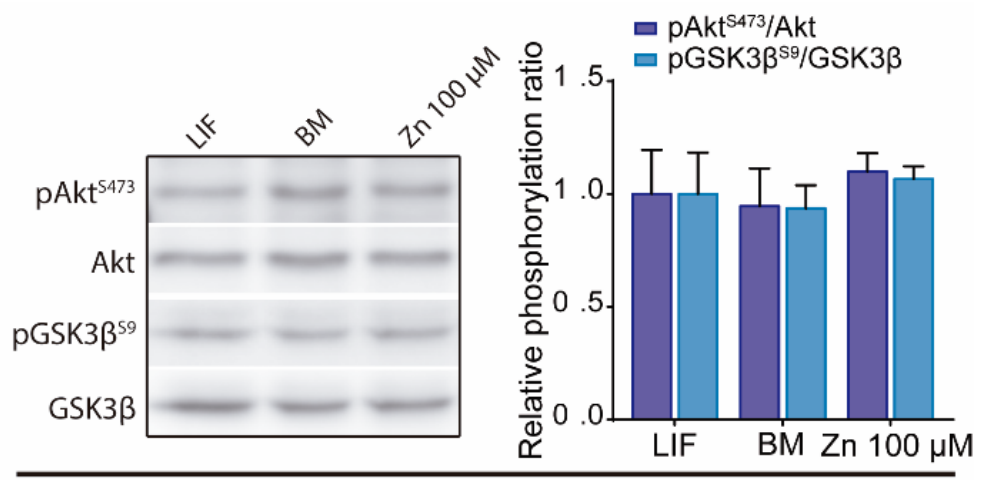

After $4 \mathrm{~h}$

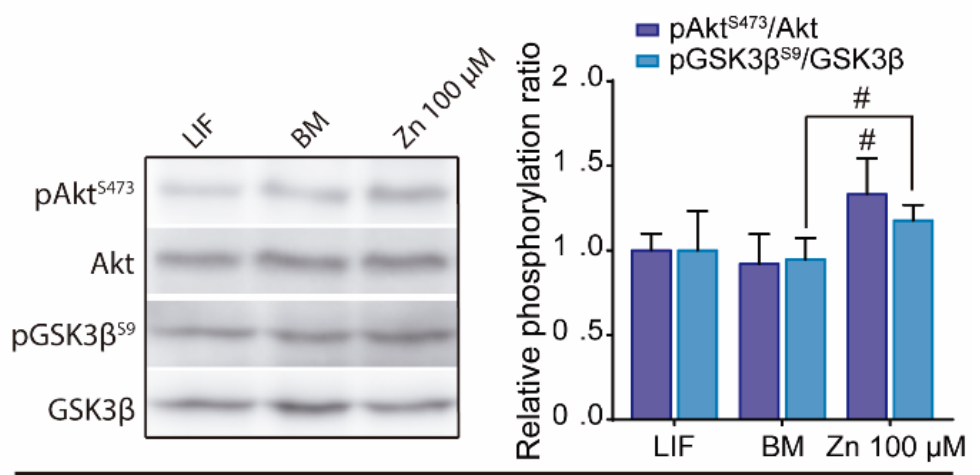

After $24 \mathrm{~h}$

Figure 28. Zinc mediated activation of Akt subsequently phosphorylates its target substrates.

Analysis of pAkt/Akt (S473) and pGSK3ß/GSK3 $\beta$ (S9) ratios by western blot in ESCs cultured in BM, medium supplemented with LIF or medium supplemented with $100 \mu \mathrm{M}$ of $\mathrm{Zn}^{2+}$ during $4 \mathrm{~h}$ or $24 \mathrm{~h}$. GAPDH was used as loading control protein. $(n=4)$.

Graphs show mean \pm standard deviation. $(n=4)$. Significant differences were determined by ANOVA test; ${ }^{*} p<0.05$. 


\section{$\mathrm{Zn}^{2+}$-mediated activation of Akt is strongly associated with intra- nuclear presence of transcription factor Oct4}

In order to establish how Akt interacts with the key regulators of pluripotency Oct4 and Sox2, we have investigated their intracellular location. Immunostaining for Oct4, Sox2 and pAkt (S473) showed that they are located into the cell nuclei independently of the presence of $\mathrm{Zn}^{2+}$. We also observed that cell nuclei were surrounded by $\mathrm{Zn}^{2+}$ transporter Zip7, which is anchored to the endoplasmic reticulum (Fig. 29 a). Both Sox2 and Oct4 possess an Akt recognition motif RXRXXS/T (221) like GSK3ß (Fig. 29b). Previous reports have demonstrated that these proteins are substrates for Akt phosphorylation activity $(207,208,222)$. Phosphorylation of both Oct4 and Sox 2 is critical for their interaction to achieve the pluripotency associated genes expression. To further analyse whether nuclear presence of Oct4 and Sox2 is dependent of nuclear pAkt, ESCs were

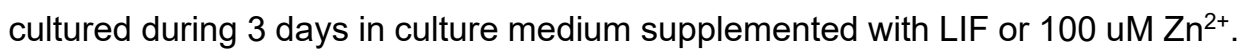
In addition to normal BM, we have also used BM supplemented with $10 \mu \mathrm{M}$ LY294002 to diminish Akt phosphorylation. We next analysed the nuclear expression of Oct4, Sox2 and pAkt by immunostaining (Fig. 29c). 
Zinc maintains embryonic stem cells pluripotency and multilineage differentiation potential via Akt activation

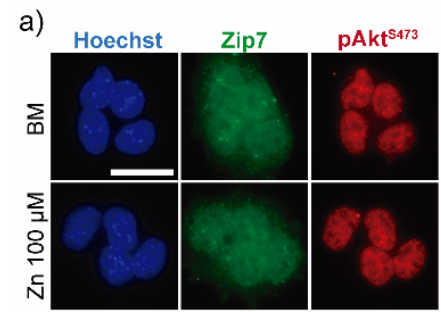

b)

$\begin{array}{lc}\text { GSK3 } & \text { SGRPRTTSFAESCKP } \\ \text { Sox2 } & \text { KYRPRRKTKTLMKKD } \\ \text { Oct4 } & \text { QARKRKRTSIENRVR } \\ \text { Akt rec. motif } & \text { RXRXXS/T }\end{array}$

d)
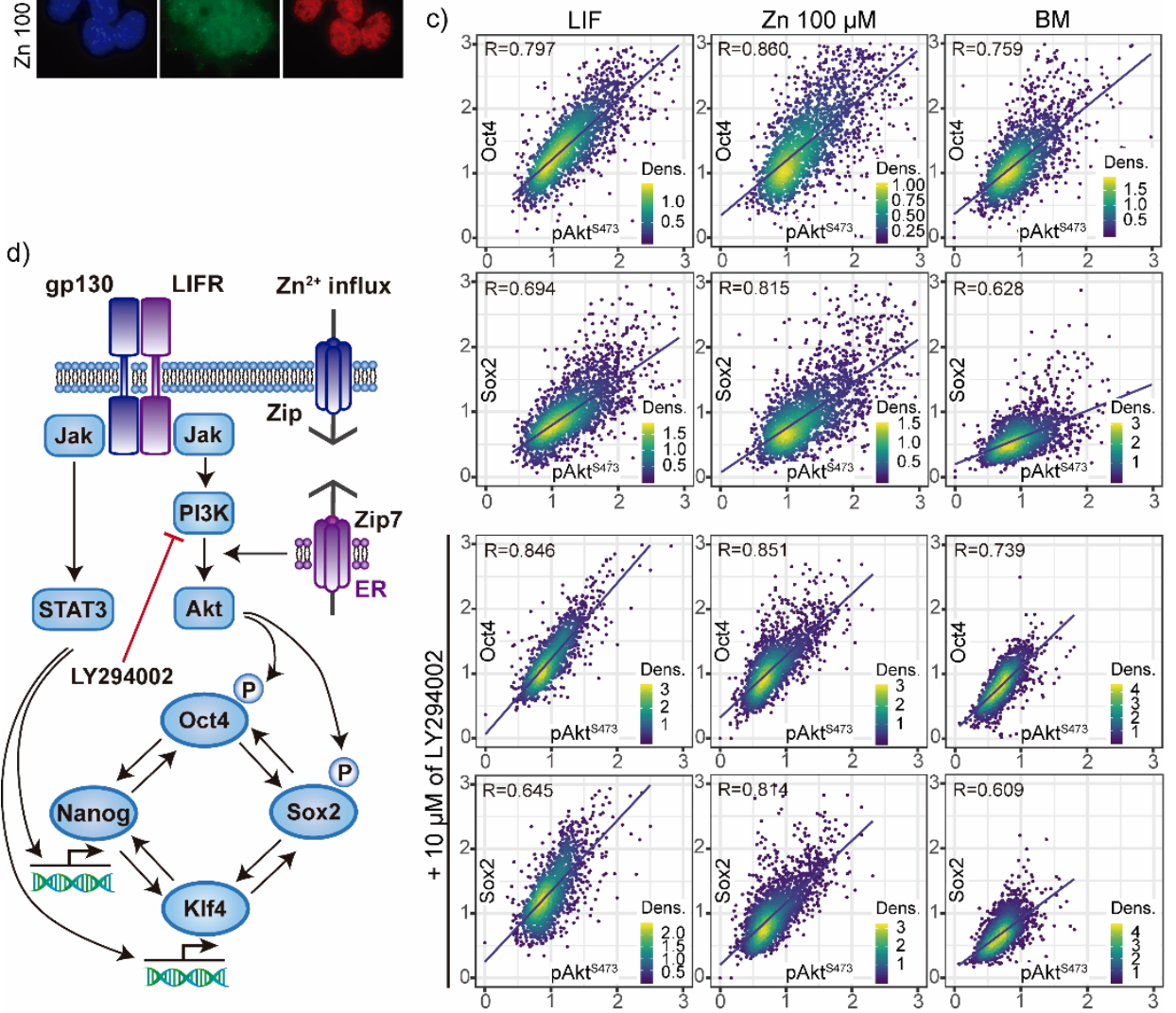

Figure 29. Relationship between nuclear pAkt and the core transcriptional network for ESCs self-renewal.

a) Immunostaining of $\mathrm{Zn}^{2+}$ traspoter ZIP7 and pAKT (S473) in ESCs cultured during $24 \mathrm{~h}$ in only BM or BM suplemented with $100 \mu \mathrm{M}$ of $\mathrm{Zn}^{2+}$. (Scale bar $50 \mu \mathrm{m}$ ).

b) Aminoacid sequence alignments of mouse GSK3 $\beta$, Oct4 and Sox2 showing target motifs for Akt- mediated phosphorilation. NetPhos 3.1 Server was used to indentify these sequences and then were aligned with the minimal recognition motif of Akt.

c) Immunofluorescence detection and quantification of pluripotency markers Oct4, Sox2 and PAKT (S473) in ESCs cultured during 3 days in normal medium and medium supplemented with $10 \mu \mathrm{M}$ of PI3K inhibitor LY294002. Obtained data were represented and Perarson's correlation $\mathrm{R}$ values were obtained using $\mathrm{R}$. 
$\mathrm{Zn}^{2+}$ treated cells displayed the highest values of correlation between nuclear presence of both transcription factors with pAkt. Furthermore, the addition of both $\mathrm{Zn}^{2+}$ and LIF increased nuclear accumulation of pAkt and Sox2. The incorporation of PI3K inhibitor produced a negative effect in pAkt, which in case of cells grown in $\mathrm{BM}$ and $\mathrm{Zn}^{2+}$ is also transferred to the levels of Oct4. In contrast, Sox2 levels did not experiment important variations. These results suggest that alterations in Akt signalling strongly affects Oct4 nuclear presence in absence of any additional stimuli such as STAT3 activation via LIF.

The hypothetical mechanism observed in these experiments, that explains how $\mathrm{Zn}^{2+}$ interacts with Akt and the core transcriptional network that regulates ESCs pluripotency, is represented in figure $29 \mathrm{~d}$.

\section{$\mathrm{Zn}^{2+}$ maintains ESC pluripotency in long-term cultures}

After assessing that zinc promotes maintenance of ESCs stemness, we further investigate whether ESCs maintain pluripotency after long-term cultures in medium supplemented with $\mathrm{Zn}^{2+}$. Cells were cultured in expansion conditions (seeding density: 30,000 cells $/ \mathrm{cm}^{2}$, passaged every: 2-3 days at sub-confluence) in order to reduce spontaneous differentiation (185). After 30 days of culture in

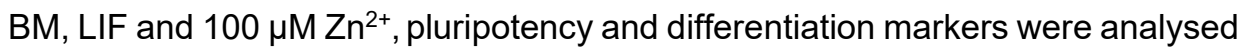
by immunofluorescence and RT-qPCR (Fig. 30a and 30b). Immunofluorescence shows still high expression of Oct4 and Sox 2 after 30 days of culture in the presence of zinc, with similar values to LIF and higher than the BM control (Fig. 30a). Indeed, the ratio of AP positive colonies was similar for $\mathrm{Zn}^{2+}$ and LIF-treated cells and approximately $50 \%$ more than for BM condition.

qPCR analysis of specific genes related to pluripotency (Oct4, Nanog, Klf4) showed that $\mathrm{Zn}^{2+}$ resulted in similar expression levels to LIF (Fig. 30b) confirming immunofluorescence images (Fig. 30 a). In contrast, specific genes related to differentiation, Foxa2 (endoderm) expression was higher for $\mathrm{Zn}^{2}$ than LIF-treated cells. Brachyury/T (mesoderm) expression was higher for BM cultured cells than cells treated with $\mathrm{Zn}^{2+}$ or LIF that presented similar values. Finally, Sox1 (ectoderm) expression was similar for $\mathrm{Zn}^{2+}$ and BM cultured cells (Fig. 30b). 
a)

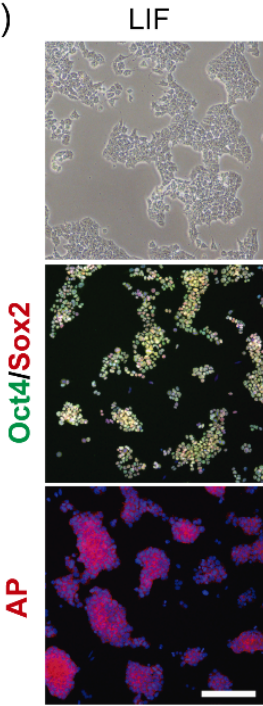

Zn $100 \mu \mathrm{M}$

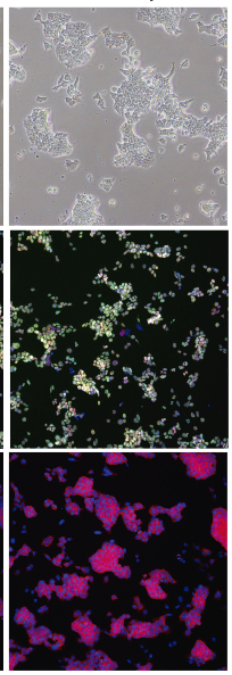

b)

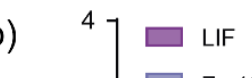

BM

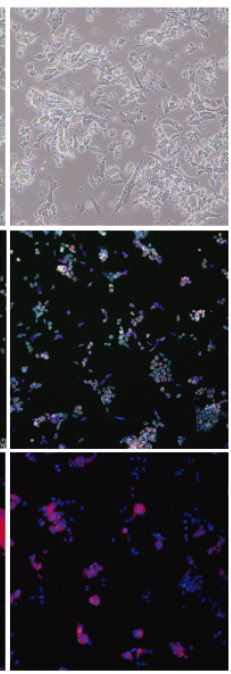

$+\infty$
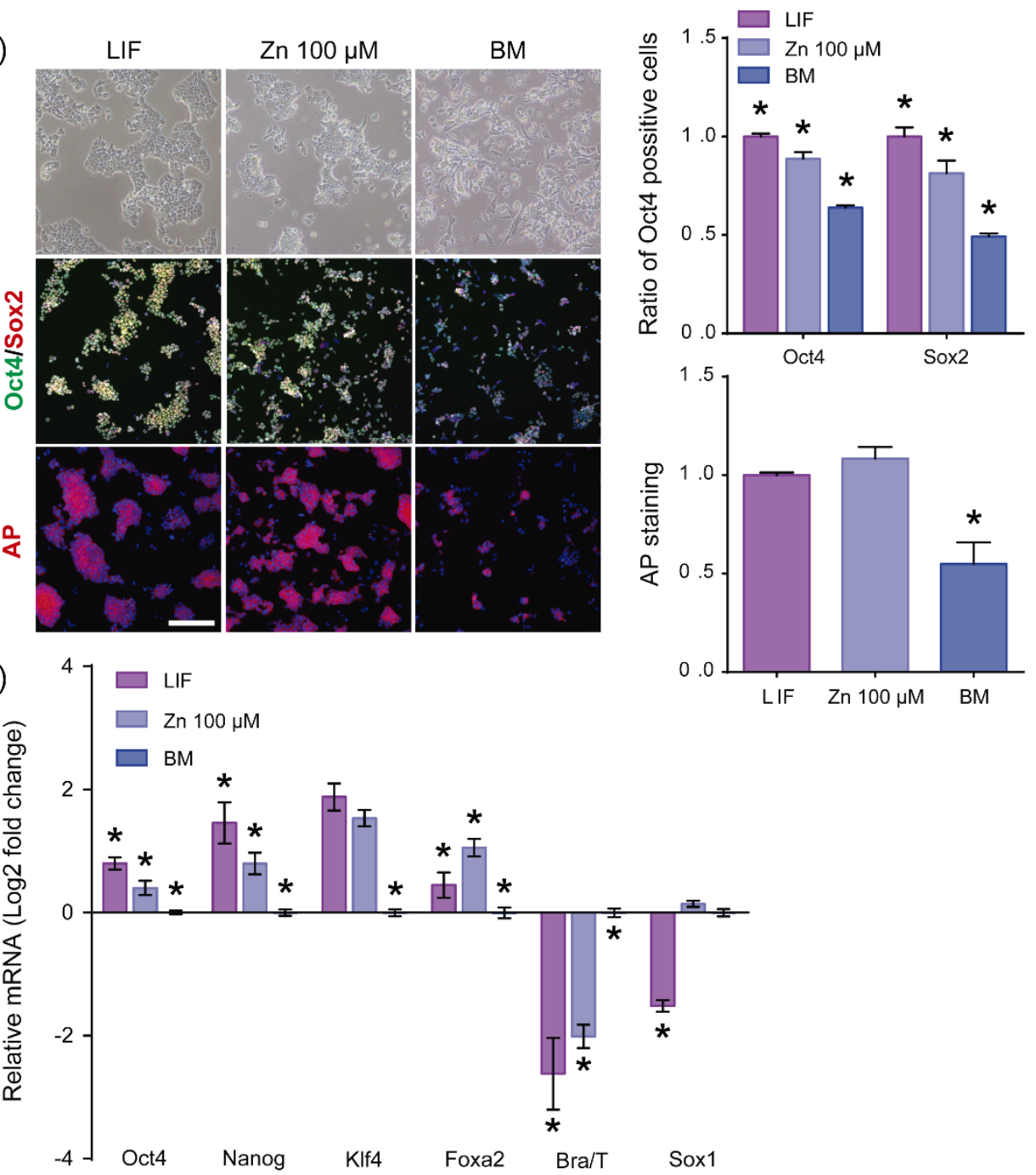

Figure 30. Role of zinc in ESCs pluripotency maintenance after $\mathbf{3 0}$ days of culture.

a) Immunofluorescence detection of pluripotency markers: Oct4-green, Sox2-red and alkaline phosphatase-magenta, determined after 30 days of ESCs cultured in BM, medium supplemented with LIF or medium supplemented with $100 \mu \mathrm{M}$ of $\mathrm{Zn}^{2+}$. (n=5). Scale bar $200 \mu \mathrm{m}$.

b) qPCR detection of pluripotency markers (Oct4, Nanog, Klf4) and differentiation markers (endoderm: Foxa2; mesoderm: Brachyury/T and ectoderm: Sox1). GAPDH was used as housekeeping gene. $(n=4)$.

Graphs show mean \pm standard deviation. Significant differences were determined by ANOVA test; ${ }^{*} p<0.05$. 
We further evaluated Akt activity along the 30 days culture at 5 and 30 days. Figure 31 shows that pAkt/Akt ratio remained higher for ESCs supplemented with zinc, supporting the hypothesis that zinc-mediated stemness is mediated by Akt phosphorylation.
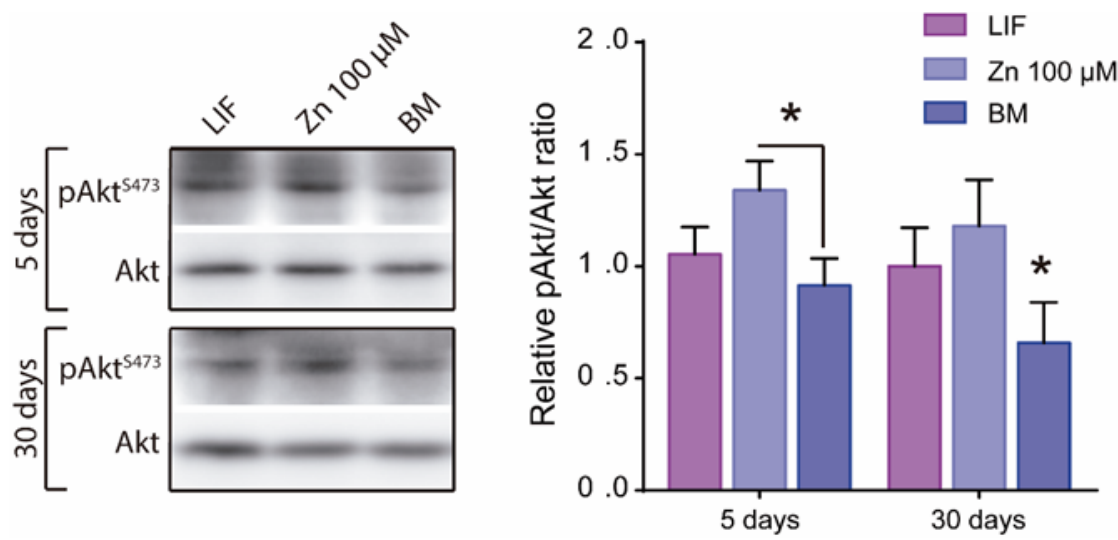

Figure 31. Zinc mediated increase of Akt phosphorylation after long term culture.

Western blot detection of Akt and pAkt (S473) on ESCs cultured in BM, medium supplemented with LIF or medium supplemented with $100 \mu \mathrm{M}$ of $\mathrm{Zn}^{2+}$ after 5 and 30 days of culture. $(n=4)$.

Graphs show mean \pm standard deviation. Significant differences were determined by ANOVA test; ${ }^{*} p<0.05$.

To disregard aberrant chromosome content in ESCs due to long-term culture times, we analysed ESCs karyotype after 30 days of culture (Fig. 32). No differences were found between the different conditions, showing all of them a modal distribution of 40 chromosomes. 

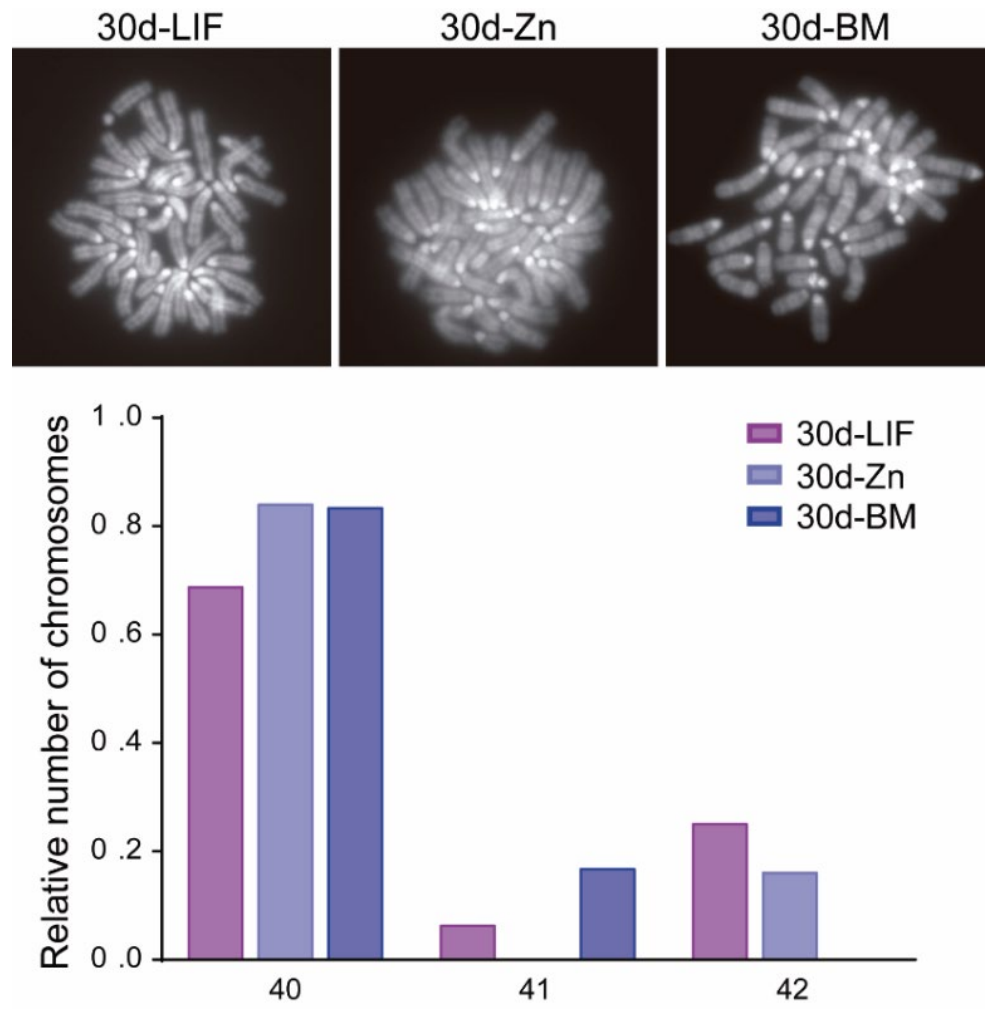

Figure 32. ESCs karyotype after long-term culture.

Analysis of chromosome number of ESCs cultured during 30 days in BM, medium

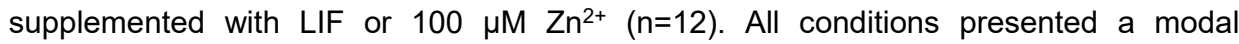
distribution of 40 chromosomes/cell.

\section{$\mathrm{Zn}^{2+}$ maintains ESC differentiation capacity after long-term cultures}

We have shown that $\mathrm{Zn}^{2+}$ maintains ESCs self-renewal potential rather than differentiating into specific primary germ layers. Next, we evaluated whether ESCs differentiation potential into different lineages was maintained after longterm cultures. Spontaneous differentiation capacity of ESCs after 30 days of culture (30d-ESC) in BM (30d-BM), medium supplemented with $100 \mu \mathrm{M} \mathrm{Zn^{+2 }}$ (30d-Zn) or LIF (30d-LIF) was assessed after embryoid body (EBs) formation. New EB formed from low passage ESCs (i.e. not cultured for $30 \mathrm{~d}$ before introducing differentiation conditions) were included as a control of embryoid body formation (1d-LIF). EBs were formed in hanging drops for 5 days and 
subsequently transferred to non-adhesive plates for 10 additional days. 5 days old EBs were collected to analyse gene expression of spontaneous differentiated primary germ layers' markers. 15 days old EBs were collected and fixed for analysis of histological sections. No appreciable morphological differences were found between EBs obtained from 30d-Zn or 30d-LIF EBs and control EBs (1dLIF) (Fig. 33). Nevertheless, EBs generated from 30d-BM cells presented reduced diameter which suggests less growth after 3 days, (Fig. 33a). Expression of genes related to primary germ layers showed an important increase in Sox1 (ectoderm) levels and a strong decrease in Brachyury/T (mesoderm) levels (Fig. $33 b)$. 
Zinc maintains embryonic stem cells pluripotency and multilineage differentiation potential via Akt activation

a)
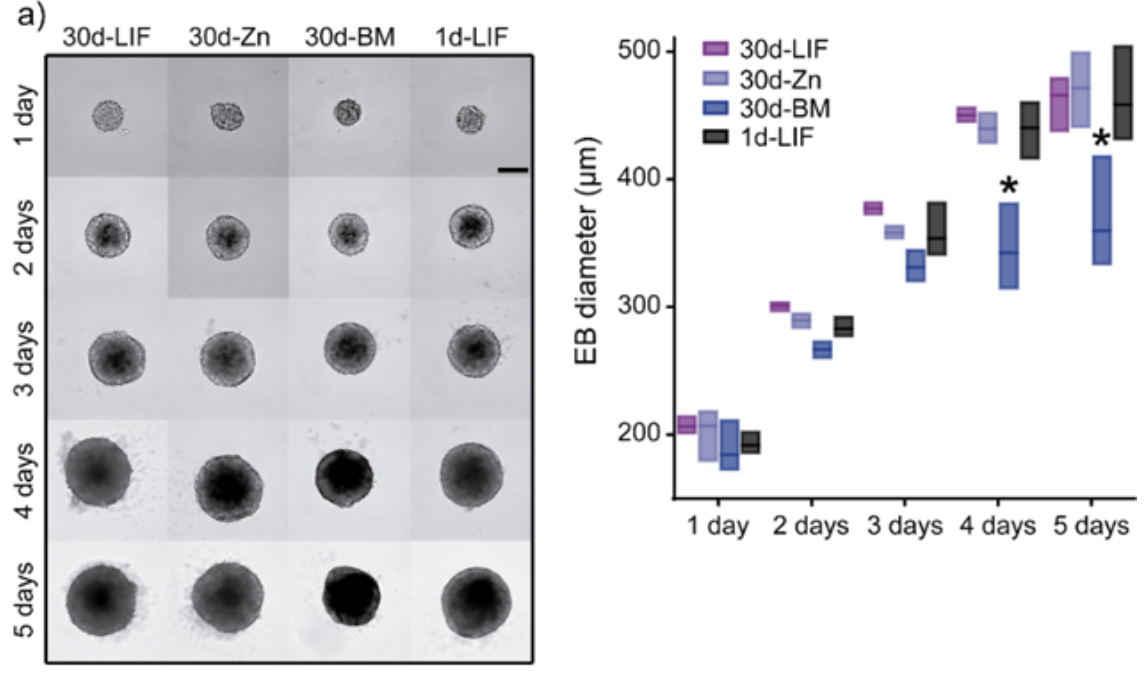

b)

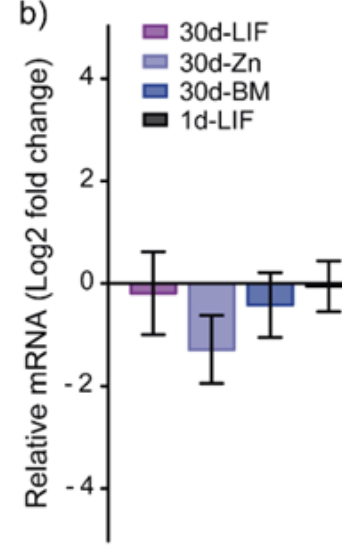

Foxa2

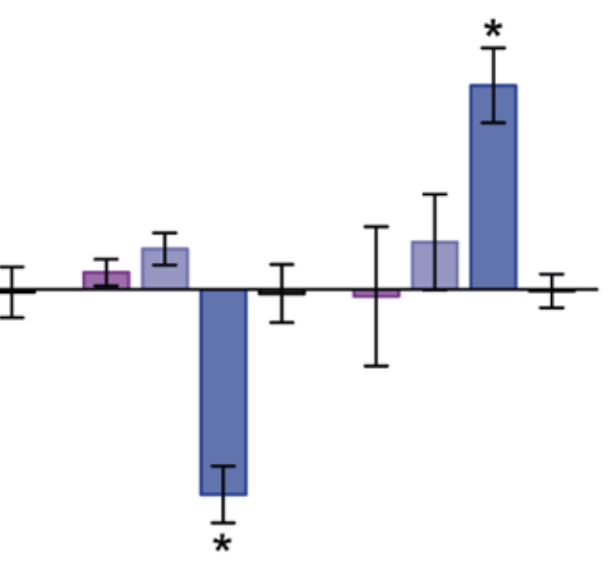

Sox 1

Figure 33. Role of zinc in spontaneous embryoid body differentiation after $\mathbf{3 0}$ days of culture.

a) Embryoid bodies formation from ESCs cultured 30 days in BM, medium supplemented

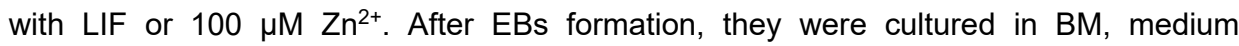

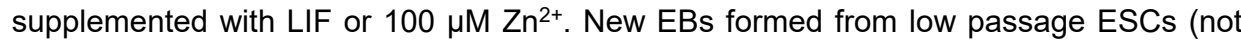
previously cultured $30 \mathrm{~d}$ under different conditions) were included as a control of embryoid body formation (1d-LIF). Measurements of EBs diameters (Scale bar: $200 \mu m)$. $(n=9)$.

b) Evaluation of spontaneous differentiation of EBs formed after culture of ESCs 30 days

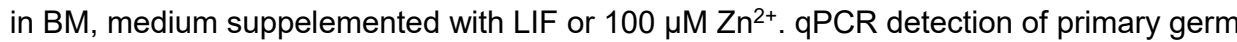
layer markers: endoderm (Foxa2), mesoderm (Brachyury/T) and ectoderm (Sox1). GAPDH was used as housekeeping gene. $(n=4)$.

Graphs show mean \pm standard deviation. Significant differences were determined by ANOVA test; ${ }^{*} p<0.05$. 
Figure 34 shows histological sections of EBs, revealing a complex organised cellular structure for $30 \mathrm{~d}-\mathrm{Zn}, 30 \mathrm{~d}-\mathrm{LIF}$ and 1d-LIF cells in contrast with the homogeneous cell dispersion found within EBs obtained from 30d-BM cells. These results show the ability of zinc to support spontaneous ESCs lineage commitment after long-term cultures.
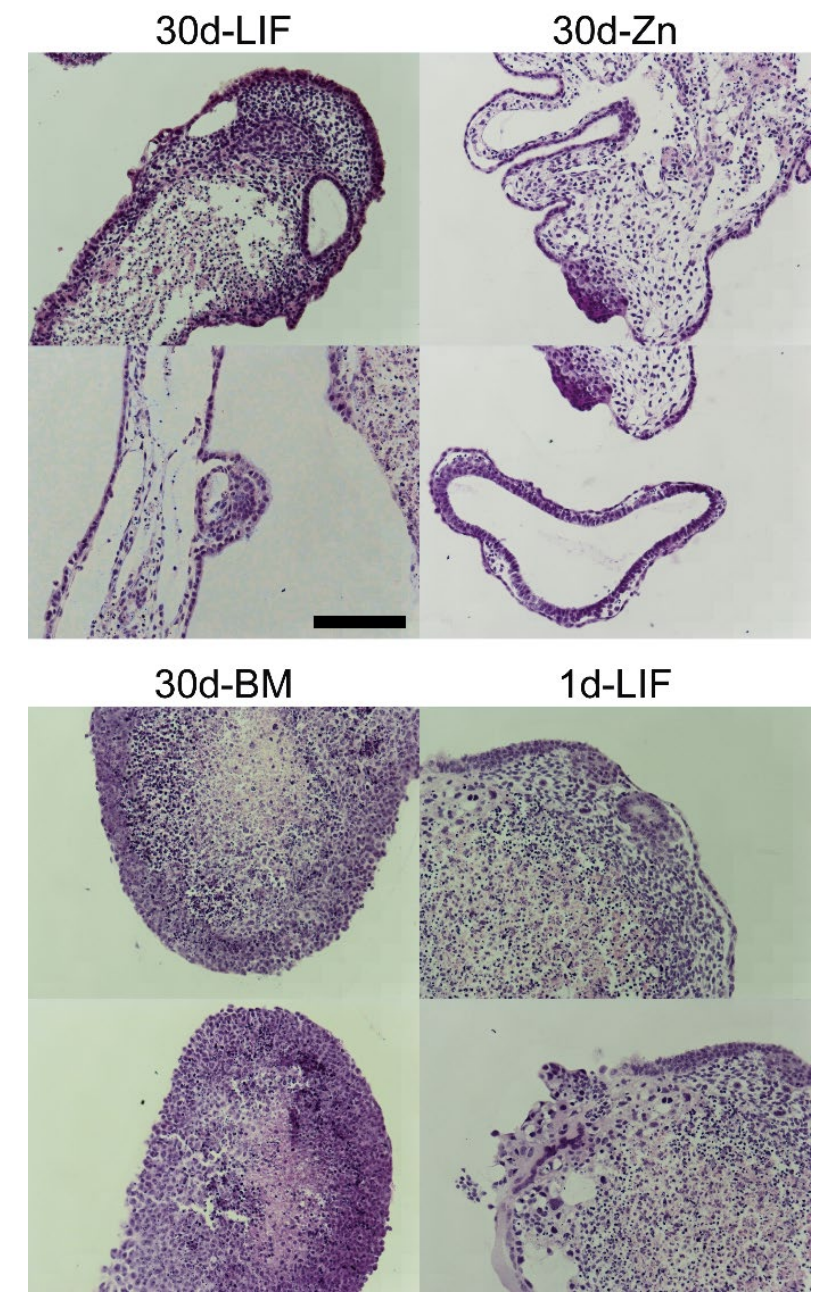

Figure 34. Histological analysis of embryoid bodies spontaneously differentiated from ESCs previously cultured during $\mathbf{3 0}$ days in different conditions.

EBs were formed after culture of ESCs 30 days in BM, medium supplemented with LIF or $100 \mu \mathrm{M} \mathrm{Zn}{ }^{2+}$. Afterwards, EBs were cultured during 15 days and histological sections were stained for Haematoxylin/Eosin (Scale bar: $200 \mu \mathrm{m}$ ). 
In parallel, we investigated the differentiation capacity of ESCs previously cultured during 30 days in BM, medium supplemented with LIF or $100 \mu \mathrm{M} \mathrm{Zn^{2+ }}$ under defined media conditions (Fig. 35). Similar results were found for all induced lineages using $30 \mathrm{~d}$-LIF cells and $1 \mathrm{~d}$-LIF cells. Nevertheless, $30 \mathrm{~d}-\mathrm{Zn}$ cells showed important differences compared with the other conditions. For mesoderm differentiation $30 \mathrm{~d}-\mathrm{Zn}$ presented lower cell density and substantially decreased expression of CD31 and CD34 markers, together with neural-like morphology (Fig. 35b). For endoderm differentiation 30d-Zn cells expressed Sox17, but appeared more clustered than 30d-LIF and 1d-LIF cells. Finally, for neuroectoderm differentiation similar images of Sox 10 and $\beta$ III-tub were obtained in all conditions, with 30d-BM cells showing the highest levels. Altogether, the results indicated that long-term addition of zinc to the culture medium maintains the ability of ESCs to differentiate to the three lineages similarly to LIF treated cells. 
a)

b)
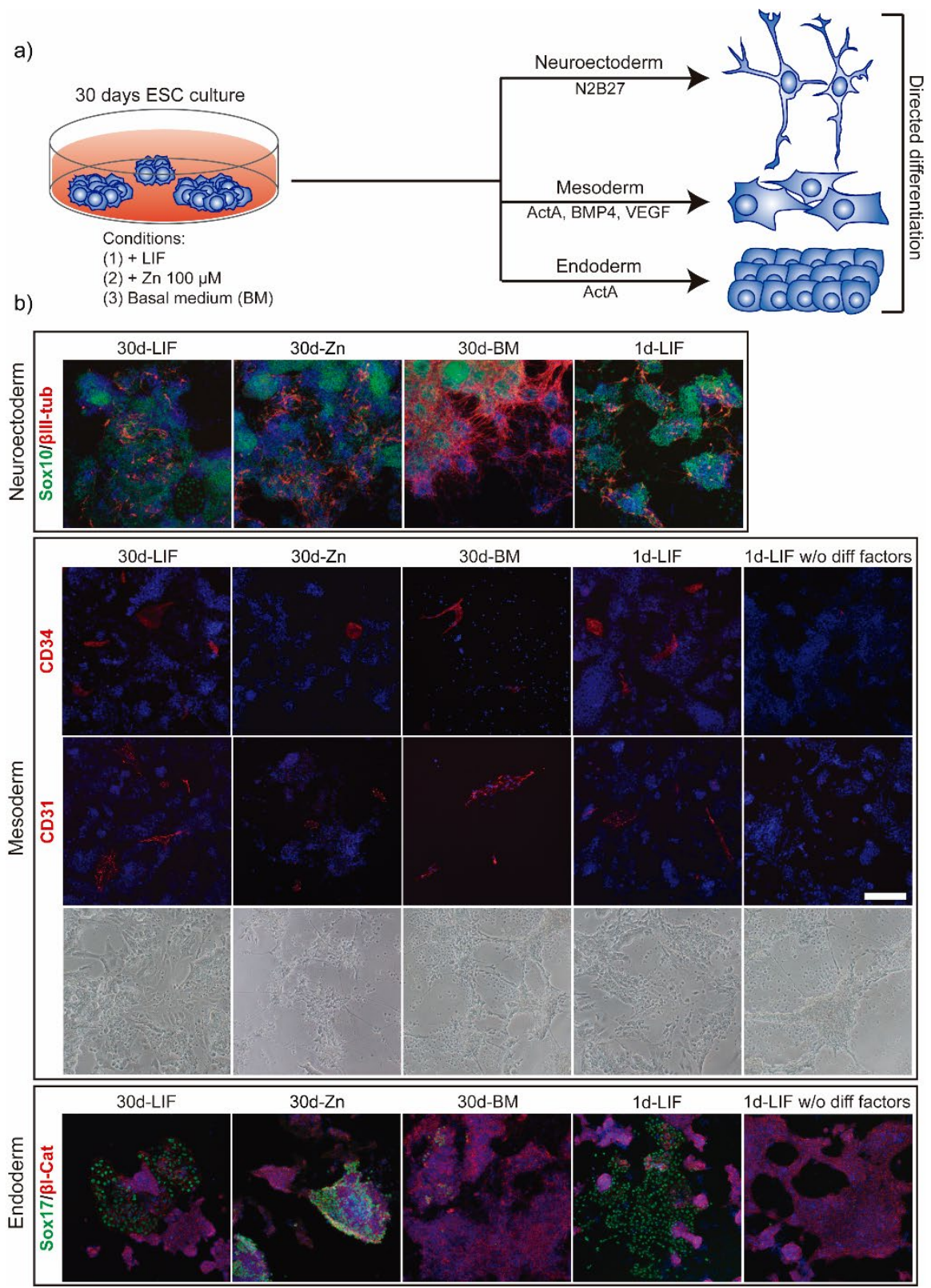

Figure 35. Evaluation of differentiation ability of ESCs cultured during $\mathbf{3 0}$ days under different conditions.

a) Experimental design carried out to assess the pluripotent potential of ESCs cultured for

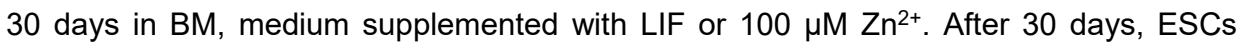
differentiation to endoderm, mesoderm or ectoderm was analysed in EBs and in monolayer culture under defined media. 
Zinc maintains embryonic stem cells pluripotency and multilineage differentiation potential via Akt activation

b) Analysis of differentiation potential of ESCs cultured for 30 days in BM, medium

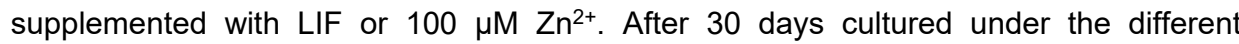
conditions, ESCs were seeded in monolayer culture with specific differentiation media. Afterwards, differentiation to neuroectoderm, mesoderm or endoderm was analysed.

Low passage ESC with and without supplementation of differentiation factors (conditions $\mathrm{mESC}$ and $\mathrm{mESC}$ w/o diff factors) were used as a control. Differentiation markers were analysed by immunofluoresence. Neurectoderm linage: neural linage markers $\beta$ III-tubulin (red) and Sox10 (green) were determined $(n=5)$. Mesoderm linage: ESCs were cultured in suspension with SF medium (markers CD31 and CD34 showed as red) $(n=5)$. Endoderm linage: ESCs were supplemented with Activin A (endoderm markers Sox 17 (green) and $\beta$ catenin (magenta)) $(n=5)$ (Scale bar: $200 \mu \mathrm{m})$.

\section{$\mathrm{Zn}^{2+}$ maintains a stable ESCs pluripotent state after long-term cultures}

Variation in gene expression is an important feature of ESCs, thus they exhibit great heterogeneity (193). ESCs populations present at the same time cells in naïve and primed for differentiation states, with cellular heterogeneity and transcriptome variations concerning pluripotency associated gene expression (62). Our results demonstrate that $30 \mathrm{~d}-\mathrm{Zn}$ cells maintained their self-renewal capacity (expression of pluripotency markers) and then spontaneous differentiation towards all primary germ layers in embryo bodies, but with lower levels of mesoderm-directed differentiation (Fig. 35b). To investigate whether this behaviour is related to ESCs gene expression heterogeneity after long-term cultures, we performed an additional experiment. ESCs previously cultured for 30 days in BM (30d-BM), medium supplemented with LIF (30d-LIF) or $100 \mu M \mathrm{Zn}^{+2}$ $(30 \mathrm{~d}-\mathrm{Zn})$ were then treated with LIF for 3 more days seeking to revert ESC priming to naive state. Figures 36 and 37 show immunofluorescence and qPCR results for pluripotency (Oct4, Nanog, Sox2) and differentiation (Gata6, Fgf5, Brachyury) markers. When $30 \mathrm{~d}-\mathrm{Zn}$ cells were exposed to LIF, the ratio of Oct4 positive cells increased ca. $12 \%$, while $30 \mathrm{~d}$-LIF and $30 \mathrm{~d}-\mathrm{BM}$ levels remained constant. Sox2 values decreased for $30 \mathrm{~d}-\mathrm{BM}$ cells, whilst $30 \mathrm{~d}-\mathrm{Zn}$ and $30 \mathrm{~d}-\mathrm{LIF}$ cells levels did not present significant variation. In parallel, ESCs previously cultured for 30 days in BM (30d-BM), medium supplemented with LIF (30d-LIF)

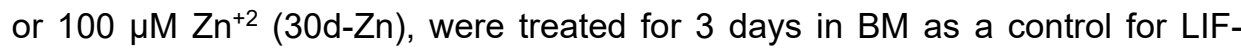
mediated signalling. We found that $30 \mathrm{~d}-$ LIF and $30 \mathrm{~d}-\mathrm{BM}$ conditions presented a reduction in Oct4 and Sox2 levels compared to the initial values, whilst in $30 \mathrm{~d}-\mathrm{Zn}$ levels remained almost invariable (Fig. 36). 


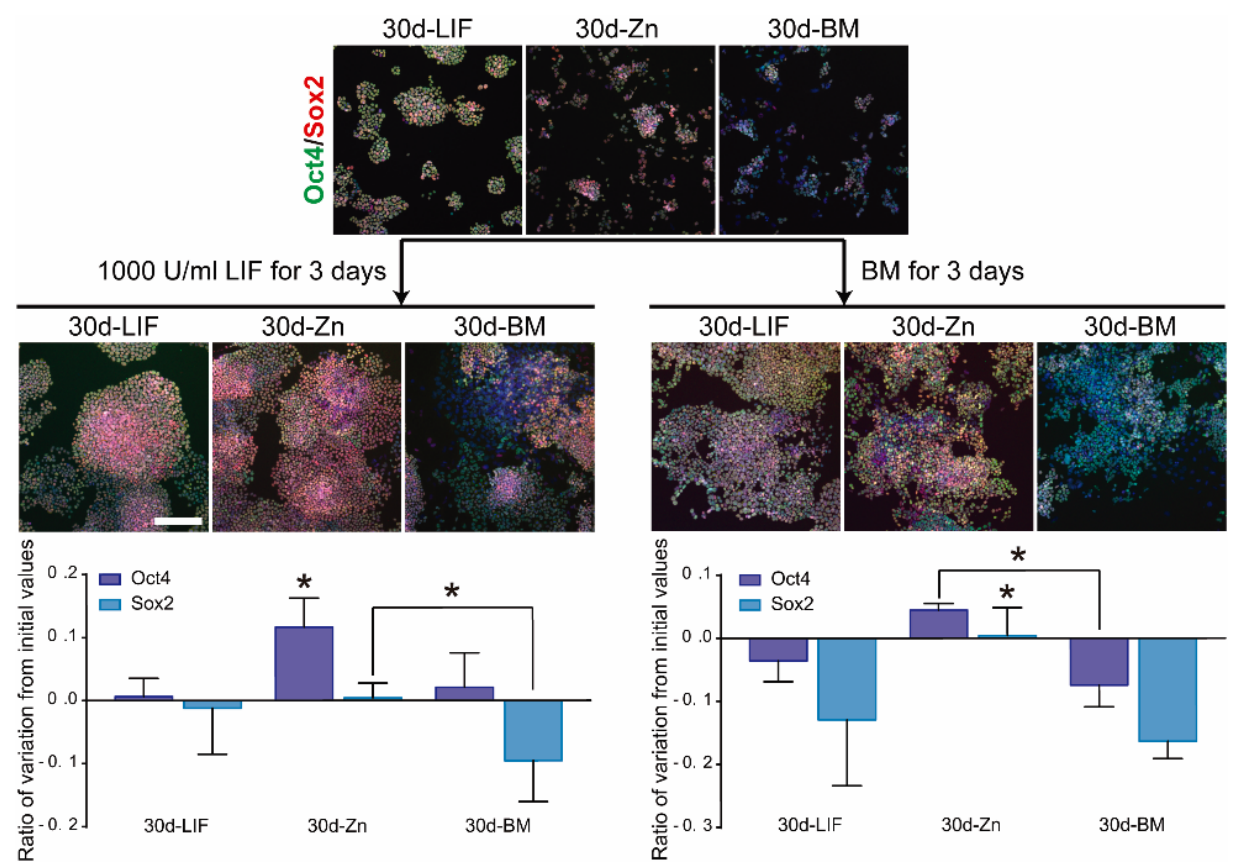

Figure 36. ESCs maintained with zinc are sensible to LIF signalling after long-term cultures.

ESCs previously cultured for 30 days in BM (30d-BM), medium supplemented with LIF

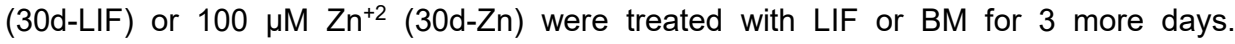
Pluripotency markers (Oct4, green and Sox2, red) were determined by immunofluorescence (Scale bar: $200 \mu \mathrm{m})(\mathrm{n}=5)$.

Graphs show mean \pm standard deviation. Significant differences were determined by ANOVA test; ${ }^{*} p<0.05$.

Before the treatment with LIF for 3 days (Fig. 37b), similar results were obtained after gene expression analysis. Nanog expression was significantly higher for $30 \mathrm{~d}$-LIF cells, whilst $30 \mathrm{~d}-\mathrm{Zn}$ and $30 \mathrm{~d}-\mathrm{BM}$ cells showed similar expression. Furthermore, Gata6 was more expressed for 30d-LIF and 30d-Zn cells, whilst other differentiation markers (Fgf5, Brachyury) appeared diminished compared with 30d-BM cells. After 3 days of LIF treatment (Fig. 37c), 30d-Zn cells rescued Nanog expression, with similar values to $30 \mathrm{~d}$-LIF cells, and the expression of differentiation markers Gata6, and Fgf5 decreased substantially, suggesting reversion from primed to naïve state. Although 30d-BM cells exhibited a similar trend regarding Nanog, Gata6 and Fgf5 levels after 3 days LIF treatment, the differences were significantly higher for $30 \mathrm{~d}-\mathrm{Zn}$ cells. Note that Brachyury expression increased substantially for 30d-BM cells despite LIF treatment (Fig. 
Zinc maintains embryonic stem cells pluripotency and multilineage differentiation potential via Akt activation

37c), suggesting incomplete transition from primed to naïve state for this condition.

a)
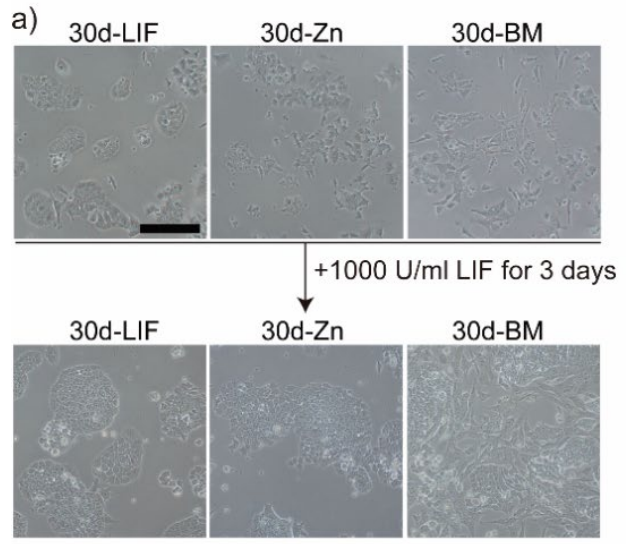

b)

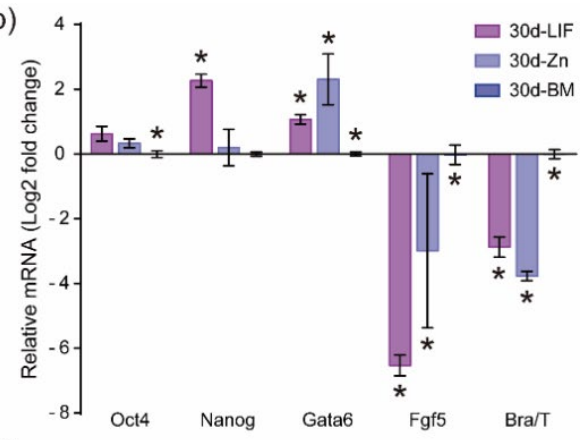

c)

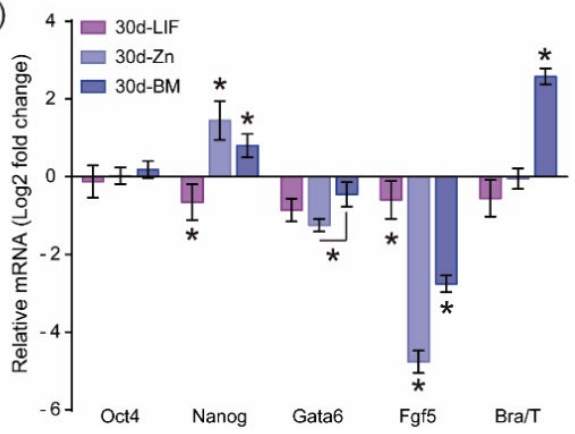

Figure 37. Zinc maintained ESCs are able to reverse their primed for differentiation stage to a naïve pluripotency stage after LIF treatment.

a) Bright field images of 30d-ESC cultured in BM (30d-BM), medium supplemented with

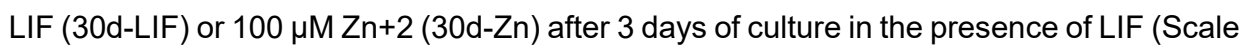
bar: $200 \mu \mathrm{m})$.

b) RT-qPCR evaluation of stemness related markers of pluripotency (Oct4, Nanog) indicative of naïve state, and differentiation markers (Gata6, Brachyury/T, Fgf5) indicative of primed state, of ESCs previously cultured for 30 days in BM (30d-BM), medium

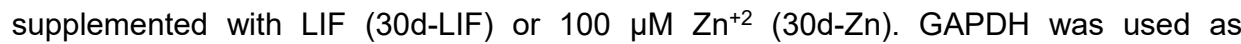
housekeeping gene $(n=4)$.

c) qPCR evaluation of stemness related markers of pluripotency (Oct4, Nanog) indicative of naïve state, and differentiation markers (Gata6, Brachyury/T, Fgf5) indicative of primed state, of ESCs previously cultured for 30 days in BM (30d-BM), medium supplemented with LIF (30d-LIF) or $100 \mu \mathrm{M} \mathrm{Zn+2} \mathrm{(30d-Zn)} \mathrm{and} \mathrm{treated} \mathrm{with} \mathrm{LIF} \mathrm{for} 3$ more days in order to reverse primed to naïve state. GAPDH was used as housekeeping gene $(n=4)$.

Graphs show mean \pm standard deviation. Significant differences were determined by ANOVA test; ${ }^{*} p<0.05$. 


\section{The combination of LIF and $\mathrm{Zn}^{2+}$ strongly increases LIF effects}

Our results demonstrated that $\mathrm{Zn}^{2+}$ successfully sustains ESCs pluripotency. Nevertheless, although 30d-Zn ESCs share many features with 30d-LIF ESCs, these cells possess some traits which suggest that $30 \mathrm{~d}-\mathrm{Zn}$ cells are more differentiated. Previous observations indicated that the combination of LIF and $\mathrm{Zn}^{2+}$ resulted in a strong inhibition of ESCs differentiation (Fig.24). We therefore assessed additional experiments combining different concentrations of LIF (LIF: 1,000 U/ml and 1/4LIF: $250 \mathrm{U} / \mathrm{ml})$ with $\mathrm{Zn}^{2+}(100 \mu \mathrm{M})$ to enhance pluripotency maintenance. Thus, ESCs were cultured during 15 days (5 passages) in presence of LIF, 1/4LIF, LIF-Zn and 1/4LIF-Zn. In each passage cells were fixed and the ratio of AP positive colonies as well as Sox2 and Sox17 positive cells were determined. After 15 days, the expression of both pluripotency (Nanog) and differentiation (Brachyury/T, Gata6 and Fgf5) markers were analysed by qPCR, and protein expression was analysed by Western Blot. Our results show that ESCs grown with $250 \mathrm{U} / \mathrm{ml}$ of LIF resulted in a gradual loss of pluripotency after 15 days (Fig. 38a). These cells exhibited lower ratios of AP positive colonies and Sox2 positive cells, in addition to higher expression of Brachyury and Fgf5 (Fig $38 \mathrm{~b})$. On top of that, cells cultured with $250 \mathrm{U} / \mathrm{ml}$ of LIF also possessed the lowest Akt activity and STAT3 phosphorylation. But the addition of $100 \mu \mathrm{M}$ of $\mathrm{Zn}^{2+}$ to this condition reinforced pluripotency to levels comparable to ESCs cultured with $1,000 \mathrm{U} / \mathrm{ml} \mathrm{LIF} \mathrm{(Fig} \mathrm{38c).} \mathrm{On} \mathrm{the} \mathrm{other} \mathrm{hand,} \mathrm{the} \mathrm{combination} \mathrm{of} 1,000 \mathrm{U} / \mathrm{ml}$ with $100 \mu \mathrm{M} \mathrm{Zn}{ }^{2+}$ showed a higher expression for Nanog than other conditions and a significantly higher amount of pSTAT3 than ESCs in presence of only $250 \mathrm{U} / \mathrm{ml}$ of LIF. Surprisingly, the conditions that contained $\mathrm{Zn}^{2+}$ also expressed slightly higher values of Gata6. 
Zinc maintains embryonic stem cells pluripotency and multilineage differentiation potential via Akt activation

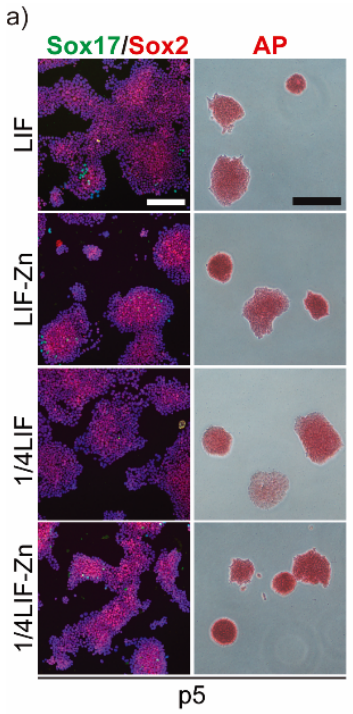

b) $\square$ LIF
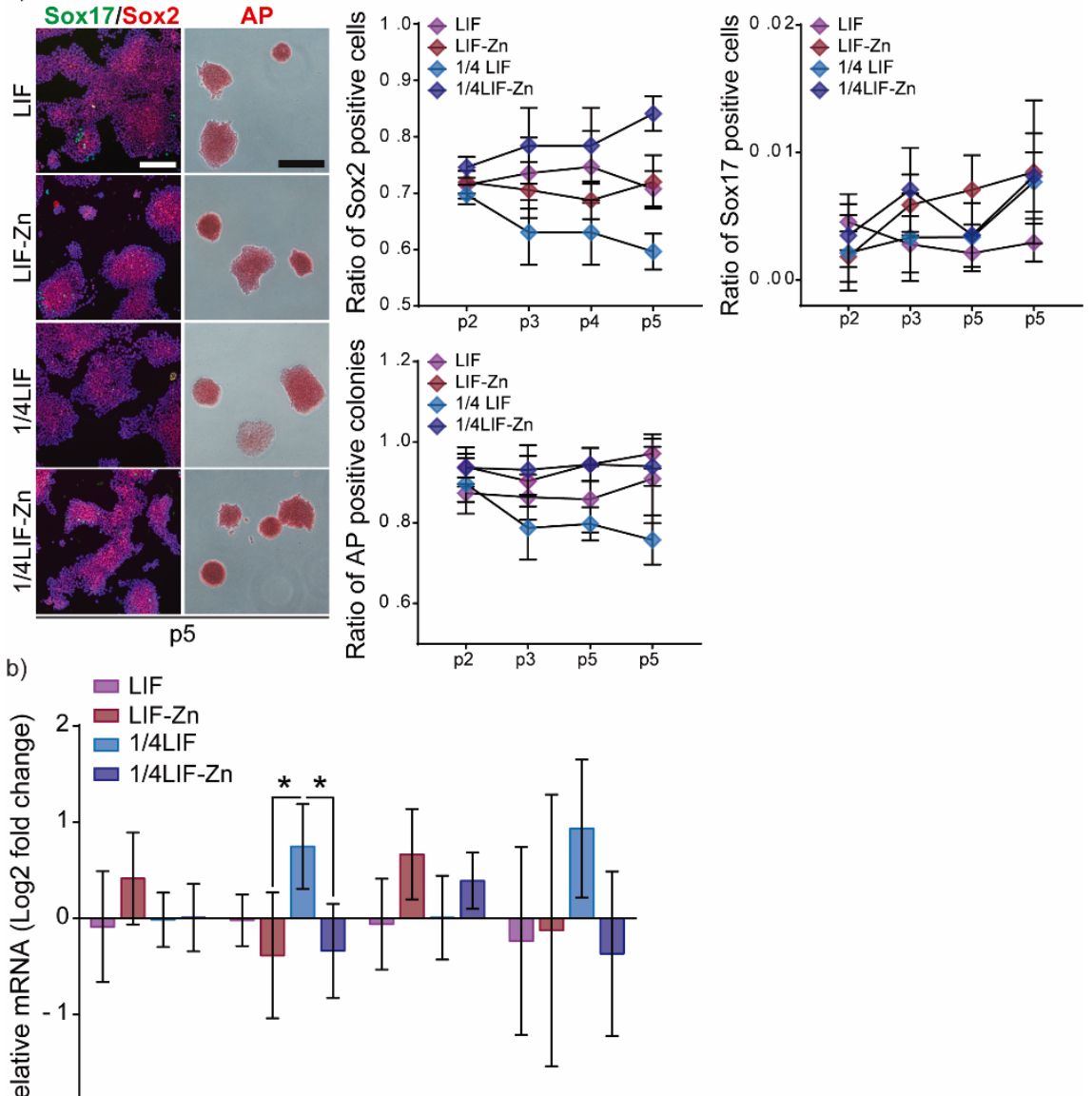

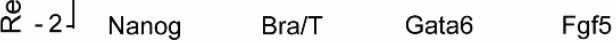

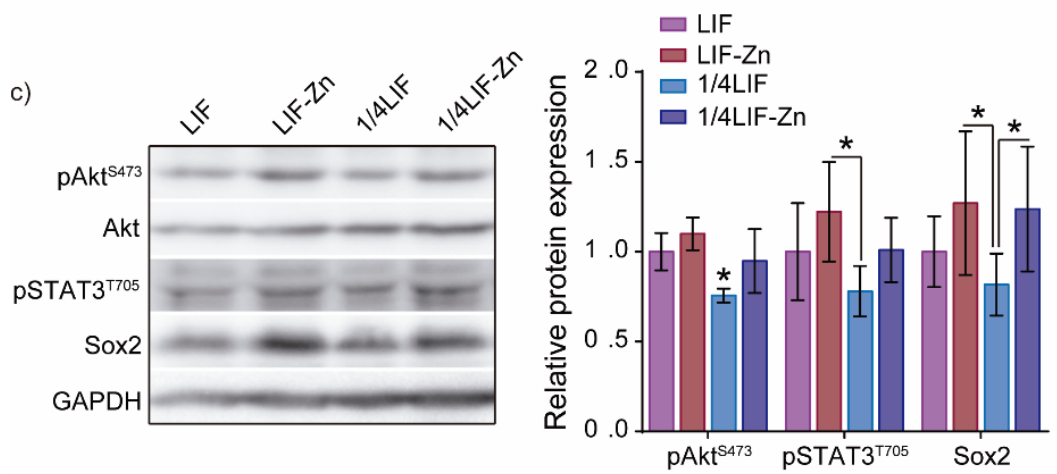

Figure 38. The combination of LIF with $\mathrm{Zn}^{2+}$ sustains ESCs pluripotency with greater efficiency.

a) ESCs were cultured during 15 days, passaging cells each 3 days, in presence of either

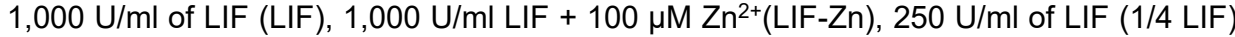




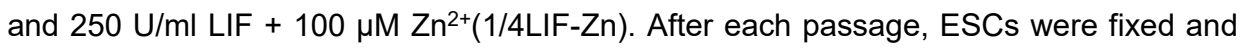
stained for alkaline phosphatase (AP) $(n=4)$ and immunostained for Sox2 and Sox17 $(n=5)$. (Scale bar: $200 \mu \mathrm{m})$

b) qPCR evaluation of stemness related markers of pluripotency (Nanog) indicative of naïve state, and differentiation markers (Gata6, Brachyury/T, Fgf5) indicative of primed state, of ESCs previously cultured for 15 days. GAPDH was used as housekeeping gene $(n=4)$.

c) Western blot detection of Akt, pAkt (S473), pSTAT3 (T705) and Sox2 on ESCs cultured during 15 days. GAPDH was used as a housekeeping gene $(n=4)$.

Graphs show mean \pm standard deviation. Significant differences were determined by ANOVA test; ${ }^{*} p<0.05$.

\section{Discussion}

The need of zinc in biological processes has been often associated to its function as a cofactor in metalloproteins (223), yet its role in signalling processes is becoming increasingly important. Description of $\mathrm{Zn}^{2+}$ as a second messenger (114) allows much better understanding of the mechanisms associated with $\mathrm{Zn}^{2+}$ signalling, as a useful tool for cell fate control. However, our results indicated that

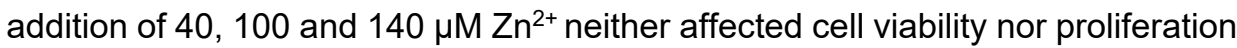
compared to LIF or BM conditions (Fig. 20). Further, zinc dynamics studies indicated that intracellular zinc uptake is dependent of extracellular zinc presence (Fig. 22) and controlled by Zip7 transporter.

We have demonstrated that $\mathrm{Zn}^{2+}$-mediated signalling resulted in the promotion of ESCs self-renewal (Fig. 23). The expression pattern of pluripotency markers was

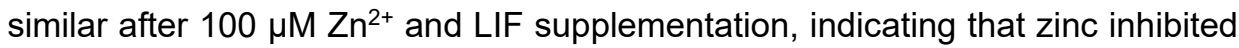
spontaneous ESCs differentiation and maintained the self-renewal potential rather than differentiating into specific germ layers, even under accelerated differentiation conditions (Fig. 24).

To better understand the underlying mechanisms involved in $\mathrm{Zn}^{2+}$-dependent ESCs stemness maintenance, we focused over PI3K/Akt activation as a consequence of $\mathrm{Zn}^{2+}$ wave (115). Inhibition of PI3K/Akt activity by LY-294002 significantly increased ESCs differentiation markers levels in zinc and BM conditions, whereas the LIF condition remained unaltered (Fig. 25). Although with lower effects, similar results were obtained for $\mathrm{Zn}^{2+}$ treated cells after Zip7 silencing (Fig. 26). These findings are supported by previous reports describing the link between Zip7 and $\mathrm{Zn}^{2+}$-mediated Akt activation $(96,115)$. Our results 
Zinc maintains embryonic stem cells pluripotency and multilineage differentiation potential via Akt activation

suggest that Zip7 plays a key role in $\mathrm{Zn}^{2+}$ mediated ESC self-renewal. It must be emphasised that LIF is not acting exclusively via Akt activation for inhibition of ESCs spontaneous differentiation, as neither Akt inhibition nor Zip7 silencing affected LIF treated cells (Fig. 26). The observed differences might be related to the mechanism whereby these molecules $\left(\mathrm{Zn}^{2+}\right.$ or LIF) inhibit ESCs differentiation. It has been reported that LIF promotes pluripotency gene expression by activation of the transcription factor STAT3 and PI3K/Akt phosphorylation by JAK $(224,225)$. Nevertheless, $\mathrm{Zn}^{2+}$ mechanism would be associated only with PI3K/Akt signalling, downstream activated after stimulating Zip7 transporter with extracellular $\mathrm{Zn}^{2+}(96,115)$ as we have demonstrated (Fig. 26 and 29). The activation of the protein kinase Akt entails the phosphorylation of its target substrates such as GSK3 $\beta$, which subsequent to be phosphorylated is inactivated and stops promoting ESCs differentiation (73,226) (Fig. 28). Akt role in ESC self-renewal has been already demonstrated by several authors $(75,220)$. In addition, we have also observed that phospho-Akt (S473) as well as Zip7 are essentially located in the ESCs nuclei (Fig. 29), which in response of the increase of extracellular concentration of $\mathrm{Zn}^{2+}$ promotes Akt phosphorylation (Figs. 25, 26, 29 and 31). It is likely that Akt subcellular situation makes it more available for substrates involved in ESCs self-renewal located in the same subcellular compartment such as GSK3 $\beta$ (73), Oct4 (207) or Sox2 (222) (Fig. 29b). Moreover, Akt is also a strong anti-apoptotic agent, targeting and inactivating pro-apoptotic proteins such as Bax (227). It was recently reported that ESC absent for Bax and Bak are unable to exit from pluripotency (228), adding more relevance to Akt activity in ESCs self-renewal.

Importantly we have also shown that $\mathrm{Zn}^{2+}$ signalling is strong enough to promote ESCs self-renewal even after 30 days of culture, maintaining both ESCs associated pluripotency markers expression and Akt phosphorylation (Figs. 30 and 31). Further, 30d-Zn treated ESCs were also able to spontaneously differentiate after EBs formation, similarly to 30d-LIF and 1d-LIF conditions (Fig. 33). When ESCs differentiation was triggered by external stimuli, $30 \mathrm{~d}-\mathrm{Zn}$ cells allowed directed differentiation towards all primary germ layers in monolayer culture, notwithstanding the lack of mesoderm-directed differentiation (Fig. 35). We hypothesise that this lack of mesodermic differentiation is due to the pluripotency state of $\mathrm{Zn}^{2+}$ maintained ESC (15). As we have next observed, after treatment of $30 \mathrm{~d}-\mathrm{Zn}$ cells with $1,000 \mathrm{U} / \mathrm{ml}$ LIF, seeking to revert ESCs priming to naive state by counterbalancing pro-differentiation signals $(15,62), 30 \mathrm{~d}-\mathrm{Zn}$ cells rescued Nanog expression, whereas differentiation associated genes expression 
(Gata6, Fgf5, Brachyury/T) dropped significantly, indicating an efficient transition from primed to naïve state (Figs. 36 and 37 ). Even though this $30 \mathrm{~d}-\mathrm{Zn}$ cells are in a more differentiated stage than LIF supplemented ESCs, their phenotype is highly reversible. Heterogeneity and more primed for differentiation state in the $30 \mathrm{~d}-\mathrm{Zn}$ cells would explain the different response to differentiation signals compared with LIF cultured cells. Furthermore, higher expression of Gata6 suggests an important population of ESCs primed for endoderm linage $(62,203)$.

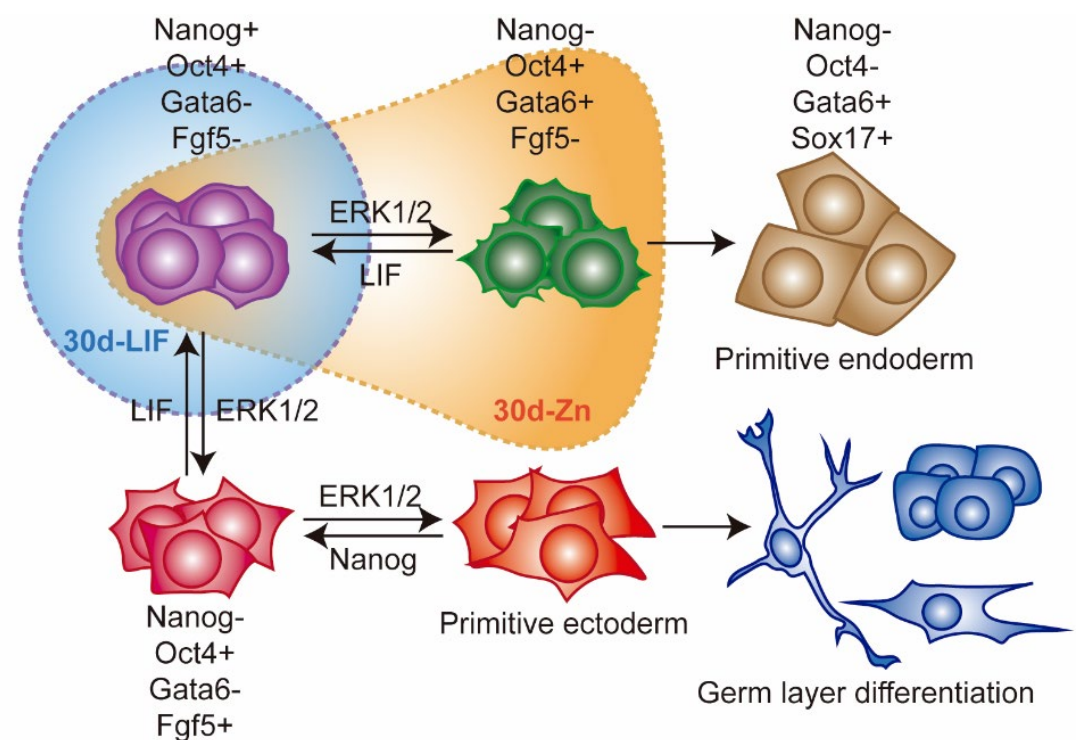

Figure 39. Scheme of ESC pluripotency dynamics, indicating the state of the ESCs population cultured with LIF (blue) and Zn (orange) after $\mathbf{3 0}$ days.

The incorporation of $\mathrm{Zn}^{2+}$ has demonstrated to be enough for maintaining ESCs pluripotency. Further, the combination of $\mathrm{Zn}^{2+}$ with LIF showed a synergistic-like effect which successfully increased ESCs self-renewal even in differentiation conditions (Fig. 24). $\mathrm{Zn}^{2+}$-LIF combination not only increased the resistance of ESCs against differentiation significantly more than only LIF or $\mathrm{Zn}^{2+}$, but also enhanced the effect of LIF after long-term culture (Fig. 38). Although LIF and $\mathrm{Zn}^{2+}$ have demonstrated different mechanisms, the combination of both reinforced Akt and STAT3 activity. This LIF enhancing effect allows to reduce the concentration of LIF from $1,000 \mathrm{U} / \mathrm{ml}$ to $250 \mathrm{U} / \mathrm{ml}$ without loss in efficiency in terms of ESCs self-renewal.

Altogether, here we present $\mathrm{Zn}^{2+}$ as a small molecule capable of sustaining a stable ESCs state as well as increasing LIF effect in both expansion and 
Zinc maintains embryonic stem cells pluripotency and multilineage differentiation potential via Akt activation

differentiation conditions. $\mathrm{Zn}^{2+}$-dependent activity of ESCs self-renewal is mediated via Zip7 and Akt activation, and it is further maintained for a long time (more than 30 days) without addition of growth factors or soluble molecules. Furthermore, $\mathrm{Zn}^{2+}$-treated ESCs maintained pluripotency after long-term cultures and successfully differentiated to all primary germ layers. We propose $\mathrm{Zn}^{2+}$, alone or combined with other factors, as a novel approach for controlling ESCs fate regulation in cellular therapies. 


\section{Chapter III}

\section{Lithium inhibits}

GSK $3 \beta$, activating $\beta$ catenin and promoting ESCs differentiation

towards hemogenic endothelium 
Lithium inhibits GSK3 $\beta$, activating $\beta$-catenin and promoting ESCs differentiation towards hemogenic endothelium

\section{Introduction}

Embryonic stem cells (ESCs) are pluripotent stem cells (PSC) derived from the inner cell mass of pre-implantation blastocyst (229). The unique and remarkable differentiation capability of ESCs makes them a very helpful tool for many applications. Some of the most common approaches are: the study of developmental biology processes $(85,230)$, testing the therapeutic potential of new drugs (46), disease modelling (231), and the development of new strategies for regenerative medicine (31). However, the potential application of ESCs in research or therapies requires an extensive knowledge of the appropriate stimuli to manipulate their fate. The development of mesoderm-derived lineages, including the hematopoietic and vascular endothelial cells, usually requires a complex combination of cytokines and growth factors such as Activin A, BMP4, FGF2 or Wnt(85). The combination of these factors plays a key role in mesoderm induction and subsequent cell survival. In addition, canonical Wnt/ß-catenin signalling pathway is shown as crucial for mesoderm commitment from PSCs. Disruption of Wnt signalling at early stages in differentiating PSCs blocks mesoderm development $(232,233)$. This fact emphasises the importance of $\mathrm{Wnt} / \beta$-catenin signalling in the specification of mesoderm-derived lineages.

Canonical $W n t / \beta$-catenin signalling regulation follows an intricate process by which, in absence of Wnt signalling, cytosolic $\beta$-catenin is sequentially phosphorylated by Axin complex proteins casein kinase 1 and glycogen synthase kinase 3 (GSK3), triggering its proteasomal degradation $(125,126)$. This process allows to keep away $\beta$-catenin from the nuclei and consequently prevents $\beta$ catenin transcriptional activity (125). The binding of Wnt to its target ligand leads to phosphorylation and Axin recruitment, disrupting Axin-mediated degradation of $\beta$-catenin. This allows $\beta$-catenin translocation and accumulation in the nucleus, where it serves as a coactivator for TCF/LEF transcription factors to activate Wntresponsive genes $(121,125,234)$. $\beta$-catenin activation leads to the expression of several genes associated with development such as cdx2, cdx4 (235) and Brachyury/T (236). Wnt/ $\beta$-catenin activity is critical for the organogenesis process, contributing significantly to the establishment of the body axis, formation of neural crest $(126,237)$,cardiac specification $(80,238)$, and development of hematopoietic stem cells (HSCs) $(239,240)$. HSCs are multipotent stem cells capable of self-renewal and differentiation, being the precursors of the cellular blood component (241). The niche of adult hematopoietic stem cells is found in the bone marrow in conditions of relative hypoxia (241). Despite the fact that 
HSCs have been studied for more than 100 years, embryonic development of adult HSCs was not well defined until the last decade. Recently, image tracing experiments supports the idea that definitive HSCs arise from specialised vascular endothelial cells that acquire blood-forming potential (hemogenic endothelium) $(240,242,243)$. The specification of hemogenic endothelium responds to the need of developing a functional circulatory system that provides nutrients and oxygen to all tissues during embryogenesis (242). On this fact, the latest studies indicate that $\mathrm{Wnt} / \beta$-catenin signalling is critical for the embryonic development of definitive multipotent HSCs $(239,244)$. These findings allow a wide range of possibilities concerning the in vitro development of blood cells for regenerative medicine. The efficient synthesis of hematopoietic cells from PSCs allows a more careful study of developmental mechanisms and blood cell diseases (245). Furthermore, HSCs transplantation is the most widely used cell therapy today to treat blood diseases (245). However, there are several limitations for the clinical use of these therapies, such as the source of HSCs and the compatibility between donor and receptor $(245,246)$. PSCs-derived HSCs represents a major breakthrough in this regard. Nevertheless, the low efficiency in the synthesis of hematopoietic cells from PSCs is one of the major hurdles of this approach (245).

Although the most common way to activate $\beta$-catenin is via canonical Wnt pathway, pharmacological inhibitors of GSK3 such as CHIR99021, CHIR 98014 or lithium chloride have also proven to be capable of stabilizing $\beta$-catenin and promoting its nuclear translocation and transcriptional activity $(80,121)$. Activation of Wnt pathway via GSK3 inhibitor CHIR99021 at the first stages of ESCs differentiation followed by vascular endothelial growth factor (VEGF), induces the differentiation of PSCs to hemogenic endothelium, and subsequently to hematopoietic stem cells (247), supporting the endothelial origin of adult HSCs.

Lithium is another well-defined inhibitor of GSK3(120). Its use for medical applications has been carried out for decades (120), approved by the FDA and its safety has been demonstrated. The role of lithium on stem cells has been subject to many studies in the last years, demonstrating that lithium addition increases the reprogramming efficiency of mouse embryonic fibroblasts (248) and promotes mesenchymal stem cell proliferation via activation of wnt/ $\beta$-catenin pathway (124). The role of GSK3 inhibition in ESCs has been well established in the literature. GSK3 activity is related to both ESCs self-renewal/differentiation (12) and $\beta$-catenin inhibition (121). It was recently described that there is a dual 
role of GSK3 on both PSCs self-renewal and differentiation distinguished by GSK3 activity levels. Low inhibited GSK3 promotes self-renewal and clonogenic expansion, whereas high inhibited GSK3 results in the expression of cdx2 and brachyury, promoting rat ESCs differentiation to mesoderm lineage (12). That being said, the effect of lithium as GSK3 inhibitor on ESCs differentiation is controversial. Previous studies have suggested that murine ESCs cultured in embryoid bodies treated with lithium tend to differentiate towards neural cells (124). Despite the fact that human and mouse ESCs are not absolutely identical, the $\beta$-catenin-mediated mechanism for HSCs development seems to be conserved in both species $(239,244,247)$.

The objective of this chapter is to reveal the role of lithium on murine ESCs differentiation and self-renewal, paying attention to the mechanisms activated by lithium. We will focus on lithium mediated inhibition of GSK3 $\beta$ activity and how this effect can modulate both $\beta$-catenin expression and nuclear translocation, driving ESCs differentiation towards hemogenic endothelium.

\section{Materials and methods}

\section{ESCs culture}

Murine embryonic stem cells D3 (ESCs, ATCC) were cultured in feeder-free conditions using basal medium (BM: DMEM high glucose (Lonza) supplemented with 10\% Knockout Serum Replacement (KSR, ThermoFisher), 1\% Foetal Bovine Serum (FBS, Gibco), 1\% 100X Nucleosides (Millipore), 1\% L-Glutamine (Sigma-Aldrich), 1\% Non-essential Amino Acids (Sigma-Aldrich), 1\% of 100X Penicillin/Streptomycin (10,000 U/ml Penicillin-10,000 $\mathrm{\mu g} / \mathrm{ml}$ Streptomycin, P/S, ThermoFisher) and $10 \mathrm{mM}$ 2-Mercatoethanol (Gibco) at $37^{\circ} \mathrm{C}$ in a humidified incubator containing $5 \% \mathrm{CO}_{2} .1,000 \mathrm{U} / \mathrm{ml}$ ESGRO Leukaemia inhibitory factor (LIF, Millipore) was used to inhibit spontaneous ESCs differentiation (growth medium). Before seeding, culture dishes were coated with $0.2 \%$ gelatine (SigmaAldrich). Lithium chloride (Sigma-Aldrich) was used as source of $\mathrm{Li}^{+}$for the experiments.

\section{ESCs viability and proliferation in presence of different concentrations of lithium}

To analyse the role of $\mathrm{Li}^{+}$on ESCs proliferation and viability, cells were cultured on gelatine coted plates at 10,000 cells $/ \mathrm{cm}^{2}$ in BM either supplemented with 
different concentration of $\mathrm{Li}^{+}$or $1,000 \mathrm{U} / \mathrm{ml}$ of LIF during 3 days. After 1 and 3 days, bright field pictures of the ESCs in each condition were taken. Then, ESCs were lysed by Tris/Triton X100/EDTA (10 mMTris pH 8, 0.5\% Triton X100, $1 \mathrm{mM}$ EDTA) buffer, and proliferation was analysed quantifying total DNA concentration. Whole DNA was quantified by Quant-iT PicoGreen dsDNA Assay Kit (ThermoFisher).

\section{ESCs differentiation experiments}

For ESCs spontaneous differentiation experiments, cells were cultured at a very low density $\left(2,000 \mathrm{cells} / \mathrm{cm}^{2}\right)$ on gelatine coated plates and exposed to increasing concentrations of $\mathrm{Li}^{+}(2,5$ and $10 \mathrm{mM})$ during 5 days as monolayer culture. Then, pluripotency markers were evaluated by immunofluorescence (Oct4 and Sox2) and alkaline phosphatase (AP) staining.

\section{Hemogenic endothelium differentiation experiment}

In order to assess $\mathrm{Li}^{+}$-mediated differentiation of ESCs to hemogenic endothelium, ESCs were cultured at $10,000 \mathrm{cells} / \mathrm{cm}^{2}$ on gelatine coated plates during 6 days in BM and BM supplemented with low $(2 \mathrm{mM})$ and high (10 mM) concentrations of lithium. After the first 3 days, cells were passaged to avoid confluence and were sub-cultured for another 3 days.

After 6 days, hemogenic endothelial cells developed from ESCs were characterized. Then, endothelial cells were maturated to HSCs replacing normal culture medium with maturation medium consisting of DMEM/F12 (SigmaAldrich) supplemented with $\mathrm{N}-2$ (Thermofisher), B27 (Thermofisher) supplements, $1 \%$ L-Glutamine (Sigma-Aldrich), $0.05 \%$ of BSA (Sigma-Aldrich) and $1 \%$ Penicillin/Streptomycin (P/S, Gibco), without addition of $\mathrm{Li}^{+}$. Cells were cultured in these condition for an additional 11 days.

\section{Immunofluorescence and stains}

Cells were fixed with $4 \%$ formaldehyde during 20 minutes at room temperature. Then, samples were washed with TBS and blocked with TBS/Triton X 100 $0.1 \% / B S A 2 \%$ for $1 \mathrm{~h}$ at room temperature. Cells were incubated with primary antibodies overnight at $4^{\circ} \mathrm{C}$ (Table 4). Then, samples were washed and subsequently incubated with secondary antibodies for $1 \mathrm{~h}$ at room temperature (Table 4). Hoechst (dil: 1/7,000, Sigma-Aldrich) was used for nuclear staining. Samples were mounted with $85 \%$ glycerol and imaged by a Nikon Eclipse i80 
Lithium inhibits GSK3 $\beta$, activating $\beta$-catenin and promoting ESCs differentiation towards hemogenic endothelium

fluorescence microscope. The percentage of protein staining was quantified by image analysis with imageJ software.

\begin{tabular}{|l|c|l|}
\hline \multicolumn{3}{|l|}{ Table 4. Antibodies for western blot. } \\
\hline Primary antibodies & Dilution & Reference \\
\hline Goat anti-Oct4 & $1 / 400$ & SantaCuz Biotechnology \\
\hline Rabbit anti-Sox2 & $1 / 500$ & ThermoFisher \\
\hline Goat anti-Sox17 & $1 / 500$ & R\&D systems \\
\hline Rat anti-Sca1 (clone: E13 161-7) & $1 / 1000$ & Abcam \\
\hline Rbbit anti-CD31 1 & $1 / 300$ & Abcam \\
\hline Rabbit anti-CD34 & $1 / 300$ & Abcam \\
\hline Rabbit anti- $\beta$ Catenin & $1 / 500$ & ThermoFisher \\
\hline Secondary antibodies & Dilution & Reference \\
\hline Alexa 488 conjugated goat anti-mouse & $1 / 700$ & ThermoFisher \\
\hline Alexa 555 conjugated goat anti-mouse & $1 / 700$ & ThermoFisher \\
\hline Alexa 488 conjugated goat anti-rabbit & $1 / 700$ & ThermoFisher \\
\hline Alexa 555 conjugated goat anti-rabbit & $1 / 700$ & ThermoFisher \\
\hline Alexa 633 conjugated goat anti-rabbit & $1 / 300$ & ThermoFisher \\
\hline DyLight 488 conjugate donkey anti-goat IgG & $1 / 700$ & ThermoFisher \\
\hline
\end{tabular}

To analyse the number of alkaline phosphatase (AP) positive colonies, ESCs were fixed and stained with Naphthol AS-MX/Fast Red TR (both from SigmaAldrich) for $30 \mathrm{~min}$ at room temperature as previously described(217). Then, samples were washed and nuclei were labelled with Hoechst. The samples were imaged by a Nikon Eclipse i80 fluorescence microscope. The percentage of AP stained colonies was quantified through image analysis with image J software.

For histological sections, EBs were fixed with $4 \%$ formaldehyde for $30 \mathrm{~min}$ at room temperature. Then, EBs were embedded into low temperature gelling agarose (Sigma-Aldrich) and included in OCT (Tissue-Tek) for $15 \mu \mathrm{m}$ cryosections obtained using CM1520 (Leica). OCT sections were immunostained as was previously described.

\section{Western Blot experiments}

Protein extraction was performed by RIPA buffer supplemented with protease inhibitor cocktail tablets (Roche). Then, proteins were separated in $10 \%$ SDSPAGE with Mini-PROTEAN Electrophoresis System (Bio-Rad) and subsequently transferred to PVDF (GE-Healthcare) membranes by Trans-Blot Semi-Dry Transfer Cell (Bio-Rad). Membranes were blocked with 5\% BSA (Sigma-Aldrich), or alternatively with 5\% skied milk (Sigma-Aldrich), in TBS/0.1\% Tween 20 (Sigma-Aldrich) for $1 \mathrm{~h}$ and incubated with primary antibodies (Table 5) diluted in TBS, $0.1 \%$ Tween 20 and $3 \%$ BSA overnight at $4^{\circ} \mathrm{C}$. Membranes were washed 
and incubated with HRP linked secondary antibody (Table 5) for $1 \mathrm{~h}$ at room temperature. Chemiluminescence band detection was done by ECL-Plus reactive (ThermoFisher). Fujifilm Las-3000 imager device was used for protein bands visualisation.

\begin{tabular}{|l|c|l|}
\hline \multicolumn{3}{|l|}{ Table 5. Antibodies and dilutions used for western blot experiments. } \\
\hline Primary antibodies & Dilution & Reference \\
\hline Rabbit anti-Akt (Clone J.314.4) & $1 / 1500$ & ThermoFisher \\
\hline Mouse anti-phospho Akt-serine 473 (Clone 6F5) & $1 / 1500$ & Millipore \\
\hline Rabbit anti-VE cadherin & $1 / 1000$ & Abcam \\
\hline Rabbit anti- $\beta$ Catenin & $1 / 500$ & ThermoFisher \\
\hline Rabbit anti-GSK3ß (Clone 3D10) & $1 / 1500$ & ThermoFisher \\
\hline Rabbit anti-phospho GSK3ß-serine 9 (Clone C.367.3) & $1 / 1000$ & ThermoFisher \\
\hline Rabbit anti-GAPDH & $1 / 3000$ & ThermoFisher \\
\hline Secondary antibodies & Dilution & Reference \\
\hline Donkey anti-mouse HRP conjugate & $1 / 10000$ & GE Healthcare \\
\hline Donkey anti-rabbit HRP conjugate & $1 / 10000$ & GE Healthcare \\
\hline
\end{tabular}

\section{Quantitative real time PCR}

Whole RNA was isolated by Quick RNA Miniprep kit (ZYMO Research) and quantified using Q3000 micro volume spectrophotometer (Quawell). RNAs were retrotranscribed using Maxima First Strand cDNA Synthesis Kit with Thermolabile dsDNase (ThermoFisher). Real-time qPCR was carried out using the PowerUp SYBR Master Mix (Thermofisher) and 7500 Fast Real-Time PCR System (ThermoFisher). The primers used for amplification are indicated in table 6 . The fractional cycle number at which fluorescence passed the threshold ( $\mathrm{Ct}$ value) was used for gene expression quantification using the comparative $\Delta \Delta C T$ method (158). Sample values were normalized to the threshold value of housekeeping gene GAPDH.

\begin{tabular}{|c|l|l|}
\hline \multicolumn{2}{|l|}{ Table 6. RT-qPCR primer sequences. } \\
\hline Primers & Sequence \\
\hline \multirow{2}{*}{ Brachyury/T } & 5'-Forward & GGTGGCTTGTTCCTGGTGC \\
\cline { 2 - 3 } & 5'-Reverse & GTAGGTGGGCTGGCGTTAT \\
\hline \multirow{2}{*}{ Cdx2 } & 5'-Forward & AAACCTGTGCGAGTGGATG \\
\cline { 2 - 3 } & 5'-Reverse & TCTGTGTACACCACCCGGTA \\
\hline \multirow{2}{*}{ Gata4 } & 5'-Forward & CCTAAACCTTACTGGCCGTAGC \\
\cline { 2 - 3 } & 5'-Reverse & ACAATGTTAACGGGTTGTGGAG \\
\hline \multirow{2}{*}{ Nkx2-5 } & 5'-Forward & CAAGTGCTCTCCTGCTTTCC \\
\cline { 2 - 3 } & 5'-Reverse & GGCTTTGTCCAGCTCCACT \\
\hline \multirow{2}{*}{ GAPDH } & 5'-Forward & AGGTCGGTGTGAACGGATTTG \\
\cline { 2 - 3 } & 5'-Reverse & TGTAGACCATGTAGTTGAGGTCA \\
\hline
\end{tabular}


Lithium inhibits GSK3 $\beta$, activating $\beta$-catenin and promoting ESCs differentiation towards hemogenic endothelium

\section{Statistical analyses}

Obtained data were reported as mean \pm standard deviation. In order to establish if the obtained data followed a normal distribution, we resorted to D'AgostinoPearson omnibus test. Results were analysed by one-way ANOVA using GraphPad Prism 6.0. When differences were determined to be significant, pairwise comparisons were made, using the Tukey test in case of normal data distribution or Dunn's test in the opposite case. A 95\% confidence level was considered significant.

\section{Results}

\section{High concentrations of $\mathrm{Li}^{+}$are toxic for ESCs and can reduce cell proliferation}

Lithium is an element routinely used in the literature as a tool to inhibit the activity of GSK3(120). However, high concentrations of $\mathrm{Li}^{+}$have shown both cytotoxic and antiproliferative effects (249). Thus, $\mathrm{Li}^{+}$can be potentially toxic for cells. To determine the effect of $\mathrm{Li}^{+}$on mouse ESCs survival and proliferation, cells were cultured at 10,000 cells $/ \mathrm{cm}^{2}$ on gelatine coated plates in BM and BM supplemented with increasing concentrations of extracellular $\mathrm{Li}^{+}(2,5$ and $10 \mathrm{mM})$ during 3 days (Fig. 40). After 1 day, $\mathrm{Li}^{+}$concentrations above $10 \mathrm{mM}$ resulted toxic for ESCs, and an important decrease in the number of attached cells was observed, compared to the rest of the conditions, where small ESCs colonies could be appreciated (Fig. 40a). After 3 days, bright field images showed that cell density varied inversely to $\mathrm{Li}^{+}$concentration. We observed a high cell density in ESCs cultured with BM and BM supplemented with LIF. For ESCs supplemented with $\mathrm{Li}^{+}$, cell density decreased monotonically in a $\mathrm{Li}^{+}$concentration-dependent manner. No adhered ESCs were observed for ESCs cultured with $20 \mathrm{mM} \mathrm{Li}^{+}$. 


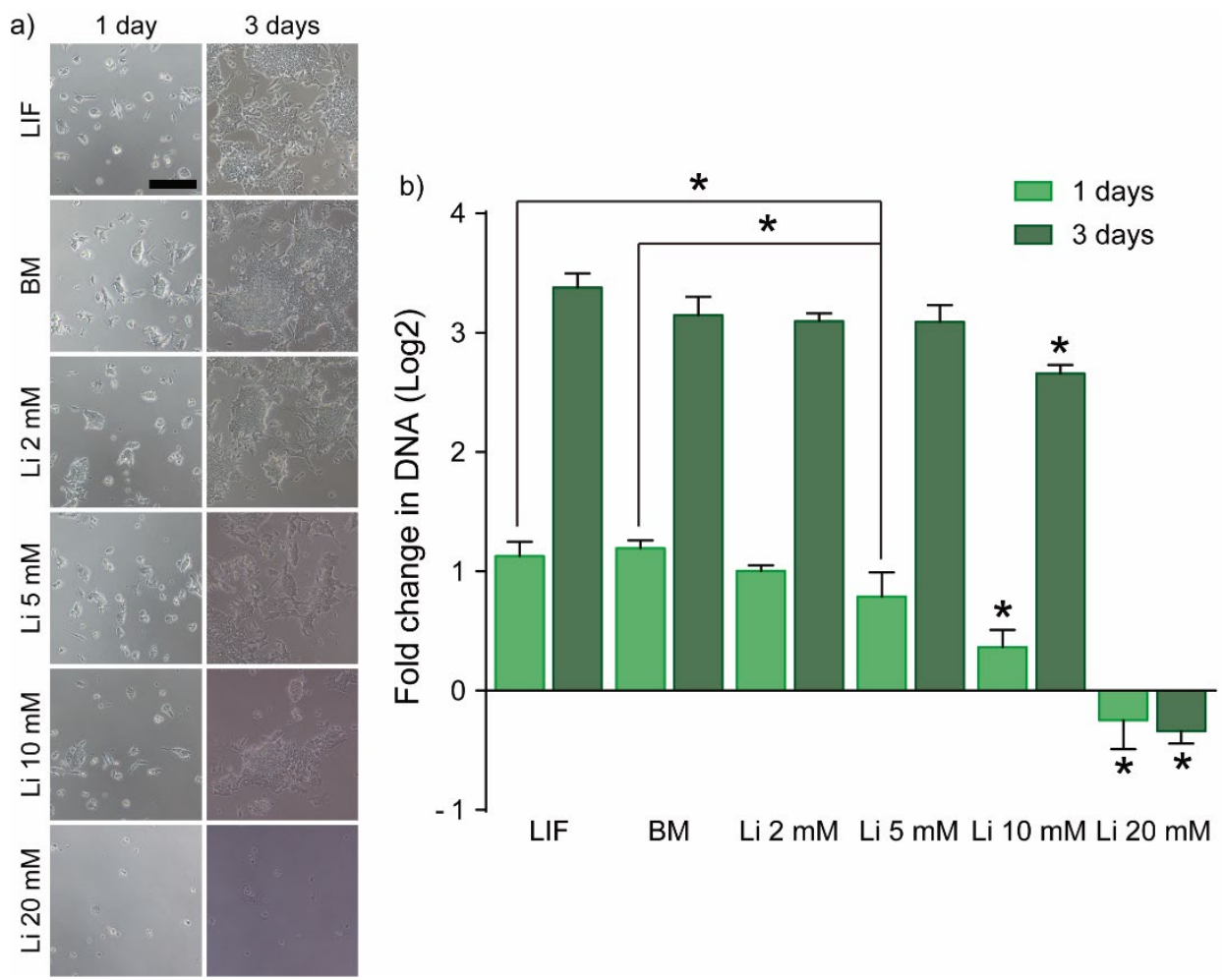

Figure 40. Role of lithium in ESCs proliferation and viability.

a) Bright field images of ESCs cultured with different concentrations of $\mathrm{Li}^{+}$after 1 and 3 days of culture (Scale bar: $200 \mu \mathrm{m}$ ).

b) Proliferation activity of ESCs cultured with different concentrations of $\mathrm{Li}^{+}$was analysed by total DNA quantification after 1 and 3 days of culture. $(n=4)$.

Graphs show mean \pm standard deviation.

DNA concentration was analysed after 1 and 3 days to determine cell proliferation. Our results indicated that high concentrations of $\mathrm{Li}^{+}(5$ and $10 \mathrm{mM})$ showed both reduced cells density and DNA concentration compared with lower concentrations of $\mathrm{Li}^{+}$and cell grown in BM (Fig. 40). Furthermore, unlike the cells treated with $20 \mathrm{mM} \mathrm{Li}^{+}$, these conditions showed no floating apoptotic cells. These results indicated that high concentrations of $\mathrm{Li}^{+}$alter cell proliferation without apparently affecting viability. Thus, concentrations above $10 \mathrm{mM} \mathrm{Li}^{+}$were excluded for future experiments. 


\section{$\mathrm{Li}^{+}$inhibits GSK3 $\beta$ activity without affecting ESCs spontaneous differentiation}

The phosphorylation of GSK3 $\beta$ in ESCs can tip the balance towards both, cell differentiation or self-renewal, depending on its activity (12). To determine whether $\mathrm{Li}^{+}$has some effect in ESCs spontaneous differentiation, cells were cultured in presence of increasing concentrations of $\mathrm{Li}^{+}$during 5 days. Then, pluripotency markers Oct4, Sox2 and alkaline phosphatase (AP) were analysed (Fig. 43). The comparison between cells grown in BM and $\mathrm{Li}^{+}$-treated conditions showed that the ratio of Oct4 and Sox 2 positive cells remained constant, with no significant variations. This suggest that $\mathrm{Li}^{+}$does not have a significant effect on PSCs self-renewal. To further analyse the role of $\mathrm{Li}^{+}$on PSCs differentiation, we have stained alkaline phosphatase from PSCs colonies. Results showed no differences on AP stain between cells grown in $\mathrm{BM}$ and $\mathrm{Li}^{+}$concentrations up to $5 \mathrm{mM}$. However, ESCs treated with $10 \mathrm{mM} \mathrm{Li}^{+}$possessed a higher number of AP positive cells, although less than LIF-treated cells. This suggested that ESCs spontaneous differentiation is not affected by the presence of extracellular $\mathrm{Li}^{+}$. 

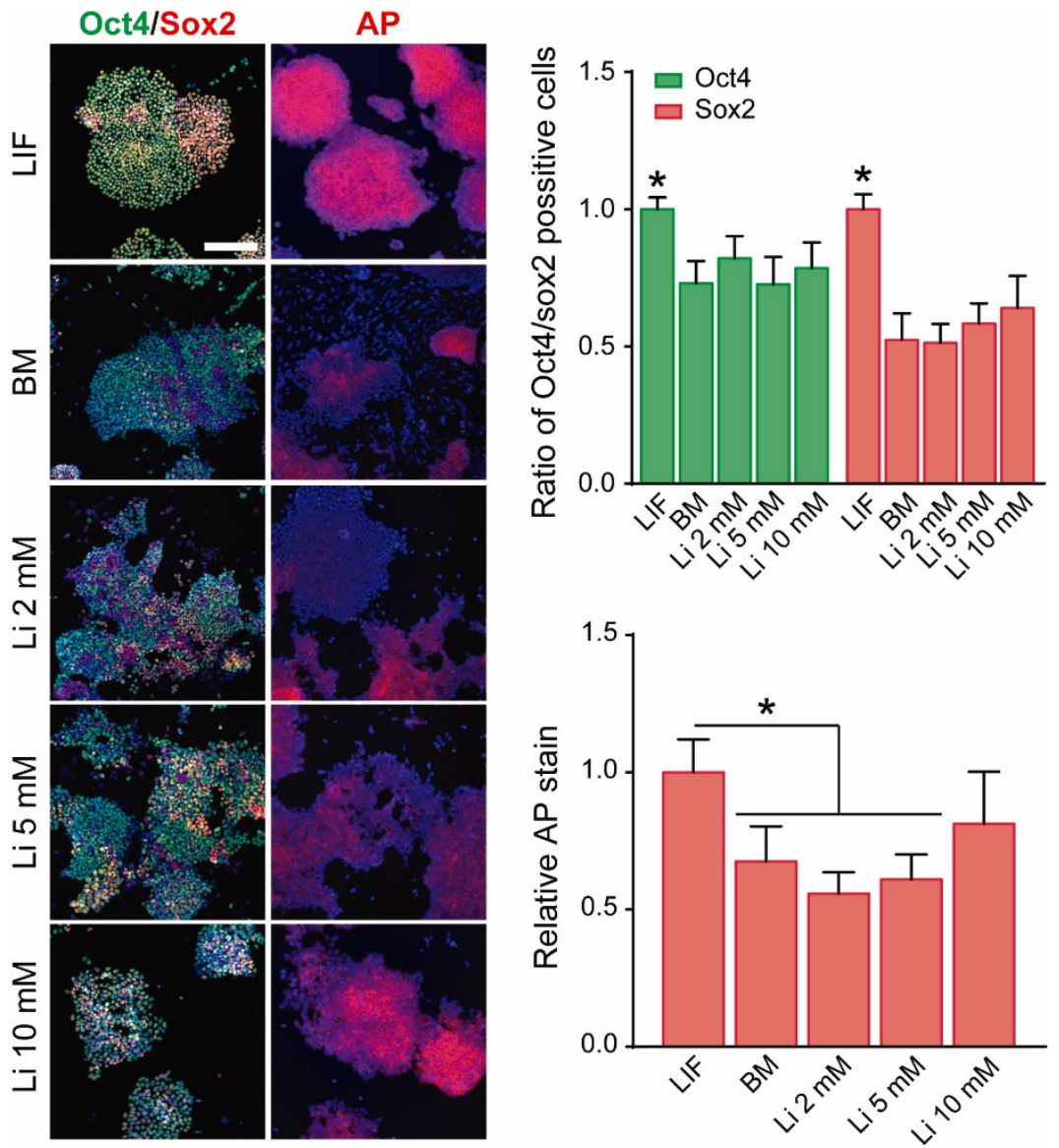

Figure 41. The effect of different concentrations of $\mathrm{Li}^{+}$on the expression of ESCs pluripotency markers.

Immunofluorescence detection (Oct4-green and Sox2-red) and staining (alkaline phosphatase-red, AP) of pluripotency markers determined after 5 days of culture in BM, medium supplemented with LIF, or medium supplemented with different concentrations of $\mathrm{Li}^{+}$(Scale bar: $\left.200 \mu \mathrm{m}\right)$. ( $\left.\mathrm{n}=5\right)$.

Graphs show mean \pm standard deviation. Significant differences were determined by ANOVA test; ${ }^{*} p<0.05$.

We next evaluated the $\mathrm{Li}^{+}$-mediated activation/inactivation of two key signalling pathways in PSCs self-renewal and differentiation, such as GSK3 $\beta$ and Akt. It should be noted that GSK3 $\beta$ is a target substrate for Akt-mediated phosphorylation $(121,126)$. Therefore, we also analysed Akt activity on $\mathrm{Li}^{+}-$ treated ESCs. The pGSK3 $\beta / G S K 3 \beta$ and $p A k t / A k t$ ratios were quantified by 
western blot after 4 and $24 \mathrm{~h}$ to assess the evolution of GSK3 $\beta$ phosphorylation

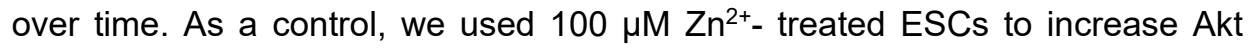
phosphorylation (Fig. 42) (115).
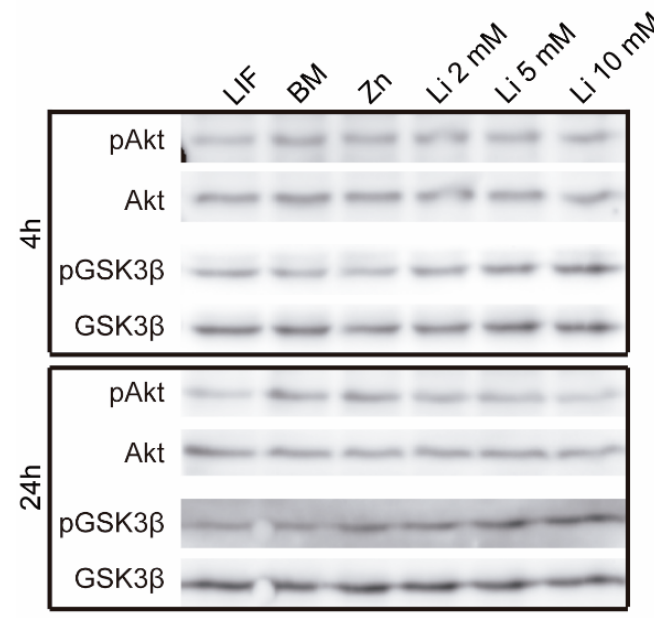
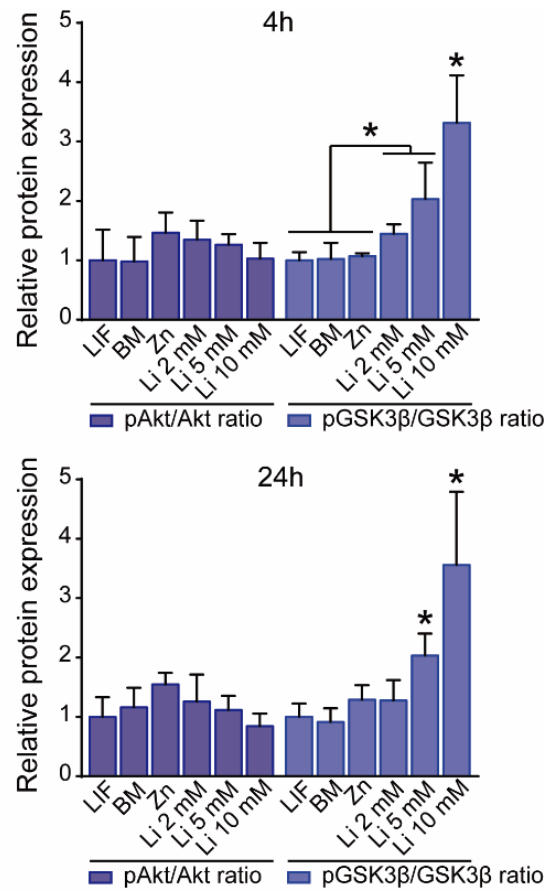

Figure 42. Influence of different $\mathrm{Li}^{+}$concentrations in the phosphorylation of the protein kinases Akt and GSK3 $\beta$ after 4 and $24 \mathrm{~h}$.

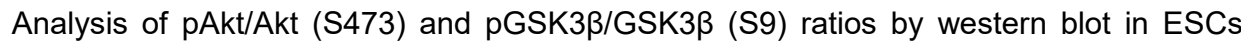
cultured in BM, medium supplemented with LIF, or medium supplemented with $100 \mu \mathrm{M}$ of $\mathrm{Zn}^{2+}$ and different concentrations of $\mathrm{Li}^{+}$during $4 \mathrm{~h}$ or $24 \mathrm{~h}$. GAPDH was used as loading control protein. $(n=4)$.

Graphs show mean \pm standard deviation. Significant differences were determined by ANOVA test; ${ }^{*} p<0.05$.

The results indicated that GSK3 $\beta$ phosphorylation after $24 \mathrm{~h}$ does not undergo significant changes compared with the pGSK3 $\beta / G S K 3 \beta$ ratio after $4 \mathrm{~h}$. For both time points, ESCs supplemented with 5 and $10 \mathrm{mM} \mathrm{Li}^{+}$showed significantly higher GSK3 $\beta$ phosphorylation than ESCs cultured in either BM and BM

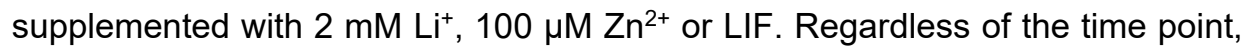
$\mathrm{Li}^{+}$-mediated phosphorylation of GSK3 $\beta$ showed a strong dependence on $\mathrm{Li}^{+}$ concentration. We obtained the highest value for $\mathrm{pGSK} 3 \beta / G S K 3 \beta$ ratio for ESCs 
treated with $10 \mathrm{mM} \mathrm{Li}^{+}$, followed by a gradual reduction depending on the concentration of $\mathrm{Li}^{+}$.

Regarding Akt phosphorylation, $\mathrm{Li}^{+}$-treated cells showed similar pAkt/Akt values to those of BM cultured cells. These results indicated that $\mathrm{Li}^{+}$has no remarkable effect on the phosphorylation of Akt.

\section{$\mathrm{Li}^{+}$-mediated inhibition of GSK3 $\beta$ increases over time and enhances $\beta$-catenin expression and nuclear translocation}

GSK3 $\beta$ activity is critical for inhibition of $\beta$-catenin through axin complex (125). It has been demonstrated that $\beta$-catenin activity is necessary for ESCs integrity maintenance (250). However, an excessive accumulation of $\beta$-catenin in the nucleus leads to the expression of transcription factors such as $C d x 1, C d x 2$ and Brachyury/T implicated in lineage differentiation (12). To investigate how $\mathrm{Li}^{+}-$ mediated inhibition of GSK3 $\beta$ affects $\beta$-catenin expression and subcellular distribution, we have cultured ESCs in presence of BM and BM supplemented with low $(2 \mathrm{mM})$ and high $(10 \mathrm{mM})$ concentrations of $\mathrm{Li}^{+}$. After 1 and 3 days, both protein expression and subcellular localisation of $\beta$-catenin and GSK3 $\beta$ were analysed by western blot and immunofluorescence (Fig. 43 and 44). Figure $43 a$ shows a remarkable accumulation of $\beta$-catenin after 1 and 3 days in the edges of the cells, contributing to cell-cell interactions $(125,126)$, with no apparent relation to culture time. Further to the structural function, the comparison between the analysed conditions showed that $10 \mathrm{mM} \mathrm{Li}+$-treated cells showed significantly higher $\beta$-catenin staining on the nuclear area (Fig. 44b), implying nuclear accumulation of $\beta$-catenin. 
a)

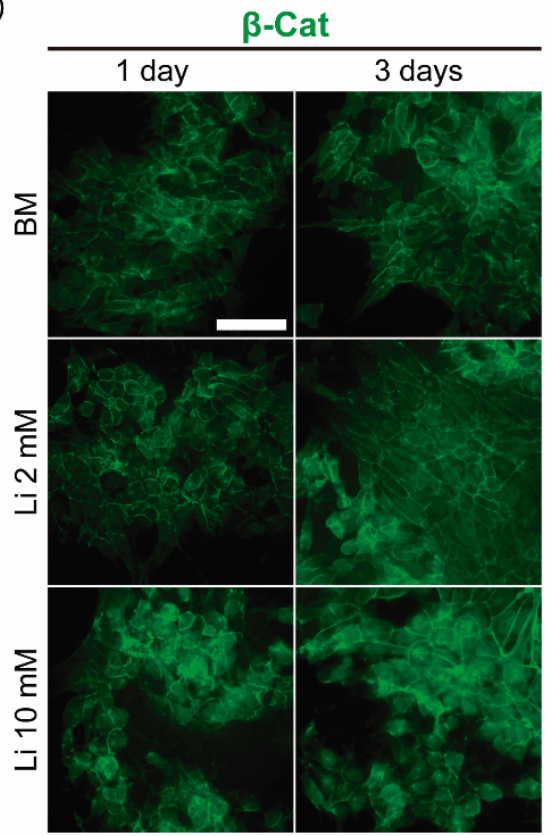

b)
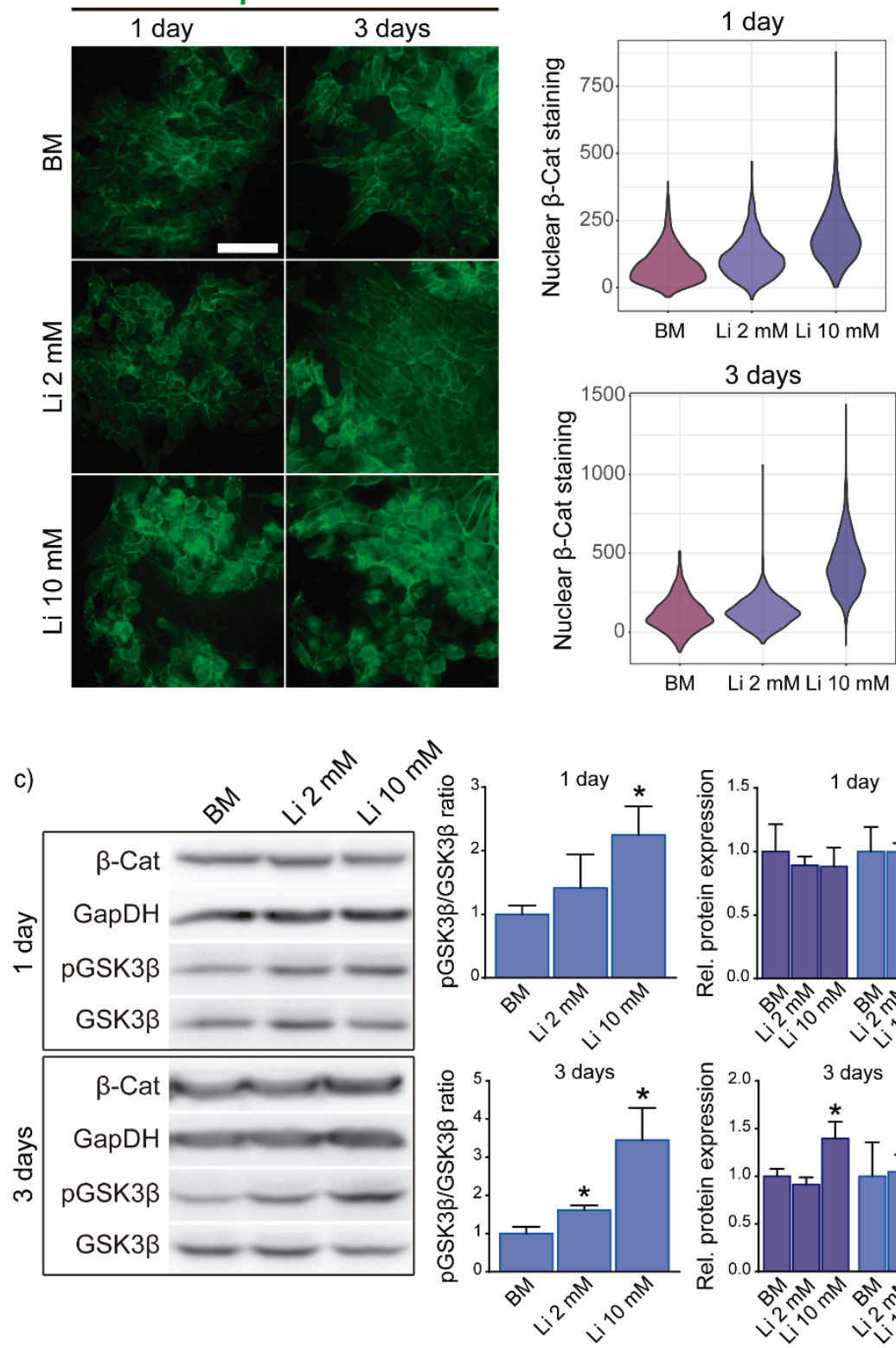

Figure 43. Relationship between GSK3 $\beta$ activity and $\beta$-catenin expression and subcellular localization in Li+-treated cells.

a) Immunofluorescence detection of $\beta$-catenin after 1 and 3 days of culture in BM or medium supplemented with different concentrations of $\mathrm{Li}^{+}$. $(\mathrm{n}=5)$.

b) Quantification (pixel density) of $\beta$-catenin immunostaining after 1 and 3 days of culture. ( $n>100$ random nuclei from 15 fields captured. 3 fields/sample). 
c) Analysis of $\beta$-catenin and pGSK3 $\beta /$ GSK3 $\beta$ (S9) ratios by western blot in ESCs cultured in $\mathrm{BM}$ and medium supplemented with different concentrations of $\mathrm{Li}^{+}$for 1 and 3 days. GAPDH was used as loading control protein. $(n=4)$.

Graphs show mean \pm standard deviation. Significant differences were determined by ANOVA test; ${ }^{*} p<0.05$.

To assess whether different concentrations of $\mathrm{Li}^{+}$affected pGSK3 $\beta / G S K 3 \beta$ ratio and the expression of $\beta$-catenin, both conditions were analysed by western blot after 1 and 3 days (Fig 43b). As expected, after 1 day, the phosphorylation of GSK3 $\beta$ was significantly higher for $10 \mathrm{mM} \mathrm{Li}^{+}$-treated ESCs and the expression of $\beta$-catenin remained constant with no difference between high and low concentrations of $\mathrm{Li}^{+}$. After 3 days, pGSK3 $\beta / G S K 3 \beta$ ratio increased even more for both $2 \mathrm{mM}$ and $10 \mathrm{mM} \mathrm{Li}{ }^{+}$-treated cells compared with ESCs cultured in BM. Indeed, after 3 days in presence of $10 \mathrm{mM} \mathrm{Li}^{+}$, the expression of GSK3 $\beta$ decreased, whilst the expression of $\beta$-catenin increased. These results, along with the high phosphorylation of GSK3 $\beta$, indicated that $10 \mathrm{mM} \mathrm{Li}^{+}$efficiently inhibits the $\beta$-catenin destruction complex, resulting in an increased concentration of both total and nuclear $\beta$-catenin after 3 days.

\section{Nuclear accumulation of $\beta$-catenin activates Brachyury/T and $\mathrm{Cdx} 2$ expression}

Our previous results showed that $10 \mathrm{mM} \mathrm{Li}^{+}$increased $\beta$-catenin expression and promoted its nuclear accumulation $(126,234,236)$. To confirm whether nuclear localisation of $\beta$-catenin also triggers its transcriptional activity, we analysed the expression of two target genes of $\beta$-catenin: Brachyury/T and $\mathrm{Cdx} 2$. Both analysed transcription factors are key regulators of early mesoderm commitment in ESCs (12). qPCR experiments showed a significantly higher expression of both Brachyury/T and Cdx2 for ESCs treated with $10 \mathrm{mM} \mathrm{Li}^{+}$(Fig. 44a). These results support previous evidences about the activation and nuclear accumulation of $\beta$ catenin through GSK3 $\beta$ phosphorylation (Fig. 44b). Furthermore, the increased expression of Brachyury/T and $\mathrm{Cdx} 2$ indicates the capability of high concentrations of $\mathrm{Li}^{+}$of promoting ESCs differentiation towards mesoderm lineage. 
a)

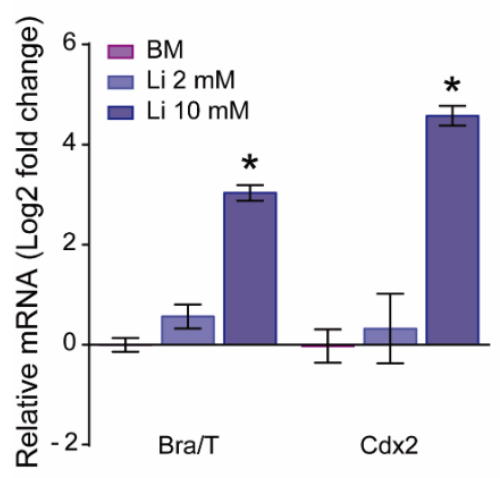

b)

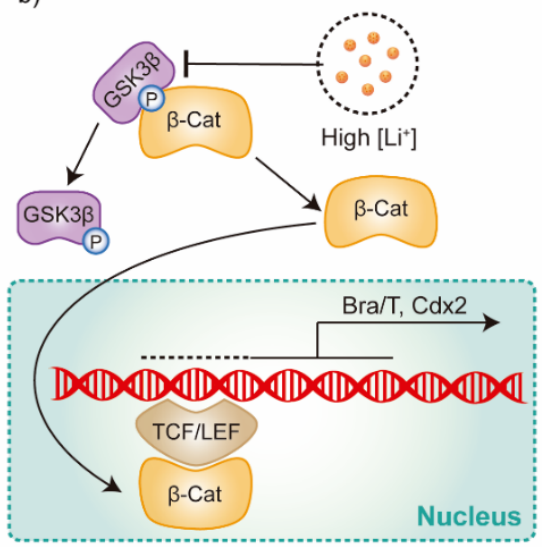

Figure 44. Gene expression of mesoderm differentiation markers in lithium-treated cells.

a) RT-qPCR evaluation of mesoderm related markers Brachyury/T and Cdx2 expression in ESCs cultured in BM or medium supplemented with 2 or $10 \mathrm{mM} \mathrm{Li}^{+}$after 3 days. GAPDH was used as housekeeping gene. $(n=4)$. Graphs show mean \pm standard deviation. Significant differences were determined by ANOVA test; * $p<0.05$.

b) Proposed chain of events that occurs in ESCs as a consequence of high concentration of $\mathrm{Li}^{+}$. High $\mathrm{Li}^{+}$triggers GSK3 $\beta$ inactivation releasing $\beta$-catenin from axin complex. Free $\beta$ catenin translocate into the nucleus co-activating the expression of mesoderm differentiation master regulators, inducing mesoderm specification.

\section{High concentration of $\mathrm{Li}^{+}$leads to ESCs differentiation to Sca1 and CD31 positive endothelial cells}

Previous studies have demonstrated that GSK3 $\beta$ inhibition and consequently $\beta$ catenin transcriptional activation induces the development of hemogenic endothelium from ESCs $(239,247)$. We next investigated whether continued exposition to $10 \mathrm{mM} \mathrm{Li}^{+}$drives ESCs differentiation to any specific lineages among the various mesodermal lineages. To do so, ESCs were cultured during 6 days in presence of $2 \mathrm{mM}$ (low) and $10 \mathrm{mM}$ (high) $\mathrm{Li}^{+}$for 6 days. We then analysed both pluripotency and hemogenic endothelial specific markers by immunofluorescence and RT-qPCR (Fig. 46). The ratio of Oct4 positive cells after

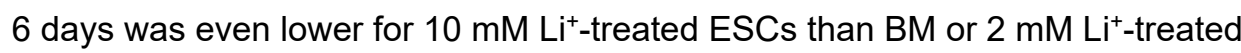
cells. No differences were observed in the ratio of Sox2 positive cells. This suggests that a high concentration of $\mathrm{Li}^{+}$is far from being a pluripotency sustaining factor. In fact, $10 \mathrm{mM} \mathrm{Li}^{+}$-treated cells displayed an accelerated 
differentiation (Fig 45a). Immunofluorescence staining of hemogenic endothelium markers Sca-1 and CD31 showed that only ESCs cultured with high concentration $\mathrm{Li}^{+}$expressed them. We found that the resulting population of 10 $\mathrm{mM} \mathrm{Li+-treated} \mathrm{cells} \mathrm{was} \mathrm{composed} \mathrm{by} \mathrm{a} \mathrm{combination} \mathrm{of} \mathrm{Sca-1+} \mathrm{cells,} \mathrm{CD31+}$ cells, and Sca-1+/CD31+ cells. Even though some cells also expressed CD34, their population was negligible (Fig. 45d).
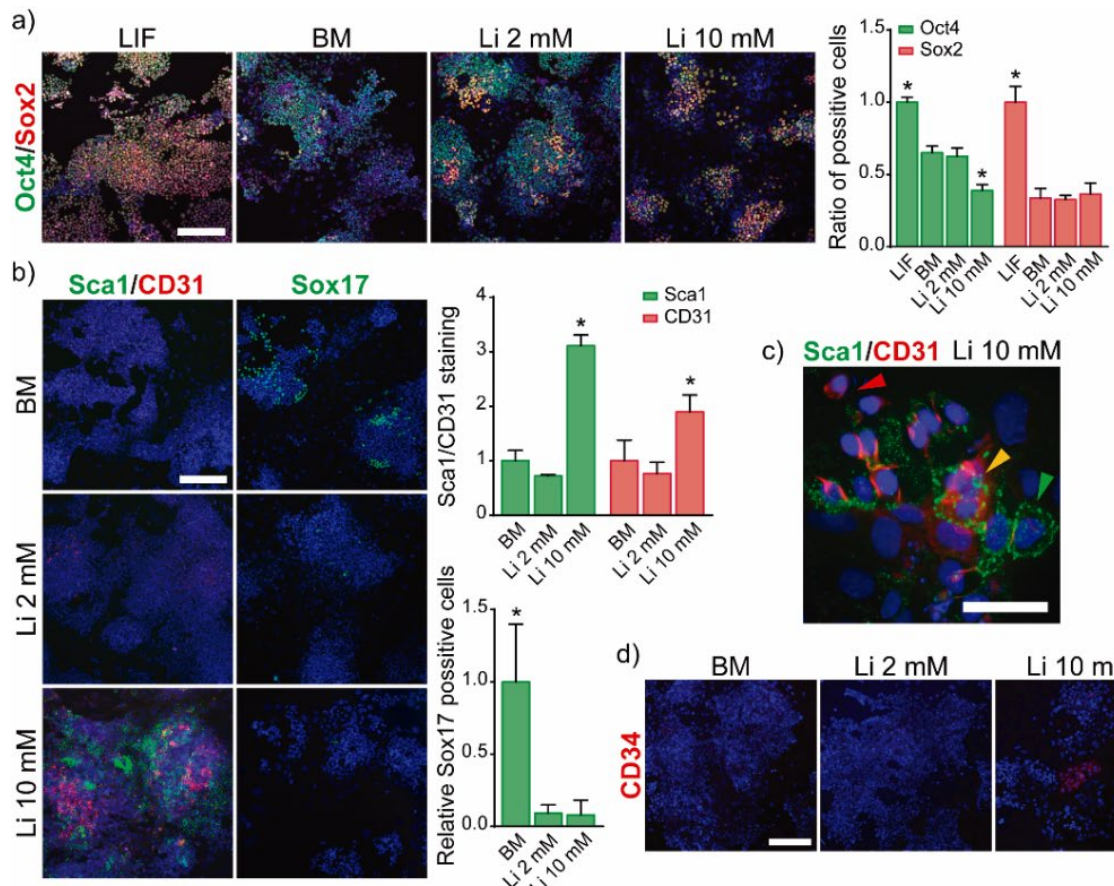

- Sca1

c) Sca1/CD31 Li $10 \mathrm{mM}$
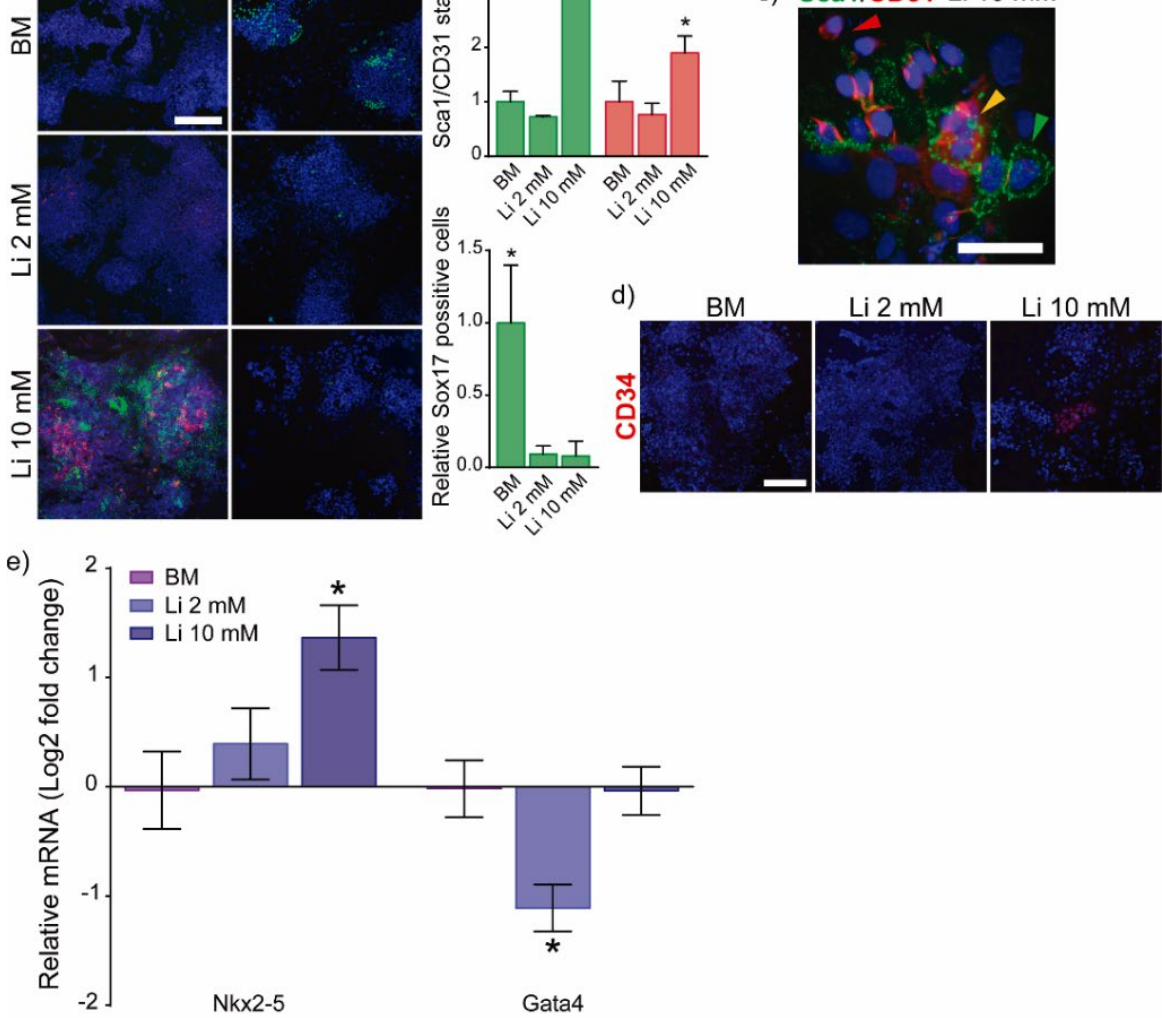

Figure 45. Role of $\mathrm{Li}^{+}$on ESCs cultured during 7 days in monolayer.

a) Immunofluorescence detection and quantification of pluripotency markers (Oct4 and Sox2) after 7 days of culture in BM, medium supplemented with LIF, and medium supplemented with 2 or $10 \mathrm{mM} \mathrm{Li}^{+}$(Scale bar: $\left.200 \mu \mathrm{m}\right)$. ( $\left.\mathrm{n}=5\right)$. 
Lithium inhibits GSK3 $\beta$, activating $\beta$-catenin and promoting ESCs differentiation towards hemogenic endothelium

b) Mesoderm (Sca-1 and CD31) and endoderm (Sox17) differentiation markers analysed by immunofluorescence after 7 days of culture in BM or medium supplemented with different concentrations of $\mathrm{Li}^{+}$(Scale bar: $\left.200 \mu \mathrm{m}\right)$. ( $(\mathrm{n}=5)$.

c) Representative images of ESCs cultured with $10 \mathrm{mM} \mathrm{Li+}$, where a variety of coexisting CD31+ (red arrow), sca-1+ (green arrow), and CD31+/sca-1+ (yellow arrow) positive cells were found (Scale bar: $50 \mu \mathrm{m}$ ).

d) Immunofluorescence detection of endothelial marker CD34 after 7 days of culture in BM or medium supplemented with different concentrations of $\mathrm{Li}+($ Scale bar: $200 \mu \mathrm{m}) .(\mathrm{n}=5)$.

e) Expression of cardiac/endothelial stem cell markers (Nkx2-5 and Gata4) by RT-qPCR of ESCs cultured in BM or medium supplemented with different concentrations of $\mathrm{Li}^{+}$for 7 days. $(n=4)$.

Graphs show mean \pm standard deviation. Significant differences were determined by ANOVA test; ${ }^{*} p<0.05$.

We further analysed the expression of cardiovascular stem cell transcription factors Nkx2-5 and Gata4 after 6 days. The expression of Nkx2-5 only showed increased values for ESCs supplemented with $10 \mathrm{mM} \mathrm{Li}^{+}$(Fig. 45e). Despite no significant differences were observed between BM and $10 \mathrm{mM} \mathrm{Li}^{+}$-treated ESCs, the expression of Gata4 in these conditions was significantly higher than in $2 \mathrm{mM}$ $\mathrm{Li}^{+}$-treated cells. It should be pointed out that Gata4 is also expressed in ESCs differentiating to early endoderm lineage (251). In order to clarify whether GATA4 expression is associated to endoderm or mesoderm lineage, we have assessed the expression of early endoderm marker Sox17. Our results demonstrated that Sox17 is only significantly expressed in ESCs cultured in just BM. This indicated that Gata4 expression for ESCs cultured in BM is related to early endoderm differentiation instead of cardiovascular progenitor development.

Protein expression analysis after 6 days revealed an upregulation in $\beta$-catenin expression and phosphorylation of GSK3 $\beta$ in ESCs supplemented with $10 \mathrm{mM}$ $\mathrm{Li}^{+}$(Fig. 46). Furthermore, VE-cadherin was also more expressed in ESCs treated

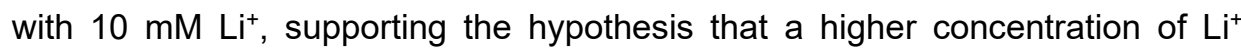
induces hemogenic endothelium development form ESCs via GSK3 $\beta$ phosphorylation and $\beta$-catenin activation. Even though the phosphorylation of GSK3 $\beta$ is still high for $10 \mathrm{mM} \mathrm{Li}^{+}$-treated cells GSK3 $\beta$, protein expression appears to be restored after 6 days. Results showed no differences in the expression of GSK3 $\beta$ between the different conditions (Fig. 46). 


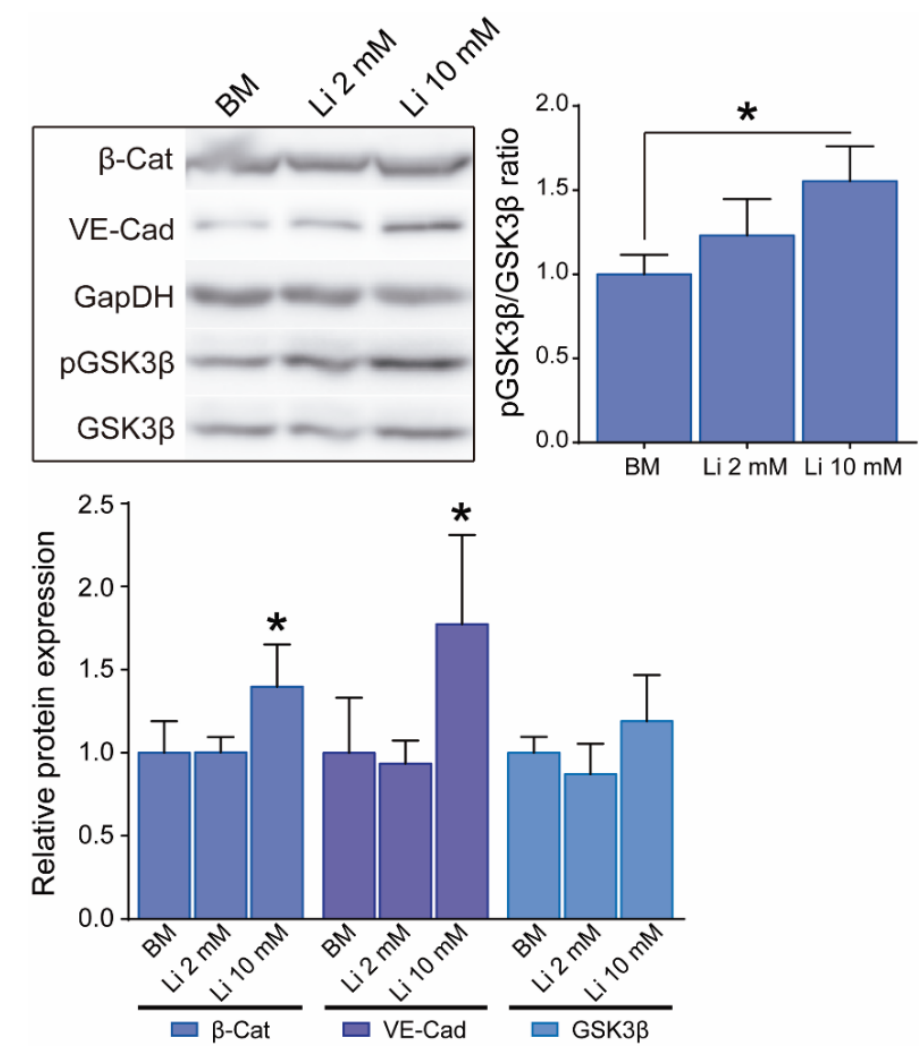

Figure 46. Protein expression of ESCs cultured in presence of different concentration of Lithium for 6 days.

Analysis of pGSK3 $\beta / G S K 3 \beta$ (S9) ratios and expression of $\beta$-catenin, vascular endothelial cadherin, and GSK3 $\beta$ by western blot in ESCs cultured in BM or medium supplemented with 2 and $10 \mathrm{mM} \mathrm{Li}^{+}$after 6 days. GAPDH was used as loading control protein $(n=4)$. Graphs show mean \pm standard deviation. Significant differences were determined by ANOVA test; ${ }^{*} p<0.05$.

\section{ESCs-derived hemogenic endothelial cells can be maturated to obtain HSCs}

The expression of cell surface protein Sca-1 is a particular feature of a subset of cells with multilineage differentiation capability $(238,252-254)$. Sca-1 expressing cells were prior successfully differentiated to both cardiovascular lineages, such as cardiomyocytes (35) or endothelial cells (252), and haematopoietic cells (253). HSCs that derive from hemogenic endothelium arise from a subset of population characterised by the expression of both Runx1 and Sca-1 $(126,254)$. To further 
investigate the potential of Sca-1 positive cells derived from ESCs to differentiate into HSCs, we cultured these cells in maturation medium (medium supplemented with N2B27) for 11 days. The expression of hemogenic endothelial (Sca-1 and CD31) and HSCs (Sox17) markers was analysed by immunostaining after the initial 5 days. Despite ESCs pre-cultured with10 $\mathrm{mM} \mathrm{Li}^{+}$still showed Sca-1 staining, its expression appeared reduced after 5 days in maturation medium (Fig. $47 \mathrm{a}$ and $47 \mathrm{~d}$ ). Conversely, early HSCs marker Sox17 was upregulated. We observed a significant increase of Sox17 positive cells outside the clumped colonies. These results indicated that a high concentration of $\mathrm{Li}^{+}$efficiently leads ESCs differentiation to hemogenic endothelium. Moreover, bright field pictures showed that ESCs pre-treated with $10 \mathrm{mM} \mathrm{Li}^{+}$and then maturated for 7 days possessed both endothelial-like cell and clustering rounded cell morphologies, supporting the idea of hematopoietic specification (Fig. 47b). After 11 days, the resulting cell morphology was clearly different between ESCs pre-cultured in BM or $2 \mathrm{mM} \mathrm{Li}^{+}$and ESCs treated with $10 \mathrm{mM} \mathrm{Li}^{+}$(Fig. 47b). Whilst high concentration of $\mathrm{Li}^{+}$-treated cells displayed an important population of rounded cells over endothelial-like cell colonies, the other conditions showed a large number of cells with neural morphology. Furthermore, endothelial and HSCs marker analysis showed that cell colonies were formed mainly by CD31 and Sca-1 positive cells. By contrast, the remaining population of cells were positive for Sox17. We also observed an important increase in the number of Sca-1 positive cells after 11 days. Surprisingly the morphology of these cells was divided between hemogenic endothelial-like cells and rounded cells. After 11 days in presence of N2B27, we also showed cell clusters positive for CD34 in ESCs pre-treated with $10 \mathrm{mM} \mathrm{Li}^{+}$. This, along with the circular cell morphology, suggested a successful differentiation of endothelial cells into HSCs. Moreover, the emerging of rounded Sca-1 positive cells, together with CD34 positive colonies and the increase of Sox17 expressing cells after 11 days in presence of N2B27 reinforce the hypothesis that hemogenic endothelial Sca-1 positive cells are the main contributors of the developing HSCs. 
a)
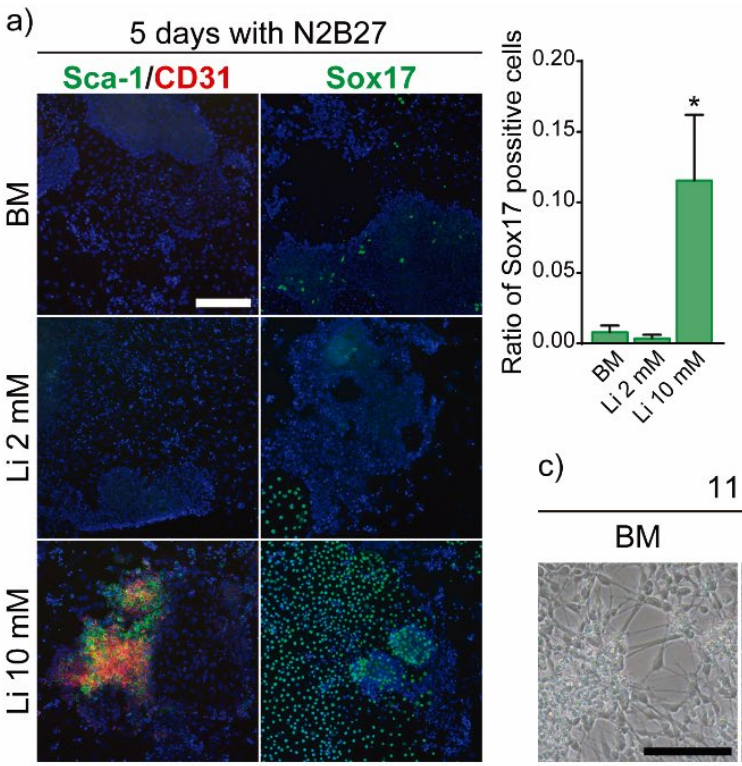

b)

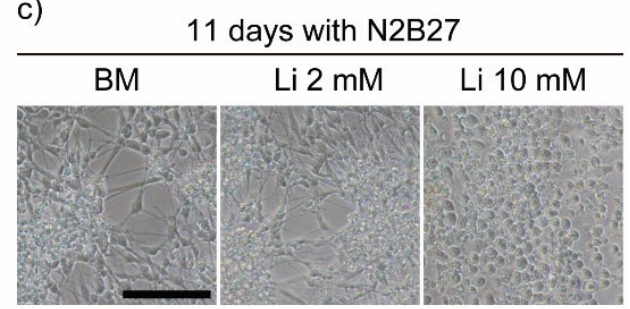

d)

11 days with N2B27

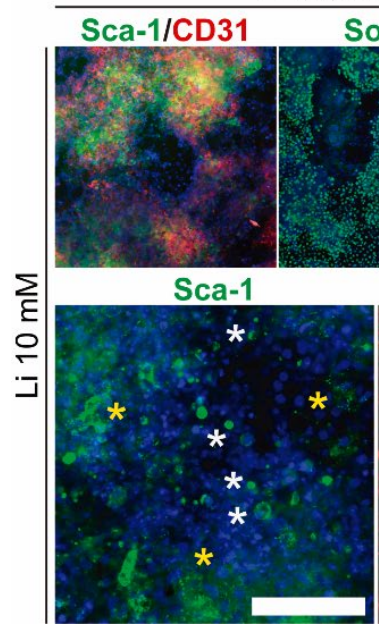

Sox17

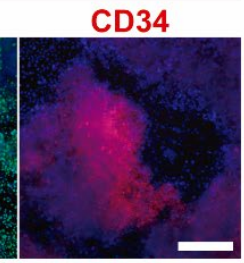

Sox17/Actin

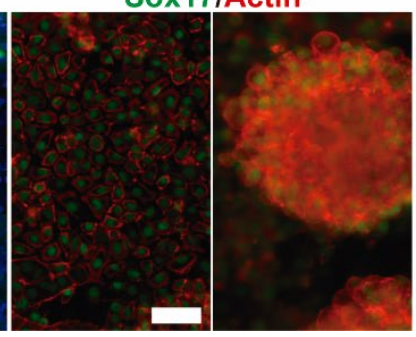

e)

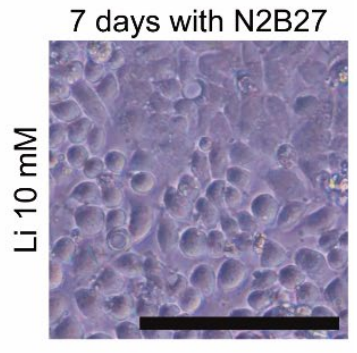

Figure 47. Maturation of hemogenic endothelial cells derived from ESCs treated with $10 \mathrm{mM} \mathrm{Li}^{+}$.

a) Immunofluorescence detection of markers associated to hemogenic endothelium lineage (Sca-1 and CD31) and HSCs (Sox17) in ESCs pre-cultured during 6 days in presence of different concentrations of $\mathrm{Li}^{+}$and then maturated for 5 days in N2B27 (Scale bar: $200 \mu \mathrm{m})$.

b) Bright field image of cell morphology in ESCs pre-cultured in presence of $10 \mathrm{mM} \mathrm{Li}^{+}$ and then maturated with N2B27 for 7 days. In the picture can be observed both endothelial cells like morphology and the formation of rounded cells clusters. 
c) Bright field images of cell morphology after 11 days in N2B27 medium.

d) Immunofluorescence detection of markers associated to hemogenic endothelium lineage (Sca-1 and CD31) and foetal (Sox17) and adult (CD34 and Sca-1) HSCs in ESCs pre-cultured during 6 days in presence $10 \mathrm{mM} \mathrm{Li}^{+}$and then maturated for 11 days in N2B27. White asterisks: rounded cells expressing Sca-1, yellow asterisks: endothelial-like expression of Sca-1. (Scale bars: $50 \mu \mathrm{m}$ ).

e) Analysis of the expression of Sca-1, CD31, and Sox17 during hemogenic endothelium development and maturation into HSCs $(n=5)$.

Graphs show mean \pm standard deviation.

\section{Discussion}

The discovery that the definitive HSCs comes from the specialised region of the endothelium known as hemogenic endothelium allows a much better understanding of the developmental processes of HSCs $(242,243,254)$. With this knowledge, it is possible to design new strategies to synthetize HSCs in vitro from PSCs. Previous advances in this field have demonstrated that $\mathrm{Wnt} / \beta$-catenin signalling pathway plays a key role in PSCs-derived HSCs formation $(239,244)$. In this work we have identified lithium as an element capable of inducing ESCs differentiation to mesoderm lineage, and subsequently to hemogenic endothelium. These results are highly consistent with previous descriptions about the role of GSK3 inhibitors on ESCs differentiation (247). Our results demonstrated that $\mathrm{Li}^{+}$-mediated inhibition of $\mathrm{GSK} 3 \beta$ is strictly concentrationdependent. High concentrations of $\mathrm{Li}^{+}$were more efficient in GSK3 $\beta$ inhibition, whilst lower concentrations lead to reduced phosphorylation levels of GSK3 $\beta$ (Fig. 42 and 43). The activity of GSK3 $\beta$ is an important factor controlling ESCs differentiation (12,255). However, addition of $\mathrm{Li}^{+} 2 \mathrm{mM}$ did not influence selfrenewal capacity of ESCs since the obtained results were similar to those obtained in ESCs cultured with BM (Fig. 41 and 46). These results are supported by prior findings on the fact that just GSK3 $\beta$ inhibition is not enough to sustain ESCs pluripotency (255). In contrast, a strong inhibition of GSK3 $\beta$ using $10 \mathrm{mM}$ $\mathrm{Li}^{+}$, successfully activated Wnt target genes after stabilising $\beta$-catenin protein. Nuclear accumulation of stabilised $\beta$-catenin promotes its interaction with the TCF/LEF family of transcription factors activating the expression of Wnt target genes $(125,234)$. In ESCs, the cascade of events comprising GSK3 $\beta$ inactivation through $\mathrm{Li}^{+}$and the consequent activation of $\beta$-catenin resulted in the expression 
of early mesoderm associated transcription factors Brachyury/T and Cdx2 (Fig. 44). Thus, just the addition of $10 \mathrm{mM} \mathrm{Li}^{+}$was enough to induce mesoderm differentiation in ESCs.

We also demonstrated that the continued exposition of ESCs to a high concentration of $\mathrm{Li}^{+}$during 6 days gave rise to hemogenic endothelium specification. Previous works studying whether $\mathrm{Li}^{+}$drives PSCs differentiation, suggested that high concentrations of $\mathrm{Li}^{+}$inhibited ESCs cardiac cell development and favour neural differentiation (124). Despite these findings, we did not observe neural differentiation using $10 \mathrm{mM} \mathrm{Li}^{+}$. However, the inhibition of cardiac specification occurred due to the continued activation of Wnt signalling. Therefore, to induce the development of cardiac mesoderm, a strong inhibition of Wnt signalling is required after mesoderm commitment (80). We have demonstrated that exposing ESCs to high concentrations of $\mathrm{Li}^{+}$for 6 days induced their differentiation to hemogenic endothelium (Fig. 45 and 46), although our results do not agree with previously published ones on $\mathrm{Li}^{+}$-mediated neurogenesis (124). In contrast, our findings are supported by other publications using GSK3 $\beta$ inhibitors. The activation of Wnt signalling either by Wnt or GSK3 $\beta$ inhibitors have demonstrated to induce hemogenic endothelial differentiation in ESCs $(120,239,247)$. After 6 days, initial ESCs colonies expressed Sca-1, CD31, VE-cadherin and Nkx2-5 (Fig. 45 and 46). These markers are characteristic of endothelium with the potential to develop HSCs $(240,256)$. Even though Nkx2-5 is a master regulator of cardiogenesis, and is extensively used in cardiac lineage cell identification (257), its expression has been also observed in endothelial cells with hemogenic potential (256).

The hemogenic capability of endothelial cells obtained with $10 \mathrm{mM}$ of $\mathrm{Li}^{+}$has been confirmed after maturating these cells (Fig. 47). After 11 days in N2B27 medium, the number of Sca-1 positive HSCs precursors progressively decreased followed by an important increase. At the same time as Sca-1 expressing cells decreased, we observed a progressive increase of rounded cells expressing Sox17. The expression of Sox17 is a feature of foetal HSCs, and acts before the acquisition of the adult phenotype (258). Thus, it is expected that the first HSCs developed form PSCs share many characteristics with foetal HSCs because of their embryonic-like origin (259). The successful development of HSCs from ESCs pre-treated with $10 \mathrm{mM} \mathrm{Li}^{+}$was confirmed after 11 days in N2B27 medium. We observed a large increase of Sox17 expressing cells from the $15 \%$ of the total population after 5 days up to $73 \%$ after 11 days in N2B27 medium (Fig. 47). We 
have found colonies of CD31 and Sca-1 positive endothelial cells remaining under Sox17 expressing cells (Fig. 47). This phenomenon shares some similarities with the one occurring at the ventral wall of the dorsal aorta during embryonic definitive HSCs development (243). In this scenario, hematopoietic cells arise directly from aortic endothelial CD31/Sca-1 positive cells with hemogenic potential. These HSCs form clusters over both kinds of CD31 cells, those with and without hemogenic potential (243).

We showed that $10 \mathrm{mM} \mathrm{Li}{ }^{+}$treated cells give rise to CD31, CD31/Sca-1, and Sca1 positive cells (Fig. 46). However only Sca-1 positive cells possess hemogenic potential (254). This explains why Sca-1 positive cells decreased during HSCs development after 5 days in N2B27 whilst CD31 increased, suggesting that there is a remaining population of CD31 positive cells that are not HSCs precursors. Further, we have observed that after 11 days in N2B27, the expression of Sca-1 reached the maximum value observed along the differentiation experiment. However, we have found different Sca-1 positive cell morphologies. We showed both endothelial-like Sca-1 expressing cells and spherical cells positive for Sca1. The expression of Sca-1 is not only restricted to hemogenic endothelium. This marker is also characteristic of adult stem cells such as adult HSCs (260). In addition, after 11 days in N2B27, we also detected the presence of CD34 positive colonies, which in fact is also a characteristic marker of adult HSCs (261). These, together with the rounded morphology of some Sca-1 positive cells, support the hypothesis of definitive HSCs differentiation and suggest the development of some mature HSCs. 


\section{Discussion}

The control of stem cells fate towards a specific behaviour is a challenge which comprises substantial knowledge about the mechanisms involved in cell regulation and signalling. This goes from understanding the embryonic developmental process of an organism to unravelling the adult stem cell niche and understanding the balance of signals that govern it $(67,85)$. Stem cell research has numerous applications $(7,190,238)$. However, the applicability of this technology requires a deep knowledge of the regulatory mechanisms that lead stem cell fate. Cell-cell communication is mediated by a complex pool of molecules such as growth factors, cytokines, hormones, transmembrane proteins, and extracellular matrix proteins (106). These molecules allow cells to establish a close communication between them, responding co-ordinately to different stimuli. Moreover, cell-cell communication is critical for developmental processes. In this scenario, the factors released by neighbouring cells influence the fate of cells that surround them. This communication is critical for the correct behaviour of multicellular organisms to achieve the appropriate contribution of each single cell of the system $(61,106)$. Failures in cell-cell communication could give rise to diseases or abnormalities, such as developmental disorders or cancer, as a consequence of impaired signalling mechanisms (262-264).

One of the most relevant applications related to the understanding of signalling mechanisms between cells is to develop methods for manipulating adult or embryonic stem cell development. Stem cell communication is critical for embryonic organogenesis, injured tissue regeneration, and stem cell-based 
regenerative medical therapies. During the development process of an organism, the "cross-talk" between cells decides when and where a stem cell must be specified to a certain lineage $(6,10,11)$. In injured tissue, similar signals allow adult stem cells to be recruited from their niches to the damaged region to carry out the healing process $(22,24)$. The aforementioned mechanisms are extremely complex signalling processes and occur in vivo orchestrated by multiple factors. Consequently, reproducing of these signalling processes for in vitro cell fate manipulation becomes really complicated. In this context, some of the most clinically relevant molecules used for cell signalling are growth factors (265). These are molecules released by cells to their surroundings, used for cell-cell interaction (266). Immediately after binding with their receptors, these molecules trigger an intracellular signalling cascade producing significant changes in terms of post-translational modification or activation/repression of certain gene expression $(266,267)$. Due to their short life in the organisms, growth factors usually operate at short distances, giving rise to autocrine or paracrine signalling (266). It has been demonstrated that growth factors are involved in many processes, such as cell proliferation, metabolism, differentiation, and migration $(266,268)$. This multifunctional effect of growth factors makes them versatile tools for many in vitro applications to increase cell proliferation, manipulate cell fate, or induce/avoid the differentiation of stem cells $(265,268)$. The understanding of the role of the growth factors in biological process such as cell differentiation or migration has opened new strategies to use them for tissue regeneration, enhancing the healing process. This approach was used for the regeneration of tissues like bone and muscle with BMP2 or IGF respectively $(267,268)$. However, the in vivo expression of growth factors takes place in a very localised manner at well-defined concentrations $(267,269)$. Therefore, some effects observed in vitro are not appreciable in vivo (270-272). To overcome this obstacle, some strategies use growth factors at high doses (supraphysiological doses) to achieve the desired effect in vivo. Nevertheless, it is important to keep in mind that these molecules are a two-edged sword. In a sane, normal tissue, growth factors work as intermediary molecules for cell-cell interactions. However, some anomalies or diseases such as cancer use these molecules to modify the architecture and function of normal tissue $(273,274)$. Cancer cells release growth factors for autocrine signalling to self-stimulate, achieving a clonal expansion and subsequent tumour progression $(266,275)$. Some of the most studied released factors that can affect normal tissue architecture are VEGF, FGFs, and TGFs (275). These growth factors are involved in the generation on new blood vessels, 
which is critical for tumour progression $(79,266,275)$. Moreover, the family of TGF proteins are also involved in the mesenchymal-epithelial transition, a phenomenon that modifies the compact and organised structure of the epithelium into motile individual cells enabling tumour metastasis (275). Nevertheless, besides before mentioned questions, it should be noted that the half-life of growth factors is really short (274). This fact, combined with the high cost of protein purification processes, is an important drawback for their clinical use. To avoid these problems, many researchers have focused their attention on the so-called "small molecules" to achieve the same effect without using growth factors (29). Considering that, the effect of a growth factor on cells is defined by the subsequent intracellular transduction of the specific signals (71); the activation of these intracellular intermediaries makes it possible to achieve a similar result without growth factors. Following this approach, during the development of this doctoral thesis, we have focused our attention on the use of metallic ions to drive stem cell fate. Some of the main advantages of these molecules are their low cost and high stability. They do not need to be frozen or used with organic solvents like DMSO to keep them protected from hydrolysis. These molecules can be maintained in a dry environment and their half-life and purity are both remarkable.

One of the most important signalling pathways studied in this work was the PI3K/Akt cascade. This signalling pathway is critical for many biological processes such as cell survival, proliferation, correct skeletal muscle differentiation, and sustained ESCs pluripotency. Several growth factors and hormones can induce Akt phosphorylation. Among these we can find FGFs, IGF1/2 or insulin $(71,72,276,277)$. As we have shown in this work, metallic ions such as zinc are perfectly able to mimic the growth factor mediated activation of PI3K/Akt cascade. We obtained results similar to those described in the literature for muscle progenitors and ESCs self-renewal (chapters I and II). However, it should be noted that the general working way of growth factors or hormones is to activate the signalling pathways subsequently to binding to their extracellular receptors $(278,279)$. In the case of ions such as zinc, as has been previously reported and observed in this work, an extracellular receptor is not necessary for the zinc-mediated activation of PI3K/Akt signalling $(95,115)$. This difference is an advantage when it comes to cells that do not express some extracellular growth factor receptors, making it possible to activate specific protein kinases despite lacking an extracellular receptor. 
Moreover, the comparison between growth factor- and ion-mediated activation of signalling cascades is not restricted only to the presence of extracellular receptors. As was mentioned above, the use of growth factors entails many risks about which FDA has warned many times, especially in terms of cancer development. Both IGF and zinc are able to activate the PI3K/Akt cascade. However, IGF is closely associated with the progression of several types of cancer $(280,281)$, while the role of zinc in cancer development, despite it also activating the PI3K/Akt cascade, is the opposite. There are many types of cancer whose progression is associated to an important decline in intracellular concentration of zinc $(95,111,282)$. This phenomenon is related to the mechanisms developed by cancer cells to escape from apoptosis mediated by zinc (282). Moreover, some authors have also suggested that zinc intake can prevent the progression of prostatic malignancy (111). This evidence contrasts significantly with the effect of growth factors, making ions such as zinc more suitable for strategies based on the release of bioactive molecules for regenerative medicine. As we have shown in this work (chapter I), the addition of extracellular zinc has an appreciable effect on mouse myoblast differentiation and hypertrophy. This dual role of zinc combined with its non-tumorigenic properties make it a very interesting tool for muscle regeneration strategies.

Furthermore, we used in this work both zinc and lithium to drive PSCs fate (chapter II and III). As has been introduced, PSCs are able to develop every cell type of an adult organism, which is extremely useful for several applications (54). However, their clinical use is closely linked to the elevated costs of the reagents and equipment used for their handling (283). In order to maintain PSCs in culture while avoiding their spontaneous differentiation, it is necessary to keep them in specific conditions $(185,202,284)$. The most widely used method is to culture PCSs over an inactivated feeder layer of mouse embryonic fibroblasts (184). However, in clinical application, the use of reagents or cells from animal sources is not possible. Moreover, even for non-clinical applications, isolation of the feeder layer is often necessary (283). This problematic makes it necessary to develop feeder-free methods to keep PSCs undifferentiated. Depending on the species, pluripotency sustaining mechanisms can be different. For rodent PSCs, which are in a more primitive stage of pluripotency, leukaemia inhibitory factor (LIF) is very effective to sustain pluripotency (15). However, for human PSCs, which share more features with mouse epiblast stem cells (EpiSCs, also pluripotent) than with mouse PSCs, some of the established methods to sustain pluripotency require the combination of FGF2, activin A, and IGF (194). 
Nevertheless, production and purification of these molecules are not economical. Considering that one of the key regulators of pluripotency in mouse PSCs, EpiSCs, and human PSCs is the protein kinase Akt (chapter II) (75), the use of zinc could be an interesting and cost-effective alternative to sustain PSCS selfrenewal in feeder-free conditions.

On the other hand, the relevance of PSCs lies in their multilineage differentiation capability $(20,85,251,285)$. In absence of the appropriate stimuli, these cells trend to spontaneously differentiate into the three primary germ layers of the early embryo (ectoderm, endoderm, and mesoderm) $(193,286)$. However, from the perspective of their application, random spontaneous differentiation is a problem. The challenge of PSCs is how to direct their differentiation towards a specific lineage, being able to both develop lineage-specific progenitors or adult specialised cells with the minimum presence of unwanted cells (49). There are many strategies for the directed differentiation of PSCs. However, almost all of them use one or more cytokines, growth factors, or small molecules. In this work we have demonstrated that just lithium addition is enough to successfully induce ESCs differentiation into mesoderm lineage, and subsequently to hemogenic endothelial cells (chapter III). Even though we have characterised endothelial cells with hemogenic potential through detection of Sca-1 marker, a protein that does not exists in humans, the signalling pathway that induces HSCs progenitor development is intrinsically conserved $(239,244,247)$. This indicates that the role of lithium on murine ESCs differentiation could also be conserved in human PSCs, constituting a worthy alternative to other mentioned approaches.

Even though in this work we have obtained promising results, any kind on new result or therapy need to be carefully tested before its implementation. In this case, the use of ions as signalling elements is gaining more and more importance. However, should be noted that ions are very small elements and to predict all of their targets is a difficult challenge. It is therefore important to test properly all these findings before of their application for regenerative medicine. In terms of the use of zinc for muscle tissue regeneration, probably the main caution is about neural cells sensitivity to low concentrations of zinc. Even though this should be addressed in future in vivo experimentation, it is noteworthy that the range of concentrations used for our experiments was always lower than the toxic concentrations described in the literature for neural cells $(166,168)$. Regarding to the use of zinc for ESCs self-renewal, as this approach is exclusively for in vitro culture of ESCs, does not make sense to consider side effects on different cell 
types. However, as can be found in the literature and we have demonstrated, PSCs population display an important heterogeneity. It would be interesting to investigate the implication of zinc in epigenetic modification and how the culture media used to maintain PSCs self-renewal can affect to PSCs fate decision and potential for regenerative medicine. In the case of lithium, as well as the use of zinc to keep PSCs undifferentiated, this approach is focused on in vitro development of HSCs. However, the arising Sox17 positive cells must be tested through in vivo experiments in order to see if they are able to self-integrate in the host and develop functional hematopoietic cells or would be necessary a previous step of maturation before the implantation.

During the development of this Doctoral Thesis, we have described zinc and lithium as powerful tools for cell signalling. These molecules are able to successfully trigger signal transduction to achieve myoblast differentiation and ESCs zinc-mediated self-renewal, or inducing lithium-mediated ESCs hemogenic endothelial differentiation. 


\section{Conclusions}

After the experimental evidences shown along this work concerning to the role of zinc on murine myoblasts and ESCs as well as the role of lithium on ESCs, we can highlight the following conclusions:

Chapter I:

1. Addition of high concentrations of zinc $(20$ and $40 \mu \mathrm{M})$ to myoblasts triggers a remarkable increase of intracellular zinc promoting the phosphorylation and activation of the protein kinase Akt.

2. Zinc-mediated activation of Akt requires the presence of zinc transporter Zip7, which is also needed to regulate intracellular zinc levels as a consequence of increased extracellular zinc stimulation.

3. Myotubes developed after myoblast differentiation possess higher levels of expression of zinc transporter Zip7 and accumulate higher levels of intracellular zinc than undifferentiated myoblasts.

4. Zinc-mediated activation of protein kinase Akt enhances myogenic differentiation in murine myoblasts.

5. Zinc transporter Zip7 is needed for zinc-mediated differentiation and development of myotubes in murine myoblasts.

Chapter II:

6. Addition of high extracellular concentrations of zinc in the culture medium produce a "wave like" increase of intracellular zinc. 
7. High extracellular concentrations of zinc $(100 \mu \mathrm{M})$ promote ESCs selfrenewal, with higher expression of pluripotency markers and lower expression of differentiation markers.

8. Zinc-mediated maintenance of ESCs pluripotency occurs through Zip7mediated activation of protein kinase Akt.

9. ESCs cultured during 30 days in the presence of zinc retained their multilineage differentiation capacity, spontaneously developing endoderm, mesoderm and ectoderm in the embryoid body assay.

10. Sustained addition of zinc maintains ESCs in a reversible stage of pluripotency known as primed for differentiation, were ESCs are reversibly committed to a primary germ layer lineage.

11. The combination of LIF and zinc resulted in a synergic-like increase of LIF activity, strongly inhibiting ESC differentiation.

Chapter III:

12. Concentrations of lithium above $10 \mathrm{mM}$ produce a high toxicity on ESCs, whereas concentrations comprised between 5 and $10 \mathrm{mM}$ affect cell proliferation.

13. Lithium is able to induce phosphorylation and inactivation of the protein kinase GSK3 $\beta$ in a concentration-dependent manner. However, only GSK3 $\beta$ inhibition does not affect ESCs self-renewal.

14. ESCs treated with $10 \mathrm{mM}$ lithium induced accumulation of $\beta$-catenin into the nuclei activating Wnt responsive genes and triggering ESCs differentiation to mesoderm.

15. ESCs treated with $10 \mathrm{mM}$ lithium for 6 days expressed markers associated to endothelial cells with hemogenic potential.

16. HSCs progenitors developed from ESCs treated with $10 \mathrm{mM}$ lithium were successfully maturated into Sox 17 expressing HSCs. 


\section{Contributions}

The work realised along this doctoral thesis has resulted in a large number of results. These results were diffused through several publications in scientific journals and international conferences listed following.

Publications in scientific journals:

1. HAYK MNATSAKANYAN; Roser Sabater i Serra; Patricia Rico; Manuel Salmerón Sánchez. Zinc uptake promotes myoblast differentiation via Zip7 transporter and activation of Akt signalling transduction pathway. Scientific Reports. 8, pp. 1 - 14. 2018. ISSN 2045-2322. DOI: 10.1038/s41598-01832067-0.

2. Patricia Rico; HAYK MNATSAKANYAN; Matthew J. Dalby; Manuel Salmerón Sánchez. Material-Driven Fibronectin Assembly Promotes Maintenance of Mesenchymal Stem Cell Phenotypes. Advanced Functional Materials. 26, pp. 6563 - 6573. 2016. ISSN 1616-301X. DOI: 10.1002/adfm.201602333.

3. HAYK MNATSAKANYAN; Patricia Rico; Eleni Grigoriou; Aaron Maturana Candelas; Aleixandre Rodrigo Navarro; Manuel Salmerón Sánchez; Roser Sabater i Serra. Controlled Assembly of Fibronectin Nanofibrils Triggered by Random Copolymer Chemistry. ACS Applied Materials \& Interfaces. 7, pp. 18125 - 18135. 2015. ISSN 1944-8244. DOI: 10.1021/acsami.5b05466.

4. HAYK Mnatsakanyan; Roser Sabater i Serra; Manuel Salmerón-Sánchez; Patricia Rico. Zinc maintains embryonic stem cell pluripotency and multilineage differentiation potential via Akt activation. Stem Cell Reports. Submitted. 2019. 
International conferences:

1. Title of the work: Zinc maintains ESC stemness through Zip7 activation via Akt pathway

Name of the conference: 29th European Conference on Biomaterials (ESB 2018)

City of event: Maastricht, the Netherlands,

Date of event: 13/09/2018

HAYK MNATSAKANYAN; Roser Sabater i Serra; Manuel Salmerón Sánchez; Patricia Rico.

pp. 0-0.

2. Title of the work: Myogenic differentiation triggered by zinc ions

Name of the conference: 5th TERMIS World Congress

City of event: Kyoto, Japan,

Date of event: 07/09/2018

HAYK MNATSAKANYAN; Roser Sabater i Serra; Patricia Rico; Manuel Salmerón Sánchez.

pp. 439-439.

3. Title of the work: $\mathrm{NaBC} 1$ cooperates with $\mathrm{FN}$-binding integrins for intracellular signalling activation

Name of the conference: Biointerfaces International 2018 Conference

City of event: Zurich, Switzerland,

Date of event: 16/08/2018

Patricia Rico; Aleixandre Rodrigo Navarro; HAYK MNATSAKANYAN; Mercedes Costell; Manuel Salmerón Sánchez.

pp. 0-0. 
4. Title of the work: Material-driven Fibronectin nanonetworks promote maintenance of mesenchymal stem cell phenotypes

Name of the conference: 43th Annual European Society for Artificial Organs Congress (ESAO 2016)

City of event: Warsaw, Poland,

Date of event: 17/09/2016

Patricia Rico; HAYK MNATSAKANYAN; Manuel Salmerón Sánchez. "International Journal of Artificial Organs. 2016, VOL:39, ISUE: 7". pp. 330331.

5. Title of the work: Role of zinc in myogenic differentiation

Name of the conference: 43th Annual European Society for Artificial Organs Congress (ESAO 2016)

City of event: Warsaw, Poland,

Date of event: 17/09/2016

HAYK MNATSAKANYAN; Patricia Rico; Roser Sabater i Serra; Manuel Salmerón Sánchez.

"International Journal of Artificial Organs. 2016, VOL:39, ISUE: 7".

pp. 372-372.

6. Title of the work: Role of zinc in the differentiation of stem cells

Name of the conference: World Conference on Regenerative Medicine 2015

City of event: Leipzig, Germany,

Date of event: 23/10/2015

HAYK MNATSAKANYAN; Patricia Rico; Vladimira Moulisova; Roser Sabater i Serra; Manuel Salmerón Sánchez.

pp. 181-181. 
7. Title of the work: Material-driven fibronectin networks: modulating the degree of fibrillogenesis

Name of the conference: 26th Annual Conference of the European Society for Biomaterials (ESB 2014)

City of event: Liverpool, UK,

Date of event: 03/09/2014

HAYK MNATSAKANYAN; Aaron Maturana Candelas; Aleixandre Rodrigo Navarro; Patricia Rico; José Antonio Gómez Tejedor; Manuel Salmerón Sánchez; Roser Sabater i Serra.

pp. 706-706.

8. Title of the work: Role of Fibronectin assembly in Mesenchymal Stem Cell differentiation

Name of the conference: 26th Annual Conference of the European Society for Biomaterials (ESB 2014)

City of event: Liverpool, UK,

Date of event: 03/09/2014

Patricia Rico; HAYK MNATSAKANYAN; Manuel Salmerón Sánchez. pp. 0-0. 


\section{References}

1. Cleland CE, Chyba CF. Defining 'life.' 2002;387-93.

2. Nelson DL, Cox MM. Lehninger Principles of Biochemistry. Lehninger. $2004 ; 1120$.

3. O'Connor C, Adams JU. Essentials of Cell Biology. NPG Education. 2010. 7-9 p.

4. Cooper GM, Hausman RE. The Cell: A Molecular Approach 2nd Edition. Sinauer Associates. 2000. p. 1-820.

5. B Alberts Johnson, A, Lewis J, Raff M, Roberts K WP. Molecular Biology of the Cell 4th Edition. Moecular Biol cell. 2002;

6. Gilbert SF. Developmental Biology. 6th edition. In: The Epidermis and the Origin of Cutaneous Structures. 2000.

7. Yamanaka S. Induced pluripotent stem cells: Past, present, and future. Cell Stem Cell [Internet]. 2012;10(6):678-84. Available from: http://dx.doi.org/10.1016/j.stem.2012.05.005

8. Adams GB, Chabner KT, Alley IR, Olson DP, Szczepiorkowski ZM, Poznansky MC, et al. Stem cell engraftment at the endosteal niche is specified by the calcium-sensing receptor. Nature. 2006;439(7076):599_ 603.

9. Lee MSY, Beck RMD. Mammalian Evolution: A Jurassic Spark. Curr Biol [Internet]. 2015;25(17):R759-61. Available from: http://dx.doi.org/10.1016/j.cub.2015.07.008

10. Wang H, Dey SK. Roadmap to embryo implantation: Clues from mouse models. Nat Rev Genet. 2006;7(3):185-99.

11. Rossant J, Tam PPL. Blastocyst lineage formation, early embryonic asymmetries and axis patterning in the mouse. Development [Internet]. 2009;136(5):701-13. Available from:

http://dev.biologists.org/cgi/doi/10.1242/dev.017178

12. Chen $\mathrm{Y}$, Blair $\mathrm{K}$, Smith $\mathrm{A}$. Robust self-renewal of rat embryonic stem cells requires fine-tuning of glycogen synthase kinase-3 inhibition. Stem Cell Reports [Internet]. 2013;1(3):209-17. Available from: http://dx.doi.org/10.1016/j.stemcr.2013.07.003

13. Granger DN, Kvietys PR. Reperfusion injury and reactive oxygen species: The evolution of a concept. Redox Biol [Internet]. 2015;6:52451. Available from: http://dx.doi.org/10.1016/j.redox.2015.08.020

14. Yu J, Thomson J a. Pluripotent stem cell lines. Genes Dev [Internet]. 
2008 Aug 1 [cited 2014 Jun 5];22(15):1987-97. Available from:

http://www.pubmedcentral.nih.gov/articlerender.fcgi?artid=2735345\&tool $=$ pmcentrez\&rendertype $=$ abstract

15. Weinberger L, Ayyash M, Novershtern N, Hanna JH. Dynamic stem cell states: naive to primed pluripotency in rodents and humans. Nat Rev Mol Cell Biol [Internet]. 2016;17(3):030676. Available from: http://biorxiv.org/content/early/2015/11/06/030676.abstract

16. Clevers H. Modeling Development and Disease with Organoids. Cell [Internet]. 2016;165(7):1586-97. Available from:

http://dx.doi.org/10.1016/j.cell.2016.05.082

17. Hsu Y-C, Fuchs E. A family business: stem cell progeny join the niche to regulate homeostasis. Nat Rev Mol Cell Biol [Internet]. 2012 Feb 1;13(2):103-14. Available from: http://dx.doi.org/10.1038/nrm3272

18. Jones DL, Wagers AJ. No place like home: anatomy and function of the stem cell niche. Nat Rev Mol Cell Biol [Internet]. 2008 Jan [cited 2014 Mar 21];9(1):11-21. Available from:

http://www.ncbi.nlm.nih.gov/pubmed/18097443

19. Lin $\mathrm{H}$. The stem-cell niche theory: lessons from flies. Nat Rev Genet [Internet]. 2002 Dec [cited 2014 May 31];3(12):931-40. Available from: http://www.ncbi.nlm.nih.gov/pubmed/12459723

20. Clarke D, Frisén J. Differentiation potential of adult stem cells. Curr Opin Genet Dev [Internet]. 2001 Oct;11(5):575-80. Available from: http://linkinghub.elsevier.com/retrieve/pii/S0959437X00002355

21. Alvarado AS, Tsonis PA. Bridging the regeneration gap: genetic insights from diverse animal models. Nat Rev Genet [Internet]. 2006 Nov;7(11):873-84. Available from: http://www.nature.com/articles/nrg1923

22. Poss KD. Advances in understanding tissue regenerative capacity and mechanisms in animals. Nat Rev Genet [Internet]. 2010;11(10):710-22. Available from: http://dx.doi.org/10.1038/nrg2879

23. Bergmann A, Steller H. Apoptosis, stem cells, and tissue regeneration. Sci Signal. 2010;3(145).

24. Forbes SJ, Rosenthal N. Preparing the ground for tissue regeneration: From mechanism to therapy. Nat Med [Internet]. 2014;20(8):857-69. Available from: http://dx.doi.org/10.1038/nm.3653

25. Galliot B, Crescenzi M, Jacinto A, Tajbakhsh S. Trends in tissue repair and regeneration. Development [Internet]. 2017;144(3):357-64.

Available from: http://dev.biologists.org/lookup/doi/10.1242/dev.144279

26. Schieber M, Chandel NS. ROS function in redox signaling and oxidative stress. Curr Biol [Internet]. 2014;24(10):R453-62. Available from: http://dx.doi.org/10.1016/j.cub.2014.03.034 
27. Gieseck RL, Wilson MS, Wynn TA. Type 2 immunity in tissue repair and fibrosis. Nat Rev Immunol [Internet]. 2018;18(1):62-76. Available from: http://dx.doi.org/10.1038/nri.2017.90

28. Julier Z, Park AJ, Briquez PS, Martino MM. Promoting tissue regeneration by modulating the immune system. Acta Biomater [Internet]. 2017;53:13-28. Available from:

http://dx.doi.org/10.1016/j.actbio.2017.01.056

29. Christ GJ, Saul JM, Furth ME, Andersson K-E. The Pharmacology of Regenerative Medicine. Pharmacol Rev [Internet]. 2013;65(3):1091133. Available from:

http://pharmrev.aspetjournals.org/cgi/doi/10.1124/pr.112.007393

30. Mao AS, Mooney DJ. Regenerative medicine: Current therapies and future directions. Proc Natl Acad Sci [Internet]. 2015;112(47):14452-9.

Available from:

http://www.pnas.org/lookup/doi/10.1073/pnas.1508520112

31. Tabar V, Studer L. Pluripotent stem cells in regenerative medicine: challenges and recent progress. Nat Rev Genet [Internet]. 2014 Feb [cited 2014 Jul 12];15(2):82-92. Available from: http://www.ncbi.nlm.nih.gov/pubmed/24434846

32. Khademhosseini A, Langer R. A decade of progress in tissue engineering. Nat Protoc. 2016;11(10):1775-81.

33. Bianco P, Robey PG. Stem cells in tissue engineering. Nature. 2001;414(6859):118-21.

34. Yin H, Price F, Rudnicki M a. Satellite cells and the muscle stem cell niche. Physiol Rev [Internet]. 2013;93(1):23-67. Available from: http://www.ncbi.nlm.nih.gov/pubmed/23303905

35. Matsuura K, Nagai T, Nishigaki N, Oyama T, Nishi J, Wada H, et al. Adult Cardiac Sca-1-positive Cells Differentiate into Beating Cardiomyocytes. J Biol Chem. 2004;279(12):11384-91.

36. Abkowitz JL, Catlin SN, Mccallie MT, Guttorp P. Evidence that the number of hematopoietic stem cells per animal is conserved in mammals Brief report Evidence that the number of hematopoietic stem cells per animal is conserved in mammals. October [Internet]. 2009;100(7):2665-7. Available from: http://www.bloodjournal.org/content/100/7/2665.abstract

37. Izadpanah R, Joswig T, Tsien F, Dufour J, Kirijan JC, Bunnell BA. Characterization of Multipotent Mesenchymal Stem Cells from the Bone Marrow of Rhesus Macaques. Stem Cells Dev. 2005;14(4):440-51.

38. Dixit $P$, Katare R. Challenges in identifying the best source of stem cells for cardiac regeneration therapy. Stem Cell Res Ther. 2015;6(1):1-12.

39. Tweedell KS. The adaptability of somatic stem cells: a review. J Stem 
Cells Regen Med [Internet]. 2017;13(1):3-13. Available from: http://www.ncbi.nlm.nih.gov/pubmed/28684892\%0Ahttp://www.pubmedc entral.nih.gov/articlerender.fcgi?artid=PMC5494437

40. Yang Y-HK, Ogando CR, Wang See C, Chang T-Y, Barabino GA. Changes in phenotype and differentiation potential of human mesenchymal stem cells aging in vitro. Stem Cell Res Ther [Internet]. 2018;9(1):131. Available from: https://stemcellres.biomedcentral.com/articles/10.1186/s13287-0180876-3

41. Fleischhauer K, Locatelli F, Zecca M, Orofino MG, Giardini C, De Stefano $\mathrm{P}$, et al. Graft rejection after unrelated donor hematopoietic stem cell transplantation for thalassemia is associated with nonpermissive HLA-DPB1 disparity in host-versus-graft direction. Blood. 2006;107(7):2984-92.

42. Chen S, Lewallen M, Xie T. Adhesion in the stem cell niche: biological roles and regulation. Development [Internet]. 2013;140(2):255-65. Available from: http://dev.biologists.org/cgi/doi/10.1242/dev.083139

43. Tateishi K, Ashihara E, Takehara N, Nomura T, Honsho S, Nakagami T, et al. Clonally amplified cardiac stem cells are regulated by Sca-1 signaling for efficient cardiovascular regeneration. J Cell Sci [Internet]. 2007;120(10):1791-800. Available from:

http://jcs.biologists.org/cgi/doi/10.1242/jcs.006122

44. Muller-Sieburg CE, Sieburg HB, Bernitz JM, Cattarossi G. Stem cell heterogeneity: Implications for aging and regenerative medicine. Blood. 2012;119(17):3900-7.

45. Krieger T, Simons BD. Dynamic stem cell heterogeneity. Development [Internet]. 2015;142(8):1396-406. Available from: http://dev.biologists.org/cgi/doi/10.1242/dev.101063

46. Robinton DA a., Daley GQ. The promise of induced pluripotent stem cells in research and therapy. Nature [Internet]. 2012 Jan 19 [cited 2013 Dec 12];481(7381):295-305. Available from:

http://www.pubmedcentral.nih.gov/articlerender.fcgi?artid=3652331\&tool $=$ pmcentrez\&rendertype=abstract

47. Shu J, Wu C, Wu Y, Li Z, Shao S, Zhao W, et al. Induction of pluripotency in mouse somatic cells with lineage specifiers. Cell [Internet]. 2013 May 23 [cited 2013 Dec 14];153(5):963-75. Available from: http://www.ncbi.nlm.nih.gov/pubmed/23706735

48. Takahashi K, Yamanaka S. Induction of Pluripotent Stem Cells from Mouse Embryonic and Adult Fibroblast Cultures by Defined Factors. Cell. 2006;126(4):663-76.

49. Miyoshi N, Ishii H, Nagano H, Haraguchi N, Dewi DL, Kano Y, et al. Reprogramming of Mouse and Human Cells to Pluripotency Using 
Mature MicroRNAs. Stem Cell [Internet]. 2011;8(6):633-8. Available from: http://dx.doi.org/10.1016/j.stem.2011.05.001

50. González F, Boué S, Izpisúa Belmonte JC. Methods for making induced pluripotent stem cells: reprogramming à la carte. Nat Rev Genet [Internet]. 2011 Apr [cited 2013 Dec 11];12(4):231-42. Available from: http://www.ncbi.nlm.nih.gov/pubmed/21339765

51. Goh PA, Caxaria S, Casper C, Rosales C, Warner TT, Coffey PJ, et al. A systematic evaluation of integration free reprogramming methods for deriving clinically relevant patient specific induced pluripotent stem (iPS) cells. PLoS One. 2013;8(11):1-12.

52. Okita K, Yamanaka S. Induced pluripotent stem cells: Opportunities and challenges. Philos Trans R Soc B Biol Sci. 2011;366(1575):2198-207.

53. Dutta D, Heo I, Clevers H. Disease Modeling in Stem Cell-Derived 3D Organoid Systems. Trends Mol Med [Internet]. 2017;23(5):393-410. Available from: http://dx.doi.org/10.1016/j.molmed.2017.02.007

54. Martin U. Therapeutic Application of Pluripotent Stem Cells: Challenges and Risks. Front Med [Internet]. 2017;4(December). Available from: http://journal.frontiersin.org/article/10.3389/fmed.2017.00229/full

55. Ilic D, Devito L, Miere C, Codognotto S. Human embryonic and induced pluripotent stem cells in clinical trials: Table 1. Br Med Bull [Internet]. 2015 Nov 17;(November):Idv045. Available from:

https://academic.oup.com/bmb/article-lookup/doi/10.1093/bmb/ldv045

56. Shi Y, Inoue H, Wu JC, Yamanaka S. Induced pluripotent stem cell technology: A decade of progress. Nat Rev Drug Discov [Internet]. 2017;16(2):115-30. Available from:

http://dx.doi.org/10.1038/nrd.2016.245

57. Chin MH, Mason MJ, Xie W, Volinia S, Singer M, Peterson C, et al. Induced Pluripotent Stem Cells and Embryonic Stem Cells Are Distinguished by Gene Expression Signatures. Cell Stem Cell [Internet]. 2009;5(1):111-23. Available from:

http://dx.doi.org/10.1016/j.stem.2009.06.008

58. Bilic J, Izpisua Belmonte JC. Concise review: Induced pluripotent stem cells versus embryonic stem cells: Close enough or yet too far apart? Stem Cells. 2012;30(1):33-41.

59. Bigarella CL, Liang R, Ghaffari S. Stem cells and the impact of ROS signaling. Development [Internet]. 2014;141(22):4206-18. Available from: http://dev.biologists.org/cgi/doi/10.1242/dev.107086

60. Vining $\mathrm{KH}$, Mooney DJ. Mechanical forces direct stem cell behaviour in development and regeneration. Nat Rev Mol Cell Biol [Internet]. 2017;18(12):728-42. Available from:

http://dx.doi.org/10.1038/nrm.2017.108 
61. Geiger B, Spatz JP, Bershadsky AD. Environmental sensing through focal adhesions. Nat Rev Mol Cell Biol [Internet]. 2009 Jan [cited 2014 Jul 10];10(1):21-33. Available from:

http://www.ncbi.nlm.nih.gov/pubmed/19197329

62. Lanner $F$, Rossant J. The role of FGF/Erk signaling in pluripotent cells. Development [Internet]. 2010;137(20):3351-60. Available from: http://dev.biologists.org/cgi/doi/10.1242/dev.050146

63. Kunath T, Saba-El-Leil MK, Almousailleakh M, Wray J, Meloche S, Smith A. FGF stimulation of the Erk1/2 signalling cascade triggers transition of pluripotent embryonic stem cells from self-renewal to lineage commitment. Development. 2007;134(16):2895-902.

64. Xu Z, Robitaille AM, Berndt JD, Davidson KC, Fischer KA, Mathieu J, et al. Wnt/ $\beta$-catenin signaling promotes self-renewal and inhibits the primed state transition in naïve human embryonic stem cells. Proc Natl Acad Sci [Internet]. 2016;113(42):E6382-90. Available from:

http://www.pnas.org/lookup/doi/10.1073/pnas.1613849113

65. Li L, Bennett SAL, Wang L. Role of E-cadherin and other cell adhesion molecules in survival and differentiation of human pluripotent stem cells. Cell Adh Migr [Internet]. 2012;6(1):59-70. Available from: http://www.tandfonline.com/doi/abs/10.4161/cam.19583

66. Scadden DT. The stem-cell niche as an entity of action. Nature [Internet]. 2006 Jun 29 [cited 2014 May 26];441(7097):1075-9. Available from: http://www.ncbi.nlm.nih.gov/pubmed/16810242

67. Kretzschmar K, Clevers H. Organoids: Modeling Development and the Stem Cell Niche in a Dish. Dev Cell [Internet]. 2016;38(6):590-600. Available from: http://dx.doi.org/10.1016/j.devcel.2016.08.014

68. Cheung TH, Rando TA. Molecular regulation of stem cell quiescence. Nat Rev Mol Cell Biol [Internet]. 2013;14(6):329-40. Available from: http://www.ncbi.nlm.nih.gov/pubmed/23698583\%0Ahttp://www.pubmedc entral.nih.gov/articlerender.fcgi?artid=PMC3808888

69. Li L, Bhatia R. Stem cell quiescence. Clin Cancer Res. 2011;17(15):4936-41.

70. Johnson-Farley NN, Patel K, Kim D, Cowen DS. Interaction of FGF-2 with IGF-1 and BDNF in stimulating Akt, ERK, and neuronal survival in hippocampal cultures. Brain Res. 2007;1154(1):40-9.

71. Franke TF. PI3K/Akt: Getting it right matters. Oncogene. 2008;27(50):6473-88.

72. Chen YG, Li Z, Wang XF. Where PI3K/Akt meets smads: The crosstalk determines human embryonic stem cell fate. Cell Stem Cell [Internet]. 2012;10(3):231-2. Available from:

http://dx.doi.org/10.1016/j.stem.2012.02.008 
73. Bechard M, Dalton S. Subcellular Localization of Glycogen Synthase Kinase 3 Controls Embryonic Stem Cell Self-Renewal. Mol Cell Biol [Internet]. 2009;29(8):2092-104. Available from:

http://mcb.asm.org/cgi/doi/10.1128/MCB.01405-08

74. Armstrong L, Hughes O, Yung S, Hyslop L, Stewart R, Wappler I, et al. The role of PI3K/AKT, MAPK/ERK and NFK $\beta$ signalling in the maintenance of human embryonic stem cell pluripotency and viability highlighted by transcriptional profiling and functional analysis. Hum Mol Genet. 2006;15(11):1894-913.

75. Yu JSL, Cui W. Proliferation, survival and metabolism: the role of $\mathrm{PI} 3 \mathrm{~K} / \mathrm{AKT} / \mathrm{mTOR}$ signalling in pluripotency and cell fate determination. Development [Internet]. 2016;143(17):3050-60. Available from: http://dev.biologists.org/lookup/doi/10.1242/dev.137075

76. Crane JL, Zhao L, Frye JS, Xian L, Qiu T, Cao X. IGF-1 Signaling is Essential for Differentiation of Mesenchymal Stem Cells for Peak Bone Mass. Bone Res [Internet]. 2013;1(2):186-94. Available from: http://www.nature.com/articles/boneres201314

77. Engert J, Berglund E, Rosenthal N. Proliferation Precedes Differentiation in IGF-I stimulated Myogenesis. J Cell Biol. 1996;135(2):431-40.

78. Schiaffino S, Mammucari C. Regulation of skeletal muscle growth by the IGF1-Akt/PKB pathway: insights from genetic models. Skelet Muscle [Internet]. 2011;1(1):1-14. Available from:

http://www.ncbi.nlm.nih.gov/pubmed/21798082\%5Cnhttp://www.pubmed central.nih.gov/articlerender.fcgi?artid=PMC3143906

79. Wagner EF, Nebreda ÁR. Signal integration by JNK and p38 MAPK pathways in cancer development. Nat Rev Cancer [Internet]. 2009;9(8):537-49. Available from: http://dx.doi.org/10.1038/nrc2694

80. Lian X, Hsiao C, Wilson G, Zhu K, Hazeltine LB, Azarin SM, et al. Robust cardiomyocyte differentiation from human pluripotent stem cells via temporal modulation of canonical Wnt signaling. Proc Natl Acad Sci [Internet]. 2012 Jul 3;109(27):E1848-57. Available from: http://www.pnas.org/cgi/doi/10.1073/pnas.1200250109

81. Wray J, Kalkan T, Gomez-Lopez S, Eckardt D, Cook A, Kemler R, et al. Inhibition of glycogen synthase kinase-3 alleviates Tcf3 repression of the pluripotency network and increases embryonic stem cell resistance to differentiation. Nat Cell Biol [Internet]. 2011 Jul [cited 2014 Sep 28];13(7):838-45. Available from:

http://www.pubmedcentral.nih.gov/articlerender.fcgi?artid=3160487\&tool =pmcentrez\&rendertype=abstract

82. Guilak F, Cohen DM, Estes BT, Gimble JM, Liedtke W, Chen CS. Control of stem cell fate by physical interactions with the extracellular matrix. Cell Stem Cell [Internet]. 2009 Jul 2 [cited 2014 Jul 10];5(1):1726. Available from: 
http://www.pubmedcentral.nih.gov/articlerender.fcgi?artid=2768283\&tool $=$ pmcentrez\&rendertype $=$ abstract

83. Blanpain C, Simons BD. Unravelling stem cell dynamics by lineage tracing. Nat Rev Mol Cell Biol [Internet]. 2013 Aug [cited 2014 May 26];14(8):489-502. Available from:

http://www.ncbi.nlm.nih.gov/pubmed/23860235

84. Schugar RC, Robbins PD, Deasy BM. Small molecules in stem cell selfrenewal and differentiation. Gene Ther [Internet]. 2008 Jan [cited 2014 Mar 20];15(2):126-35. Available from: http://www.ncbi.nlm.nih.gov/pubmed/17989703

85. Murry CE, Keller G. Differentiation of Embryonic Stem Cells to Clinically Relevant Populations: Lessons from Embryonic Development. Cell. 2008;132(4):661-80.

86. Fukada T, Kambe T. Molecular and genetic features of zinc transporters in physiology and pathogenesis. Metallomics. 2011;3(7):662-74.

87. Karalaki M, Fili S, Philippou A, Koutsilieris M. Muscle regeneration: cellular and molecular events. In Vivo [Internet]. 2009;23(5):779-96. Available from: http://www.ncbi.nlm.nih.gov/pubmed/19779115

88. Barrientos S, Brem H, Stojadinovic O, Tomic-Canic M. Clinical application of growth factors and cytokines in wound healing. Wound Repair Regen. 2014;22(5):569-78.

89. Andrae J, Gallini R, Betsholtz C. Role of platelet-derived growth factors in physiology and medicine. Genes Dev. 2008;22(10):1276-312.

90. Mouriño V, Cattalini JP, Boccaccini AR. Metallic ions as therapeutic agents in tissue engineering scaffolds: an overview of their biological applications and strategies for new developments. J R Soc Interface [Internet]. 2012;9(68):401-19. Available from:

http://www.ncbi.nlm.nih.gov/pubmed/22158843\%5Cnhttp://www.pubmed central.nih.gov/articlerender.fcgi?artid=PMC3262432

91. O'Neill E, Awale G, Daneshmandi L, Umerah O, Lo KWH. The roles of ions on bone regeneration. Drug Discov Today [Internet]. 2018;23(4):879-90. Available from: https://doi.org/10.1016/j.drudis.2018.01.049

92. Clapham DE. Calcium Signaling. Cell. 2007;131(6):1047-58.

93. Mayr B, Glaudo M, Schöfl C. Activating Calcium-Sensing Receptor Mutations: Prospects for Future Treatment with Calcilytics. Trends Endocrinol Metab. 2016;27(9):643-52.

94. Monteith GR, Prevarskaya N, Roberts-Thomson SJ. The calcium-cancer signalling nexus. Nat Rev Cancer [Internet]. 2017;17(6):367-80. Available from: http://dx.doi.org/10.1038/nrc.2017.18

95. Murakami M, Hirano T. Intracellular zinc homeostasis and zinc signaling. 
Cancer Sci [Internet]. 2008 Aug;99(8):1515-22. Available from: http://doi.wiley.com/10.1111/j.1349-7006.2008.00854.x

96. Taylor KM, Vichova P, Jordan N, Hiscox S, Hendley R, Nicholson RI. ZIP7-mediated intracellular zinc transport contributes to aberrant growth factor signaling in antihormone-resistant breast cancer cells. Endocrinology. 2008;149(10):4912-20.

97. Torti S V., Torti FM. Iron and cancer: more ore to be mined. Nat Rev Cancer [Internet]. 2013 May [cited 2014 Apr 29];13(5):342-55. Available from: http://www.ncbi.nlm.nih.gov/pubmed/23594855

98. Rouault $\mathrm{T}$ a. The role of iron regulatory proteins in mammalian iron homeostasis and disease. Nat Chem Biol [Internet]. 2006 Aug [cited 2014 May 1];2(8):406-14. Available from:

http://www.ncbi.nlm.nih.gov/pubmed/16850017

99. Muckenthaler MU, Galy B, Hentze MW. Systemic Iron Homeostasis and the Iron-Responsive Element/Iron-Regulatory Protein (IRE/IRP)

Regulatory Network. Annu Rev Nutr [Internet]. 2008;28(1):197-213.

Available from:

http://www.annualreviews.org/doi/10.1146/annurev.nutr.28.061807.1555 21

100. Gilfillan AM, Tkaczyk C. Integrated signalling pathways for mast-cell activation. Nat Rev Immunol. 2006;6(3):218-30.

101. Prelich G. Gene overexpression: Uses, mechanisms, and interpretation. Genetics. 2012;190(3):841-54.

102. Lemmon MA, Freed DM, Schlessinger J, Kiyatkin A. The Dark Side of Cell Signaling: Positive Roles for Negative Regulators. Cell [Internet]. 2016;164(6):1172-84. Available from:

http://dx.doi.org/10.1016/j.cell.2016.02.047

103. Lee G, Santat LA, Chang MS, Choi S. RNAI methodologies for the functional study of signaling molecules. PLoS One. 2009;4(2):1-10.

104. Clemens JC, Worby CA, Simonson-Leff N, Muda M, Maehama T, Hemmings BA, et al. Use of double-stranded RNA interference in Drosophila cell lines to dissect signal transduction pathways. Proc Natl Acad Sci [Internet]. 2000;97(12):6499-503. Available from: http://www.pnas.org/cgi/doi/10.1073/pnas.110149597

105. Theillet F-X, Binolfi A, Frembgen-Kesner T, Hingorani K, Sarkar M, Kyne $C$, et al. Physicochemical Properties of Cells and Their Effects on Intrinsically Disordered Proteins (IDPs). Chem Rev [Internet]. 2014;114(13):6661-714. Available from: http://pubs.acs.org/doi/abs/10.1021/cr400695p

106. Lodish H, Berk A, Zipursky SL, Matsudaira P, Baltimore D, Darnell J. Molecular Cell Biology. 4th edition. New York: W. H. Freeman. 2000. Section 11.4. 
107. Waldron KJ, Rutherford JC, Ford D, Robinson NJ. Metalloproteins and metal sensing. Nature [Internet]. 2009 Aug 13 [cited 2014 Mar 20];460(7257):823-30. Available from: http://www.ncbi.nlm.nih.gov/pubmed/19675642

108. Robinson KR. The responses of cells to electrical fields: A review. J Cell Biol. 1985;101(6):2023-7.

109. Lu Y, Yeung N, Sieracki N, Marshall NM. Design of functional metalloproteins. Nature. 2009;460(7257):855-62.

110. Bafaro $E$, Liu $Y, X u Y$, Dempski RE. The emerging role of zinc transporters in cellular homeostasis and cancer. Signal Transduct Target Ther [Internet]. 2017;2(April):17029. Available from: http://www.nature.com/articles/sigtrans201729

111. Kolenko V, Teper E, Kutikov A, Uzzo R. Zinc and zinc transporters in prostate carcinogenesis. Nat Rev Urol [Internet]. 2013 Apr [cited 2015 Jan 4];10(4):219-26. Available from:

http://www.pubmedcentral.nih.gov/articlerender.fcgi?artid=3702371\&tool $=$ pmcentrez\&rendertype=abstract

112. Tonelli FMP, Santos AK, Gomes DA, da Silva SL, Gomes KN, Ladeira LO, et al. Stem Cells and Calcium Signaling. In: Islam MS, editor. Dordrecht: Springer Netherlands; 2012. p. 891-916. (Advances in Experimental Medicine and Biology; vol. 740). Available from: http://link.springer.com/10.1007/978-94-007-2888-2

113. Tharmalingam S, Hampson DR. The calcium-sensing receptor and integrins in cellular differentiation and migration. Front Physiol. 2016;7(MAY):1-18.

114. Yamasaki S, Sakata-Sogawa K, Hasegawa A, Suzuki T, Kabu K, Sato $\mathrm{E}$, et al. Zinc is a novel intracellular second messenger. J Cell Biol [Internet]. 2007 May 21 [cited 2014 Oct 14];177(4):637-45. Available from:

http://www.pubmedcentral.nih.gov/articlerender.fcgi?artid=2064209\&tool $=$ pmcentrez\&rendertype=abstract

115. Taylor KM, Hiscox S, Nicholson RI, Hogstrand C, Kille P. Protein Kinase CK2 Triggers Cytosolic Zinc Signaling Pathways by Phosphorylation of Zinc Channel ZIP7. Sci Signal [Internet]. 2012 Feb 7;5(210):1-10. Available from: http://dx.doi.org/10.1126/scisignal.2002585

116. Chowanadisai W, Graham DM, Keen CL, Rucker RB, Messerli MA. Neurulation and neurite extension require the zinc transporter ZIP12 (slc39a12). Proc Natl Acad Sci [Internet]. 2013;110(24):9903-8. Available from: http://www.pnas.org/cgi/doi/10.1073/pnas.1222142110

117. Ohashi K, Nagata Y, Wada E, Zammit PS, Shiozuka M, Matsuda R. Zinc promotes proliferation and activation of myogenic cells via the PI3K/Akt and ERK signaling cascade. Exp Cell Res [Internet]. 2015;333(2):228- 
37. Available from: http://dx.doi.org/10.1016/j.yexcr.2015.03.003

118. Hu J, Yang Z, Wang J, Yu J, Guo J, Liu S, et al. Zinc Chloride Transiently Maintains Mouse Embryonic Stem Cell Pluripotency by Activating Stat3 Signaling. Pereira L V., editor. PLoS One [Internet]. 2016 Feb 24;11(2):e0148994. Available from: http://dx.plos.org/10.1371/journal.pone.0148994

119. Shahzad B, Mughal MN, Tanveer M, Gupta D, Abbas G. Is lithium biologically an important or toxic element to living organisms? An overview. Environ Sci Pollut Res [Internet]. 2017;24(1):103-15. Available from: http://dx.doi.org/10.1007/s11356-016-7898-0

120. Freland L, Beaulieu J-M. Inhibition of GSK3 by lithium, from single molecules to signaling networks. Front Mol Neurosci [Internet]. 2012;5(February):1-7. Available from: http://journal.frontiersin.org/article/10.3389/fnmol.2012.00014/abstract

121. Wu D, Pan W. GSK3: a multifaceted kinase in Wnt signaling. Trends Biochem Sci [Internet]. 2010;35(3):161-8. Available from: http://dx.doi.org/10.1016/j.tibs.2009.10.002

122. Zhu Z, Yin J, Guan J, Hu B, Niu X, Jin D, et al. Lithium stimulates human bone marrow derived mesenchymal stem cell proliferation through GSK$3 \beta$-dependent $\beta$-catenin/Wnt pathway activation. FEBS J. 2014;281(23):5371-89.

123. Zhu Z, Kremer P, Tadmori I, Ren Y, Sun D, He X, et al. Lithium suppresses astrogliogenesis by neural stem and progenitor cells by inhibiting stat3 pathway independently of glycogen synthase kinase 3 beta. PLoS One. 2011;6(9).

124. Schmidt MM, Guan K, Wobus AM. Lithium influences differentiation and tissue-specific gene expression of mouse embryonic stem (ES) cells in vitro. Int J Dev Biol [Internet]. 2001;45(2):421-9. Available from: http://www.ijdb.ehu.es/web/paper.php?doi=11330862\%5Cnpapers3://pu blication/uuid/8A824E6C-BFD3-4F4D-8E89-EC23C7F88912

125. MacDonald BT, Tamai K, He X. Wnt/ $\beta$-Catenin Signaling: Components, Mechanisms, and Diseases. Dev Cell [Internet]. 2009;17(1):9-26. Available from: http://dx.doi.org/10.1016/j.devcel.2009.06.016

126. Valenta $T$, Hausmann $G$, Basler $K$. The many faces and functions of $\beta$ catenin. EMBO J [Internet]. 2012 Jun 13;31(12):2714-36. Available from: http://emboj.embopress.org/cgi/doi/10.1038/emboj.2012.150

127. Frontera WR, Ochala J. Skeletal muscle: a brief review of structure and function. Calcif Tissue Int. 2015;96(3):183-95.

128. Wolfe RR, Frontera WR, Ochala J. The underappreciated role of muscle in health and disease. Am J Clin Nutr [Internet]. 2006 Sep;84(3):475-82. Available from: http://www.ncbi.nlm.nih.gov/pubmed/16960159 
129. Sciorati C, Rigamonti E, Manfredi AA, Rovere-Querini P. Cell death, clearance and immunity in the skeletal muscle. Cell Death Differ [Internet]. 2016;23(6):927-37. Available from: http://www.nature.com/doifinder/10.1038/cdd.2015.171

130. Wang YX, Rudnicki MA. Satellite cells, the engines of muscle repair. Nat Rev Mol Cell Biol [Internet]. 2011;13(2):127-33. Available from: http://www.ncbi.nlm.nih.gov/pubmed/22186952

131. Dhawan J, Rando TA. Stem cells in postnatal myogenesis: Molecular mechanisms of satellite cell quiescence, activation and replenishment. Trends Cell Biol. 2005;15(12):666-73.

132. Yun K, Wold B. Skeletal muscle determination and differentiation: Story of a core regulatory network and its context. Curr Opin Cell Biol. 1996;8(6):877-89.

133. Gharaibeh B, Chun-Lansinger Y, Hagen T, Ingham SJM, Wright V, Fu F, et al. Biological approaches to improve skeletal muscle healing after injury and disease. Birth Defects Res Part C Embryo Today Rev [Internet]. 2012 Mar;96(1):82-94. Available from: http://doi.wiley.com/10.1002/bdrc.21005

134. Sandri M. Signaling in muscle atrophy and hypertrophy. Physiology (Bethesda) [Internet]. 2008;23(3):160-70. Available from: http://www.ncbi.nlm.nih.gov/pubmed/18556469

135. Fujio Y, Guo K, Mano T, Mitsuuchi Y, Testa JR, Walsh K. Cell cycle withdrawal promotes myogenic induction of Akt, a positive modulator of myocyte survival. Mol Cell Biol. 1999;19(7):5073-82.

136. Wilson EM, Rotwein P. Control of MyoD function during initiation of muscle differentiation by an autocrine signaling pathway activated by insulin-like growth factor-II. J Biol Chem. 2006;281(40):29962-71.

137. Sun L, Liu L, Yang X, Wu Z. Akt binds prohibitin 2 and relieves its repression of MyoD and muscle differentiation. J Cell Sci [Internet]. 2004 Jun 15;117(14):3021-9. Available from: http://jcs.biologists.org/cgi/doi/10.1242/jcs.01142

138. Milner D, Cameron J. Muscle repair and regeneration: stem cells, scaffolds, and the contributions of skeletal muscle to amphibian limb regeneration. Stocum D, Heber-Katz E, editors. Curr Top Microbiol Immunol. 2013;367:133-59.

139. Liu C, Su T, Li F, Li L, Qin X, Pan W, et al. PI3K / Akt signaling transduction pathway is involved in rat vascular smooth muscle cell proliferation induced by apelin-13. Acta Biochim Biophys Sin. 2010;42:396-402.

140. Eriksson M, Taskinen M, Leppä S. Mitogen Activated Protein KinaseDependent Activation of C-Jun and C-Fos is required for Neuronal differentiation but not for Growth and Stress Reposne in PC12 cells. J 
Cell Physiol. 2006;207(1):12-22.

141. Lynch GS, Schertzer JD, Ryall JG. Anabolic agents for improving muscle regeneration and function after injury. Clin Exp Pharmacol Physiol. 2008;35(7):852-8.

142. Arsic N, Zacchigna S, Zentilin L, Ramirez-Correa G, Pattarini L, Salvi A, et al. Vascular endothelial growth factor stimulates skeletal muscle regeneration in Vivo. Mol Ther. 2004;10(5):844-54.

143. Borselli C, Storrie H, Benesch-Lee F, Shvartsman D, Cezar C, Lichtman $\mathrm{JW}$, et al. Functional muscle regeneration with combined delivery of angiogenesis and myogenesis factors. Proc Natl Acad Sci U S A [Internet]. 2010;107(8):3287-92. Available from:

http://www.ncbi.nlm.nih.gov/pubmed/19966309\%5Cnhttp://www.ncbi.nlm .nih.gov/pmc/articles/PMC2840452/pdf/pnas.200903875.pdf

144. Hanft JR, Pollak R a, Barbul A, van Gils C, Kwon PS, Gray SM, et al. Phase I trial on the safety of topical rhVEGF on chronic neuropathic diabetic foot ulcers. J Wound Care [Internet]. 2008;17(1):34-7. Available from: http://www.ncbi.nlm.nih.gov/pubmed/18210954

145. Simón-Yarza T, Formiga FR, Tamayo E, Pelacho B, Prosper F, BlancoPrieto MJ. Vascular endothelial growth factor-delivery systems for cardiac repair: An overview. Vol. 2, Theranostics. 2012. p. 541-52.

146. Briquez PS, Hubbell JA, Martino MM. Extracellular Matrix-Inspired Growth Factor Delivery Systems for Skin Wound Healing. Adv Wound Care [Internet]. 2015;4(8):479-89. Available from: http://online.liebertpub.com/doi/10.1089/wound.2014.0603

147. Barthel A, Ostrakhovitch EA, Walter PL, Kampkötter A, Klotz LO. Stimulation of phosphoinositide 3-kinase/Akt signaling by copper and zinc ions: Mechanisms and consequences. Arch Biochem Biophys. 2007;463(2):175-82.

148. Ostrakhovitch E a, Lordnejad MR, Schliess F, Sies H, Klotz L-O. Copper ions strongly activate the phosphoinositide-3-kinase/Akt pathway independent of the generation of reactive oxygen species. Arch Biochem Biophys. 2002;397(2):232-9.

149. Kaur K, Gupta R, Saraf SA, Saraf SK. Zinc: The metal of life. Compr Rev Food Sci Food Saf. 2014;13(4):358-76.

150. Coleman JE. Zinc proteins: enzymes, storage proteins, transcription factors, and replication proteins. Annu Rev Biochem. 1992;61:897-946.

151. Hogstrand C, Kille P, Nicholson RI, Taylor KM. Zinc transporters and cancer: a potential role for ZIP7 as a hub for tyrosine kinase activation. Trends Mol Med. 2009;15(3):101-11.

152. Myers S a., Nield A, Chew GS, Myers M a. The zinc transporter, SIc39a7 (Zip7) is implicated in glycaemic control in skeletal muscle cells. PLoS 
One. 2013;8(11).

153. Kambe T, Tsuji T, Hashimoto A, Itsumura N. The Physiological, Biochemical, and Molecular Roles of Zinc Transporters in Zinc Homeostasis and Metabolism. Physiol Rev [Internet]. 2015;95(3):749_ 84. Available from: http://physrev.physiology.org/cgi/doi/10.1152/physrev.00035.2014

154. Jinno N, Nagata M, Takahashi T. Marginal zinc deficiency negatively affects recovery from muscle injury in mice. Biol Trace Elem Res. 2014;158(1):65-72.

155. Sumitani S, Goya K, Testa JR, Kouhara H, Kasayama S. Akt1 and Akt2 differently regulate muscle creatine kinase and myogenin gene transcription in insulin-induced differentiation of $\mathrm{C} 2 \mathrm{C} 12$ myoblasts. Endocrinology. 2002;143(3):820-8.

156. Chesters JK. Biochemistry of Zinc in Cell Division and Tissue Growth. In: Zinc in human biology [Internet]. 1989. p. 109-18. Available from: http://link.springer.com/10.1007/978-1-4471-3879-2_7

157. Burattini S, Ferri R, Battistelli M, Curci R, Luchetti F, Falcieri E. C2C12 murine myoblasts as a model of skeletal muscle development: Morphofunctional characterization. Eur J Histochem. 2004;48(3):223-33.

158. Pfaffl MW. A new mathematical model for relative quantification in realtime RT-PCR. Nucleic Acids Res [Internet]. 2001;29(9):e45. Available from:

http://www.ncbi.nlm.nih.gov/pubmed/11328886\%0Ahttp://www.pubmedc entral.nih.gov/articlerender.fcgi?artid=PMC55695

159. Mnatsakanyan H, Rico P, Grigoriou E, Candelas AM, Rodrigo-Navarro A, Salmeron-Sanchez M, et al. Controlled Assembly of Fibronectin Nanofibrils Triggered by Random Copolymer Chemistry. ACS Appl Mater Interfaces. 2015;7(32):18125-35.

160. Jeong J, Eide DJ. The SLC39 family of zinc transporters. Vol. 34, Molecular Aspects of Medicine. 2013. p. 612-9.

161. Huang L, Kirschke CP, Zhang Y, Yan YY. The ZIP7 gene (Slc39a7) encodes a zinc transporter involved in zinc homeostasis of the Golgi apparatus. J Biol Chem. 2005;280(15):15456-63.

162. Vallee BL, Falchuk KH. The biochemical basis of zinc physiology. Vol. 73, Physiological reviews. 1993. 79-118 p.

163. Ganju N, Eastman a. Zinc inhibits Bax and Bak activation and cytochrome $c$ release induced by chemical inducers of apoptosis but not by death-receptor-initiated pathways. Cell Death Differ [Internet]. 2003 Jun [cited 2015 Jan 4];10(6):652-61. Available from: http://www.ncbi.nlm.nih.gov/pubmed/12761574

164. Chai F, Truong-Tran AQ, Ho LH, Zalewski PD. Regulation of caspase 
activation and apoptosis by cellular zinc fluxes and zinc deprivation: A review. Immunol Cell Biol. 1999;77(3):272-8.

165. Smith PJ, Wiltshire M, Furon E, Beattie JH, Errington RJ. Impact of overexpression of metallothionein-1 on cell cycle progression and zinc toxicity. Am J Physiol Cell Physiol. 2008;295(September 2008):C1399_ 408.

166. Bozym RA, Chimienti F, Giblin LJ, Gross GW, Korichneva I, Li Y, et al. Free zinc ions outside a narrow concentration range are toxic to a variety of cells in vitro. Exp Biol Med (Maywood) [Internet]. 2010;235(6):741-50. Available from:

http://www.pubmedcentral.nih.gov/articlerender.fcgi?artid=2896872\&tool =pmcentrez\&rendertype=abstract

167. Plum LM, Rink L, Hajo H. The essential toxin: Impact of zinc on human health. Int J Environ Res Public Health. 2010;7(4):1342-65.

168. Chen C-J, Liao S-L. Zinc toxicity on neonatal cortical neurons: involvement of glutathione chelation. J Neurochem. 2003;85(2):443-53.

169. Chassot AA, Lossaint G, Turchi L, Meneguzzi G, Fisher D, Ponzio G, et al. Confluence-induced cell cycle exit involves pre-mitotic CDK inhibition by p27Kip1 and cyclin D1 downregulation. Cell Cycle. 2008;7(13):203846.

170. Spencer SL, Cappell SD, Tsai FC, Overton KW, Wang CL, Meyer T. $X$ The proliferation-quiescence decision is controlled by a bifurcation in CDK2 activity at mitotic exit. Cell [Internet]. 2013;155(2):369-83.

Available from: http://dx.doi.org/10.1016/j.cell.2013.08.062

171. Walsh K, Perlman H. Cell cycle exit upon myogenic differentiation. Curr Opin Genet Dev [Internet]. 1997 Oct [cited 2014 Jul 6];7(5):597-602. Available from:

http://linkinghub.elsevier.com/retrieve/pii/S0959437X97800056

172. Puri PL, Sartorelli V. Regulation of muscle regulatory factors by DNAbinding, interacting proteins, and post-transcriptional modifications. Vol. 185, Journal of Cellular Physiology. 2000. p. 155-73.

173. Zammit PS, Partridge TA, Yablonka-Reuveni Z. The skeletal muscle satellite cell: the stem cell that came in from the cold. J Histochem Cytochem [Internet]. 2006;54(11):1177-91. Available from: http://www.ncbi.nlm.nih.gov/pubmed/16899758

174. Dirksen RT. Sarcoplasmic reticulum-mitochondrial through-space coupling in skeletal muscleThis paper is one of a selection of papers published in this Special Issue, entitled 14th International Biochemistry of Exercise Conference - Muscles as Molecular and Metabolic . Appl Physiol Nutr Metab [Internet]. 2009 Jun;34(3):389-95. Available from: http://www.nrcresearchpress.com/doi/abs/10.1139/H09-044

175. Groth C, Sasamura T, Khanna MR, Whitley M, Fortini ME. Protein 
trafficking abnormalities in Drosophila tissues with impaired activity of the ZIP7 zinc transporter Catsup. Development [Internet].

2013;140(14):3018-27. Available from:

http://www.ncbi.nlm.nih.gov/pubmed/23785054

176. Ellis CD, Wang F, MacDiarmid CW, Clark S, Lyons T, Eide DJ. Zinc and the Msc2 zinc transporter protein are required for endoplasmic reticulum function. J Cell Biol. 2004;166(3):325-35.

177. Koch U, Lehal R, Radtke F. Stem cells living with a Notch. Development [Internet]. 2013;140(4):689-704. Available from:

http://www.ncbi.nlm.nih.gov/pubmed/23362343

178. Gardner S, Anguiano M, Rotwein P. Defining Akt actions in muscle differentiation. Am J Physiol Physiol [Internet]. 2012 Dec 15;303(12):C1292-300. Available from: http://www.physiology.org/doi/10.1152/ajpcell.00259.2012

179. Knight JD, Kothary R. The myogenic kinome: protein kinases critical to mammalian skeletal myogenesis. Skelet Muscle [Internet]. 2011;1:29. Available from: http://www.pubmedcentral.nih.gov/articlerender.fcgi?artid=3180440\&tool $=$ pmcentrez\&rendertype $=$ abstract

180. Roth SM. Genetic aspects of skeletal muscle strength and mass with relevance to sarcopenia. Bonekey Rep [Internet]. 2012;1(APRIL):1-7. Available from: http://www.nature.com/doifinder/10.1038/bonekey.2012.58

181. Mebratu Y, Tesfaigzi Y. How ERK1/2 Activation Controls Cell Proliferation and Cell Death Is Subcellular Localization the Answer? Cell Cycle [Internet]. 2009;8(8):1168-75. Available from:

http://www.ncbi.nlm.nih.gov/pmc/articles/PMC2728430/\%5Cnhttp://www. ncbi.nlm.nih.gov/pmc/articles/PMC2728430/pdf/nihms137264.pdf

182. Evans M. Discovering pluripotency: 30 years of mouse embryonic stem cells. Nat Rev Mol Cell Biol [Internet]. 2011;12(10):680-6. Available from: http://dx.doi.org/10.1038/nrm3190

183. Niwa H. How is pluripotency determined and maintained? Development. 2007;134(4):635-46.

184. Ohtsuka S, Dalton S. Molecular and biological properties of pluripotent embryonic stem cells. Gene Ther [Internet]. 2008 Jan [cited 2014 Dec 7];15(2):74-81. Available from: http://www.ncbi.nlm.nih.gov/pubmed/17989701

185. Tremml G, Singer M, Malavarca R. Culture of mouse embryonic stem cells. Curr Protoc Stem Cell Biol [Internet]. 2008 Apr [cited 2014 Jun 29]; Chapter 1(April):Unit 1C.4. Available from: http://www.ncbi.nlm.nih.gov/pubmed/18770628

186. Wichterle H, Lieberam I, Porter JA, Jessell TM. Directed differentiation of 
embryonic stem cells into motor neurons. Cell. 2002;110(3):385-97.

187. West J a, Park I-H, Daley GQ, Geijsen N. In vitro generation of germ cells from murine embryonic stem cells. Nat Protoc [Internet]. 2006 Jan [cited 2014 Nov 2];1(4):2026-36. Available from:

http://www.ncbi.nlm.nih.gov/pubmed/17487192

188. Kattman SJ, Witty AD, Gagliardi M, Dubois NC, Niapour M, Hotta A, et al. Stage-specific optimization of activin/nodal and BMP signaling promotes cardiac differentiation of mouse and human pluripotent stem cell lines. Cell Stem Cell [Internet]. 2011;8(2):228-40. Available from: http://dx.doi.org/10.1016/j.stem.2010.12.008

189. Evseenko D, Zhu Y, Schenke-Layland K, Kuo J, Latour B, Ge S, et al. Mapping the first stages of mesoderm commitment during differentiation of human embryonic stem cells. Proc Natl Acad Sci [Internet]. 2010 Aug 3;107(31):13742-7. Available from:

http://www.pnas.org/cgi/doi/10.1073/pnas.1002077107

190. Yiangou L, Ross ADB, Goh KJ, Vallier L. Human Pluripotent Stem CellDerived Endoderm for Modeling Development and Clinical Applications. Cell Stem Cell [Internet]. 2018;22(4):485-99. Available from: https://doi.org/10.1016/j.stem.2018.03.016

191. Czechanski A, Byers C, Greenstein I, Schrode N, Donahue LR, Hadjantonakis A-K, et al. Derivation and characterization of mouse embryonic stem cells from permissive and nonpermissive strains. Nat Protoc [Internet]. 2014 Mar [cited 2014 May 28];9(3):559-74. Available from: http://www.ncbi.nlm.nih.gov/pubmed/24504480

192. Heo J, Lee JS, Chu IS, Takahama Y, Thorgeirsson SS. Spontaneous differentiation of mouse embryonic stem cells in vitro: Characterization by global gene expression profiles. Biochem Biophys Res Commun. 2005;332(4):1061-9.

193. Nair G, Abranches E, Guedes AMV, Henrique D, Raj A. Heterogeneous lineage marker expression in naive embryonic stem cells is mostly due to spontaneous differentiation. Sci Rep [Internet]. 2015;5(November 2014):1-12. Available from: http://dx.doi.org/10.1038/srep13339

194. Stewart MH, Bendall SC, Bhatia M. Deconstructing human embryonic stem cell cultures: Niche regulation of self-renewal and pluripotency. J Mol Med. 2008;86(8):875-86.

195. Llames S, García-Pérez E, Meana Á, Larcher F, del Río M. Feeder Layer Cell Actions and Applications. Tissue Eng Part B Rev [Internet]. 2015;21(4):345-53. Available from:

http://online.liebertpub.com/doi/10.1089/ten.teb.2014.0547\%5Cnhttp://w ww.ncbi.nlm.nih.gov/pubmed/25659081\%5Cnhttp://www.pubmedcentral. nih.gov/articlerender.fcgi?artid=PMC4533020

196. Tamm C, Pijuan Galitó S, Annerén C. A comparative study of protocols 
for mouse embryonic stem cell culturing. PLoS One [Internet]. 2013 Jan [cited 2014 Apr 19];8(12):e81156. Available from:

http://www.pubmedcentral.nih.gov/articlerender.fcgi?artid=3858223\&tool $=$ pmcentrez\&rendertype $=$ abstract

197. Singhal PK, Sassi S, Lan L, Au P, Halvorsen SC, Fukumura D, et al. Mouse embryonic fibroblasts exhibit extensive developmental and phenotypic diversity. Proc Natl Acad Sci [Internet]. 2016;113(1):122-7. Available from: http://www.pnas.org/lookup/doi/10.1073/pnas.1522401112

198. Pera MF, Tam PPL. Extrinsic regulation of pluripotent stem cells. Nature [Internet]. 2010 Jun 10 [cited 2014 Aug 26];465(7299):713-20. Available from: http://www.ncbi.nlm.nih.gov/pubmed/20535200

199. Oshimori N, Fuchs $\mathrm{E}$. The harmonies played by TGF- $\beta$ in stem cell biology. Cell Stem Cell [Internet]. 2012;11(6):751-64. Available from: http://dx.doi.org/10.1016/j.stem.2012.11.001

200. Niwa H, Burdon T, Chambers I, Smith A. Self-renewal of pluripotent embryonic stem cells is mediated via activation of STAT3. Genes Dev [Internet]. 1998;12(13):2048-60. Available from:

http://www.pubmedcentral.nih.gov/articlerender.fcgi?artid=316954\&tool= pmcentrez\&rendertype=abstract

201. Li W, Ding S. Small molecules that modulate embryonic stem cell fate and somatic cell reprogramming. Trends Pharmacol Sci [Internet]. 2010 Jan [cited 2014 Dec 11];31(1):36-45. Available from: http://www.ncbi.nlm.nih.gov/pubmed/19896224

202. Chen S, Do JT, Zhang Q, Yao S, Yan F, Peters EC, et al. Self-renewal of embryonic stem cells by a small molecule. Proc Natl Acad Sci. 2006;103(46):17266-71.

203. Hamilton WB, Brickman JM. Erk Signaling Suppresses Embryonic Stem Cell Self-Renewal to Specify Endoderm. Cell Rep [Internet]. 2014;9(6):2056-70. Available from: http://dx.doi.org/10.1016/j.celrep.2014.11.032

204. Jaenisch R, Young R. Stem Cells, the Molecular Circuitry of Pluripotency and Nuclear Reprogramming. Cell. 2008;132(4):567-82.

205. Kennedy SG, Wagner AJ, Conzen SD, Jordan J, Bellacosa A, Tsichlis $\mathrm{PN}$, et al. The PI 3-kinase/Akt signaling pathway delivers an antiapoptotic signal. Genes Dev [Internet]. 1997 Mar 15;11(6):701-13. Available from: http://www.genesdev.org/cgi/doi/10.1101/gad.11.6.701

206. Cardone MH. Regulation of Cell Death Protease Caspase- 9 by Phosphorylation. Science (80- ) [Internet]. 1998;282(5392):1318-21. Available from: http://www.sciencemag.org/cgi/doi/10.1126/science.282.5392.1318

207. Lin Y, Yang Y, Li W, Chen Q, Li J, Pan X, et al. Reciprocal Regulation of 
Akt and Oct4 Promotes the Self-Renewal and Survival of Embryonal Carcinoma Cells. Mol Cell [Internet]. 2012;48(4):627-40. Available from: http://dx.doi.org/10.1016/j.molcel.2012.08.030

208. Doble BW. GSK-3: tricks of the trade for a multi-tasking kinase. J Cell Sci [Internet]. 2003;116(7):1175-86. Available from: http://jcs.biologists.org/cgi/doi/10.1242/jcs.00384

209. Berge D Ten, Kurek D, Blauwkamp T, Koole W, Maas A, Eroglu E, et al. Embryonic stem cells require Wnt proteins to prevent differentiation to epiblast stem cells. Nat Cell Biol [Internet]. 2011;13(9):1070-7. Available from: http://dx.doi.org/10.1038/ncb2314

210. Morgani SM, Canham MA, Nichols J, Sharov AA, Migueles RP, Ko MSH, et al. Totipotent Embryonic Stem Cells Arise in Ground-State Culture Conditions. Cell Rep [Internet]. 2013 Jun;3(6):1945-57. Available from: 10.1016/j.celrep.2013.04.034

211. Eiselleova L, Matulka K, Kriz V, Kunova M, Schmidtova Z, Neradil J, et al. A complex role for FGF-2 in self-renewal, survival, and adhesion of human embryonic stem cells. Stem Cells. 2009;27(8):1847-57.

212. Jo H, Mondal S, Tan D, Nagata E, Takizawa S, Sharma AK, et al. Small molecule-induced cytosolic activation of protein kinase Akt rescues ischemia-elicited neuronal death. Proc Natl Acad Sci [Internet]. 2012;109(26):10581-6. Available from:

http://www.pnas.org/cgi/doi/10.1073/pnas.1202810109

213. Cohen L, Sekler I, Hershfinkel M. The zinc sensing receptor, ZnR/GPR39, controls proliferation and differentiation of colonocytes and thereby tight junction formation in the colon. Cell Death Dis [Internet]. 2014;5(6):e1307-12. Available from:

http://dx.doi.org/10.1038/cddis.2014.262

214. Shao Y, Wolf PG, Guo S, Guo Y, Rex Gaskins H, Zhang B. Zinc enhances intestinal epithelial barrier function through the $\mathrm{PI3K/AKT/mTOR} \mathrm{signaling} \mathrm{pathway} \mathrm{in} \mathrm{Caco-2} \mathrm{cells.} \mathrm{J} \mathrm{Nutr} \mathrm{Biochem}$ [Internet]. 2017;43:18-26. Available from:

http://dx.doi.org/10.1016/j.jnutbio.2017.01.013

215. Zhou J, Wulfkuhle J, Zhang H, Gu P, Yang Y, Deng J, et al. Activation of the PTEN/mTOR/STAT3 pathway in breast cancer stem-like cells is required for viability and maintenance. Proc Natl Acad Sci [Internet]. 2007;104(41):16158-63. Available from:

http://www.pnas.org/cgi/doi/10.1073/pnas.0702596104

216. Kim E, Kim M, Woo DH, Shin Y, Shin J, Chang N, et al. Phosphorylation of EZH2 Activates STAT3 Signaling via STAT3 Methylation and Promotes Tumorigenicity of Glioblastoma Stem-like Cells. Cancer Cell [Internet]. 2013;23(6):839-52. Available from:

http://dx.doi.org/10.1016/j.ccr.2013.04.008 
217. Ziomek CA, Lepire ML, Torres I. A highly fluorescent simultaneous azo dye technique for demonstration of nonspecific alkaline phosphatase activity. J Histochem Cytochem [Internet]. 1990 Mar 5;38(3):437-42. Available from: http://journals.sagepub.com/doi/10.1177/38.3.1689343

218. Fischer AH, Jacobson KA, Rose J, Zeller R. Hematoxylin and eosin staining of tissueand cell sections. Cold Spring Harb Protoc. 2008;3(5).

219. Hamatake M, Iguchi K, Hirano K, Ishida R. Zinc induces mixed types of cell death, necrosis and apoptosis, in Molt-4 cells. J Biochem. 2000;128(6):933-9.

220. Watanabe S, Umehara H, Murayama K, Okabe M, Kimura T, Nakano T. Activation of Akt signaling is sufficient to maintain pluripotency in mouse and primate embryonic stem cells. Oncogene. 2006;25(19):2697-707.

221. Manning BD, Cantley LC. AKT/PKB Signaling: Navigating Downstream. Cell [Internet]. 2007 Jun;129(7):1261-74. Available from: http://linkinghub.elsevier.com/retrieve/pii/S0092867407007751

222. Jeong $\mathrm{CH}$, Cho YY, Kim MO, Kim SH, Cho EJ, Lee SY, et al. Phosphorylation of Sox2 cooperates in reprogramming to pluripotent stem cells. Stem Cells. 2010;28(12):2141-50.

223. Anzellotti Al, Farrell NP. Zinc metalloproteins as medicinal targets. Chem Soc Rev [Internet]. 2008;37(8):1629-51. Available from: http://xlink.rsc.org/?DOI=b617121b

224. Murray P, Edgar D. The regulation of embryonic stem cell differentiation by leukaemia inhibitory factor (LIF). Differentiation [Internet]. 2001;68(45):227-34. Available from: http://dx.doi.org/10.1046/j.14320436.2001.680410.x

225. Rose-John S. GP130 stimulation and the maintenance of stem cells. Trends Biotechnol [Internet]. 2002 Oct;20(10):417-9. Available from: http://linkinghub.elsevier.com/retrieve/pii/S0167779902020565

226. Fang X, Yu SX, Lu Y, Bast RC, Woodgett JR, Mills GB. Phosphorylation and inactivation of glycogen synthase kinase 3 by protein kinase A. Proc Natl Acad Sci U S A. 2000;97(22):11960-5.

227. Yamaguchi $\mathrm{H}$, Wang HG. The protein kinase PKB/Akt regulates cell survival and apoptosis by inhibiting Bax conformational change. Oncogene. 2001;20(53):7779-86.

228. Wang ES, Reyes NA, Melton C, Huskey NE, Momcilovic O, Goga A, et al. Fas-activated mitochondrial apoptosis culls stalled embryonic stem cells to promote differentiation. Curr Biol [Internet]. 2015;25(23):3110-8. Available from: http://dx.doi.org/10.1016/j.cub.2015.10.020

229. Plusa B, Hadjantonakis A. Embryonic stem cell identity grounded in the embryo. Nat Cell Biol [Internet]. 2014 Jun 1;16(6):502-4. Available from: http://dx.doi.org/10.1038/ncb2984 
230. Sakurai H, Era T, Jakt LM, Okada M, Nakai S, Nishikawa SS, et al. In vitro modeling of paraxial and lateral mesoderm differentiation reveals early reversibility. Stem Cells [Internet]. 2006;24(3):575-86. Available from:

http://eutils.ncbi.nlm.nih.gov/entrez/eutils/elink.fcgi?dbfrom=pubmed\&id= 16339996\&retmode=ref\&cmd=prlinks\%5Cnpapers3://publication/doi/10. 1634/stemcells.2005-0256

231. Vierbuchen T, Wernig M. Molecular roadblocks for cellular reprogramming. Mol Cell [Internet]. 2012 Sep 28 [cited 2014 Apr 28];47(6):827-38. Available from:

http://www.pubmedcentral.nih.gov/articlerender.fcgi?artid=3809030\&tool =pmcentrez\&rendertype=abstract

232. Naito AT, Shiojima I, Akazawa H, Hidaka K, Morisaki T, Kikuchi A, et al. Developmental stage-specific biphasic roles of Wnt/beta-catenin signaling in cardiomyogenesis and hematopoiesis. Proc Natl Acad Sci [Internet]. 2006;103(52):19812-7. Available from: http://www.pnas.org/cgi/doi/10.1073/pnas.0605768103

233. Lindsley RC. Canonical Wnt signaling is required for development of embryonic stem cell-derived mesoderm. Development [Internet]. 2006;133(19):3787-96. Available from: http://dev.biologists.org/cgi/doi/10.1242/dev.02551

234. Schuijers J, Mokry M, Hatzis P, Cuppen E, Clevers H. Wnt-induced transcriptional activation is exclusively mediated by TCF/LEF. EMBO J. 2014;33(2):146-56.

235. Nakamura Y, de Paiva Alves E, Veenstra GJC, Hoppler S. Tissue- and stage-specific Wnt target gene expression is controlled subsequent to $\beta$ catenin recruitment to cis-regulatory modules. Development [Internet]. 2016;143(11):1914-25. Available from: http://dev.biologists.org/lookup/doi/10.1242/dev.131664

236. Arnold SJ, Stappert J, Bauer A, Kispert A, Herrmann BG, Kemler R. Brachyury is a target gene of the Wnt/ $\beta$-catenin signaling pathway. Mech Dev. 2000;91(1-2):249-58.

237. Hari L, Brault V, Kléber M, Lee HY, Ille F, Leimeroth R, et al. Lineagespecific requirements of $\beta$-catenin in neural crest development. J Cell Biol. 2002;159(5):867-80.

238. Cyganek L. Cardiac Progenitor Cells and their Therapeutic Application for Cardiac Repair. J Clin Exp Cardiolog [Internet]. 2013;01(S11).

Available from: https://www.omicsonline.org/2155-9880/2155-9880-S11008.php?aid=14262

239. Sturgeon CM, Ditadi A, Awong G, Kennedy M, Keller G. Wnt signaling controls the specification of definitive and primitive hematopoiesis from human pluripotent stem cells. Nat Biotechnol [Internet]. 2014;32(6):55461. Available from: http://dx.doi.org/10.1038/nbt.2915 
240. Ackermann M, Liebhaber S, Klusmann J, Lachmann N. Lost in translation: pluripotent stem cell-derived hematopoiesis. EMBO Mol Med [Internet]. 2015;7(11):1388-402. Available from:

http://embomolmed.embopress.org/lookup/doi/10.15252/emmm.201505 301

241. Ng AP, Alexander WS. Haematopoietic stem cells: past, present and future. Cell Death Discov [Internet]. 2017;3(December 2016):17002. Available from: http://www.nature.com/articles/cddiscovery20172

242. Hirschi KK. Hemogenic endothelium during development and beyond. Blood [Internet]. 2012 May 24;119(21):4823-7. Available from: http://www.bloodjournal.org/cgi/doi/10.1182/blood-2011-12-353466

243. Swiers G, Rode C, Azzoni E, De Bruijn MFTR. A short history of hemogenic endothelium. Blood Cells, Mol Dis [Internet]. 2013;51(4):206-12. Available from: http://dx.doi.org/10.1016/j.bcmd.2013.09.005

244. Ruiz-Herguido C, Guiu J, D’Altri T, Inglés-Esteve J, Dzierzak E, Espinosa L, et al. Hematopoietic stem cell development requires transient Wnt/B-catenin activity. J Exp Med [Internet]. 2012;209(8):145768. Available from: http://www.jem.org/lookup/doi/10.1084/jem.20120225

245. Chen T, Wang F, Wu M, Wang ZZ. Development of Hematopoietic Stem and Progenitor Cells From Human Pluripotent Stem Cells. J Cell Biochem [Internet]. 2015 Jul;116(7):1179-89. Available from: http://doi.wiley.com/10.1002/jcb.25097

246. Esiashvili N, Pulsipher MA. Hematopoietic stem cell transplantation. Pediatr Oncol. 2018;(9783319435442):301-11.

247. D'Souza SS, Maufort J, Kumar A, Zhang J, Smuga-Otto K, Thomson JA, et al. GSK3 $\beta$ Inhibition Promotes Efficient Myeloid and Lymphoid Hematopoiesis from Non-human Primate-Induced Pluripotent Stem Cells. Stem Cell Reports [Internet]. 2016;6(2):243-56. Available from: http://dx.doi.org/10.1016/j.stemcr.2015.12.010

248. Wang Q, Xu X, Li J, Liu J, Gu H, Zhang R, et al. Lithium, an antipsychotic drug, greatly enhances the generation of induced pluripotent stem cells. Cell Res [Internet]. 2011;21(10):1424-35. Available from: http://dx.doi.org/10.1038/cr.2011.108

249. Allagui MS, Vincent C, El feki A, Gaubin Y, Croute F. Lithium toxicity and expression of stress-related genes or proteins in A549 cells. Biochim Biophys Acta - Mol Cell Res. 2007;1773(7):1107-15.

250. Raggioli A, Junghans D, Rudloff S, Kemler R. Beta-catenin is vital for the integrity of mouse embryonic stem cells. PLoS One [Internet]. 2014;9(1):e86691. Available from:

/Users/anaguedes/Documents/ReadCube Media/Raggioli et al-2014PLoS ONE.pdf\%5Cnhttp://dx.doi.org/10.1371/journal.pone.0086691 
251. Keller G. Embryonic stem cell differentiation: emergence of a new era in biology and medicine. Genes Dev [Internet]. 2005 May 15 [cited 2014 Jul 17];19(10):1129-55. Available from: http://www.ncbi.nlm.nih.gov/pubmed/15905405

252. Xiao Q, Zeng L, Zhang Z, Margariti A, Ali ZA, Channon KM, et al. Sca-1+ progenitors derived from embryonic stem cells differentiate into endothelial cells capable of vascular repair after arterial injury. Arterioscler Thromb Vasc Biol Q, Zeng, L, Zhang, Z, Margariti, A, Ali, ZA, Channon, KM, Xu, Q, Hu, Y (2006) Sca-1+ progenitors Deriv from embryonic stem cells Differ into Endothel cells Capab vascu. 2006;26(10):2244-51.

253. Bailey B, Fransioli J, Gude NA, Alvarez R, Zhan X, Gustafsson ÅB, et al. Sca-1 knockout impairs myocardial and cardiac progenitor cell function. Circ Res. 2012;111(6):750-60.

254. Yzaguirre AD, Speck NA. Insights into blood cell formation from hemogenic endothelium in lesser-known anatomic sites. Dev Dyn. 2016;245(10):1011-28.

255. Martello G, Sugimoto T, Diamanti E, Joshi A, Hannah R, Ohtsuka S, et al. Esrrb is a pivotal target of the Gsk3/Tcf3 axis regulating embryonic stem cell self-renewal. Cell Stem Cell. 2012;11(4):491-504.

256. Zamir L, Singh R, Nathan E, Patrick R, Yifa O, Yahalom-Ronen Y, et al. $\mathrm{Nkx2.5}$ marks angioblasts that contribute to hemogenic endothelium of the endocardium and dorsal aorta. Elife. 2017;6:1-31.

257. Akazawa $\mathrm{H}$, Komuro I. Cardiac transcription factor Csx/Nkx2-5: Its role in cardiac development and diseases. Pharmacol Ther. 2005;107(2):25268.

258. Kim I, Saunders TL, Morrison SJ. Sox17 Dependence Distinguishes the Transcriptional Regulation of Fetal from Adult Hematopoietic Stem Cells. Cell. 2007;130(3):470-83.

259. Hanif MA, Bhatti HN, Ali MA, Asgher M, Bhatti IA. Heavy metals tolerance and biosorption potential of white rot fungi. Asian $\mathrm{J}$ Chem. 2010;22(1):335-45.

260. Holmes C, Stanford WL. Concise Review: Stem Cell Antigen-1:

Expression, Function, and Enigma. Stem Cells [Internet]. 2007;25(6):1339-47. Available from:

http://doi.wiley.com/10.1634/stemcells.2006-0644

261. Chotinantakul K, Leeanansaksiri W. Hematopoietic Stem Cell Development, Niches, and Signaling Pathways. Bone Marrow Res [Internet]. 2012;2012:1-16. Available from: http://www.hindawi.com/journals/bmr/2012/270425/

262. Shiozawa $Y$, Taichman RS. Cancer Stem Cells and the Bone Marrow Microenvironment. Bonekey Rep [Internet]. 2012 Mar 1 [cited 2014 Jul 
13];2012(1):1-5. Available from:

http://www.pubmedcentral.nih.gov/articlerender.fcgi?artid=3671623\&tool =pmcentrez\&rendertype=abstract

263. Lamouille S, Xu J, Derynck R. Molecular mechanisms of epithelialmesenchymal transition. Nat Rev Mol Cell Biol [Internet]. 2014 Feb 21 [cited 2014 Mar 19];15(3):178-96. Available from: http://www.ncbi.nlm.nih.gov/pubmed/24556840

264. Hanahan D, Weinberg RA. Hallmarks of cancer: the next generation. Cell [Internet]. 2011 Mar 4 [cited 2013 Nov 6];144(5):646-74. Available from: http://dx.doi.org/10.1016/j.cell.2011.02.013

265. Heldin $\mathrm{C}-\mathrm{H}$, Westermark B. Growth factors: Mechanism of action and relation to oncogenes. Cell [Internet]. 1984 May;37(1):9-20. Available from: http://linkinghub.elsevier.com/retrieve/pii/0092867484902964

266. Aaronson S. Growth factors and cancer. Science (80- ) [Internet]. 1991 Nov 22;254(5035):1146-53. Available from: http://www.sciencemag.org/cgi/doi/10.1126/science.1659742

267. Werner S, Grose R, Rosenthal N. Regulation of Wound Healing by Growth Factors and Cytokines. Physiol Rev. 2008;835-70.

268. Lind M. Growth factors: Possible new clinical tools: A review. Acta Orthop Scand [Internet]. 1996;67(4):407-17. Available from: http://www.tandfonline.com/doi/full/10.3109/17453679609002342

269. Puche JE, Castilla-Cortázar I. Human conditions of insulin-like growth factor-I (IGF-I) deficiency. J TransI Med. 2012;10(1):1-29.

270. Krishnan J, Kirkin V, Steffen A, Hegen M, Weih D, Tomarev S, et al. Differential in vivo and in vitro expression of vascular endothelial growth factor (VEGF)-C and VEGF-D in tumors and its relationship to lymphatic metastasis in immunocompetent rats. Cancer Res [Internet]. $2003 \mathrm{Feb}$ 1;63(3):713-22. Available from: http://www.ncbi.nlm.nih.gov/pubmed/12566318

271. Tanaka $\mathrm{H}$, Quarto $\mathrm{R}$, Williams S, Barnes J, Liang $\mathrm{CT}$. In vivo and in vitro effects of insulin-like growth factor-I (IGF-I) on femoral mRNA expression in old rats. Bone. 1994;15(6):647-53.

272. Rulifson IC, Collins P, Miao L, Nojima D, Lee KJ, Hardy M, et al. In vitro and in vivo analyses reveal profound effects of fibroblast growth factor 16 as a metabolic regulator. J Biol Chem. 2017;292(5):1951-69.

273. Marquèze-Pouey B, Mailfert S, Rouger V, Goaillard JM, Marguet D. Physiological epidermal growth factor concentrations activate high affinity receptors to elicit calcium oscillations. PLoS One. 2014;9(9).

274. Wang Z, Wang Z, Lu WW, Zhen W, Yang D, Peng S. Novel biomaterial strategies for controlled growth factor delivery for biomedical applications. NPG Asia Mater [Internet]. 2017;9(10):e435-17. Available 
from: http://dx.doi.org/10.1038/am.2017.171

275. Witsch E, Sela M, Yarden Y. Roles for Growth Factors in Cancer Progression. Physiology [Internet]. 2010;25(2):85-101. Available from: http://physiologyonline.physiology.org/cgi/doi/10.1152/physiol.00045.200 9

276. Ornitz DM, Itoh $\mathrm{N}$. The fibroblast growth factor signaling pathway. Wiley Interdiscip Rev Dev Biol. 2015;4(3):215-66.

277. Fruman D a, Rommel C. PI3K and cancer: lessons, challenges and opportunities. Nat Rev Drug Discov [Internet]. 2014;13(2):140-56. Available from: http://www.ncbi.nlm.nih.gov/pubmed/24481312

278. Ziegler AN, Levison SW, Wood TL. Insulin and IGF receptor signalling in neural-stem-cell homeostasis. Nat Rev Endocrinol [Internet]. 2014;11(3):161-70. Available from: http://www.nature.com/doifinder/10.1038/nrendo.2014.208

279. Cabail MZ, Li S, Lemmon E, Bowen ME, Hubbard SR, Miller WT. The insulin and IGF1 receptor kinase domains are functional dimers in the activated state. Nat Commun [Internet]. 2015;6:6406. Available from: http://www.nature.com/doifinder/10.1038/ncomms7406

280. Pollak $\mathrm{M}$. The insulin and insulin-like growth factor receptor family in neoplasia: an update. Nat Rev Cancer [Internet]. 2012;12(3):159-69. Available from: $\mathrm{http}: / / \mathrm{dx}$.doi.org/10.1038/nrc3215

281. Clayton PE, Banerjee I, Murray PG, Renehan AG. Growth hormone, the insulin-like growth factor axis, insulin and cancer risk. Nat Rev Endocrinol [Internet]. 2011;7(1):11-24. Available from: http://dx.doi.org/10.1038/nrendo.2010.171

282. Costello LC, Feng P, Milon B, Tan M, Franklin RB. Role of zinc in the pathogenesis and treatment of prostate cancer: Critical issues to resolve. Prostate Cancer Prostatic Dis. 2004;7(2):111-7.

283. Burton A, Billingham LJ, Bryan S. Cost-effectiveness in clinical trials: using multiple imputation to deal with incomplete cost data. Clin Trials [Internet]. 2007;4(2):154-61. Available from:

http://wrap.warwick.ac.uk/92/2/WRAP_Marshall_Burton_-_Costeffectiveness_in_clinical_trials_-

Clinical_trials_post_print_versionREFERENCES.doc\%0Ahttp://ctj.sage pub.com/cgi/doi/10.1177/1740774507076914

284. Tsuji $\mathrm{Y}$, Tsuji Y, Yoshimura N, Aoki H, Sharov A a, Ko MSH, et al. Maintenance of undifferentiated mouse embryonic stem cells in suspension by the serum- and feeder-free defined culture condition. Dev Dyn [Internet]. 2008 Aug [cited 2014 Jun 28];237(8):2129-38. Available from:

http://www.pubmedcentral.nih.gov/articlerender.fcgi?artid=2559871\&tool =pmcentrez\&rendertype=abstract 
285. Inami $\mathrm{Y}$, Yoshikai T, Ito $\mathrm{S}$, Nishio $\mathrm{N}$, Suzuki $\mathrm{H}$, Sakurai $\mathrm{H}$, et al. Differentiation of induced pluripotent stem cells to thymic epithelial cells by phenotype. Immunol Cell Biol. 2011;89(2):314-21.

286. Buta C, David R, Dressel R, Emgård M, Fuchs C, Gross U, et al.

Reconsidering pluripotency tests: Do we still need teratoma assays? Stem Cell Res [Internet]. 2013;11(1):552-62. Available from: http://dx.doi.org/10.1016/j.scr.2013.03.001 